\title{
Tackling the Anarchy Within: The Role of Deterrence and Great Power Intervention in Peace Operations
}

\author{
Sarah-Myriam Martin-Brûlé
}

Department of Political Science

McGill University

Montréal, Québec, Canada

June 16, 2010

A thesis submitted to McGill University in partial fulfillment of the requirements of the degree of Doctor in Philosophy.

CCopyright 2010 All rights reserved. 


\section{DEDICATION}

To Hélène, Michel and Stéphane 


\section{ACKNOWLEDGEMENTS}

"Begin at the beginning and go on till you come to the end: then stop."

Lewis Carroll

I first want to express my deepest gratitude to my supervisor, Professor Stephen M. Saideman, who provided me with crucial guidance throughout this doctoral process. I am grateful for his no-nonsense advice and insightful tips on how to improve my work, to sharpen my ideas and to clarify my writing. Professor Saideman generously provided me with the opportunity to publish my work in his co-edited volume, to participate in panels, and to do research for and with him.

Professor Marie-Joëlle Zahar (Université de Montréal) has been an extraordinary ally in the intellectual journey that is graduate studies. First as my Masters degree supervisor and then as my doctoral co-supervisor, her constant and generous support as well as her sharp insights and inputs have been and continue to be of immense value. Her passionate dedication to her work and students are a great source of inspiration.

I also want to express my heartfelt appreciation to Professor Rex Brynen. His thoughtful advice, valuable suggestions and constant support have aided me throughout this doctoral process, particularly in puzzling through some of the intellectual challenges involved in combining theoretical knowledge and empirical observations. He has also helped me by providing advice on post-thesis projects, and by sharing many insightful pedagogical tips that will remain precious assets in the future. The passion that he brings to his work, his profound respect for students, and his commitment and success in combining both academia and policy work are a source of admiration and inspiration.

My thanks to the faculty of the McGill Political Science Department, who have been so helpful during my doctoral studies. I am grateful to Professor Juliet Johnson for being so generous with her time and for her valuable advice. I am also indebted to Professor T.V. Paul and Professor Khalid Medani, who encouraged me in my fieldwork.

The staff of the department has been a constant source of support and assistance. Helen Wilicka, Pina Giobbi, Andrew Stoten, Della Maharajh, Tara Alward, Stephanie Scognamiglio and Angie Coppola, thank you for your help and for making the administrative aspects of things much less complicated and burdensome than they sometimes threatened to become.

I would like to thank REGIS (now CIPSS) for funding my attendance at many conferences and for financing part of my field work. I also received crucial funding from the J.W. McConnell Fellowship, the McGill Graduate Studies Fellowship and the Arts Graduate Student Travel Award.

Professor Philippe Faucher (Université de Montréal) was a milestone in my intellectual life. Professor Faucher involved me in the aspects of his work that parallel my 
own, and has been a great source of support throughout my graduate studies. His quick wit and his inclination toward contrarian views challenged me to think outside the box, and have greatly contributed to my intellectual growth and learning.

I want to offer a special thanks to Robert Stewart, a friend and colleague on whom I could always rely, and who did an amazing job at helping me in revising this dissertation. His editing contributed to making it much clearer than it ever could have been, and his support encouraged me throughout my writing process.

This thesis would never have been possible without the incomparable support of my closest friends Marcelle Dubois, Thomas Collombat, Thomas Gulian, Sylvie Brunet, David Côté, Félix-Brian Corriveau and Tracy McNicoll. My dear friends, I owe you more than I could ever properly express. Thank you for always being there for me.

During my time at McGill, I have also had the chance to establish many cherished friendships. A special thanks to all the wonderful people with who I have shared my doctoral journey, and who have been a constant source of encouragement and motivation: Bahar Akman, Amy Cox, Matthias Imboden, Nina Valiquette Moreau, Françoise Montambeault, Ginger DiGaetano, Daniel Douek, Julia Aynsley, Jeffrey Sachs, Melanee Thomas, Ora Szekely, Ece Atikcan, Imad Mansour, Jonathan Paquin, Monica Trevino, Omar Ashour, James Devine, Merouan Mekouar and Aisha Ahmad.

Outside of McGill but no less close to my heart are Philippe Allard, Alexandra Armijo-Fortin, Pierre Avignon, Sirma Bilge, Mélanie Bourque, Marie-Anne Cantin, Fernando Chinchilla, Magdalena Dembinska, Sébastien Dubé, Thierry Giasson, Isabelle Hudon, Karine Poirier, Caroline Proulx, Marie-Pierre Rouette, Catherine Slakmon, Benoit Thierry and Laurent Turcot.

A special thank you to Raphaël Lambert, my partner at the beginning of this long process. Your supportiveness, constancy and enduring friendship were and are most important to me, and your exemplary self-discipline has been an inspiration, particularly during some of the more difficult parts of this process.

This thesis would not have been the same without Philippe Ducros. Philippe traveled with me in many of the most remote locations that I visited during my fieldwork. He taught me a lot about daring the outback and about being street wise no matter what the setting. Philippe challenged me to "walk the talk", and I will always be grateful for that.

I had the chance to meet many amazing people during my fieldwork, one of whom was Nhlanhla Ngwenya. Our meeting was a great gift and showed me how true friendship can develop quickly and last, no matter the distance or time. I also met many extraordinary scholars, and will remain indebted to Dr. Adekeye Adebajo, Dr. Kwesi Aning and Dr. Thomas Jaye, who devoted precious time to answering my many questions. I am also grateful to Lt. Colonel Larry Gbevlo Lartey, Lt-General Arnold 
Quainoo, General Joe Wylie, Kumar Gupta and LCdr Nicholas Smith, Ambassador Yves Boulanger, Colonel Ali Abdurahman Reinhard Linz, Joseph-Louis Hounton, GeorgesPatrick Menze and Sara McHattie for helping me make the most of my field research. I want to thank the inspirational people that I met in Addis and in the refugee camps, including Menherit, whose enduringly bright smile in the face of adversity is a source of inspiration and humility.

My family has always been supportive and cheered me on during my graduate studies, and I would like to thank Ann Corbett, Yolande Mainville, Clarisse Olivier and Giles Lepage.

Finally, I want to offer a deep and heartfelt thank you to my father, Michel Brûlé, my mother, Hélène Martin, and my husband, Stéphane Moulin. I dedicate this thesis to them.

Michel, thank you for your constant encouragement and for all of your invaluable advice. Your wisdom and your sense of humour never failed to lift my spirits and were a source of comfort and motivation. Your intellectual curiosity always inspired me and our lunches in tête-à-tête have remained precious moments of rich exchanges which I hope will long continue to punctuate our lives. You have helped me in the face of all kinds of obstacles, always reminding me to take it one bite at a time. Thanks to your loving and continuous support, I can finally say that this elephant has been eaten.

Hélène, thank you for your love and unfailing support, even when I undertook activities that seemed to be (too) risky. Your admirable sensibility and your sound judgement helped to guide me on countless occasions, and your generosity and your continuous concern have been precious sources of comfort that helped to ease this doctoral process in an immeasurable way. I am most grateful for our daily updates which remain a source of joy that always energizes and motivates me.

Thanks to both of you for your love and for the rich part that you play in my life. Our complicity is an everyday joy.

Stéphane, you've made all the difference. Your dedication in helping me to carry this dissertation through to its conclusion, your always cheerful encouragement, your patience and insights during our evening-long conversations that helped me to surmount various theoretical hurdles, your constant reminders about the passion and interest that initially drew me to doing my doctorate, your diligent revising, and your infallible belief in me and in my work, all have been beyond measure. As a result of your laughter, your wit and your love, the process of writing this thesis while also teaching and being pregnant became a wonderful experience. What an amazing partner you are, and what a great father you will be. Our daily smiles and laughter make life as beautiful as it has ever been. You are the reason why we should all believe in the benefits of match-making and in love at first sight. 


\section{TABLE OF CONTENTS}

Dedication

Acknowledgements

i

Table of Contents

List of Figures

List of Acronyms

Abstract

Résumé

Foreword

ii

$\mathrm{V}$

ix

$\mathrm{X}$

xii

xiii

xiv

\section{Introduction}

1. Tackling the Anarchy Within

2. Puzzles: What is Success? How is it Achieved?

3. Peacekeeping Literature and Contribution 3

3.1. Literature 3

3.2. Contribution 6

3.2.1. Assessing Outcomes: 2 Dimensions and 4 Outcomes 7

3.2.2. Assessing Processes: Strategic Ingredients and Types of 8 Intervener

4. Sources

5. Dissertation Outline

\section{Chapter 1}

Peace Operations Success: Recent Conclusions \& Questions

1. Puzzles: What is Success? How is it Achieved? 15

2. Gaps in the Peacekeeping Literature on Success: Outcomes and 16 Process

2.1. What constitutes peace operation success? 16

2.2. What makes peace operations successful? 22

2.2.1. Initial Setting: Context \& Timing 22

2.2.2. Part of the Process 27

3. Scope of my Research: Intra-state wars 44

4. Toward my hypotheses 46

\section{Chapter $2 \quad 48$}

Hypothesis, Expected Findings \& Research Design

1. Introduction 48

2. Hypotheses 49

2.1. Success: Accomplishment and Order 49

2.1.1. Accomplishment of Mandate $\quad 50$

2.1.2. Order 53

2.1.3. Distinguishing Categories of Outcomes 55 
2.2. Strategy as the independent variable $\quad 57$

2.3. Great powers as intervening variable 60

3. Expected Findings 62

3.1. Outcomes 62

3.2. Success/Failure of Deterrence and Success of Peace 64 Operations

4. Research Design 68

4.1. Case Studies $\quad 68$

4.2. Similar Cases $\quad 69$

4.3. Contrasting Cases $\quad 71$

4.4. Avoiding Selection Bias 72

5. Organization of the Dissertation 74

$\begin{array}{ll}\text { Chapter } 3 & 75\end{array}$

Partial Failure: Accomplishing Mandate without Establishing Order

1. Assessing Outcomes 77

1.1. UNOSOM II (1993-1995) 78

$\begin{array}{ll}\text { 1.1.1. Initial Setting } & 78\end{array}$

1.1.2. No Order $\quad 81$

1.1.3. Accomplishment of Mandate 83

1.2. ECOMOG in Liberia (1990-1998) 86

1.2.1. Initial Setting 86

1.2.2. No Order $\quad 87$

1.2.3. Accomplishment of Mandate 88

1.3. ECOMOG in Sierra Leone (1998-2000) 91

1.3.1. Initial Setting 91

1.3.2. No Order 92

1.3.3. Accomplishment of Mandate 92

2. Assessing Process 94

2.1. UNOSOM II 94

2.1.1. Type of intervener $\quad 94$

2.1.2. Choice of Strategy 95

2.2. ECOMOG in Liberia 105

2.2.1. Type of Intervener 105

2.2.2. Choice of Strategy 105

2.3. ECOMOG in Sierra Leone 112

2.3.1. Type of Intervener 112

$\begin{array}{ll}\text { 2.3.2. Choice of Strategy } & 113\end{array}$

3. Conclusion 118

$\begin{array}{ll}\text { Chapter } 4 & 121\end{array}$

Failure: No Accomplishment of Mandate \& No Order Re-established

1. Assessing Outcomes 123

1.1. UNOSOM (1991-1992) 124

1.1.1. Initial Setting 124

1.1.2. No Order 127 
1.1.3. Non-Accomplishment of Mandate $\quad 129$

1.2. UNOMIL (1993-1997) 130

1.2.1. Initial Setting 130

1.2.2. No Order 132

1.2.3. Non-Accomplishment of Mandate 133

1.3. UNOMSIL (1998-1999) 135

1.3.1. Initial setting 135

1.3.2. No Order 136

1.3.3. Non-Accomplishment of Mandate 137

1.4. Different Dynamics between an Efficient Process \& the 139 Establishment of Order

2. Assessing Process 140

2.1. UNOSOM I 141

2.1.1. Type of intervener 141

2.1.2. Choice of Strategy 142

$\begin{array}{ll}\text { 2.2. UNOMIL } & 147\end{array}$

2.2.1. Type of Intervener 147

2.2.2. Choice of Strategy 148

2.3. UNOMSIL 154

2.3.1. Type of Intervener 154

2.3.2. Choice of Strategy 154

3. Conclusion 160

$\begin{array}{ll}\text { Chapter } 5 & 163\end{array}$

Partial Success: Non-Accomplishment of Mandate \& Order

1. Assessing Outcomes 166

1.1. ECOMIL (2003) 167

$\begin{array}{ll}\text { 1.1.1. Initial Setting } & 167\end{array}$

$\begin{array}{ll}\text { 1.1.2. Order } & 170\end{array}$

1.1.3. Non- accomplishment of Mandate 171

1.2. UNAMSIL Take 1 (1999-2000) 172

$\begin{array}{ll}\text { 1.2.1. Initial setting } & 172\end{array}$

$\begin{array}{ll}\text { 1.2.2. Order } & 175\end{array}$

1.2.3. Non- accomplishment of Mandate 176

1.3. Comparative Assessment 176

2. Assessing Process 177

2.1. ECOMIL 178

2.1.1. Type of Interveners 178

2.1.2. Choice of Strategy 183

2.2. UNAMSIL Take 1 192

2.2.1. Type of Intervener 192

2.2.2. Choice of Strategy 193

3. Conclusion 203 
Chapter 6

Success: Accomplishment of Mandate \& Establishing Order

1. Assessing Outcome 208

1.1. UNITAF (1992-1993) 208

1.1.1. Initial Setting 208

1.1.2. Order 210

1.1.3. Accomplishment of Mandate 211

1.2. UNMIL (2003-2009) 212

1.2.1. Initial Setting 212

1.2.2. Order 213

1.2.3. Accomplishment of Mandate 214

1.3. UNAMSIL Take II (2000-2005) 215

1.3.1. Initial Setting 215

1.3.2. Order 216

1.3.3. Accomplishment of Mandate 217

2. Assessing Process 218

2.1. UNITAF 219

2.1.1. Type of Intervener 219

2.1.2. Choice of Strategy 219

2.2. UNMIL 229

2.2.1. Type of Intervener 229

2.2.2. Choice of Strategy 230

2.3. UNAMSIL 236

2.3.1. Type of Intervener 236

2.3.2. Choice of Strategy 238

3. Conclusion 243

Conclusion 245

1. Contributions 245

1.1. Theoretical contribution 245

1.2. Empirical contribution 248

2. For further investigation 257

2.1. Type of Great Power Intervention 257

2.2. From Communicating to Sharing Information 258

2.3. Decision-Making Process 259

3. Extending the case studies 260

3.1. The Peacekept in Intra-state Wars within Failed State 261 Settings: All Alike?

3.2. A combination of Qualitative and Quantitative Methods 262

4. Concluding remarks 264

Bibliography 266 


\section{LIST OF FIGURES}

Figure 1. Operationalization of the Accomplishment of Mandate 53

Figure 2. Operationalization of Order $\quad 55$

Figure 3. Peace Operation Success: Order and Accomplishment of 57 Mandate

Figure 4. Strategy: Components and Indicators 59

Figure 5. Typology of Peace Operations' Success 64

Figure 6. Typology of the Role of Deterrence \& Great Power 68 Intervention in Peace Operations in Somalia, Sierra Leone and Liberia (1990-2009) 


\section{LIST OF ACRONYMS}

AFL: Armed Force of Liberia

AFRC: Armed Forces Revolutionary Council

CDF: Civil Defence Force

CENTCOM: United States Central Command

DDR: Demobilization, Disarmament and Reintegration Program

ECOMIL: ECOWAS Mission in Liberia

ECOWAS: Economic Community of West African States

ECOMOG: ECOWAS Cease-fire Monitoring Group

HACU: Humanitarian Affairs Coordination Unit

HOC: Humanitarian Operations Center

IGNU: Interim Government of National Unity

INPFL: Independent National Patriotic Front of Liberia

LPC: Liberian People's Council

LURD: Liberians United for Reconciliation and Democracy

MODEL: Movement for Democracy in Liberia

NGO: non-governmental organization

NPFL: National Patriotic Front of Liberia

NPRC: National Provisional Ruling Council

OAU: Organization of African Unity

PSYOP: psychological operations

ROE: Rules of Engagement

RPG: Rocket Propelled Grenades 
RUF: Revolutionary United Front

SLA: Sierra Leone Army

SNA: Somalia National Alliance

SPM: Somali Patriotic Movement

SRSG: Special Representative of the Secretary-General

UK: United Kingdom

ULIMO: United Liberation Movement of Liberia for Democracy

UN: United Nations

UNAMSIL: United Nations Assistance Mission in Sierra Leone

UNICEF: United Nations Children's Fund

UNITAF: United Nations International Task Force

UNMIL: United Nations Mission in Liberia

UNOMIL: United Nations Observer Mission in Liberia

UNOMSIL: United Nations Observer Mission in Sierra Leone

UNOSOM: United Nations Operation in Somalia

UNSC: UN Security Council

UNSG: UN Secretary-General

US: United States

WSB: West Side Boys 


\begin{abstract}
My dissertation strives to understand the conditions under which peace operations in intra-state wars succeed or fail. I address two main questions: What is peace operation success, and what contributes to such an outcome? I define the success of a peace operation based on two dimensions: a) the accomplishment of the peace operation's mandate, and b) the establishment of order. This definition allows me to avoid a binary framework of assessment in terms of success vs. failure by introducing intermediate categories: partial failure and partial success. To explain peace operations' outcomes, I look at the role of the type of strategy adopted and the type of intervener. I suggest that the three major ingredients of any strategy are: communication, capacity and knowledge. These ingredients all interact differently depending on which strategy is adopted. I apply my theoretical framework to empirical cases, testing the saliency of my postulates by examining 11 peace operations in three countries: Somalia (1991-1995), Sierra Leone (19992005) and Liberia (1990-2009). I assess these operations' outcomes and the processes by which they succeeded/failed at accomplishing their mandate while simultaneously contributing/hindering their chances at re-establishing order. I argue that, for a peace operation in an intra-state war, the adoption of a deterrence strategy works best for re-establishing order while the involvement of a great power facilitates the accomplishment of the mandate.
\end{abstract}




\section{RÉSUMÉ}

Cette thèse porte sur les conditions et les facteurs de succès des opérations de la paix dans les guerres civiles au sein d'États déstructurés. Nous cherchons à répondre à deux principales questions: qu'est-ce que le succès dans le cadre d'une opération de la paix, et qu'est-ce qui contribue à ce succès? Nous identifions d'abord deux axes principaux du succès des opérations de la paix: a) l'accomplissement du mandat et b) le rétablissement de l'ordre. Nous proposons ainsi un modèle de classification qui nuance la simple opposition succès/échec par l'ajout de catégories intermédiaires (succès partiel et échec partiel). Nous cherchons ensuite à mettre en valeur l'influence respective du type de stratégie utilisée (dissuasion, coercition et auto-défense) et du type d'intervenant (présence/absence d'une grande puissance, organisation régionale/internationale) sur le succès d'une opération de la paix. Nous nous intéressons aux trois principaux ingrédients de toute stratégie, soit la communication, la force de frappe et la connaissance des milieux humain et géophysique. Ces ingrédients interagissent différemment selon la stratégie adoptée. Nous appliquons notre cadre théorique et nous testons la pertinence de nos hypothèses en examinant 11 opérations de la paix qui ont eu lieu dans trois pays, en Somalie (1991-1995), au

Sierra Leone (1999-2005) et au Liberia (1990-2009). Nous évaluons le type de succès/échec ainsi que le processus par lequel ces opérations réussissent/échouent à accomplir leur mandat tout en contribuant/nuisant à leur chance de rétablir l'ordre. Nous soutenons que lors d'une opération de la paix au sein d'un État déstructuré, la dissuasion est la stratégie la plus apte à rétablir l'ordre alors que l'intervention d'une grande puissance facilite l'accomplissement du mandat. 


\section{FOREWORD}

\section{Had I said yes}

"Maybe we could get married" said a former rebel leader - jokingly - as my interview with him was coming to an end. We laughed and I politely declined the offer from this very senior leader, who was after all already married many times over. Yet I have since wondered what might have happened if I had said 'yes' one near-certainty is that this thesis would surely have been filled with many more obscure and colourful anecdotes.

The opportunity to interview a Liberian belligerent who had been an active participant in, and even a partial architect of, the wars in Liberia and Sierra Leone, who had orchestrated raids and missions both for and against external interveners, was an extremely appealing intellectual opportunity for someone who studies the impact of the military strategies employed by peace operations in intra-state wars within failed states. Yet at the same time, such an interview was highly unappealing on so many levels: the rebel group in question was responsible for the deaths of thousands of civilians, and was accused of having committed serious abuses such as summary executions of alleged government collaborators, rape, forced recruitment of civilians (including child soldiers), subjecting hundreds of civilians to forced labour, and abducting refugees who had recently crossed into the neighbouring country (HRW, 2003).

By talking to this leader, I was able to gain an insider's perspective on so many different issues: the motives behind the group's actions, the strategies that it 
employed, and its perception of the external intervener's aims and means. He explained to me how, in the absence of a great power's intervention, his group was formed as a last ditch effort to save the people from governmental abuse. He explained how the group had to fight, since the interventions of regional interveners were not only inefficient but had become part of the problem. He detailed the shattered hopes following the UN intervention. He recalled how his group helped out the international mission and, ironically, how little the UN recognized their contribution in return. He described how his men took the uniforms of the less well-equipped UN contingents and carried out their more demanding tasks, and he explained how and why some contingents of blue helmets were then accused of violating their rules of engagement. According to the leader, because it was not the peacekeepers but was rather rebels disguised as peacekeepers who carried out certain missions, it is unsurprising that they either did not know, or consciously chose to ignore, the rules of engagement. He also said that given some UN contingents' known lack of adequate equipment and training, and given their poor knowledge of the terrain, rebels were ready to help the blue helmets in their mission to re-establish peace in the country. Throughout the interview, the ex-belligerent stressed how his people had hoped for a forceful American intervention, one akin to the 1991 American-lead UN mission in Somalia.

My initial interest in interventions in intra-state wars within failed states dates back to this very event in December 1991. The powerful TV images of US marines disembarking on the beaches of Mogadishu, the beautiful white sand 
beach and turquoise water juxtaposed with army helicopters, fully-geared American soldiers, and skinny AK-toting kids watching them, were immediately striking. This mix of beauty and fear, of forceful deployment and vulnerability, was fascinating. Was it really the best way to save them? And who exactly was "them"? All these naive questions would ultimately motivate me to learn more about the underlying issue: How can we effectively intervene in what seems to be one of the worst of all scenarios, that is, intra-state wars within failed states?

Eighteen years later, when I first went to sub-Saharan Africa to do my field research for this dissertation, I was once again struck by the same flashes of vulnerable beauty and fear that I had perceived on television. During the course of my interviews, I was amazed at the coded language and carefully formulated vocabulary used by the local actors. Former rebel leaders spoke in terms of games, of big power interests, and of deterrence as well. The acuity of the actors and of the peacekept, and particularly the extent of their knowledge of the interveners, was a surprise to me. It confirmed my intuitive sense of the importance of communication in an intervention, and highlighted the significance of the proverbial truism "know your "enemy",, to which a caution could be appended: "because maybe your 'enemy' knows you”.

Going to the Somali refugee camps in the contested Ogaden region of Ethiopia $^{1}$ was an eye-opening experience. At the camps, I interviewed Somali refugees who had left Somalia at various times, some at the beginning of the war

\footnotetext{
${ }^{1}$ Ogaden is a territory in the southeastern portion of the Somali Regional State in Ethiopia. The population is predominantly ethnic Somali and Muslim. Somali irredentists call it "Somali Galbeed" (Western Somalia).
} 
in 1992, others after the Americans and the UN left in 1995, and still others in the 2000s, after the second round of war between the Islamists. Again, I was struck by the extent of the knowledge and awareness of these refugees. Perhaps the long days spent in the camps, coupled with the system of internal schooling for young people organized by the elders, had given them the time to recall their past and to begin to make sense of it. We mostly talked about events of the 1990s, particularly the American and UN interventions. What immediately became clear was the extent to which they were aware of the subtleties of the various interventions, from the tensions between the different contingents to the dynamics within their relationships. They were thus able to tell a Canadian researcher that they liked Canada because the country had judged and punished abusive soldiers, and that they liked the Americans because they made them feel secure. I was intellectually inspired by these interactions, as well as pushed to challenge some of my preconceived ideas: the extent of the passivity frequently attributed to the peacekept, the extent of the rebel groups' "rogue" behaviour, and the extent to which the power of communication with the peacekept should never be underestimated. A force's capabilities matter, but privileging non-coercive means while having the means to coerce matters more. 


\section{INTRODUCTION}

\section{Tackling the Anarchy Within}

When the government of a country collapses, states and international organizations are confronted with a situation in which one of their options is intervention. When that collapse is caused by the outbreak of an intra-state war, the insecurity of the setting and the humanitarian disasters that often ensue immediately raise the cost of stepping in. Yet the cost of non-intervention is higher both in the short and in the longer run. Somalia and Afghanistan are cases in point.

Interventions took place in Somalia at the beginning of the 1990s, yet the international community left in the mid-1990s, leaving the country to approximately 20 years without a government, "failed peace talks, violent lawlessness and warlordism, internal displacement and refugee flows, chronic underdevelopment, intermittent famine, piracy, regional proxy wars, and Islamic extremism" (Menkhaus, 2008:1). While these phenomena are bad enough when they are confined to the border areas of states, they are much worse when they spread across an entire country and spill over to neighbouring states since they then threaten international security as a whole.

The government of Afghanistan collapsed in the early 1980s. Subsequent mismanaged interventions failed to re-establish a strong central authority, which 
facilitated the rise of the Taliban, who themselves went on to contribute to the destabilization of the international community.

Thus one might argue that these failed interventions spurred many of the problems that the international community faces today, such as piracy and international terrorism. In particular, the attacks of September 11, 2001 and the ensuing war in Afghanistan are prime examples of the sorts of impacts that a failed state can have on international security. These problems are not the result of an absence of organization within each so-called failed state, but rather stem from the re-organizations of groups within such states whose actions are often at odds with the well-being and proper-functioning of the international system as we know it. Criminality and high levels of violence within the state affect the wellbeing of its citizens, which requires attention through intervention according to the principles of the responsibility to protect. Meanwhile, lawlessness that spills across borders affects the stability of neighbouring countries, and thus adds another dimension of threat to the international system as a whole. The proliferation of non-state actors defying/threatening other states and their citizens makes intervening even more necessary, so as to re-establish the state's monopoly on coercive force and thereby safeguard the stability of the international state system. What emerges therefore is that there is a clear need for intervention in the case of failed states. The question is, how to do it? 


\section{Puzzles: What is Success? How is it Achieved?}

Missions in Sudan, Congo, and Afghanistan are all part of the important trend of peacekeepers attempting to replace governments in providing security, and ultimately, in restoring the government's monopoly on violence in countries coming out of civil war. And yet while multilateral organizations have sought to establish lasting peace in many different countries around the world, we still do not fully understand why they succeed or fail at this critical task.

One of the defining aspects of state authority is to deter violence i.e. to possess a monopoly on the legitimate use of force, and to wield it so that individuals and groups refrain from engaging in serious conflict. But how can we expect outsiders to play this essential role when the state itself is too weak to do so?

This dissertation examines the phenomenon of interveners substituting themselves as state authorities to provide security and to restore a monopoly on the legitimate use of force in countries coming out of civil war. I thus strive to understand the conditions under which peace operations succeed in failed states. I address two main questions: What is peace operation success, and what contributes to such an outcome?

\section{Peacekeeping Literature and Contribution}

\subsection{Literature}

Since 2001, a robust literature on peacekeeping has emerged, provoking a number of discussions on the positive effects of such efforts, as well as the 
sources of both success and failure in operations. Peace operations aim to create and sustain the conditions necessary for peace to thrive. They comprise three types of activities: support to diplomacy (peacemaking, peace building, and preventive diplomacy), peacekeeping, and peace enforcement. Protection of humanitarian assistance, establishment of order and stability, enforcement of sanctions, guarantee and denial of movement, establishment of protected zones, and forcible separation of belligerents are part of peace operations activities (FM 100-23, 1994).

The peace operations covered in this dissertation thus vary in their activities, means and mandate but most share all three principles detailed in the United Nations Department of Peacekeeping Operations "Capstone Doctrine" for peacekeeping (2008): consent of the parties, impartiality and non-use of force except in self-defense and defence of the mandate. Yet some operations are enforcement mission, carried by the UN or ad hoc coalitions of Member States or regional organizations acting under United Nations Security Council authorization, without the consent of the parties to the conflict. The UN Capstone doctrine specifies that this is only the case when

it believes that the conflict presents a threat to
international peace and security (...). It may also take
enforcement action for humanitarian or protection
purposes; where there is no political process and where the
consent of the major parties may not be achievable, but
where civilians are suffering (UNDPKO, 2008: endnote
20, 43).

Scholars have recently arrived at a relative consensus that peace operations can be effective (Fortna: 2008), while still debating what constitutes a successful 
peace operation (Pushkina, 2006) and how to account for success or failure (Bellamy \& Williams, 2005; Downs \& Stedman, 2002). The lack of a clear understanding of the multidimensionality of peacekeeping success has been an obstacle to fully conceptualizing such success (Fortna, 2008). Recently, attempts have been made to identify clearer ways to assess the performance of peace operations (Gutner \& Thompson, 2010; Lipson, 2010) and to differentiate between different types of successes and failures. Gutner and Thompson (2010: 227-248) have suggested a new model to assess the performance of international organizations. Lipson (2010) highlighted ways to go beyond the intrinsic "ambiguity" of peace operations' effectiveness. Another set of authors, for instance Call (2008), assess and classify the success or failure of peace operations based on security, as well as political and social factors. Others, such as Bratt (1997), attempt to scale success, by associating different levels of accomplishment with the terms success, moderate success and failure. Yet there is no work that explicitly offers clear categories for classifying the different outcomes of peace operations.

The first gap in the peacekeeping literature is thus related to the multidimensionality of peacekeeping success, which seems in itself to be an obstacle to fully conceptualizing and measuring such success (Pushkina, 2006). The classification of missions as successes or failures is done using a set of criteria that includes the fulfillment of a mission's mandate, as well as its contribution to the broader goals of limiting violence, reducing human suffering, containing the conflict, and promoting conflict resolution. Yet collapsing these 
criteria into a simple yet comprehensive and workable definition of success and failure remains elusive, leading to a lack of precision in distinguishing successful interventions from failed ones.

The second gap in the peacekeeping literature is related to what makes peace operations successful. The main explanations are based on the type of interveners, the mandate, the coercive potential of the mission and the human terrain (Pushkina, 2006; Goertz et al., 2002; Weiss, 1994; Hirsh \& Oakley, 1995; Drysdale, 1997; Walter, 2002; Nathanail, 2001; Howard, 2006). While each of these factors contributes to the success of a mission, no single factor among them has been definitively established as being either necessary or sufficient to explain a mission's success or failure. Fortna (2008:3) has gone some distance to identifying the gaps in the present body of literature, determining three points of particular merit: first, there is a limited understanding of whether peacekeepers contribute empirically to lasting peace, and if so, to what degree; second, we lack a firm understanding of how peacekeepers affect the stability of peace; and third, the perspective of the local population ("the peacekept") is often lost. There is thus still a profound need to identify why and how peace operations succeed (and fail), and an equal need to understand how interveners contribute to these outcomes.

\subsection{Contribution}

The contribution in this dissertation is threefold (two theoretical and one empirical): 1) I put forward a new definition of peace operation success based on 
what I identify as two crucial elements: the (re)establishment of order and the accomplishment of the mandate. This leads me to outline a new typology for better assessing and classifying peace operations, as failures, partial failures, partial successes, or successes; 2) I provide an explanation for the different outcomes of peace operations (based on the type of success/failure) by outlining the effect(s) of the combination of the key ingredients-strategy and the type of interveners. I contend that deterrence strategy combined with the intervention of a great power is key for a peace operation's success in the context of intra-state wars; 3) I apply my theoretical framework to empirical cases, testing the saliency of my postulates by examining 11 peace operations which took place in three countries: Somalia (1991-1995), Sierra Leone (1999-2005) and Liberia (19902009).

\subsubsection{Assessing Outcomes: Two Dimensions and Four Outcomes}

I define the success of a peace operation based on two dimensions: a) the accomplishment of the peace operation's mandate, and b) the establishment of order within the state and by the state. This definition flows from the premise that peace operations can vary in the details of their mission and thus in what constitutes the successful accomplishment of that particular mission, but all share the common aim of restoring order that is legitimately enforced by the state. I assess peace operation's success based on its capacity at re-establishing order and at accomplishing its mandate. This leads me to classify each operation into one of four categories: failure, partial failure, partial success, and success. 
I contend that a failed peace operation is one that ultimately fails to reestablish order and to accomplish its mandate. By closely examining the UNOMIL operation in Liberia (1993-1997), the UNOMSIL operation in Sierra Leone (1998-1999) and the UNOSOM I operation in Somalia (1991-1992), I detail how the failure to accomplish a mission's mandate may undermine its capacity to re-establish order.

Peace operations are a partial failure when they fail to re-establish order yet nonetheless succeed at accomplishing their mandate. I elaborate this definition through an appraisal of the ECOMOG missions in Liberia (1990-1997) and Sierra Leone (1997-1998), as well as of the UN mission in Somalia (UNOSOM II, 19931995).

Peace operations partially succeed when they re-establish order yet fail to accomplish their mandate. Both in Liberia (ECOMIL 2003) and Sierra Leone (UNAMSIL part I, 1999-2000), success at re-establishing order did not lead to the accomplishment of the mandate.

Finally, I argue that peace operations are successful where they both reestablish order and accomplish their mandate. The peace operations in Somalia (UNITAF 1992-1993), Liberia (UNMIL 2003-2009) and Sierra Leone (UNAMSIL part II, 2000-2005) all proved successful in both dimensions.

\subsubsection{Assessing Process: Strategic Ingredients and Types of Intervener}

What explains each of the four outcomes? In answering this question, I look at the role of the type of strategy adopted and the type of intervener. 
As discussed in the literature, notably by Doyle and Sambanis (2006; 303319) and Fortna (2008: 86-103) peace operations strategies typically comprise a combination of security, development and governance measures. However, in this thesis, I use a definition of strategy drawn from the warfare literature. I thus define the term as "a chain of relationships among means and ends that span several levels of analysis from the manoeuvres of units in specific engagements through larger campaigns, whole wars, grand strategies and foreign policies" (Betts, 2000: 6). I thus use the term "strategy" to designate the principles governing the use of force in peace operations.

I more particularly examine the process by which peace operations succeed/fail at accomplishing their mandate while simultaneously contributing/hindering their chances at re-establishing order. I suggest that the three major ingredients of any strategy are: communication, capacity and knowledge. These ingredients all interact differently depending on which strategy is adopted. I thus highlight how the force-based strategy that is adopted (compellence, deterrence or self-defence), combined with the type of intervener, influence the communication, the use of capabilities, and the knowledge of the intervener and of the peacekept (based on reputation and known interests). In so doing, I demonstrate that the strategy frames the operation in such a way as to either enable or hinder the interveners in quickly achieving an important part of their mandate, but that while doing so either sabotages or contributes to the sabotage of the very means by which they could re-establish order in the country, that is the monopoly of coercive means within and by the state. 
Four typical situations will be analyzed: compellence strategy used by a great power/by a collective intervener (lead by a regional great power); selfdefence strategy used by a collective intervener; deterrence strategy employed by a collective intervener; and finally, deterrence strategy adopted by a great power.

I contend that the adoption of a compellence strategy in a peace operation lead by a great power or by a collective intervener (lead by a regional great power) may facilitate the accomplishment of the mission's mandate while hindering its capacity to re-establish order. Because compellence strategy is predicated on the use of force, less effort is invested in communication with the peacekept, and the peacekeepers can come to be seen as parties to the conflict. Thus while the use of force might very well expedite the accomplishment of the mandate, it also strongly risks hindering the re-establishment of order, since the use of force other than in self-defence tends to more generally legitimize force and warfare. Mandates may be temporarily forced upon the peacekept, yet without order the situation will either revert to warfare or will at the very least worsen once the peacekeepers are gone.

I argue that peace operations within the context of an intra-state war in a failed state are bound to be inefficient and to fail at ultimately re-establishing order when they do not include an intentional and strategic coercive component. The adoption of a self-defence strategy by a collective intervener may not just fail, but may actually contribute to fuelling the conflict. Focusing solely on the communication component without coercive means to back up the talk may not only fail to stop the violence, but might in fact trigger violence. Having limited 
coercive means and a restricted use of force for an intervention in an intra-state war within a failed state sends "cues" to the adversaries that the operation has limited strength and is backed up by limited resolve, as well as that it suffers from poor knowledge/understanding of belligerents' actions, and of the insecurity of the setting in general. The relatively benign nature of such operations becomes an incentive for belligerents to target international organizations' resources and workers/peacekeepers, thereby increasing insecurity for both civilians and for intervening troops.

When a deterrence strategy is adopted by an actor other than a great power, I contend that order might be re-established, but that it will tend to be harder to accomplish the mandate. Because collective interveners have less means and leverage, they risk being seen as less credible and/or less committed, as well as less likely to mobilize sufficient troops and adequate equipment to accomplish their mandate. Deterrence strategy implies greater investment in communication, the capacity to back up threats with forceful actions, and that the known interests of the belligerents have been taken into account. However, the unwillingness of great powers to commit themselves to the operation sends a stronger signal, of the international community's limited will to ensure the mission's success. This hinders the accomplishment of the mandate.

The adoption of a deterrence strategy by a great power will lead to both the re-establishment of order and the accomplishment of the mandate. When a deterrence strategy is adopted, peacekeepers spend significant amounts of energy communicating with the belligerents and the population regarding the intent of the 
operation and the sanctions if transgressions occur. A deterrence strategy entails the clear communication of the operation's aims and mandate, as well as of the capacity for action. Its prioritization of non-coercive means, albeit backed up by overwhelming force and the authority to use it, sends strong signals to the peacekept, of a refusal to legitimize warfare and of a concomitant capacity to punish prohibited actions. Better mutual understanding contributes to significant reductions in the possibility of violent confrontations between the interveners and the peacekept. The presence of a great power and its involvement in the mission signals strong resolve (and the deployment of strong means) for the success of the operation. The combination of a deterrence strategy and great power intervention will produce fewer casualties, thereby facilitating the re-establishment of order and the accomplishment of the mandate.

\section{Sources}

All the chapters draw upon official documents and expert reports to assess the arguments and hypotheses advanced. I reviewed speeches and debates, and especially official and administrative documents, as well as a wide variety of published sources. I used the data made available by the United Nations and by intervening nation-states regarding the number and the type of personnel dispatched, as well as the material allocated for achieving the operations' ends etc.

My research on each peace operation was also supplemented by interviews with key figures, such as the first commander of ECOMOG troops in Liberia, the 
spokesman and military advisor to one of the main Liberian rebel groups; Somali refugees who lived in three of the main Somali cities at the time of peace operations in Somalia, from 1991 until 1995; and key experts who have studied the peace operations in Liberia, Sierra Leone and Somalia. It is important to underline that the perspectives of the peacekept are rarely taken into account when examining the impact of an intervention. Their insights and experiences provided me with an insider's view to the conflicts that helped to hone the ideas presented in this dissertation.

\section{Dissertation Outline}

This dissertation is divided into six chapters. In the first chapter, I present a literature review, detailing the recent questions and conclusions in the peacekeeping literature and highlighting the questions that seem to have been either left out or insufficiently addressed. I then build upon these questions by presenting my own queries that this dissertation will attempt to answer.

In the second chapter, I present my hypotheses and explain and justify its main variables: success, deterrence strategy and great powers. I also explain my expected findings, and highlight how different combinations of a particular strategy and of intervener(s) can be expected to result in various levels of success/failure. Next, I detail the research design, looking at the operationalization of the main variables, the justification for my case studies and the identification of my sources. 
The subsequent chapters follow the typology presented above. I thus compare the experiences of the three countries in light of the failure, partial failure, partial success and success of their peace operations. I examine the extent to which the accomplishment of a peace operation's mandate is on one hand a function of coercive potential (and the extent to which non-coercive means backed by this coercive potential are responsible for the success of an operation), and on the other hand, the extent to which the type of intervener alters the process and outcome of operations. I conclude with a comparison of the outcomes and processes of the various peace operations examined, and by an assessment of the applicability of my findings to a broader variety of settings. 


\section{Chapter 1}

\section{Peace Operations Success: Recent Conclusions \& Questions}

\section{Puzzles: What is Success? How is it Achieved?}

In the introduction, I stressed that an important literature on peacekeeping success has emerged in the last decade. This literature has provoked a variety of discussions regarding the positive effects of such efforts, as well as the sources of both success and failure in operations. Despite the abundance of literature on peacekeeping success however, two important puzzles remain unsolved: if peace operations can be effective, what constitutes a successful peace operation (Pushkina, 2006) and how can we account for success or failure (Bellamy \& Williams, 2005; Downs \& Stedman, 2002)?

This first chapter will be divided into two sections. The first section will highlight two gaps in the peacekeeping literature on peace operations' success: 1) the definition of what constitutes success, 2) what accounts for this success. I will thus present recent questions and conclusions on the multidimensionality of peace operations' success, as well as the debates on what constitutes the threshold for determining whether a mission has succeeded or failed. I will address the literature that explains such outcomes, focusing on what seem to be the key ingredients in explaining the process by which peace operations become successful: context and timing of the peace operation, the type of intervener and the type of strategy. I will follow up by detailing the scope of my research. Based 
on the gaps identified and the purview of the dissertation, I will conclude by highlighting my own perspective and the contribution that I will make to the literature.

\section{Gaps in the Peacekeeping Literature on Success: Outcomes and Process}

Two main gaps can be identified in the peacekeeping literature on the success of peace operations. The first one relates to the outcomes of peace missions. The multidimensionality of peacekeeping success seems in itself to be an obstacle to fully conceptualizing and measuring such success. There is no comprehensive and workable definition of success and failure, leading to a lack of precision in identifying thresholds to differentiate successful peace operations from failed ones. The second gap relates to what makes peace operations successful. There is a need to identify the process by which peace operations succeed, that is, the ingredients that contribute to (or hamper) such an outcome.

\subsection{Literature on Outcomes: What constitutes peace operation success?}

Recent works have been critical of the ambiguity in assessments of the performance of peace operations, and have highlighted the need to accurately delineate the criteria according to which a peace operation's effectiveness is evaluated. The lack of a clear understanding of the multidimensionality of peacekeeping success has been an obstacle to fully conceptualizing such success (Fortna, 2008). Recently, attempts have been made to identify clearer ways to 
assess the performance of peace operations (Gutner \& Thompson, 2010; Lipson, 2010) and to differentiate between different types of successes and failures. Yet there is no work that explicitly offers clear categories for classifying the different outcomes of peace operations.

\section{Identifying the criteria for peace operations' success}

Goertz et al. identify four main dimensions that authors disagree about in assessing success: conflict management vs. conflict resolution, short-term outcomes vs. long-term outcomes, a fixed point vs. an ongoing process, and the perspective(s) of disputants vs. the perspective(s) of citizens who live in the area and are affected by the conflict (Goertz et al. 2002: 293-295; also cited in Kim, 2005: 39).

Haklin Kim (2005) groups the different approaches to assessing peace operation success into three sets. The first is the standard approach, which assesses the success of a peace operation according to the degree to which that operation achieves the goals mandated by the UN (Kim, 2005:39). The problem with this approach is that mandates are often strategically ambiguous. Because they must satisfy all members of the Security Council, they often fail to mention the specific type of operation envisioned or to give operational guidelines. UN practitioners tend to want mandates to be more ambiguous so as to keep the capacity to flexibly adapt to changing ground conditions (Kim, 2005:39; International Peace Academy 1984). Yet having the completion of the mandate as a criterion might very well exclude the evaluation of the actual achievements of the mandate. Using mandates as the sole benchmark for evaluating success may 
not reveal enough about the accomplishments achieved or the opportunities created by the use of a particular strategy (Bellamy \& Williams, 2004). Hence "a mission that is only partly successful in fulfilling an ambitious mandate nonetheless may generate benefits far higher than those brought about by a mission that is nominally more successful by fulfilling a weak mandate" (Downs \& Stedman, 2002:46; cited in Kim 2005: 40).

A second set of approaches measures the success of peacekeeping operations by assessing their contributions to other UN activities (UN, 2000). The success of peacekeeping is thus evaluated relative to its impact on the achievement of other UN goals (Doyle \& Sambanis, 2006:86). Yet, it does not address the achievements of a peace operation that could fall outside of these goals.

The third set of approaches to assessing peacekeeping according to Haklin Kim (2005) focuses upon its effects on a conflict. This approach is concerned with the common goals of UN peacekeeping (cessation of hostilities, conflict containment, political settlement, the limitation of casualties, conflict transformation, etc.). Since such assessments do not depend on the self-declared goal of a particular operation, this type of measure is said to be more "objective". Yet, there is no agreement on what standard is best for comparing peacekeeping operations. Kim then rightly highlights that each "researcher suggests his or her own criteria for comparison according to theoretical or pragmatic demands" (Kim, 2005: 42). 


\section{Grouping the criteria for peace operations success}

Call and Cousens (2008) suggest a way to clarify the different standards used in assessing peace operations success differentiating the authors between the minimalist, maximalist, and moderate. The maximalist standard is drawn from the United Nations Security Council (2001) in a Presidential Statement on peacebuilding in February 2001. ${ }^{2}$ By this standard, a peace operation is deemed successful when it has successfully resolved the "root causes" of conflict (Call \& Cousens, 2008: 6). This criterion of peace operation success is also shared by Roland Paris (2004) for whom, the "stable and lasting peace within the host country" depends on whether there has been political and economic liberalization (Paris, 2004:56-58).

Call and Cousens (2008) identify three main problems with such maximalist standards to assess the success of peace missions: 1) focusing on root causes offer but "a simplistic understandings of why specific conflicts occur" (for example, poor countries do not necessarily fall into civil wars); 2) these root causes cannot be addressed by third party interveners, who have punctual and short missions; 3) this standard does not take into account the difference in the difficulty of the settings. Some cases are more difficult to address than others, and hence the criteria cannot be the same for these countries. Call and Cousens

${ }^{2}$ The Security Council recognizes that peacebuilding is aimed at preventing the outbreak, the recurrence or the continuation of armed conflict and therefore encompasses a wide range of political, development, humanitarian and human rights programmes and mechanism. This requires short- and long-term actions tailored to address the particular needs of societies sliding into conflict or emerging from it. These actions should focus on fostering sustainable development, the eradication of poverty and inequalities, transparent and accountable governance, the promotion of democracy, respect for human rights and the rule of law and the promotion of a culture of peace and nonviolence. (UN Security Council, 2001). 
deplore that this standard " fails to differentiate among very different types and degrees of failure or acknowledge the value of more modest goals, let alone capture a sense of meaningful difference among specific contexts" (Call \& Cousens, 2008: 7).

By the minimalist standard, peace operation is deemed successful in the absence of renewed warfare. Yet this standard does not take into account the conditions of the state in the absence of warfare (i.e. can a peace operation succeed even the state remains 'failed'?), nor does it set a time frame to know for how long warfare must be absent in order to qualify a peace operation of success (Call \& Cousens, 2008).

Finally, Call and Cousens (2008) call for a moderate standard, which refers to an absence of warfare plus 'decent governance. According to this criterion, a peace operation is successful by taking into account the quality of the governance (Call \& Cousens, 2008: 58). For these two authors, this represent the best standard for it seems "to best capture understandings within the policy community."

\section{Establishing Thresholds}

If this moderate standard is useful to define success, it does not take into account the initial mandate of the peace operation. Highlighting this problem , Lise Morjé Howard (2008) puts forward definition of peacekeeping success to assess the success of peace operations based on the accomplishment of the mandate and the institutional capacity of the state after the peacekeepers' withdrawal (Howard, 2008:7). Howard thus stresses the importance of 
considering these two criteria together. She argues that field level organizational learning, moderate levels of Security Council members' interest and permissive situational factors are necessary and sufficient when combined for peacekeeping success. She also suggests thresholds to qualify the outcomes of peace operations as either success, mixed successes or failures. Her definition significantly contributes to clarifying the definition of peace operation success. What is missing however is a hierarchy between the two criteria. The question thus remains: what happens when an operation succeeds in one dimension while failing at another? How can we define success when all the different dimensions of success of peace operations are not compatible?

\section{A need to clarifying blurry outcomes}

There is thus a need to add a new degree of analytical nuance by introducing intermediate outcome categories between success and failure in order to improve our understanding of so-called 'blurry' outcomes.

In sum, when there is no one definition of success, it becomes hard to assess whether a peace operation has succeeded. There thus remains a strong need to define success, in spite of the various distinctions between the different types of peace operations and the means by which they are waged that have been outlined. Secondly, and linked to this first need, is the requirement of delineating the threshold that distinguishes a failed peace operation from a successful one. Thirdly, there is a need for intermediate outcome categories between success and failure in order to improve our understanding of what happens when different dimensions of success of peace operations are not compatible: how can a peace 
operation succeed in one dimension while failing at another? It is thus important to take into account the 'blurry' outcomes in order to provide a clearer methodological framework to better understand what contributes to successful peace operations.

\subsection{Literature on Process: What makes peace operations successful?}

The second gap in the peacekeeping literature is regarding what makes peace operations successful. As was argued in the introduction, there is a significant need to identify why and how peace operations succeed (or fail), and an equal need to understand how interveners contribute to these outcomes. In the literature, most explanations for the success of peace missions are based on the initial context and timing of the intervention, the type of interveners, or the coercive potential of the mission (Nathanail 2001; Pushkina, 2006; Goertz et al., 2002; Weiss, 1994; Hirsh \& Oakley, 1995; Drysdale, 1997; Walter, 2002; Zartman, 2001; Touval, 1994). While each of these factors contributes to the success of a mission, no single factor among them has been definitively established as being either necessary or sufficient to explain a mission's success or failure.

\subsubsection{Initial Setting: Context \& Timing}

To explain the success of peace operations, some authors have focused on the context in which an operation takes place and/or the timing of the operation (Jakobsen, 1996; Gilligan \& Stedman 2003; de Jonge Oudraat, 1996; Zartman, 
2001). Other authors have wondered whether peacekeepers are more likely to pick the easy cases (Fortna, 2008:24-33), in which case easier contexts would be an explanatory variable for the success of peace operations. But this point of view, of peacekeepers choosing the easy cases over the hard ones, has been robustly challenged, most notably by Gilligan \& Stedman (2003) as well as Fortna (2008). She concludes that peacekeeping operations in fact tend to be focused upon the hard cases, where peacekeepers have not necessarily been asked for and where peace is deemed most difficult to keep (Fortna, 2008: 45).

These insights point toward the need for analyzing the difficulty of the context in which peace operations take place, and more specifically the extent to which the "human" and "geographical" terrain on which they are waged affects the success or failure of such missions.

The term "human terrain" refers to the different characteristics of the population: its divisions, links and networks. Also important are the types of belligerents, as well as whether or not they can be clearly identified as belligerents (rather than having dual roles as both civilians and militia members, which is referred to as being "sobel-like", i.e. soldiers by day and rebels by night) (De Waal, 1997). ${ }^{3}$ With the multiplication of failed states and with the new challenges in Iraq and Afghanistan, there has been a new wave of literature on psychological operations (PSYOPs) and counterinsurgency operations (COIN), which has

\footnotetext{
${ }^{3}$ The literature on human terrain has been flourishing for many decades, yet it was previously more associated with anthropological studies than with peace operation planning.
} 
highlighted the importance of taking into account the type of human terrain in which a peace operation is being waged. ${ }^{4}$

Peters (2000) refers to the concept of "human architecture", arguing that the success of a military intervention (within or outside of a peace mission) is linked to getting information on who lives where and what they do. ${ }^{5}$ Increasingly, interveners are asked to create human terrain maps as part of their daily routine in the field, so as to gain a better understanding of the social context in which their intervention is taking place (Marr, Cushing, Garne \& Thompson, 2008). Because actors must constantly adapt to the war context by learning and evolving, Kilcullen (2006a) stresses the importance of peacekeepers understanding that the war produces new actors with new and changing interests, and most importantly, that interveners become part of that adaptive context, indeed part of what he qualifies as an ecosystem: "it is a dynamic, living system that changes in response to our actions and requires continuous balancing between competing requirements" (Kilcullen, 2006a: 3). This creates particular challenges for achieving control, with control understood not as "forcing order" upon the actors but rather as establishing contact and then collaborating upon a shared set of objectives (Kilcullen 2006a), which is a pre-condition for peace operations to succeed.

\footnotetext{
${ }^{4}$ The importance of this concept is highlighted by Kilcullen who states that "more has been written on it in the last four years than in the last four decades" (Kilcullen, 2006b: 111).

5 "Analyzing the "human architecture" of a city begins with the recognition that there are three broad types of "mass terrain". For military purposes, cities can be classified as hierarchical, multicultural, or tribal. This imperfect system of classification does not offer a basis for command decisions - rather, it is only a starting point for understanding the operational environment into which the force will be thrust. It can, however, provide early warnings of the intractable nature of the problems that may await even an initially welcome peacekeeping force" (Peters, 2000:4).
} 
Major war theorists, from Sun Tzu to Clausewitz, have underlined the importance of geographic environment in the planning of a military intervention, since information about the terrain can greatly influence commanders' tactics and strategies (Eggenberger, 1967; Spink, 1996; Rose \& Pareyn, 1998; Mitchell, 1991). There is an abundant literature on war and terrain, and more specifically on the strategic challenges associated with various types of geophysical settings (Clausewitz, 1976; Gray, 1999). But there has been relatively little direct discussion about the different ways that a peace operation can be executed depending on the terrain. Discussions of terrain have been largely embedded in discussions on the difficulty of the context of interventions, and have mostly focused on specific case studies, notably Kosovo. For instance, Stedman (1992) refers to the difficult intervention context in Kosovo, while Fearon and Laitin (2003) discuss how the terrain hampered/facilitated insurgencies, etc. Indeed, the "geographical" terrain must also be taken into account when discussing the conditions of interventions and the measures to be taken to maximize the success of an operation. ${ }^{6}$ Hence knowledge of the terrain is necessary for a peace operation to be able to better address the challenges related to the setting in which the intervention takes place.

\footnotetext{
${ }^{6}$ For example, according to the Field Manual No. 3-25.26 from the Department of the US Army, on how to map reading and land navigation, communication is the biggest challenge for operations within jungle settings, which tend to feature isolated actions by small forces because of the difficulties encountered in moving and in maintaining contact between units. Moreover, close fields of observation and fire, as well as thick vegetation, make maintaining contact with the enemy difficult. As another example, peace operations in urban terrain require detailed planning to provide for decentralized execution, and hence might require greater command and control over the troops. "Urban areas tend to separate and isolate units. And the particular urban conditions in an area create many obstacles, while the destruction of many buildings and bridges during a battle further limits one's freedom of movement" (FM3-35.26 2001: par. 13.5).
} 
The timing of interventions has also been highlighted as a crucial component that explains the success of peace operations. It has often been conceptualized in terms of "ripeness". Yet authors disagree as to whether ripeness is an inherent condition, i.e. a point of evolution of the conflict, or if it is a condition fostered by interveners. For scholars like Zartman and Touval (Zartman \& Touval 2001; Crocker et al., 2004), the success of peace operations is more a function of factors intrinsic to the conflict rather than a function of third party involvement. And while the concept of ripeness is useful in conceptualizing the best timing for an intervention, it is not immediately clear when such a moment is attained, nor whether the peace operation will succeed as a result of intervening at the "ripe moment". For other authors, the moment of ripeness is created by the interactions between the intervener and the peacekept. Thus it is conceived as a fostered rather than as an inherited condition (Crocker, Hampson \& Aall, 2005). The main conditions for parties to comply with - and thereby to contribute to the success of a peace operation - lie in the peacekept's perception that such intervention is sustained, committed, and credible. ${ }^{7}$

Another issue underlined by some authors is that the pace of deployment is very important once the parties have agreed to the launch of a peacekeeping

\footnotetext{
${ }^{7}$ For a thorough discussion on timing and peacekeeping success, see Van der Lijn (2009). Van der Lijn points to Brown and Rosecrance (1999) who argue that an intervention will be most effective if ripeness is fostered early in the pre-conflict phase; to Heldt (2001) who finds that the longer the time from the start of the conflict to the deployment of the mission, the less effective will be the peace operation. By contrast, Doyle and Sambanis (2006) find that the longer has been the conflict before an intervention, the more chances there are that the intervention will be effective. Carment and Rowlands (1998) argue that "the chances of success increase considerably if the belligerents see that the third party is willing to enforce the settlement" (cited in Van der Lijn, 2009:7). For most recent authors, the evolving perspective of the peacekept should be the main focus in determining the timing of interventions. The parties' desire for peace is considered an essential condition for a peace operation to be effective.
} 
operation. According to the Brahimi report (UN, 2000), the first 12 weeks following a peace agreement or a cease-fire are of the utmost importance, because it is then that the belligerents form their first impressions of the peace operation and decide whether or not they find it credible. ${ }^{8}$

The literature on the timing of an intervention as a determining condition for the success of a peace operation is useful for highlighting the essential role of the peacekept. Yet it does not directly address how the intervention's timing changes the context, or how it offers a different appeal to the rationales of actors and thereby influences their choices.

\subsubsection{Part of the Process}

The literature identifies many components of peace operations as contributing to their success or failure: the type of intervener, the type of strategy and its components, communication, capacity and knowledge.

\footnotetext{
${ }^{8}$ The question of ownership follows upon the notion of ripeness, and refers to having the consent of the local population, as well as being accountable to them. Yet authors disagree on the timing for involving the peacekept. Pouligny (2006) highlights that a condition for peace operation success is involving the population, by taking them into account at every step of the operation's deployment. This means making sure that they understand every step of the intervention, which makes them much more likely to cooperate with the peacekeepers. Chesterman (2004) disagrees with this view, and stresses that ownership cannot be the means of a peacekeeping operation, but rather can only come at its end. He says that if the countries where operations are stationed were capable of ownership, they would not need the international community to intervene. Hence for these authors, the need for intervention by foreign actors comes from this very "absence of consensus" on ownership by the local population (Van der Ljin, 2009:10). Indeed, this is the cause of conflict, and this is what explains the need for intervention. Yet according to Chesterman (2004), the means by which a peace operation takes place is linked to the accountability of the local population, and hence contributes to building a consensus and ultimately toward achieving peace. The conditions for the success of peace operations are thus conceived as flowing from the extent to which they involve the peacekept (See also Van der Lijn, 2009:11-12).
} 


\section{The Type of Intervener}

A main set of questions and conclusions in the recent peacekeeping literature locates the conditions for success with the intervener. In the context of intra-state wars, the legitimate monopoly on force may be seen to rest in the hands of outside actors. The resulting question is twofold: to what extent are foreigners better equipped to take over the role of monopolizing violence? And, what are the advantages to having outside interveners take on this role, what are the limits of their effective action in this regard, and what are the associated short and longterm trade-offs to their intervention?

Types of interveners vary from international great powers, regional great powers, and collective interveners. "International great powers" refer to the permanent members of the UN Security Council. "Regional great powers" refer to those states that have a clear superiority in their military capacity compared to other countries in the region. "Collective interveners" refer to international/regional organizations deployed in the countries at war. To simplify, in this dissertation, international and regional great powers are grouped together under the term "great power".

\section{Regional Interveners}

Regional interveners are often deemed more appropriate for intervening because their proximity to the conflict zone means that they know more about the setting, the actors and their various interests. It has frequently been argued that regional interveners contribute to both the legitimacy and the efficiency of peace operations. Regional interveners are also seen as more committed interveners, 
because their geographical proximity means that they can be affected in terms of their own domestic stability (Berman, 2000; Adebajo \& Landsberg, 2003; Franke, 2006). ${ }^{9}$

In spite of the many advantages of regional interveners, multiple disadvantages put into question the efficiency of their capabilities: negative perceptions from the peacekept, ethical dilemmas arising from their lack of authority, incomplete and uneven geographical coverage, external threats, regional hegemons, lack of impartiality, lack of experience, and a lack of resources (Bures, 2006).

The very familiarity that regional actors have with the conflict setting can impair the trust and discourage the cooperation of both the belligerents and civilians. Two sets of issues explain the suspiciousness of belligerents and civilians toward regional interveners: 1) the interveners' perceived interests in the region (probably marked by a bias toward one party over another); and 2) the fact that regional troops are often trained and equipped by Western armed forces, which could inflame the perception of outside meddling and even of biased regional peacekeepers (Howe, 2001; Berman, 2003).

\footnotetext{
${ }^{9}$ In theory, familiarity with the region, with the values, culture and norms, and even the similarity of skin colour, will nurture trust and hence cooperation between belligerents and civilians on the field. Given the potential for spill-over and cross-border impacts of intra-state wars - social and economic spill-over effects from violent conflict include such results as massive numbers of refugees, political unrest or the spread of contagious diseases regional actors are seen as having a greater stake and hence more incentive to ensure the success of peace operations in neighbouring countries. They are deemed to be more determined, to exhibit greater staying power and to accept occasional humiliation more easily than a neutral and more distant outsider. Furthermore, this very same interest in the success of ending a conflict increases the political will to intervene and thus makes it easier to muster support among regional actors if and when the need arises, as compared to among the wider international community (Franke, 2006:5).
} 
Indeed regional and sub-regional organisations, especially in Africa, suffer from enormous resource and capacity constraints in the areas of training, interoperability, sustained readiness, transportation and logistics, as well as funding, all of which negatively impact upon their capacity. Franke explains that

Given that these resource and capacity constraints are directly related to the meagre military capabilities of the organisations' member states and their frequently dire economic situations, the regiosceptics also doubt the potential for substantial improvements in the short-term (Franke, 2006:2).

There are also several core military deficiencies that impair the ability of regional actors to efficiently "flex their muscles". For example, few African countries are capable of deploying a battalion or more for peace operations without significant outside assistance. Most do not possess specialised units with sufficient equipment or expertise to provide such necessary services as engineering, communications, medical support or movement control. With few exceptions, African countries cannot project force over great distances. It has even proven difficult for African countries to deploy with the necessary level of selfsufficiency (United Nations Institute for Disarmament Research and the Institute for Security Studies, 2000). African militaries' massive weaknesses in command and control, intelligence gathering and analysis, as well as in doctrinal preparation, can also impair their intervention abilities. ${ }^{10}$

\footnotetext{
${ }^{10}$ According to experts from the German Institute for International Politics and Security, these weaknesses leave African militaries with no choice but to return to outdated modes of warfare where "the combatants use the weaponry of the Korean war, the tactics of the First World War and the medical treatments of the 19th century".
} 
In addition to these structural limitations, many African military interveners lack military professionalism, which manifests in corruption and poor command and control (Franke, 2006:4). Africa's regional organisations necessarily determine the nature of regional multinational operations. Given the continent's ethnic, cultural and religious diversity, as well as the AnglophoneFrancophone divide, substantial friction between (and even within) the various African contingents may not always be avoidable. Similarly, the presence of at least six African organisations with serious peace operation ambitions ${ }^{11}$ may create tensions between these various organisations and their respective, often overlapping, memberships (Fanta, 2009:14).

\section{International Organizations}

Even more than for regional organizations, impartiality and burden sharing are two clear advantages of peace operations by international organizations. With respect to peace enforcement operations, these advantages are not unique to the United Nations, although legally the UN Security Council is the only body empowered to authorise military action to redress a threat to international peace and security (Coleman, 2007).

Peace operations by international organizations allow for more effective burden sharing among the intervening states, and also implicate these states in the success of the peace operations. If peace enforcement is launched through an international organization, all of its members are at least potential military and

\footnotetext{
${ }^{11}$ African Union, Economic Community of West African States, South African Development Community, the East African Cooperation, the Intergovernmental Authority on Development and the Economic Community of Central African States.
} 
financial contributors to the intervention. Hence each member has a great interest in the success of the mission (Coleman, 2007; Franke, 2006).

Yet lack of communication, inefficiency and discrepancy between means and ends are the main disadvantages associated with peace operations by international organizations. For example, Richard Gowan (2008) asserts that "there is no UN". He says that the organization is made up of so many agencies and secretariats that its main problems rest in the weight and complexity of its bureaucracy, and in the inefficiency often associated with the organization of so many entities with often divergent views.

As Doyle and Sambanis (2006) specify, at the political command level, the UN also suffers from a troubling disconnect between the Security Council and UN operations in the field. At its worst, the Security Council, by focusing on issuing resolution after resolution, appears to be seeking rhetorical solutions to strategic problems and aiming to satisfy the media and each Council member's domestic constituency rather than focusing on providing well-designed missions with sufficient forces (Doyle \& Sambanis, 2006: 188).

The UN is only as strong as its member states want it to be. There are often great discrepancies between what is promised by the UN missions and what is actually delivered, at least partly due to the fact that the UN does not have its own standing army. The countries providing troops can keep bilateral relations with the countries/governments in which the UN intervenes, and they can withdraw at any point in the mission. Relations between each contingent and its national headquarters often bypass the UN command structure of the mission. 
This multiplies the possibilities for disorganization and incoherence in the organization. Competition or tensions between national contingents are also frequent, and contribute to the discrediting of the mission and the undermining of its efficiency. The mix of many troops from different military cultures, with different equipment and training, also contributes to inefficiencies and sometimes errors during the mission. As well, it is often harder to reach the point of commitment to the mission; and even once a commitment has been made, it can often prove tenuous (Franke, 2006; Coleman, 2007; Berman \& Sams, 2000).

\section{Great Powers}

States can also intervene alone. Great powers such as the United States, France and the United Kingdom are examples of states which have taken the lead in peace operations. Once it commits itself to an operation in which it has an interest, the great power will tend to bolster its investment in the mission, giving its troops the means to minimize casualties and hence ultimately increasing the deterrent effect upon the belligerents (Hillen, 1998). The proponents of such interveners refer to the fact that military actions require close coordination between intelligence gathering and operations, a smoothly functioning decisionmaking machine, and forces with some experience of working together so as to successfully perform dangerous and complex tasks. These things are more likely to be achieved within existing national armed forces, alliances and military relationships than they are within the structure of an international or a regional organization's command (Roberts, 1994). 


\section{Credible Commitment}

In addition to the specific type of interveners, questions related to the role of third parties in peace operations have recently been addressed in the literature, by researchers focusing upon credible commitment theory (Fearon, 2004; Lake \& Rothchild, 1998; Walter, 1997; Walter, 2002; Lake, 2003; Powell, 2006). According to this theory, the anarchic character of intrastate wars makes it hard for actors to arrange credible guarantees for peace settlements on their own. The success of peace operations not only depends on the willingness and ability of third parties to intervene, but also on the confidence that the protagonists have in the commitment of the interveners (Walter, 2002).

There is no consensus regarding who is best positioned to carry out peace operations, and moreover there are two problems with the credible commitment proposition: even assuming that credible commitment and credible interveners are both important, we still do not understand the means by which a certain level of commitment is assessed and by which the actual actions of the intervener are determined. One key missing ingredient is thus whether or not there is a credible strategy. A further question is, while commitment must be credible, is it sufficient for it to be most effective? This latter issue is in fact highlighted as needing further study by Fortna and Howard (2008). Indeed, if we consider the debacles in Somalia, in Afghanistan and in Iraq, we see different actors intervening, which makes it difficult to determine who is best at restoring order and why. Put another way, the question of which kind of intervener is best remains insufficiently discussed. 


\section{The type of strategies}

Strategy determines the conditions the interveners will set for peace to be (re)established. There are many strategies available for peacekeeping interventions. Among the most common strategies are economic sanctions and/or military interventions. However, these strategies have different levels of effectiveness.

\section{Non-Military Strategies}

Economic sanctions is a type of strategy which, it could be argued, is the main determinant of success or failure for peace operations in civil wars fuelled by trafficking of such goods as arms and diamonds (Pugh, Cooper \& Goodhand 2004; Collier, 2001; Hirsh, 2001a). In Sierra Leone, numerous measures have been taken by international financial institutions and international organizations (particularly the UN under Chapter 7 of its charter) to suppress the war economy. ${ }^{12}$ Yet sanctions and restraints have produced mixed results, which have led many to question the adequacy of these measures in such settings (Orogun, 2004). For example, in a context of weak state control combined with rampant corruption such as in Sierra Leone, the adoption of an official certification system for diamonds has made it easier to launder these gems since it has eliminated the need for complicated smuggling through other countries (Cooper, 2003a, 2003b). A similar phenomenon is also said to have occurred with the arms and military equipment embargo on Liberia, which in spite of the fact that it has been in place

\footnotetext{
${ }^{12}$ The Kimberley Process Certification Scheme was implemented in January 2003. Its objective is to guarantee that parcels of rough diamonds can be tracked from their primary source of origin without confusing specific parcels with the country of provenance (Orogun, 2004).
} 
for ten years, has not managed to stop the steady re-supplying of these items in the region (Pugh, Cooper \& Goodhand, 2004). As a result, the sanctions have proven incapable of stopping the violence that prompted their imposition.

Ultimately then, while arms embargoes and economic sanctions may be useful and may represent significant obstacles to violence, they are not alone sufficient to ensure the success of peace operations (de Jonge Oudraat, 2000; Tierney, 2005). This observation points toward the need for complementarity of strategies and action.

\section{Self-Defence or Non-Coercive, Force-Based Strategies}

Those who advocate the prioritization of non-coercive means highlight the "perverse" effects linked to coercion. They claim that the use of force for reasons other than self-defence ultimately legitimizes violence and indeed warfare itself (Anderson, 1999). Furthermore, by using coercive force, peacekeepers can come to be seen as also being part of the conflict, thereby undermining perceptions of the operation's impartiality and neutrality (Roberts, 1995-1996; Lavoyer, 1998). The risk of coercion's associated slip-ups - "It's never clean nor quick" (De Waal \& Omaar, 1994) - is also evoked in defence of non-coercive means being used. In this regard, the after-effects of casualties either among belligerents or civilians risk creating resentments and undermining the long-term success of the mandate.

The use of coercion is also said to build resentment in the interveners' domestic political arena. Many studies have highlighted the fact that governmental and popular acceptance of the loss of soldiers' lives is proportional to the perceived link between the operation and the national interest (Jakobsen, 
1996). This link may be seen as being quite weak in the case of peace operations in failed or collapsed states where the nation has few direct interests. It has also been demonstrated that an intervener's domestic populace resents civilian casualties in the field just as much as belligerent casualties, perceiving such losses as being at odds with the mission's aim (Jakobsen, 1996). It is therefore said that the use of coercive force may erode an operation's legitimacy both in the field and at home, consequently undermining its chances of success.

The conclusion to be drawn from this is that the more force is used, the less chance there is of a peaceful resolution to the conflict. Thus the main explanation for a strategy's success points directly at the non-use of coercive force.

\section{Compellence or Coercive, Force-Based Strategies}

A rival school of thought insists that it is the coercive aspects of a strategy that account for its success. Success is therefore related to the capacity and authority of such operations to use force, but contrary to compellence, without actually doing so (Hirsh \& Oakley, 1995). Hence the success stems more from the credible character of this threat-based strategy.

Two major features evoked to justify the use of coercion are the insecure settings and the non-reliability of the belligerents. Indeed, the belligerents' fierceness not only toward each other but also toward civilians and even toward the staff of peace operations has led several authors to consider coercion as a necessary part of an effective operation (Roberts, 1995-1996; Stephens, 2005; Brunné \& Toope, 2004; Månsson, 2005). This position has been defended by the 
assertion that non-coercive means cannot be given priority because the belligerents' actions confirm their non-recognition of the norms promoted by the international community, and hence the non-reliability of the agreements concluded with them (Kydd \& Walter, 2002).

In response to the rival argument regarding coercion's associated "perverse effects", advocates of coercion evoke collateral damage to argue against the prioritization of non-coercive means. In a situation of scarcity and anarchy, peace operations' humanitarian equipment is highly valued as a tradable commodity for belligerents. Limited use of force in such settings could send "cues" to the adversaries that the operation has limited strength. And the perceived "benign" nature of the operation could be an incentive for belligerents to target international organizations' resources and workers/peacekeepers, thereby increasing insecurity for both civilians and for the troops taking part in the intervention (Lischer, 2003; Anderson, 1999).

The need to ensure credibility is also used to legitimize the use of coercion in such settings (Duffield, 1994). Authors argue that the prioritization of noncoercive means fails to adequately address the cultural context of intra-state war settings, sending cues to the belligerents of the interveners' misperception. With regards to domestic legitimacy linked to the use of force, some authors stress that in such insecure contexts, the possibility of the coercive use of force is necessary to ensure protection not only for the civilians but also for the troops themselves (Hillen, 2000). 
With regards to the principles of impartiality and neutrality, some authors highlight the obsolescence of impartial aims given that any intervention is perceived as necessarily biased in favour of one of the parties. Richard Betts extends the argument to suggest that taking part in the conflict may in fact be a way of contributing to accelerating its resolution, by tipping the balance of power between the belligerents (Betts, 1994). It can thus be argued that assuring one side's victory over the other may be a strategy to re-establish the order that is necessary prior to the negotiation of the conditions of peace.

Proponents of the use of force by interveners justify their stance based on an inter-state behaviour rationale. They highlight that the use of overwhelming force and the ability to blunt attacks at the various stages of violence is a way to communicate resolve to the adversaries, and thus prevents further attacks/incidences of the prohibited behaviour (Mersheimer, 1983; Huth, 1999; Touval, 1996). The use of force is deemed necessary to accomplish the mission in such settings (Mackinlay, 1995; Oakley, 2000; Hirsh \& Oakley, 1995; Solarz \& O'Hanlon, 1997). Many also suggest that the use of overwhelming force must be quick in order to avoid further deterioration of the situation. The authority and capacity to use force promptly would thus contribute to the immediate success of any strategy.

In sum, there seems to be a lack of agreement as to whether coercive or non-coercive elements are best at bringing back order, although the literature does seem to lean toward suggesting that it is a combination of both coercive and noncoercive elements that most contributes to the success of peace operations. The 
success of the strategy thus seems to lie in the potential rather than in the actual use of force, that is, in the deterring quality of a peace operation.

\section{Deterrence Strategy}

Deterrence strategy represents a combination of coercive and non-coercive means, and I will argue that it can be deemed essential for the success of peace operations. No work focusing on the specific role of deterrence in peace operations has been yet published. A systematic study of how this strategy was applied in the context of a peace operation in intra-state wars is also a clear contribution of this dissertation.

In the literature, the success of peace operations is often presented in terms of credibility (Walter, 2002; Morgan, 2005). According to Morgan (2005), credibility is both a central concern and a problem in the theory and practice of deterrence. Establishing why and how credibility is important has been a major contribution of deterrence theory, because many of the conclusions prior to doing so were not intuitively obvious. Credibility is the quality of being believed. Deterrence theorists have led the way in appreciating that it is not a state's capacity to do harm that enables it to practice deterrence, rather it is another's belief that it has such a capacity (Morgan, 2005: 15)

Deterrence is implicit within credible commitment theory, which says that in the context of intra-state wars with more than two parties that must be deterred, the accomplishment of the intervener's mandate is dependent on two kinds of guarantees, conceived as either simultaneous or consecutive depending on the context: 1) a guarantee of the security of the belligerents who comply with the 
parameters of the agreement; and 2) a guarantee of compliance to the agreement. Thus each group has two expectations: the deterrence of their adversaries, and the assurance that this deterrence will be effective.

Yet credibility does not exist or will only last a short time if there is no effort to adapt the commitment and the strategy to the setting and actors concerned. It is thus a question of making sure that the commitment is credible but also fits the requirements of the situation (Yost, 2009:15). To be effective and credible, a commitment and a strategy must be founded on detailed knowledge of particular adversaries and their particular decision-making patterns and priorities (Yost 2009:14).

The concept of "tailored deterrence" seems to have first entered the official lexicon of the US Department of Defense with the 2006 Quadrennial Defense Review, which said that the United States must move away from one size fits all deterrence and toward tailored deterrence for rogue powers, terrorist networks, and near-peer competitors (Yost, 2009:14). Tailored deterrence is a holistic approach that considers the means that may be available for the belligerents, with due attention to a full spectrum of capabilities. Knowledge of the priorities and decision-making behaviour of the peacekept improves the chances of successfully deterring aggression. The importance of the concept of tailored deterrence rests in the shift of the analysis to assessing what particular adversaries might find credible and deterring in particular contexts. The tailored deterrence approach specifically calls for paying attention to the belligerents' 
decision-making process and to the interests of the peacekept, that is, to how the peacekept define their own interests.

Authors such as Barbara Walter (Walter, 1997, 2001, 2002; Goemans, 2000; Reiter, 2009) have focused on the importance of credible commitment from the great powers. Yet it seems that in addition to credible interveners and credible commitments, it is also crucially important to have credible and tailored strategies.

Because the organization of belligerents in failed state settings is complex and dynamic, and because threats are dispersed, hidden, mobile, cunning, and changing, interveners must adopt a strategy that maximizes their ability to scatter the opposing forces, delegate authority, improvise operations, work across organizational boundaries, and make difficult yet time-sensitive decisions. The need for a tailored deterrence strategy refers to the need to understand how the particular adversary conceives threats and incentives, in order to communicate efficient messages to them that may convince them not to attempt to commit a prohibited action (Yost, 2009: 18). Credibility is a function of the belligerents' perceptions, and whether a strategy is tailored depends on the interveners' efforts to adapt their actions to the challenges specific to the environment in which the peace operation is being undertaken. Since deterrence is about influencing the perceptions - and ultimately the actions - of another party, Bunn (2007) refers to deterrence as "the ultimate mind game" (Bunn, 2007: 3). It requires detailed knowledge of many aspects of the society and leadership that one seeks to deterthat is, to understand "what makes them tick" (Bunn, 2007: 3). 


\section{Components of Any Strategy: Communication, Capacity and Knowledge}

Authors talking about strategies often refer to three main strategic components of a strategy: communication, capacity and knowledge.

The communication aspect highlights how the intervener ought to clearly define the acts that they deem unacceptable (George \& Smoke, 1989; Harvey, 1999). They can then either clearly state the sanctions if transgression occurs, or leave the consequences obscure so as to complexify and heighten the risk assessment from opponents (Lebow \& Stein, 1990). ${ }^{13}$ For example, the threat communicated by an intervener may be more or less effective depending on the belligerents' knowledge of the interveners' rules of engagement (ROE). Belligerents may be able to use this information to manipulate the force of the interveners' reaction. More specifically, knowledge of the ROEs can allow belligerents to undertake a policy of brinkmanship against the intervener, thus frustrating bargaining both at the military and the political levels. The carrot and stick available to the intervener may be limited to the other party conceding before or after the use of force. For example, in a deterrence strategy, the challenge of good communication between interveners and belligerents lies in the fine balance between threats and incentives (Saideman \& Zahar, 2008). As Goodwin summarizes: "There are often few other carrots which can be used to appeal to the other party. The nature of the stick is more obvious" (Goodwin, 2002: 116)

\footnotetext{
${ }^{13}$ The case of Israel's nuclear capacity is an example of such deterring ambiguity.
} 
The peace operations' capacity and demonstration of resolve to retaliate against a transgression of prohibited actions (and hence to make use of its capacity) is also discussed by authors on strategy (Huth, 1999). This discussion is often in line with the arguments advanced by proponents of coercive strategies who advocate for the deployment of overwhelming means to quickly defeat the adversaries (Mackinlay, 1995; Oakley, 2000; Roberts, 1995-1996; Brunné \& Toope, 2004; Månsson, 2005).

Finally, the interveners' and belligerents' knowledge of each other (based on reputation and known interests) must be assessed, to determine to what extent strategies were calibrated to the specific adversary (Zagare \& Kilgour, 2000). The interests of the adversary, whether known or suspected, also factor into the costbenefit calculation related to an attack (Lebow \& Stein, 1990). Thus if the adversaries believe that a defender has an interest in the success of his mission, they will anticipate stronger sanctions for committing a proscribed act. The probability of transgressions will thus decrease. Furthermore, awareness of the attackers' interests may enable the defender to better negotiate with his adversaries. The former will be able to stress the "relevant" benefits associated with renouncing an attack.

\section{Scope of my Research: Intra-state wars}

How can interveners contribute to setting the conditions for peace? This question would likely be relevant for studying the impact of peacekeeping in both inter-state and intra-state settings, though this dissertation will focus on the 
context of intra-state wars. Intra-state wars happen in failed states settings. Failed states refer to the absence of Weberian monopoly on the legitimate use of coercion.

Peace operations in intra-state wars must respond to peculiar challenges because failed states are characterized by an absence of government but not necessarily of governance (Menkhaus, 2007). Indeed, Menkhaus explains that communities that have been deprived of an effective state authority consistently seek to set new arrangements to make up for the essential functions that the missing state would otherwise perform (Menkhaus, 2007: 75). Peace operations in such contexts face a triple challenge: protracted warfare; chronic, often violent criminality or lawlessness; and state failure. Some peacekept, so-called spoilers, can have an interest in perpetuating one or two of these conditions. Deterring adversaries given a multiplicity of interests is clearly quite difficult.

The context of peace operation in such intra-state wars thus represent a hard sub-set of cases that are under-addressed in the literature. To answer my question 'how can interveners contribute to setting the conditions for peace?', I focus on the hard sub-set of cases in which interlocutors are diverse and changing, where it is hard to distinguish belligerents from civilians, and where the war has a dynamic that must be tackled and deconstructed for peace operations to be efficient and restore order. The conditions for the success of peace operations are more exacting in such a context, and are relatively less addressed in the literature.

In this dissertation, I examine the conditions for successful peace operations in the 'early phases' of the state's collapse, i.e. I focus on the early 
failed state setting, in which governance has still not been installed and when the networks of belligerents remain unclear for the interveners. I thus focus on missions either prior a cease-fire or in-between two cease fires (prior to a renegotiated cease-fire). The situation prior to a cease-fire is one when the entire country has not yet collapsed into full civil war. Hence, it is a precarious "peace" to keep. The situation, in-between, is a peace to keep but which necessitates backing from the interveners.

\section{Toward my hypotheses}

How can interveners contribute to setting the conditions for peace? By addressing this important question, my dissertation makes a threefold contribution to the existing literature on peace operations: 1) I put forward a new definition of peace operation success based on my identification of two crucial elements, the (re)establishment of order and the accomplishment of the mandate. This leads me to outline a new typology for better assessing and classifying peace operations, as failures, partial failures, partial successes, or successes; 2) I provide an explanation for the different outcomes of peace operations (based on the type of success/failure) by outlining the $\operatorname{effect}(\mathrm{s})$ of the combination of the key ingredients-strategy \& the type of interveners. I contend that deterrence strategy combined with the intervention of a great power is key for a peace operation's success in the context of intra-state wars; 3) I apply my theoretical framework to empirical cases, testing the saliency of my postulates by examining peace 
operations in three countries: Somalia (1991-1995), Sierra Leone (1999-2005) and Liberia (1990-2009). 


\section{CHAPTER 2}

\section{HYPOTHESES, EXPECTED FINDINGS \& RESEARCH DESIGN}

\section{Introduction}

There is a need to clearly identify why and how peace operations succeed (and fail), and how interveners contribute to these outcomes. This dissertation argues that the strategy and the type of intervener are the key determining elements for the success of peace operations. I define a peace operation as a success based on two criteria: if it accomplishes its mandate, and if order is established (by which I mean the establishment of a legitimate monopoly on coercive force by the state). I argue that the strategy of deterrence - the use of threats instead of the use of force - combined with the involvement of a great power, works best for interventions in intrastate wars. I test the argument with three case studies: the peace operations in Somalia (1991-1995), Sierra Leone (1998-2005) and Liberia (1990-2009). These case studies show that using a deterrence strategy that includes great power intervention contributes to the success of a peace operation, i.e. the accomplishment of the mandate and the establishment of order.

This chapter will be divided into three sections. The first will present my hypotheses and will explain and justify its main variables: success, deterrence strategy and great powers. The second will explain my expected findings. I will 
highlight how different combinations of a particular strategy and of intervener(s) can be expected to produce different types of success/failure. The third will present the research design, looking at the operationalization of the main variables and the justification for my case studies. I will conclude by outlining the organization of the subsequent sections of my dissertation.

\section{Hypotheses}

My claim is that deterrence should be seen as the main focus of intervention efforts aimed at restoring security and a monopoly on violence by the state within its borders. The key issue in this is how deterrence strategies interact with the relative power of intervening countries to allow for the accomplishment of peace operations' mandates, by assuring the belligerents that the peace agreement will be implemented and that the protagonists will comply. The dependent variable is thus the success of peace operations, with the independent variable being the strategy, and the intervening variable the type of intervener.

\subsection{Success: Accomplishment and Order}

I define a peace operation as a success based on two criteria: a) if the operation accomplishes its mandate; and b) if order is re-established within and by the state. This definition flows from the premise that peace operations can vary in the details of their mission and thus in what constitutes the successful accomplishment of their operations, but all share the common aim of restoring order, legitimately enforced by the state. 


\subsubsection{Accomplishment of Mandate}

The accomplishment of the mandate refers to the ratio of tasks planned vs. tasks achieved. However, other elements must also be taken into account when assessing whether a mandate has been accomplished or not, such as the context, the duration and the resources of the peace operation.

In the case of a peacekeeping intervention by a regional or international organization, the collective aspects of the mission impede the clarity and the degree to which the mandate can be designed to fit the context. As discussed in Chapter 1 , because mandates are highly political, they are often the result of compromises between the interests of the different interveners. This leads to blurry statements that are susceptible to change during the course of the operation. It is thus a challenge to gauge the success of a peace operation when all too often the mandate is either unclear and/or very broad. ${ }^{14}$

Judging the success of a peace operation based solely on the mandate would therefore be inaccurate, since such an assessment would effectively be focusing more upon the quality of the mandate than the actual achievements of the operation. In other words, the clearer the mandate and/or the less ambitious the mandate, the more likely that the peace operation would be judged a success, though not based upon the actual achievements but rather due to the design of the mission.

\footnotetext{
${ }^{14}$ As quoted in Chapter 1, I agree that "a mission that is only partly successful in fulfilling an ambitious mandate nonetheless may generate benefits far higher than those brought about by a mission that is nominally more successful by fulfilling a weak mandate" (Downs \& Stedman, 2002: 46).
} 
The duration of a peace operation, when taken on its own, is not indicative of the degree to which an operation accomplished its mandate. Indeed, a peace operation may be deemed successful whether it took three months or lasted eight years. In order to effectively incorporate the time element into my analysis, I will assess the accomplishment of the mandate by looking at the difference between the anticipated duration vs. the actual duration, and will combine this with an assessment of the rapidity with which both the required and non-required tasks were actually achieved during the peace operation (measured based on a comparison of the initial setting vs. the setting after the peace operation).

When assessing the accomplishment of the mandate, I will consider the means that were initially planned, the means that were deployed, the means that were actually employed and both the proportion and the difficulty of achievements given the quantity and the quality of means employed. The ratio between peacekeepers and belligerents will be measured in terms of the quantity and quality of peacekeepers and of peacekeepers' weapons and equipment (whether they were well trained and well equipped) vs. the quantity and quality of belligerents and of the belligerents' weapons and equipment (whether they were well trained and well equipped).

To assess the accomplishment of the mandate, three main elements that play a key role in determining whether the mandate will be fulfilled or not have to be taken into account: the context, the duration of the peace operation and its resources. Doing so also allows the assessment of success to be more thorough regarding what is actually being accomplished. This has the added benefit of 
considering the accomplishment of the mandate based upon the particular conditions of peace operations in failed state settings, something that is rarely done in the literature.

Regarding context, I will look at the many factors involved in the context and in the deployment of the peace operation. Benefits can be assessed in terms of the accomplishment of the mandate (completely or in part), and costs can refer to the magnitude of investment in the operation, the extent to which it stayed within or overran the planned budget, and the human and/or material losses etc. I thus look at the actual accomplishments of the particular quantity and quality of troops and equipment on the ground, and the ratio between their use and outcomes. I compare the initial set up with the set up once the peacekeepers have left. I look at the means deployed, as well as the activities and the accomplishments. I also examine the mandate, in terms of tasks planned vs. tasks achieved. I consider the quantity and quality of the resources mobilized/employed vs. the quantity and quality of tasks achieved. I compare the initial budget vs. total costs after the operation. Finally, I take into account the initial plan regarding the duration of the operation as a whole vs. the amount of time allocated for the peace operation.

The assessment of the accomplishment of mandate with such a plurality of indicators represents a methodological challenge since some indicators may point in some directions and others in the opposite. Fixing a standardized approach of assessment would risk losing the particularity of each case. The assessment is thus done on a case to case basis. In other words, the method used in this dissertation is 
less to code each indicator separately than to draw from these indicators a qualitative assessment of the overall accomplishment of the mandate.

Figure 1. Operationalization of the Accomplishment of Mandate

\begin{tabular}{|c|c|}
\hline $\begin{array}{c}\text { COMPONENTS OF DEPENDENT } \\
\text { VARIABLES }\end{array}$ & INDICATORS \\
\hline Accomplishment of Mandate & $\begin{array}{l}\text { Mandate: } \\
\text { - Clarity } \\
\text { - Tasks planned vs. Tasks accomplished } \\
\text { Duration of peace operation: } \\
\text { - Duration anticipated vs. Actual } \\
\text { duration } \\
\text { Resources: } \\
\text { - Human mobilization vs. Human losses } \\
\text { - Material mobilization vs. Material } \\
\text { losses }\end{array}$ \\
\hline
\end{tabular}

\subsubsection{Order}

The second aspect of my definition of success for peace operations within failed states draws upon the work of Weber (1978), who emphasized the establishment of a monopoly on violence, i.e. order within the state by the state. Capacity and order are also crucial to Samuel Huntington's definition of order (Huntington, 1968). The former is a function of authority, in terms of possessing the ability to command obedience without having to threaten coercion (Weber, 1978). This authority must be independent of enforcement or of the specific 
person who rules. ${ }^{15}$ It is what Bethany Lacina (2006) calls "institutional authority". ${ }^{16}$ The second part of Huntington's definition refers to a coercive capacity. Order requires at minimum a (re)establishment of rules that govern arms use and demobilization of belligerents, as well as the presence of a cohesive and coherent coercive force to enforce those rules.

The order dimension is important because it allows the assessment of the extent to which a state has emerged from "failed state status" by re-acquiring institutional capacity and the ability to use cohesive and coherent coercive force to ensure that rules are followed. Order can be applied by the state but not necessarily exclusively. Order can also be contingent on the presence of a peacekeeping force capable of enforcing these rules.

To assess the (re)establishment of order, this dissertation looks at whether some rules have been agreed upon to govern the use of arms and the process of demobilization, and whether there is either a state capacity or a legitimate international entity capable of enforcing these rules.

To operationalize order, I will assess the rules put in place, as well as the extent to which those rules are independent of enforcement or of the specific

\footnotetext{
${ }^{15}$ The question of legitimacy could also factor in. However, the notion of legitimacy is slippery in the context of intra-state wars. Capacity refers to the monopoly over coercive violence which ideally should be legitimate but not necessarily. It refers to the greater importance of being able to establish a certain degree of stability (which can be at the cost of legitimacy). Roland Paris critiqued the Western Liberal centric notion of institutional design, asking for democracy. Legitimacy can be enforced and might flow from this warweary preference for 'Roman method' of stability rather than more legitimate but still unstable alternatives (Paris, 2002; 1997).

${ }^{16}$ Neither institutional authority nor coercive capacity necessarily implies stable, capable, or good government.
} 
person who rules. I will also examine whether there is either a state capacity or a legitimate international entity capable of enforcing these rules.

Figure 2. Operationalization of Order

\begin{tabular}{|l|l|}
\hline $\begin{array}{l}\text { COMPONENTS OF DEPENDENT } \\
\text { VARIABLES }\end{array}$ & \multicolumn{1}{|c|}{ INDICATORS } \\
\hline \multirow{3}{*}{ Order } & $\begin{array}{l}\text { Rules } \\
\text { - Whether institutionalized } \\
\text { - Type of Institutions managing the rules } \\
\end{array}$ \\
$\begin{array}{l}\text { Enforcement } \\
\text { - whether there is monopoly of coercion } \\
\text { by the state } \\
\text { - systematic or arbitrary (whether } \\
\text { institutionalized) coercion by the state }\end{array}$ \\
\hline
\end{tabular}

\subsubsection{Distinguishing Categories of Outcomes: the Role of Order and}

\section{Accomplishment of the Mandate}

In the recent literature, attempts have been made to differentiate between

different types of successes and failures. Bratt (1997), attempt to scale success, by associating different levels of accomplishment with the notions of success, moderate success and failure. Call (2008) assesses and classifies the success or failure of peace operations based on security, as well as political and social factors. Others, such as Howard (2008), differentiate peace operations' success, mixed success and failure. Yet no work explicitly creates clear categories to classify the different types of outcomes (different types of successes and different types of failures). I address this issue, contending that peace operations can be 
categorized as successes or failures based upon if the operation accomplished its mandate and if order is re-established. When a peace operation succeeds in both, it is a success. Peace operations fail when they do not accomplish their mandate and are incapable of re-establishing order. Importantly, there are intermediate cases in which one of the two aspects of success is achieved. Hence I argue that it is useful to add intermediate categories, to improve our understanding peace operation outcomes.

I argue that for a peace operation in an intra-state war within a failed state setting, the re-establishment of order is more important than the accomplishment of the operation's mandate. Hence a peace operation will be classified as a partial success if order is re-established, though with the qualification that it failed at accomplishing its mandate. By contrast, the operation will be qualified as a partial failure if it succeeds at accomplishing its mandate yet does not re-establish order. This distinction allows us to specify the extent to which a peace operation succeeds or fails, thereby heightening the analytical precision. 
Figure 3. Peace Operation Success: Order and Accomplishment of Mandate

\begin{tabular}{|c|c|c|}
\hline MANDATE & ORDER & NO ORDER \\
\hline ACCOMPLISHMENT & SUCCESS & PARTIAL FAILURE \\
\hline NON- & PARTIAL SUCCESS & FAILURE \\
\hline ACCOMPLISHMENT & & \\
\hline
\end{tabular}

\subsection{Strategy as the Independent Variable}

I will analyze strategy by breaking the variable down into its three main component parts: communication, capacity and knowledge.

First, I will consider the communication between the belligerents and the interveners, among the belligerents, and among the interveners (among the interveners and among the belligerents is necessary to ensure the articulation of groups' actions and principles). ${ }^{17}$ I will also consider the communication between the intervening groups and third parties.

Secondly, I will look at the peace operation's capacity and demonstration of resolve to punish a transgression of prohibited actions (and hence to make use

${ }^{17}$ Even though I will address communication as a distinctive element, given its presence and importance in all the identified components of a deterrence strategy (capacity, resolve, interests, etc.) it will be conceived as a transversal component. Moreover, indirect communication, which sends "cues" to the adversary with regards to the operation's aims and resolve, will also be taken into account. I will refer to such things as the proximity of the Blue Helmets' headquarters to the belligerents, the number of scheduled/planned meetings with the various parties and among the interveners, the type, number and quality of media on the ground, the frequency of their transmission of information, the pedigree of the operations' appointed leaders, etc. (see Figure 4). 
of its capacity). The authority conferred by the UN mandate (whether it allows or prohibits coercive force, i.e. under Chapter 6 or 7 of the United Nations Charter), the importance of the military deployment (quantity and quality of weapons, number of soldiers) and the use of sanctions (number and types of transgressions from the belligerents, as well as number and types of sanctions put in place to punish the belligerents' transgressions) will serve as indicators of capacity and resolve.

Finally, the interveners' and belligerents' knowledge of each other (based on reputation and known interests) will be assessed, to determine to what extent strategies were calibrated to the specific adversary. Reputation can be assessed in terms of the results of previous encounters between the protagonists, previous similar interventions, and the number of sanctions applied by the defender after a transgression. Furthermore, awareness of the attackers' interests may enable the defender to better negotiate with his adversaries. The defender will be able to stress the "relevant" benefits associated with renouncing an attack. Interest can be gauged in terms of the financial resources invested in the operation, the number of actors engaged in the operation, the domestic political support enjoyed by the interveners, and the nature and prioritization of benefits sought (financial benefits, legitimacy, etc.). 
Figure 4. Strategy: Components and Indicators

\begin{tabular}{|c|c|}
\hline COMPONENTS OF A STRATEGY & INDICATORS \\
\hline $\begin{array}{l}\text { Communication: } \\
\text { - Interveners-Peacekept } \\
\text { - Among Interveners } \\
\text { - Among Peacekept } \\
\text { - Third party (international } \\
\text { community) }\end{array}$ & $\begin{array}{l}\text { Official Statements: } \\
\text { - Mandates } \\
\text { - Communiqués } \\
\text { Unofficial Statements: } \\
\text { - } \text { Location of the troops/groups } \\
\text { - Number of meetings } \\
\text { - } \text { Types of meetings } \\
\text { - } \text { Frequency of meetings } \\
\text { - } \text { Inclusiveness of meetings } \\
\text { - Location of meetings } \\
\text { - } \text { Use of media }\end{array}$ \\
\hline Capacity & $\begin{array}{l}\text { Rules of engagement } \\
\text { Number of troops/belligerents } \\
\text { Quantity of armaments } \\
\text { Quality of equipment }\end{array}$ \\
\hline "Knowledge": Interest \& Reputation & $\begin{array}{l}\text { Strategic location of the peace operation } \\
\text { Number of previous encounters/past } \\
\text { interactions } \\
\text { Frequency of encounters/interactions } \\
\text { Types of previous encounters/past } \\
\text { interaction } \\
\text { Timing of peace operation/attack on } \\
\text { domestic, regional \& international level } \\
\text { Sanctions applied/skipped } \\
\text { CV of leaders (of peace operations or } \\
\text { belligerent groups) }\end{array}$ \\
\hline
\end{tabular}




\subsection{Great powers as intervening variable}

Great power intervention contributes to the success of a deterrence strategy and thus to the success of a peace operation. Great powers possess two main advantages that make their commitment more credible and their execution more tailored to the context of an intervention, hence bolstering the probability of success for a peace operation that they are leading in a failed state. First, their credibility stems from their capacity to mobilize more resources, both human and material, and to do so more efficiently. Secondly, the magnitude of their human and material investment could allow the great powers to enhance their credibility, by demonstrating their stake in the success of the operation and/or their established reputation. ${ }^{18}$ Great powers share the dual advantage of being and appearing more committed. They are thus more likely to convince groups of the credibility of their commitment and hence contribute to the probability of success of the operation (Walter, 2002: 27). This will be even more true if the great power has a particular interest in the operation. One factor that can cut both ways is that the belligerents may know that great powers are relatively casualty averse and hence realize that they will be sensitive to the insecurity of the setting, a sensitivity that lowers their threshold of tolerance regarding the loss of soldiers'

\footnotetext{
${ }^{18}$ Once it commits itself to an operation, it is precisely because the great power is more likely to be casualty averse that it will tend to bolster its investment in the mission, giving its troops the means to minimize casualties and hence being the more deterring to belligerents (Hillen, 1998). Obviously, Somalia is the perfect counterexample. The belligerents may know that great powers are casualty averse and hence know that they will be highly sensitive to the insecurity of the setting, a sensitivity which in turn will lower the threshold of tolerance regarding the loss of soldiers' lives, and hence presages the bolstering of their equipment and the aggressiveness of their retaliatory attacks. Yet in Somalia, the intervention of the United States was gradual. The Americans did not have a particular interest in the peace operations, which made them even more casualty averse and resulted in the quick retreat of their troops in 1993.
} 
lives. This seeming weakness on the part of the great power is mitigated however by the fact that they will often bolster their equipment (in terms of quantity \& quality) and the aggressiveness of their retaliatory attacks exactly to avoid such losses. ${ }^{19}$ Ultimately, the presence of a great power has frequently not proven sufficient in and of itself to ensure the success of a peace operation (for instance in Somalia, Haiti, and Congo). This leads to the insight that while the intervention of a great power matters, the strategy employed by the intervener might very well be the key to the success of its mission.

Close and effective coordination of the military bolsters the efficiency and hence the credibility of great power commitment in peace operations within failed states. Moreover, tailoring is likely to be better if a great power is involved because it has more resources for gathering and collecting information. And because its resources are more integrated and better coordinated, it is more likely to take this information into account during the intervention.

However, great power involvement may be perceived as biased in favour of one party over another, or as simply being aimed at advancing the great power's own national interest. This can have a twofold effect: it can boost the credibility of the great power, since regardless of whether the great power is seen as biased or not, it is more likely to appear credibly committed because it has the means to achieve its ends, and will commit those means because it is being driven

\footnotetext{
${ }^{19}$ While support for using force is usually lower when the prospect of casualties is mentioned before the event, when force is actually employed, the public's support is conditioned by the outcome of the military intervention rather than by the number of casualties. As several scholars have argued, the public adopts a cost-benefit calculation in terms of whether the operation "was worth it" (Eichenberg, 2005).
} 
by its own national interest. The risk however is for a great power to be perceived as acting unilaterally, which increases its chances of being perceived as a party to the conflict. In spite of this however, great powers operating within the confines of neutral international organizations seem the ideal choice for peace operations, because of their means, strong interest and strong determination to be effective.

\section{Expected Findings}

\subsection{Outcomes}

I expect to find that the Success of a peace operation - the accomplishment of the mandate and the establishment of order - is most likely when a deterrence strategy is adopted and a great power leads the operation. The adoption of a deterrence strategy, particularly the use of threats instead of the use of force, is more likely to prevent the usual slip-ups associated with the use of force. During and after the negotiations for a cease-fire, the coercive potential of deterrence might convince the belligerents to remain at the negotiating table and agree to put their activities on hold. With regard to terrain, because deterrence is based on the rationality of the actor, an intervener adopting a deterrence strategy is more likely to take into account the human terrain (clans, links, networks etc.). Moreover, because deterrence is a threat-based strategy, interveners are more likely to flex their muscles and communicate in a way that is also adapted to the constraints of the physical terrain. Hence it is more likely that the cost-benefit analysis of the actors in their environment will be taken into account. 
Partial Success refers to a situation where the peace operation failed to accomplish its mandate yet order has been established. I contend that this will happen if a deterrence strategy is adopted by an actor other than a great power. Because collective interveners or less powerful actors have less means and leverage, they might be able to adopt a credible and tailored strategy that will succeed in re-establishing order, yet they are less likely to mobilize sufficient and adequate troops and equipment to accomplish their mandate.

Partial Failure is deemed to have occurred when an operation has accomplished its mandate but order has yet to be re-established. I predict that this situation is most likely if a strategy other than deterrence is adopted. Partial failure can occur in spite of the presence of a great power that has the capacity to mobilize resources and to intervene with efficient means. Yet the failure may come from the adoption of strategy of compellence. With such a strategy, there are more chances that force will be used and that there will be occasional slip-ups, which will result in the interveners being seen as parties to the conflict.

Failure refers to a situation where the peace operation failed at accomplishing its mandate and at re-establishing order. For the reasons explained above, failure can be expected when an actor other than a great power intervenes (due to their weaknesses in terms of having insufficient and/or inadequate equipment, as well as inefficient command and control), and when a strategy other than deterrence is adopted (in which case there are problems of communication, problems related to the use or non-use of force, inadequate 
knowledge, and (mis)perceptions as to the level of interest of the peacekept and of the belligerents in the conflict, and thus in the peace operation.

Figure 5. Typology of Peace Operations' Success

\begin{tabular}{|c|c|c|}
\hline & Great Power Intervention & No Great Power \\
& & Intervention \\
\hline Deterrence & Success & Partial Success \\
\hline No Deterrence & Partial Failure & Failure \\
\hline
\end{tabular}

\subsection{Success/Failure of Deterrence and Success of Peace Operations}

My hypothesis is that when a deterrence strategy is adopted, peace operations are more likely to succeed.

Deterrence strategy represents a winning combination of coercive and noncoercive elements essential for the success of peace operations. I argue that even when non-coercive means are responsible for the success of an operation's mandate, the operation would not be efficient if it was not backed by the possibility of the use of coercive means. I also suggest that even though efficiency is a function of coercive potential, it cannot ensure the accomplishment of an operation's mandate in isolation from non-coercive means. Because deterrence has both a coercive and a non-coercive dimension, this strategy has the dual advantage of increasing the efficiency and ultimately ensuring the accomplishment of the mandate. 
Having the capacity to use coercive force demonstrates to the belligerents and to the civilians the operation's decision-makers' understanding of the insecure setting and of their simultaneous resolve to go through with the mission. Yet successful deterrence does not necessarily have to depend on the capacity to impose punishment, since it can also be achieved by denying the opponent any gains from the action that is to be deterred. For example, when the goal is to stop the enemy's military forces from making territorial gains, deterring via the promise of a protracted and costly war of attrition might be a more appropriate strategy than threatening the nuclear annihilation of the adversary (Mearsheimer, 1983).

By being both capable and resolved, the intervener will increase the probability of deterring prohibited acts and hence will minimize the chance of slip ups or of casualties among the belligerents, the civilians and the intervening troops themselves. More support on the field from the different factions and civilians, as well as more domestic support for the operation, can thus be expected.

Privileging non-coercive means, albeit with the concurrent authority and capacity to use force, will avoid legitimating warfare and will contribute to the promotion of peaceful means of communication. Backing the interveners' peaceful relationship with the belligerents with an appropriate balance of power will be key to ensuring the success of the peace operation.

A deterrence strategy thus has several advantages: it answers the expectations of groups that their adversaries will be deterred, while increasing (in 
comparison with other strategies) the assurance that the deterrence sought will be effective. Keeping this balance and prioritizing non-coercive means while maintaining the capacity to use coercion may thus present the benefit of inculcating norms or standards of behaviour, reinforcing their effectiveness, and/or solidifying the commitment to them among the actors involved (Freedman, 2005; Morgan, 2005).

This hypothesis that peace operations are more likely to succeed if a deterrence strategy is adopted does not address whether the strategy adopted succeeds or fails. Hence the assumption behind my hypothesis may be read as: deterrence strategy's success will cause peace operation's success. Yet one could ask: can there be multiple strategies used in the same peace operations?

In this dissertation, the premise is that multiple strategies cannot be adopted for a single peace operation. Because a change of strategy necessarily entails a change in the mandate of a peace operation, and because both these changes necessarily imply a change in the resources deployed and even a change in the interveners mobilized to wage the peace operation, I contend that by definition, one peace operation will entail: one mandate (which can be modified, though not substantially), one strategy and one type of intervener. ${ }^{20}$

Another set of critiques of my premise is based upon when a deterrence strategy fails. More particularly, can peace operations succeed when strategies

\footnotetext{
${ }^{20}$ For example, UNOSOM continued to be called UNOSOM, yet the mandate, the strategy, the resources deployed and the mandate changed throughout the years such that UNOSOM I was eventually transformed into UNOSOM II. The same is true of UNAMSIL: because of changes, UNAMSIL is broken down into UNAMSIL part I (associated with a specific mandate, strategy, resources/interveners) and UNAMSIL part II (associated with another mandate, another strategy and other resources/interveners).
} 
fail? I argue that they can. Strategy is a necessary but not sufficient condition for the success of a peace operation. This implies that the successful execution of a strategy does not automatically ensure the operation's success, in the same way that the failure of the execution of a strategy does not automatically entail failure of the peace operation. For example, if a deterrence strategy fails, i.e. does not succeed in deterring the actors from committing the prohibited action, the outcome may be assessed in terms of the non-accomplishment of the mandate and the failure of the interveners to establish order. According to the model presented above, such an operation will be a failure. Interestingly, a failed deterrence strategy might turn into a compellence strategy. In such a circumstance, the operation might accomplish its mandate yet ultimately still prove incapable of reestablishing order, in which case it will be a partial failure. Alternatively, a successful deterrence strategy might succeed at re-establishing order without accomplishing the mandate, hence turning it into a partial success.

The model presented above seeks to clarify how the elements put in place for the execution of the strategy will be decisive in determining the outcome of the peace operation, regardless of whether the strategy itself succeeds or fails. Thus the outcome will be assessed, as described above, based upon the accomplishment of the mandate and the establishment of order. 


\section{Research Design}

\subsection{Case Studies}

This dissertation will focus on a number of African case studies, specifically the peace operations in Liberia, Sierra Leone and Somalia. The case study approach will allow for a more detailed examination of 11 individual cases in order to highlight not only if, but also how deterrence strategy works, as well as how its use by a great power influences its success.

Figure 6. Typology of the Role of Deterrence and Great Power Intervention in Peace Operations in Somalia, Sierra Leone and Liberia (1990-2009)

\begin{tabular}{|c|c|c|}
\hline & GREAT POWER INTERVENTION & $\begin{array}{l}\text { NO GREAT POWER } \\
\text { INTERVENTION }\end{array}$ \\
\hline DETERRENCE & $\begin{array}{ll}\text { UNAMSIL II (2001-2004) } \\
\text { UNMIL } & (2003-2009) \\
\text { UNITAF } & (1992-1993)\end{array}$ & $\begin{array}{l}\text { UNAMSIL I (2000-2001) } \\
\text { ECOMIL }\end{array}$ \\
\hline $\begin{array}{c}\text { No } \\
\text { DETERRENCE }\end{array}$ & $\begin{array}{l}\text { ECOMOG (LED BY NIGERIA): } \\
\text { IN LIBERIA } \quad(1990-1998) \\
\text { IN SIERRA LEONE }(1998-2000) \\
\text { UNOSOM II } \quad(1993-1995)\end{array}$ & $\begin{array}{l}\text { UNOMIL (1993-1997) } \\
\text { UNOMSIL (1998-1999) } \\
\text { UNOSOM I (1991-1992) }\end{array}$ \\
\hline
\end{tabular}

Comparing peace operations functioning under different chapters of the UN Charter (Chapter 6, which limits the use of force to self-defence, and Chapter 
7, which allows coercion) and under different authority structures (UN, regional interveners, and great powers) will allow me to test my hypothesis. Two Chapter 6 missions took place in Sierra Leone, one in Liberia and one in Somalia. The cases were also chosen to allow me to test both components of the argument: the type of strategy used and the presence/absence of a great power. In all three cases, strategies of self-defence, deterrence and compellence were adopted by the three types of possible actors (great power, regional organization and/or international organization).

\subsection{Similar Cases}

The three countries have in many ways had comparable recent histories, yet at the same time, each case-study highlights different aspects of the strategies employed, the actors involved and the outcomes of their actions.

During the Cold War, Liberia and Somalia were strategically important and were led by American-backed heads of state. No longer deemed strategically useful after the fall of the USSR, Samuel Doe in Liberia and Siad Barré in Somalia were abandoned by the United States and Russia. In the 1990s, Liberia, Sierra Leone and Somalia became synonymous with lawlessness and anarchy. The three countries entered into civil wars, as ferocious warlords fought over territory. Liberia, Sierra Leone and Somalia also typified the early efforts in the post-Cold War era to consecrate 'humanitarian intervention' as a new principle of international law (Adebajo, 2003b: 62). The lead interveners in these cases were a regional and an international power, Nigeria and the United States, whose foreign 
policies shared a history of interventionist fervour (Adebajo 2003b: 62). Their actions, undertaken under the authority of the Economic Community of West African States (ECOWAS) Ceasefire Monitoring Group (ECOMOG) and the United Nations (UN), along with key political allies, were impeded by two powerful rebels: Charles Taylor in Liberia and Mohammed Farah Aideed in Somalia. Both warlords orchestrated the killing of dozens of peacekeepers hoping to put an end to the missions. The chase for both faction leaders compromised the neutrality of the missions and led to brutal slip-ups and civilians death. The policies in both cases evolved from attacking to appeasing the rebel leaders, but the peacekeepers' coercive actions had led to different outcomes. Nigeria stayed in Liberia for eight years (1990-98), suffered about 400 fatalities, and eventually succeeded in disarming the factions and organizing elections. By contrast, the United States left Somalia after less than a year following the death of 18 of its peacekeepers in October 1993 (Adebajo, 2003b: 63). Somalia remained a failed state setting in with what Menkhaus called "a 'radical localisation' of politics" manifesting itself mainly in informal, overlapping polities loosely held by clan elders and others (Menkhaus, 2004: 155).

Interventions in Sierra Leone and Liberia involved numerous attempts to make peace with different types of interveners, by using various strategies (Fortna, 2008). Somalia did not reach any peace agreement in the period under study (the 1990s), yet three successive peace operations were undertaken there by diverse actors using different strategies. 
The three countries are examples of failed states where military interventions were undertaken by regional and international organizations, as well as by regional and international great powers (Nigeria and the United States). These three cases also incorporate powerful warlords, Charles Taylor and Mohammed Farah Aideed (Adebajo, 2003b). Finally, all three cases present different outcomes.

\subsection{Contrasting Cases}

The cases of Liberia, Somalia and Sierra Leone differ in many respects. The wars in Liberia and in Sierra Leone spread beyond their national borders and thus added a regional component to their conflicts, whereas Somalia's war remained "localised". Peacekeeping operations took place in Liberia and Sierra Leone, whereas the peace operations in Somalia were officially humanitarian assistance operations. Somalia's first war followed the collapse of the regime of Siad Barré, by which point it had slid into corruption after an extended period of drought and famine. The wars in Liberia and Sierra Leone were highly politicized. A regional actor, ECOWAS, intervened in Sierra Leone and Liberia, whereas no regional actor intervened in Somalia. The peace operations waged between 1990 and 1995 were all carried out by the United Nations and by the United States. Liberia and Sierra Leone represented a strategic setting for local, regional and international actors, since these countries are well-known for their abundant

natural resources, including diamonds and timber. No natural resources were associated with the interests of the United States (nor those of the United Nations) 
in intervening in the war. Hundreds of different ethnic groups coexist in Liberia and Sierra Leone, and much of the fighting took place along ethnic lines/affinities. In Somalia, alliances largely occur along tribal lines, with no ethnic, religious or linguistic characteristics differentiating the internal actors.

Yet in spite of these differences, it is very worthwhile to compare the peacekeeping histories in these three countries. Doing so highlights the extent to which these very differences interfered or did not interfere with the strategy used and the actors involved in particular peace operations. If the same strategy, same actors, and same kind of peace operation have similar effects in more than one setting, it will strengthen the explanatory value of our variables.

\subsection{Avoiding Selection Bias}

Such a comparative method will allow me to conduct both within-case comparisons and across-case comparisons. Indeed, each of these countries has known at least two peace operations with relatively similar mandates but with widely different composition, structure and strategy. My comparative analysis will follow the different categories presented in the charts above: comparing cases of failure, partial failure, partial success and success in light of the peace operations in Liberia, Sierra Leone and Somalia. One main argument against this way of proceeding would be with regards to selection bias: these operations may have some characteristics that differ from other peace operations.

Indeed, according to Doyle and Sambanis (2006), all three of these countries fall into what they call the "fifth ecology", "where there are many, 
incoherent, and hostile factions in a desperately poor economy" (Doyle \& Sambanis, 2006: 331). One therefore may wonder whether our argument is only valid for the fifth ecology.

Yet, this dissertation somewhat challenges the classification offered by these authors. As it will be seen in the next sections, we find that if, indeed, these countries are characterized by many hostile factions in a desperately poor economy, factions are well-defined groups with reasonably clear and stable official authorities/hierarchies. $^{21}$

According to Doyle and Sambanis, “(...) the prospects appear to be even more grim for effective peacebuilding" in the countries belonging to their fifth ecology (Doyle \& Sambanis, 2006: 331). However, I will demonstrate in this dissertation that there is a diversity of peace operations outcomes within each country, a diversity that does not appear in Doyle and Sambanis's data since they limited their study to UN peace operations which happened in these countries prior to 2001 (Doyle \& Sambanis, 2006: table 3.1:79-80). This dissertation ultimately shows that even if these countries represent challenging contexts, peace operations may succeed.

I thus intend to demonstrate that even in the "worst" context of "transitional politics", the type of strategy employed and the type of intervener involved have a determining effect on the outcome of peace operations. This

\footnotetext{
${ }^{21}$ It would be indeed interesting to explore whether a sixth ecology could be added in Doyle and Sambanis classification, one with many coherent and hostile factions. This would represent a combination of Doyle and Sambanis's third (few, hostile and coherent factions) and fifth (many, hostile and incoherent factions) ecology i.e. a sixth ecology characterized by many, hostile and coherent factions.
} 
dissertation thus tends to show that the type of ecology is less determining for peace operation outcomes than the type of strategy and of intervener. Moreover, I assume that if this is valid in these hard set of cases (failed states in which there are many, hostile and coherent factions), it must be also valid for the easier ones (ones that then would fall in the four other ecologies).

\section{Organization of the Dissertation}

The subsequent chapters will follow the typology presented above. I will compare the experiences of the three countries in light of the failure, partial failure, partial success and success of their operations. Throughout these chapters, my contribution to the literature will be twofold: highlighting the use of my definition of success in better grasping the differences in outcome of peace operations, and outlining the importance of the combination of the key ingredients-strategy and type of interveners. I will examine the extent to which the accomplishment of the mandate is on one hand a function of coercive potential (and the extent to which non-coercive means backed by this coercive potential are responsible for the success of an operation), and on the other hand, the extent to which the type of intervener alters the process and outcome of operations. I will conclude with a summary of this dissertation' main findings, and will highlight further avenues of research that could further illuminate our understanding of how various strategies and contexts interact differently depending on the interveners, their commitment and the setting in which the operation takes place. 


\section{Chapter 3}

\section{Partial Failure:}

\section{ACCOMPLISHING MANDATE WITHOUT ESTABLISHING ORDER}

As the old saying goes, all good things do not go together. A fundamental conundrum of peace operations is that the means for accomplishing their mandates are not necessarily the ones that will contribute to achieving order. Over the past 20 years, the severity of intra-state crises has often demanded strong intervention from outside interveners. The involvement of great powers and collective interveners alike has been seen as the solution to ending violent instability in the context of intra-state wars. Given the insecurity of such settings, the means deployed to back up these interventions have often been quite robust. The use of compellence when equipped with robustly coercive equipment is more likely to create slips-up i.e. casualties amongst both belligerents and civilians alike, which will result in the interveners being seen as party to the conflict.

I contend that the partial failure of a peace operation - the accomplishment of the mandate and the failure to establish order - is most likely to occur when a compellence strategy is adopted, even if a great power is involved in the peace operation. The puzzle in this section is: how can a peace operation succeed in one dimension while failing at another?

In this chapter, I will show how the adoption of a compellence strategy in a peace operation led by a great power may make it possible for that peace 
operation's mandate to be accomplished, yet by doing so, simultaneously hinder its capacity to re-establish order. I will compare three peace operations that occurred at different stages of a conflict and that involved different kinds of belligerents, and which were all led by a great power that had adopted a compellence strategy: United Nations Operation in Somalia II (UNOSOM II) (1993-1995); Economic Community of West African States Cease-fire Monitoring Group (ECOMOG) in Liberia (1990-1998); and the ECOMOG intervention in Sierra Leone (1997-2000). The diversity of the settings and of the timing involved will allow us to highlight the role played by the combination of communication, capacity and knowledge of both the peacekeepers and the peacekept in the crafting of the common outcome.

This chapter draws upon official documents, expert reports and interviews with regional experts to assess the arguments and hypotheses advanced. My research on the ECOMOG operation in Liberia was supplemented by an interview with Lieutenant-General Arnold Quainoo, the first commander of the ECOMOG force in Liberia. I will also refer to my interview with a key expert, Dr. Kwesi Aning, who has devoted considerable time to studying the peace operations in Liberia and Sierra Leone. His experience and unique perspective validated the ideas presented below.

My research on UNOSOM II was supplemented by interviews with Somalis who lived in three of the main Somali cities at the time of the operation (Mogadishu, Kismayo and Baidoa). I met them in the Ogaden region while they were refugees, and my questions were aimed at uncovering their perceptions of 
the peace operations in Somalia from 1991 until 1995. Their memories of these key events and the insights that they shared provided me with a rare, inside-view to the conflict. This was very useful, since the perspective of the peacekept is rarely taken into account when trying to understand the impact of an intervention.

This chapter will be divided into two sections. The first will focus upon the similarity in outcome for each peace operation, by closely examining the extent to which each succeeded in accomplishing its mandate while failing at reestablishing order. To do so, I will compare the setting prior to, and after, each intervention. I will highlight the dynamic between the accomplishment of the mandate and the maintenance/re-establishment ${ }^{22}$ of order, and I will show how the success of the former can lead to the failure of the latter. In the second section, I will assess the differences between the three peace operations by examining more closely the processes that made them partial failures. I will conclude by highlighting the need to distinguish between the process and result when assessing the success/failure of a peace operation. I will also highlight the importance of the type of interveners and how the strategy is key for explaining the outcome of peace operations in intra-state wars.

\section{Assessing Outcomes}

The peace operations described below occurred in different contexts and at different stages of the conflict. They involved different actors, had different

${ }^{22}$ UNOSOM II took place following an operation that had successfully re-established order (UNITAF) (See chapter 6). Hence its partial failure stems from its incapacity to maintain order while accomplishing its mandate. 
mandates, mobilized different quantities and types of resources and had varying durations. Yet in spite of these differences, they all had a similar outcome: they ultimately failed at re-establishing order while succeeding at accomplishing their mandate. It is thus worthwhile to compare them, since doing so will highlight how these differences interacted with the strategy used and the actors involved. What emerges is that the same strategy, same kind of actors, and same kind of peace operation produced similar effects in more than one setting, which strengthens the explanatory value of our variables.

\subsection{UNOSOM II (1993-1995)}

"Judging by the Somali death toll of 1992, one could reasonably estimate that upwards of a quarter of a million Somali lives were saved. Some failure." -

Chester Crocker, 1995

The second United Nations Operation in Somalia (UNOSOM II) proved effective at accomplishing important parts of its mandate, but more importantly it was efficient given the constraints of that mandate, its limited resources and the deep overall hostility to the deployment of the mission.

\subsubsection{Initial Setting}

The president of Somalia, Siad Barré, was overthrown in January 1991. The political upheavals, combined with a severe drought, devastated the country. Within a few months, quarrels between political factions and famine resulted in more than 50,000 victims. The UN fully engaged in continuous humanitarian efforts in the country, yet the insecurity of the setting forced the frequent 
temporary evacuation of its personnel (Minear \& Weiss, 1995: 110; UNDPKO 1992). Until the adoption of Resolution 733 marking the beginning of UNOSOM I in March 1992, only NGOs such as the Red Cross and Doctors without Borders (Médecins sans frontières) continued to operate permanently in the country. In November 1991, fighting between armed factions climaxed with the killing of between 20,000 and 30,000 civilians (Natsios, 1997: 80). Over the course of 1991, more than 300,000 deaths were reported (Sahnoun, 1994: 15). Andrew Natsios recalls "Measured by the numbers of lives lost in a relatively small geographic and in a relatively short period of time, Somalia was the worst humanitarian tragedy since the Ethiopia famine 1984-1985" (Natsios, 1997: 84).

Rival Somali clans became driven by violent internal fighting. In Mogadishu, the Hawiye clan broke into two quarrelling groups: the Abgal faction was headed by the self-declared president Ali Mahdi, and the Haber Gedir was led by General Hussein Farah Aideed, Mahdi's main rival (Menkhaus, 2003: 410). The warring parties benefitted from the state of war, with the leaders of each clan using violent means to gain support from the population (Menkhaus, 2003: 416). Armed men supplied and financed by weapons smuggling also disturbed regional security, often targeting humanitarian organizations' resources and workers. With the generalized famine, food became a tradable commodity.

UNOSOM II was the third successive peace operation in Somalia within a year (1992-1993), and the second peace enforcement mission in the country. The belligerents were strongly opposed to its deployment because they believed that it was biased against them (Rutherford, 2008; Hirsch \& Oakley, 1995). As a result, 
the operation was launched under the authority of the UN Charter's Chapter 7, which does not require the consent of the parties to the conflict.

UN Resolution 837 specified that UNOSOM II's objective was twofold: to consolidate, expand and maintain a secure environment and to rehabilitate Somalia's political and economic institutions (UN Security Council, Resolution 837, 1993). Oakley quotes Madeleine Albright, the American representative to the $\mathrm{UN}$, as saying that the resolution was "an unprecedented enterprise aimed at nothing less than the restoration of an entire country" (Hirsh \& Oakley, 1995: 111). The mandate of UNOSOM II was to take appropriate action, including enforcement measures, to establish a secure environment for humanitarian assistance throughout Somalia. To that end, UNOSOM II was to complete the task begun by UNITAF $^{23}$ for the restoration of peace, stability, law and order, by pursuing disarmament and reconciliation. Its main responsibilities included monitoring the cessation of hostilities, preventing a resumption of violence, seizing unauthorized small arms, maintaining security at ports and airports, securing lines of communication for the delivery of humanitarian assistance, continuing mine-clearing, and assisting in the repatriation of refugees in Somalia. UNOSOM II was also entrusted with assisting the Somali people in rebuilding their economy and social and political life, re-establishing the country's institutional structure, achieving national political reconciliation, recreating a Somali state based on democratic governance, and rehabilitating the country's

\footnotetext{
${ }^{23}$ The United Task Force operated between December 1992 and March 1993. This operation and its outcomes are discussed in Chapter 6.
} 
economy and infrastructure (United Nations Department of Peacekeeping Operations, 1993).

The resolution was conceived broadly so as to give the UN the flexibility to do what it could to make the situation better in the country. David Shinn, the State Department deputy director of the Somalia Task Force, stressed that the resolution “doesn't say, thou shalt create a national government or thou shalt recreate an economy. It says that the international community should do what it can to help the Somalis recreate a government" (cited in Rutherford, 2008: 110). According to Rutherford, "The main purpose was to lessen the likelihood that concluding the UN operation would result in the recommencement of widespread famine and violence" (Rutherford, 2008: 109).

One result of this very broad mandate was that the UN force of 28,000 had an ill-defined task for an unspecified period of time. Moreover, although it was a smaller force than the preceding peace enforcement operation (UNITAF) ${ }^{24}$, it was now given jurisdiction over the entire country. And in addition to protecting the relief effort, it was tasked with maintaining peace (UNDPKO, 1995).

\subsubsection{No Order}

While the famine ended during the UNOSOM II intervention and refugees and internally displaced persons returned to some regions, a new state was not built. "Thus, when UNOSOM II departed from Somalia in March 1995, it left the

\footnotetext{
${ }^{24}$ UNITAF took place between December 1992 and March 1993. This operation is discussed in more details in Chapter 6.
} 
country divided, without a central government" (Gundel, 2002: 256). Ultimately, the ambitious plan to rebuild the internal structures of a functioning state had not proven possible in the face of the inability of the Somali factions to come to terms with each other. But this is not to say that nothing was achieved: the United Nations had helped to put in place 52 (out of a potential 92) district councils, and eight regional councils (out of a potential 18) (UNDPKO 1997a). The Somali National Alliance (SNA) strongly opposed the formation of these councils and thus blocked the creation of the Transitional National Council conceptualized in the Addis Ababa Agreement of March 1993 (UNDPKO 1997a). ${ }^{25}$ Yet even though political reconstruction did not go as planned, these agreements continued to serve as the major political frame of reference in Somalia. Throughout much of 1994, the UN appealed to factions and factional leaders for help in creating a national government. Numerous peace conferences and informal talks were held, with the hope of brokering an agreement between General Morgan, General Aideed and Col. Abdullahi Yusuf, who UNOSOM II felt could provide sufficient military forces for stabilizing the country. Yet these efforts failed, largely because "none of the political factions (....) was sufficiently broad-based and authoritative

\footnotetext{
${ }^{25}$ The Addis Ababa Agreements, signed on 27 March 1993, offer a "broad outline of a framework for a transitional system of governance to allow for the provision of essential services, the creation of a basis for long-term planning, and for the resumption of greater administrative responsibility by Somalis". The Transitional National Council (TNC) was meant to be: "the repository of Somali sovereignty; be the prime political authority having legislative functions during the period in question; interact, as appropriate, with the international community, including UNOSOM; appoint various committees, including the Transitional Charter Drafting Committee, as required; appoint Officers for its various functions; appoint the heads of administrative departments; oversee the performance of the departments created; and establish an independent judiciary." Addis Ababa Agreement concluded at the first session of the Conference on National Reconciliation in Somalia, 27 March 1993.
} 
to implement accords of national reconciliation. Instead, all of the factions faced a serious erosion of their power base" (Menkhaus \& Prendergarst, 1995: 4). When the UN left Somalia in 1995, war was still raging.

\subsubsection{Accomplishment of Mandate}

The negative outcomes of UNOSOM II have been the most focused upon: 43 US dead, about 150 UN fatalities, 1,600 Somali fatalities, a \$2.2. billion cost for the US, and the failure to capture Aideed (Johnson \& Tierney, 2006; Hirsh \& Oakley 1995). With the US having made the capture of Aideed a central objective, their failure to do so prompted the view that the entire UN operation was a failure. ${ }^{26}$ According to Johnson and Tierney,

because of a combination of mind-sets, salient events and social pressures, people imagined that the US performance in Somalia was an outright failure. They were wrong. It was at worst a qualified success. (Johnson \& Tierney, 2006: 222)

It is likely that if UNOSOM II had been given a more realistic/precise mandate, it would have been judged a greater success, particularly given the constraints and the challenges that it faced, and in light of its accomplishments. Over the course of two years, it is estimated that millions of Somalis benefited from UNOSOM II's activities and, at a minimum, that an estimated 250,000 lives were saved (UNDPKO, 1997a). Also extremely significant is the fact that the number of refugees dropped from 1.5 million to 750,000. Militarily speaking,

\footnotetext{
26 "This has cast a long shadow over subsequent forceful humanitarian efforts - the powerlessness of the so-called Somalia syndrome is the post-Cold War equivalent of the Vietnam syndrome" (Johnson \& Tierney, 2006: 229).
} 
achievements included the capture of Aideed's associates and the killing of roughly 500 to 1,000 of Aideed's soldiers (Johnson \& Tierney, 2006: 213), which prompted some authors to label it a remarkably asymmetrical victory for the United States (Johnson \& Tierney, 2006). According to Menkhaus, the peace operation even "came to have a positive impact on governance and state building in later years.' (Menkhaus 2007: 82).

The large UN operation poured an enormous amount of money as well as sizable employment and contract opportunities into the country and helped to stimulate and strengthen legitimate businesses, thereby shifting business activities away from a war economy toward construction, telecommunications, trade, and services. In the process, it helped to reshape local interests in security and rule of law, and eventually local power relations as well (Menkhaus, 2007: 82).

Most accounts of UNOSOM II focus on the humanitarian and political development in the Somali capital of Mogadishu, paying relatively little attention to its success at improving living conditions in the countryside (Mockaitis, 1995). By mid-1993, a few months after the beginning of the operation, starvation had largely been eradicated. ${ }^{27}$ The most vulnerable population groups were receiving food aid, and 'food-for-work' schemes were established to help with the rehabilitation of schools and hospitals, as well as water, sanitation and other services.

By September 1993, only six months after the beginning of the mission, 51 schools had reopened in southern Somalia, and by the end of the year some 70,000 children were enrolled in primary schools. There was also a strong

${ }^{27}$ Although pockets of severe malnutrition could be found in certain isolated areas (UNDPKO, 1997a). 
recovery in livestock exports to the Gulf (Halim, 1996:

$80)$.

By December 1993, with the protection of UNOSOM II, UNICEF was assisting 40,000 students. Thirty-two hospitals and 103 mobile vaccination teams were functioning. Seventy thousand refugees had returned, while 39 districts councils and six regional councils were put into place. UNOSOM II had initiated its recruitment of former Somali police officer to assist in basic police functions. There were more than 5,000 in total (Doyle \& Sambanis, 2006: 152).

UNOSOM II was able to convene more than 35 local, regional, and international initiatives aimed at fostering a negotiated peace between 1991 and 1995, though all ultimately failed to result in lasting peace (Doyle \& Sambanis, 2006:154). There were also achievements in terms of setting-up a Somali police force: some 8,000 were deployed in 82 district stations. By March 1995, there were 46 district courts, 11 regional courts and 11 appeals courts, all functioning because the United Nations had helped with funds, training and rebuilding of infrastructure (UNDPKO, 1997a).

According to Crocker (1995), even if measured by the standards first set by the United States, the intervention in Somalia was not a complete failure. UNOSOM II accomplished much humanitarian relief and most analysts believe that a larger tragedy was averted. And even though a central government was not re-established, the intervention certainly helped to improve the Somali political landscape, since it put a halt to clan warfare and "opened the field for local initiatives" (Crocker, 1995:3). Assessing the overall material gains and losses resulting from the US intervention in Somalia, and taking into account the 85 
achievement of US material aims, Johnson and Tierney go so far as to characterize the intervention as a partial success (Johnson \& Tierney, 2006:220). Using my frame of analysis based on the establishment of order and the accomplishment of mandate, UNOSOM II was a clear partial failure.

\subsection{ECOMOG in Liberia (1990-1998)}

\subsubsection{Initial Setting}

The Liberian civil war was triggered by a coup led by Charles Taylor in December 1989. It was carried out by the National Patriotic Front of Liberia (NPFL), which was made up of Libyan-trained dissidents and was headed by Taylor, a former employee of President Samuel Doe's government. The fighting soon acquired ethnic overtones, this in a country with 17 different ethnic groups, with no one group representing more than $20 \%$ of the total population. The most important of these groups are the “'Americano-Liberians' who ruled the country until 1980, the Mano and Gio in the North, the Mandingo in the West and the Krahn in the Northeast" (Howe, 1996-1997: 147).

The war opposed the NPFL and their Gio and Mano affiliates against the Krahn-dominated Armed force of Liberia (AFL) and their Mandingo allies. As well, a new group was formed amongst the NPFL and started to distance itself from the main party. The Independent NPFL (INPFL), led by Prince Yourmie Johnson, fought both the AFL and their former colleagues in the NPFL. But after six months of fighting, the NPFL still controlled $90 \%$ of Liberia and was resolved to launch a decisive assault on Monrovia (Maraia, 1997:4; Adebajo, 2003a). 
By August 1990, ECOWAS had negotiated a cease-fire and decided to dispatch a multinational peacekeeping force, known as the ECOWAS Cease-fire Monitoring Group (ECOMOG) to Monrovia. ECOMOG was given a broad mandate without a defined time limit, and was justified largely on humanitarian grounds. According to the ECOWAS mandate, the ECOMOG forces had four different goals to achieve: "they were to restore law and order, negotiate a ceasefire agreement, establish an interim government, and make provisions for the free and fair election of a new government" (Shaw, 1995: 9). The AFL and the INPFL decided to work with ECOMOG, while Taylor opposed the intervention with the purpose of preventing the NPFL from gaining more power. Three thousand ECOMOG troops landed in Monrovia in August 1990 under hostile fire (Maraia, 1997).

\subsubsection{No Order}

Just like UNOSOM II, ECOMOG was heavily criticized for achieving relatively little in Liberia. When ECOMOG left the country in 1997, elections were held and were won by Charles Taylor and his National Patriotic Party (NPP). But political problems continued to plague post-war Liberia, largely as a result of the mobilization of armed ethnic groups in support of the agendas of rival warlords during the civil war. The political problems were also driven by Taylor's efforts to gain a monopoly over the legitimate use of force (Adebajo, 2003a: 231). Taylor thus made the state apparatus an extension of his personal power, and used it to silence his critics and to control the growing insurgency. 
Taylor's need to do so underlined his inability to command obedience without threatening coercion. That is, his authority following the elections was not independent of enforcement, and was personalized rather than being vested in the state's institutions. This meant that even though a coercive capacity was established, it was neither cohesive nor coherent. "Institutional authority" was thus deficient. ${ }^{28}$ The civil war resumed soon after ECOMOG's departure.

\subsubsection{Accomplishment of Mandate}

As with UNOSOM II, the ECOMOG intervention in Liberia is usually depicted as an outright failure. It did not succeed in establishing a lasting government, it did not prevent renewed conflict, and it became embroiled in the war, ultimately remaining in place for more than seven years. Yet critics of ECOMOG tend to overlook crucial accomplishments that render this peace operation a partial rather than a complete failure.

Residents of the Liberian capital greeted the intervention with great enthusiasm, reportedly chanting "Thank God for ECOMOG!" in the streets of the capital. From the outset, ECOMOG was efficient, quickly establishing a semblance of peace and order in Monrovia, which allowed international humanitarian groups to re-enter the country. It pushed back the AFL and another rebel group, Prince Johnson's INPFL; it enabled the Interim Government of National Unity (IGNU), headed by Amos Sawyer, to be installed; and it put in

\footnotetext{
${ }^{28}$ Neither institutional authority nor coercive capacity necessarily implies stable, capable, or good government.
} 
place a cease-fire. Even more importantly, ECOMOG stopped the slaughter of Krahn and Mandingo people in Monrovia. The prevailing sentiments of many of the capital's residents were reported by a Liberian medical worker, who said:

ECOMOG was our savior; it was a salvation. ECOMOG saved the population of Monrovia. They avoided fighting, but were pushed into a corner. We feel sorry for them; they have no cause to die here for this stupid, senseless war" (Truth and Reconciliation Commission of Liberia; Final Report 2009:212).

For some authors, the fact that ECOMOG's intervention in Liberia succeeded in preventing the situation from degenerating into the sort of genocidal slaughter that took place between April and July 1994 in Rwanda makes it comparable to UNOSOM II in terms of success (Draman \& Carment, 2001: 17). Other analysts argue that ECOMOG was a greater success than UNOSOM II. For instance, President Sawyer pointed out that "[it] took 28,000 U.S. troops in Somalia to distribute food. We have here less than 10,000 ECOMOG forces, assaulted by a force in Taylor's estimate of 30-70,000, whose purposes are known to everybody."(cited in Human Right Watch, 1993a).

ECOMOG proved efficient on the political level, because of its success at bringing together the disputants to discuss the terms of a peace agreement. But the peace agreements that were brokered did not hold:

Between February 1990 and August 1995, Liberia's combatants signed and subsequently ignored, thirteen peace agreements. That time period saw the birth of new factions, including the United Liberation Movement of Liberia for Democracy (ULIMO) and the Liberian People's Council (LPC), and the demise of others, such as 
INPFL which ceased operations in late 1992 (Maraia, 1997: 5). ${ }^{29}$

ECOMOG did manage to gain the cooperation of several faction leaders. Amongst the most notable personalities with whom ECOMOG managed to cooperate was AFL General Hezekiah Bowen in April 1992, and INPFL Prince Johnson, in October of the same year (i.e. after the INPFL had been defeat by the NPFL and had thus surrendered to ECOMOG forces) (Shaw, 1995: 10).

Thus while ECOMOG was able to forcefully convince rebel troops to sign numerous agreements aimed at putting in place a stable ceasefire, establishing an interim government, and preparing for free and fair elections, each of them broke down, leading to a resumption in fighting. There are two significant factors that rendered the negotiations unsuccessful: the factions were reluctant to seriously negotiate with each other, and they rejected the mediators as illegitimate, claiming that ECOMOG's military operations and the interests of neighbouring states in the conflict compromised the peacekeepers' impartiality. The faction leaders, particularly Charles Taylor, used this second issue as an excuse to fight rather than to negotiate. Ultimately then, ECOMOG accomplished its mandate, yet this did not prove sufficient to implement order in the country.

29 "Subsequent to the Banjul talks in August 1990, ECOWAS convened negotiations in Bamako, Mali (November 1990); Banjul, Gambia (December 1990); four rounds of talks in Yamoussoukrou, Côte-d'lvoire (June-October 1991, known as Yamoussoukro I, II, III, \& IV); Akasombo, Ghana (September 1994); Accra, Ghana (November-December 1994); and Abuja, Nigeria (August 1995). In addition, in conjunction with the UN Special Representative, talks were convened in Geneva, Switzerland (late June 1993) and in Cotonou, Benin (July 1993). Virtually all of these negotiating sessions resulted in some form of peace accord or ceasefire agreement, none of which have ever been successfully implemented" (Marley 1997: 113). 


\subsection{ECOMOG in Sierra Leone (1998-2000)}

\subsubsection{Initial setting}

The conflict in Sierra Leone would not have escalated to the degree that it did had it not been for spill over from the conflict in Liberia (Hirsh, 2001a). On 23 March 1991, Charles Taylor encouraged elements of his faction to enter Sierra Leone (Adebajo 2003a: 90). These factions were headed by a former corporal in the Sierra Leone Army (SLA), Foday Sankoh. Meanwhile, elements within the SLA overthrew President Joseph Momoh in April 1992, and the National Provisional Ruling Council (NPRC) was installed to run the country. Valentine Strasser was made Head of State and ruled until his own overthrow in January 1996, by his Chief of Defense Staff, Julius Maada Bio. Elections were held one month later, in February 1996. The Sierra Leone People's Party, headed by Ahmad Tejan Kabbah, won the elections and thus replaced the NPRC.

One of the rebel factions, the Revolutionary United Front (RUF), soon mounted hostilities against the government and took control of a large part of Sierra Leone's territory. Then in May 1997, elements within the SLA overthrew Kabbah. This development was enthusiastically embraced by the RUF, who formed an alliance with the new government known as the Armed Forces Revolutionary Council (AFRC). Many RUF officials were asked to serve in Koroma's government and Sankoh was made deputy by the AFRC leader (Berman, 2000:11).

Nigeria had previously signed a defence agreement with Sierra Leone, and it thus felt that an intervention to restore the overthrown government of Ahmed 
Tejan Kabbah was necessary. In 1998, at the request of the Organization of African Unity (OAU), ECOWAS agreed to contribute 9,000 troops to ECOMOG in Sierra Leone, so as to re-install the democratically elected government of Kabbah to power (Hirsh, 2001b; Adebajo, 2004a). Its mandate was meant to be accomplished within a few months.

\subsubsection{No Order}

Compared to UNOSOM II and the ECOMOG intervention in Liberia, ECOMOG's intervention in Sierra Leone had a succinct and clear mandate (reinstalling Kabbah's government), to be accomplished within a shorter time span. Quite paradoxically however, although ECOMOG did manage to quickly fulfill its mandate by restoring the government of Kabbah, it failed at re-establishing order in the country. By December 1999, rebel factions were launching violent raids against the interveners and against the government. These factions waited until ECOMOG had departed to retake Freetown, while also holding several villages hostage. They also made multiple attempts to topple the government, all of which effectively restarted the war in Sierra Leone.

\subsubsection{Accomplishment of Mandate}

As with the two previous operations, the lack of enduring order prompted many authors to severely criticize what they saw as a failed mission. By adopting an offensive compellence strategy, ECOMOG - or as it was more popularly known, "Every Object and Car Gone" - had joined in the conflict, causing a 
heavy toll in civilian casualties and committing abuses itself (Tuck, 2000). Concomitantly, it failed to stop the renewed violence and unfolding humanitarian disaster.

Nonetheless, ECOMOG did manage to accomplish its mandate. Within ten months of the operation's start, it had succeeded in forcing the AFRC/RUF government from power. It then convened a peace meeting in Conakry, and convinced the belligerents to commit to a deal for a six-month transition period to restore the Kabbah government in March 1998. All of these developments were immediately hailed as a "stunning success" by many observers (Woods \& Reese, 2008: 44).

But in spite of these successes, belligerents continued to mount attacks against the government and the interveners, and continued to hold villages hostages. Thus while the peacekeepers succeeded in 'bombing' most factions to the negotiating table ${ }^{30}$, they failed to force them to keep their commitments, since the government remained dysfunctional and the various factions continued to wage war against each other. Ultimately then, ECOMOG accomplished its mandate but did not meet its ultimate objective of re-establishing lasting order. This constitutes a partial failure according to our frame of analysis.

\footnotetext{
${ }^{30}$ This expression is used by Adekeye Adebajo in the context of the Cotonou Agreement. The author writes that "With the signing of the Cotonou agreement on 25 July 1993, ECOMOG had in effect bombed Charles Taylor to the negotiating table." (Adebajo 2003a:127). The method used by ECOMOG was similar in the case of the Conakry agreement.
} 


\section{Assessing Process}

What explains such outcomes? In answering this question, the next section looks at the role of the type of intervener and of the type of strategy adopted. I examine the process by which peace operations succeed at accomplishing their mandate while simultaneously hindering their chances of re-establishing order. I also highlight how compellence influenced the communication, the use of capacity and the knowledge/understanding of the peacekeepers toward the belligerents. I demonstrate that the strategy framed the operations in such a way as to enable interveners to quickly achieve an important part of their mandate, but while doing so, sabotaging the very means by which they could re-establish order in the country.

\subsection{UNOSOM II}

\subsubsection{Type of intervener}

Although UNOSOM II was under the authority of the UN, the United States remained a key player. American political and military decision-makers were the driving force behind the UN mission (Peterson, 2001; Hirsh \& Oakley, 1995, Rutherford, 2008). ${ }^{31}$ The UN Special Representative of the Secretary General (SRSG) was retired US Admiral Jonathan Howe (Rutherford, 2008:180). The US encouraged the UN to name the Turkish General Çevik Bir as the commander of UNOSOM II, but then pushed for a command structure that made

\footnotetext{
${ }^{31}$ Kenneth Rutherford stresses that "It would be quite wrong, however, to imagine that the United States handed the Somalia mission over to the United Nations with the creation of UNOSOM II" (Rutherford, 2008:180).
} 
sure that US armed forces would report to US Army General Thomas Montgomery, the deputy commander, rather than to General Bir (Rutherford, 2008: 122). This meant that there were two separate chains of command in place for the operation. Thus while UNOSOM II was a UN operation with 23 nations contributing to its strength, the United States promised to remain directly engaged and fully committed to the mission by providing senior officers, a strong logistical capacity with some 1,500 personnel to provide vital support, and a quick-reaction force of 1,200 troops to intervene in emergencies. In addition to the key combat units being American, the decision-makers were primarily from the United States (Peterson, 2001). Indeed, most of UNOSOM II's mandate had been written in Washington (Johnson \& Tierney, 2006: 239). It is because of this strong U.S. backing that the Security Council approved the ambitious, experimental, and virtually open-ended mandate for UNOSOM II that would inevitably "plunge the international community far more deeply into Somalia's internal affairs than any previous case since the Congo" (Crigler, 1993: 66).

\subsubsection{Choice of Strategy}

Three UN resolutions were passed during UNOSOM II's mandate. Resolution 814 was adopted under the authority of the Chapter allowing the interveners to use force other than just for self-defense. UNSC Resolution 837 (paragraph 5) explicitly encouraged the peacekeepers to adopt a compellence strategy towards the belligerents, more specifically toward General Aideed, whose 
arrest was mandated (UNSC Resolution 837 1993). ${ }^{32}$ The third resolution called for the end of the peace operation in March 1995.

\section{Communication}

The compellence strategy framed the communication between the peacekept, the belligerents and the populace alike. The strategy was not to "invest in cheap talk" but rather to put "costly signalling" to work (Slantchev, 2005: 534). Based on this, UNOSOM II did not invest much effort in communication with the local people, and indeed UNOSOM II troops did not mix with them, preferring to stay at a camp outside Mogadishu. Effectively therefore, UNOSOM II personnel were isolated from the Somalis. ${ }^{33}$ This distance from the population contributed to the impression that the operation's participants were biased against the peacekept (Peterson, 2001). ${ }^{34}$ That impression was further fuelled by the fact that the intervener did not invest in information gathering regarding the peacekept, nor did it attempt to shape the perceptions of the civilian populace. Moreover, there were no daily dialogues with the factions' commanders. Throughout UNOSOM II, US

32 "Reaffirms that the Secretary-General is authorized under resolution 814 (1993) to take all necessary measures against all those responsible for the armed attacks referred to in paragraph 1 above, including against those responsible for publicly inciting such attacks, to establish the effective authority of UNOSOM II throughout Somalia, including to secure the investigation of their actions and their arrest and detention for prosecution, trial and punishment." ( UN Resolution 837 1993; UNDPKO 1993)

${ }^{33}$ Peterson notes that "Behind its 10-foot high walls encrusted with shards of looter-proof broken glass, the UN would always be separated from Somalis, the people they have meant to save. (...) Few UN staff were ever allowed to venture beyond the walls for long. During much of the mission, they would be flown daily by helicopter the short distance from their airport quarters to the compound, completely isolated from the dusty, dangerous capital that swept past beneath them" (Peterson, 2001:78).

${ }^{34}$ Peterson recalls that "Somalis, now completely cut off from the UN operation that would make so many devastating decisions about their futures, referred with disgust to the walled compound as the 'Camp of the Murderers"' (Peterson, 2001: 79). 
forces largely ignored other essential sources of friendly information, and did not establish significant public affairs and psychological operations (PSYOP) initiatives. ${ }^{35}$ The former Special Envoy to Somalia Robert Oakley summarized the situation by saying that " $(\ldots)$ the UN had no PSYOP, no radio, ${ }^{36}$ no newspaper; it stopped meeting the Joint security committee; it stopped paying the police and removed their supporting military units" (Oakley, 2000: 349). ${ }^{37}$

Instead, the UN increasingly used lethal force, for example calling upon American $\mathrm{AH}-1 \mathrm{~F}$ attack helicopters and AC-130 aircraft to fire missiles and 40 millimetre machine gun fire on the densely populated slums of Mogadishu, in the hopes of killing Aideed or Aideed's associates. This made enemies of previously neutral individuals, which allowed the warlords, particularly Aideed, to retain and

${ }^{35}$ By adopting Resolution 837, which required arresting Aideed and which shut down possibilities of political reconciliation, UNOSOM had declared war on Aideed's forces. Rutherford quotes a senior UN official who summarized the interveners' dilemma: "We can't talk to him because he is a wanted man. We dare not go after him until the city is awash with troops, because of the backlash. And we can't beat him, because urban guerrilla wars are unwinnable." (Rutherford 2008: 147). Such actions might also have violated international law, thus giving Aideed international legal recourse. Rutherford also cites a UN report written one year later concerning the Somali fighting, "the US QRF and later the Ranger operation, all of which had connotations of war, were not under UNOSOM's control. If these operations were not under UNOSOM II, the question arises as to whether they were authorized by the UN. If they were not, then the SNA's right to defend itself was even more appropriate and hence the evolution of the entire situation into a war". (Rutherford, 2008: 147).

${ }^{36}$ In fact, UNOSOM II did broadcast on the radio and published a newspaper. Yet the radio station was operated on shortwave by the United Nations staff in Mogadishu, and while it broadcast news, inquiries about missing persons, songs, plays and poems, its signal was not strong enough to reach all over Somalia. UNOSOM II's radio station was also only on for 45 minutes per day (Borchini \& Borstelmann 1994:4).

${ }^{37}$ However, the UNSG, thought Aideed's Radio Mogadishu was not a threat because it had limited broadcasting range. Rutherford explains that "He wanted to exploit this weakness and broadcast the UNOSOM II message "to the whole country and really get the word out'.(...) Unfortunately, the UNOSOM II radio staff was hindered by the same lack of resources and qualified personnel that plagued the rest of the mission. Howe eventually convinced the UN Secretary-General that UNOSOM needed a radio system, and it finally got put into the UN budget, but at a subsequent UN General Assembly budgetary committee meeting, the group declined funding to set it up" (Rutherford 2008:130). 
broaden their popular support (Daniel, Hayes \& de Jonge Oudraat, 1999). ${ }^{38}$ Effectively, the interveners were giving credence to the message of the warlords through their adoption and execution of a compellence strategy, and were thus actually helping to fuel the fighting. ${ }^{39}$ Indeed, the level of force used in an operation that was not considered to be a regular combat operation was antithetical to the hoary yet enduring irregular war maxim to 'win hearts and minds'. With this lack of restraint in the use of force the UN had become 'Somalia's new militia” (Peterson 2000, Cassidy, 2008).

Since Aideed was the warlord who was most targeted by the peace operation, he was also the most hostile toward the operation. Aideed made good use of the low-tech tools he had at his disposal, broadcasting messages over Radio Mogadishu that branded the UN as colonizers. His public relations campaign did significant damage to the UN's image while bolstering his own as the only leader of the Somali people, particularly his argument that the UN was threatening his entire sub-clan and even to some extent all Somalis (Manseau, 2008: 30-31). This latter broadening of the threat was a key means for Aideed to rally widespread

${ }^{38}$ Oakley explains that "The U.S. and the UN made Aideed the enemy with UN Security Council Resolution 837; "after a no-warning helicopter gun ship attack on a peaceful meeting of some 200 senior members of Aideed's clan on 12 July 1993, the American forces became their enemy" (cited in Cassidy, 2008: 68).

${ }^{39}$ Cassidy (2008) explains that after the 5 June 1993 ambush of the Pakistanis, LTG Montgomery, the U.S. forces commander under UNOSOM II, decided to undertake increasingly forceful reactions to the clan's attacks. Rutherford cites LTG Montgomery according to whom: "It was a normal reaction to the Pakistani ambush - do something - kick some ass" (...) (Cassidy 2008: 69). Yet such an attitude contrasted with the nature of the (peace) operation. 
support among Somalis to fight and resist UNOSOM II forces (Rutherford, 2008)..$^{40}$

The situation of the interveners was not helped by the lack of communication between the different troops. As was described earlier, UNOSOM II had an unclear command structure: while it was nominally under UN control, the United States as the lead actor had its own parallel command structure, and moreover each part of the command had somewhat different goals. US Major General Montgomery was both Commander of US Forces in Somalia and a deputy to the UN Force Commander in Somalia, Lieutenant General Cevik Bir. Furthermore, the US command was itself divided, with a complex command structure that separated the land forces inside Somalia from the Navy and Marine Corps forces that remained under United States Central Command (CENTCOM). When the Ranger Task Force was deployed to capture Aideed, it had its own chain of command that did not go through either the US or the UN channels in Somalia. This situation was exacerbated by problems of command over the UN's diverse, multinational army, which included troops from Italy, France, Belgium and Pakistan. Different national armies interpreted the Rules of Engagement (ROEs) differently, and national contingents sought guidance from their governments before carrying out UN orders. ${ }^{41}$ Ultimately, according to Laitin,

\footnotetext{
${ }^{40}$ Rutherford (2008) explains that "the anti-UNOSOM II radio diatribes accused the UN of 'interference in the internal affairs of Somalia', and accused UN military forces of "murder, rape, and pillage against Somali citizens"” (Rutherford, 2008: 129).

${ }^{41}$ For example, Laitin explains that this became highly contentions when "the commander of the Italian contingent opened negotiations with Aideed after the SC had instructed UNOSOM II to hunt him down. There was no way the Italians could be policed or punished" (Laitin 2001:4).
} 
"nearly all of the problems in plan implementation can be traced at least in part to the ambiguous command structure" (Laitin, 2001:4).

There was also a lack of communication with the international community. This explains why so many actions by UNOSOM II remained unknown outside of Mogadishu, and therefore did not factor in to international public opinion on the mission. The only images and information that did come through showed violent combat and American soldiers dying, which greatly contributed to turning public opinion against the mission. Because the difficulty of the setting and the difficulties related to the mandate remained unknown, analysts tended to assess the mission in terms of ultimate success and failure.

\section{Capacity}

There are two major issues regarding capacity: 1) it is not so much about what you have, but rather what you do with it; 2) to what degree is the material that you have adapted to the situation. High-tech materials such as robots, sensors, and unmanned aircraft are well-suited to high-intensity conventional warfare, but are less relevant in operations where success hinges upon winning the support of the population.

In the case of UNOSOM II, the adoption of a compellence strategy made the operation a conventional war against enemies rather than one aimed at necessarily re-establishing peace. This situation was compounded by American troops being equipped with some of the most lethal and high-tech equipment available to light infantry fighters, so as to compensate for the low troop 
numbers. ${ }^{42}$ But the use of these capacities further alienated the peacekept and incited the Somali belligerents to react aggressively to the mission activities (Personal communications with Somali refugees, January 2008). Moreover, US forces failed to anticipate that belligerents would make the most of this asymmetric approach. Indeed, Somalis even used kites and slingshots as air defence weapons: "on one occasion a rock from a slingshot went through the cockpit of a scout aircraft that was travelling at 90 knots" (Cassidy, 2004: 164). The Somalis also used more conventional weapons, such as Rocket Propelled Grenades (RPG), to attack American helicopters.

\section{Knowledge}

The mission's leaders were not neophytes when it came to Somalia: Admiral Jonathan Howe had worked on the Somali situation and on the previous Operation Restore Hope as deputy national security advisor for President Bush (Hirsh \& Oakley, 1995: 110). Yet a main problem was that because the operation was framed by a compellence strategy, all the emphasis was put on the coercive aspects of the mission rather than on also emphasizing the non-coercive dimension. Thus for instance UNOSOM II was assigned tight timeframes that left

42 Among their most lethal weapons were: "AH-1 Cobra attack helicopters, which were armed with anti-tank missiles, a 20 millimetre Gatling gun and 2.75 inch rockets; an AC-130 Spectre, which could vaporize a neighbourhood block in Mogadishu; the OH-58D mastmounted ball on top of the rotor system, which included thermal sights, a TV camera, and a laser range finder that allowed the helicopter's operators to detect and identify single humans at ranges of up to 10 kilometres, at night; the 160th Special Operations Aviation Regiment's helicopters - MH-60s, MH-6s, and AH-6s, all of which amounted to some serious technology and firepower" (U.S. Army Peacekeeping Institute, 1994:7). The OH58D's lazing capability allowed the "the ground commander the flexibility to employ a wide variety of munitions with surgical precision" (U.S Army Center for Army Lessons Learned, 1994: I-6-6). 
little room for the time-intensive traditional Somali practices of political legitimisation, which would have helped greatly in promoting the reestablishment of order in the country (Heinrich, 1997:104-151).

Another problem that arose from the compellence strategy is that the mission failed to properly analyze the intentions driving the Somalis, as well as the impact that the intra-state war environment would have on strategy, operations, and tactics. UNOSOM II troops were also insufficiently informed about both the geophysical and human terrain. Most of UNOSOM II's activities were concentrated in urban settings, with raids happening in a "confusing maze of rough narrow streets and lookalike ratty houses where the number of Somali fighters was limitless" (Peterson, 2001: 140). The belligerents, mainly Aideed's fighters, used their familiarity with the geophysical setting to counter the technological superiority of the interveners and to trap the UN troops. ${ }^{43}$

Contrary to the commonly held view, the belligerents took great care to become and to stay informed about the interveners' motives and activities in the country (Personal communication with Somali refugees, January 2008). Aideed himself was a well-travelled man who had attended military academies in Italy and the former Soviet Union, had been Somalia's ambassador to India, and knew

${ }^{43}$ Recalling the Black Hawk Down event, Peterson wrote that: "Every street looked the same and the delay in relaying directions from the helicopters, turn left or turn right, meant that the convoy(s) became completely lost. The soldiers ran low on ammunition, as their Humvees and trucks became slick with blood. Casualties mounted. Three of the Somali prisoners died in cross-fire. At every narrow crossroads, each vehicle would be targeted anew. But it wasn't just the Americans whose no-holds-barred embrace of the fight lengthened casualty list. 'The problem was the Somalis everybody tried to attack', recalled Qaybdiid. They came this way, they went that way. If people had left it to the militia and the officers, it would have been no problem." (Peterson, 2001:141) 
how the UN functioned. ${ }^{44}$ The officers under Aideed were trained extensively at the Soviet military academy in Odessa and in Italy. ${ }^{45}$ Moreover as one Somali commander explained, most Somali warlords "tried to adapt the lessons learned from years of clan warfare and from extensive reading on guerrilla insurgencies, particularly in Latin America" (Atkinson, 1994a: A1). One of Giumale's subalterns, Colonel Aden, observed "if you use one tactic twice, you should not use it a third time", and the Americans had already essentially employed the same raid construct six times" (Atkinson, 1994a:A1; Peterson 2000: 139). Another advantage that the belligerents had over the Americans was their knowledge that the American Special Operations Forces had underestimated the Somalia National Alliance (SNA) militia, which had the tactical and psychological advantage of fighting in familiar terrain.

The knowledge of the Somali population at large was also underestimated. They were aware of the tensions between the different interveners, playing on the dislike between different contingents of Americans and Italians to intensify

${ }^{44}$ Report Pursuant to Paragraph 5 of Security Council Resolution 837 (1993) on the investigation into the 5 June 1993 attack on United Nations Forces in Somalia, conducted on behalf of the Secretary-General, 24 August 1993, S/26351.

${ }^{45}$ Cassidy explains that “According to Atkinson's account, Aideed's irregulars had been formulating a plan of their own to counter the combat power and technology exhibited by Task Force Ranger: hundreds of rocket-propelled grenades (RPG) had been smuggled into Mogadishu. One Somali commander, Giumale, who oversaw the October 3rd-4th Battle of Mogadishu claimed that he had 'tried to adapt the lessons learned from years of clan warfare and from extensive reading on guerrilla insurgencies, particularly in Latin America' (...) He knew that the American Special Operations Forces were considered elite but he thought they had underestimated the SNA militia, which had the tactical and psychological advantage of fighting in their own backyards. One of Giumale's subalterns, a Colonel Aden, observed 'if you use one tactic twice, you should not use it a third time', and the Americans had already essentially employed the same raid construct six times (...) Operations aimed at snatching Aideed, which culminated in the October battle, also attested to the difficulty in finding a single human target in an urban slum, even with high-tech equipment" (Cassidy, 2008:73). 
competition and to exacerbate tensions between them. They also bartered to maximize the benefits that they could extract in exchange for information (Personal communication with Somali refugees, January 2008). Somalis understood the importance of American support for UNOSOM II, and determined that the best way to expel the international community was to discourage American participation in the intervention. In this they were greatly aided by their awareness of the reasons behind the failure of previous American operations elsewhere. Oakley recalls the following anecdote: "Before the Marines arrived, one of my Somali friends said, 'We won’t oppose you, but if we don't like what you're doing, we know how to get you out. We have studied Vietnam and Lebanon."” (Oakley, 2000:338). Armed faction leaders had also studied Operation Desert Storm, and understood the domestic political impact in the United States of American soldiers' deaths. They concluded that casualties would stir American public opinion and would push US leaders to withdraw their support for the operation. Oakley and Hirsh recall the comments from one of the Aideed faction's main spokespeople, Abdi Abshir Kahiye : "If you could kill Americans, it would start problems in America directly" (Hirsh \& Oakley, 1995: 121 footnote 19).

Ultimately then, Aideed believed that if he could convince the American public that keeping troops in Somalia would be costly, or that their forces were hurting as many Somalis as they were helping, the US would withdraw its forces. And if the US forces left, the UN would be hamstrung and would itself leave soon afterward, allowing Aideed to consolidate his leadership of Somalia (U.S. Army Field Manual 3-06: Appendix C). 


\subsection{ECOMOG in Liberia}

\subsubsection{Type of Intervener}

ECOMOG would not have been possible without Nigeria. The country provided $75 \%$ of the troops and $90 \%$ of the funding ${ }^{46}$, and thus bore the heaviest burden (Yoroms, 1993). Most authors argue that it was the Nigerian determination to enter the conflict that was at the root of the ECOMOG intervention in Liberia. Four main reasons are usually given for understanding Nigeria's incentives to intervene, as well as the timing of the intervention: the close relationship between Nigerian President Babangida and Liberian President Doe; the fact that Charles Taylor's NPFL was holding Nigerian hostages; the fear of Libya using Liberian territory to recruit and train insurgency troops, as part of an anti-Nigerian alliance between Libya, Burkina Faso, and Côte d'Ivoire; and Nigeria's suspicion of French political motives and economic interests in orchestrating an antiECOMOG alliance (Adebajo, 2004a). To secure domestic as well as international political support, Nigeria chose to intervene with regional counterparts (Adebajo 2003a:60). ECOWAS authorized the Nigerian-led mission in May 1990.

\subsubsection{Choice of Strategy}

At first, ECOMOG's peacekeepers were given a mandate to keep, rather than enforce, peace. But without a ceasefire and agreement from Charles Taylor that they be allowed to deploy, this proved an impossible strategy. Troop numbers

\footnotetext{
${ }^{46}$ A foreign report in the Financial Times of London (August 27, 1991) stated that the Nigerian government was spending \$250-\$500 million from the Gulf War oil windfall on Liberian operations (cited in Yoroms 1993:89).
} 
were soon doubled and ECOMOG's mandate changed to repelling NPFL fighters from Monrovia (Adebajo 2003a). ${ }^{47}$

\section{Communication}

ECOMOG arrived in Liberia in August 1990, and received a decidedly mixed welcome from the three belligerent factions. Prince Johnson's INPFL spontaneously offered to cooperate, as did the Armed Forces of Liberia (AFL), while Charles Taylors' NPFL immediately attacked ECOMOG's forces (Howe 1996-1997). ECOMOG responded by going on the offensive. As with UNOSOM II in Somalia, ECOMOG targeted the leader of the faction that was opposing them, in this case, Charles Taylor. Several Nigerian generals called for his assassination as the most efficacious way of ending the war. This military campaign against Taylor hindered the credibility of the peacekeepers as a neutral or impartial force, and it fuelled the resentment and hostility of the peacekept toward the peacekeepers (Adebajo 2003a). Dr. Kwesi Aning explains:

(..) in Liberia for example, the sheer threat of the use of force by the Nigerians brought about a certain level of change in the behaviour of the combatants (...) Because of Nigeria's involvement, Charles Taylor then started bombarding the ECOMOG forces prior to the arrival in Monrovia precisely because Taylor's sense was that Nigerians were out to get him, that Nigeria and Nigerian troops were not following rules of law of that international (peacekeeping), so that fear that Nigeria had credible fire power and was willing and ready to use it, actually

47 Adebajo described the Nigerian commanders of the operation, more specifically General Dogonyaro: "he was a Rambo in a military attire - a no-nonsense general who thought his mandate was to use as much force as required to enforce peace" (Adebajo 2003: 80). 
brought Taylor to the negotiating table." (Aning, personal communication, January 2008).

Yet similarly to UNOSOM II, ECOMOG focused on coercing belligerents into accepting a truce, at the expense of making the effort to communicate with the populace about its mandate and activities. ${ }^{48}$ Instead of setting up radio stations and newspapers to keep the population informed of the intervention's goals - or using any other sort of psychological operation activities for that matter ECOMOG sought to control the media that were still running in the country. Like Aideed, Charles Taylor reacted by launching an aggressive anti-ECOMOG campaign on his radio station. In general, the media controlled by Taylor urged Liberians to resist "Nigerian colonisation", and dubbed ECOMOG "armed bandits". It also labelled ECOMOG the Club of Dictators, and pointed to the irony of ECOMOG attempting to restore democracy when only Gambia among the ECOMOG contributing nations could claim to have a democratically-elected government itself.

ECOMOG's unequal relationship with the various parties to the conflict also fuelled suspicions among the peacekept regarding the real motives behind the mission. It employed Prince Johnson's INPFL for combat and intelligence during its first several weeks in Monrovia, as well as to guide their troops through the baffling swamps of the capital. Later, ECOMOG air-lifted ULIMO into Monrovia, and ULIMO guided ECOMOG through the swamps (Howe, 1996-

\footnotetext{
${ }^{48}$ Such an approach soon alienated the media and the population. Williams explains that "During the early part of 1991, journalists were increasingly harassed, manhandled or threatened by the peacekeepers themselves. There were also instances where reporters were detained and news organs threatened for publishing articles that were considered to be antiECOMOG or against the peace process." (Williams, 2002: 290.)
} 
1997: 157). Prince Johnson, who had executed the ex-president Samuel Doe, was also caught providing equipment to poorer ECOMOG peacekeeping contingents (Adebajo, 2003a). Combined with the heavy use of force by the peacekeepers, this fuelled the perception by the peacekept that ECOMOG was a party to the conflict and that it had its own reasons for wanting to win the war with Charles Taylor. More specifically, many Liberians read ECOMOG's actions as proof that Nigeria was trying to use the operation to extend its control over the region. According to Dr. Kwesi Anning:

(...) while military strengths forced Taylor to the table, the political wing of the ECOWAS, those who led the negotiating process plus the UN were not able to exploit the fear of the threat. Or the fear of the potential of using Nigeria as a bargaining chip. As a result Taylor was able to outmanoeuvre the negotiators systematically for a long time during that process (....) You see, one of the thing that mandating institutions seem to overlook is that they tend to treat all rebel movements as one. (...) we need to mandate intervening institutions differently precisely because those that we intervene against are as intelligent and as political as we are and therefore have the idea how manipulate the intrinsic contradictions within a mandate of an international intervening force. I mean Taylor was able to split the ranks of ECOWAS on a systemic eventually split the rank of ECOMOG in Liberia itself (Aning, personal communication, January 2008).

Finally, efforts were not made to transparently communicate with the international community. Indeed, the UN was not involved early on, and the United States did not support the mission until later in the intervention. The isolation of the regional great power from other great powers and from international organizations also contributed to the view among Liberians that Nigeria had ulterior motives. 


\section{Capacity}

Liberia is approximately the size of New York state, and is entirely covered by forested hills and mountains. Interior roads are nearly non-inexistent. Liberia has been described as "a good ambush country, almost anywhere outside Monrovia" (cited in Howe, 1996-1997: 170). According to Lt-General Quainoo, the first commander of the ECOMOG force in Liberia, more training and more adequate equipment could have helped to avoid the use of abusive force by the ECOMOG troops. In particular, Lt-General Quainoo complained about the lack of logistical devices, as well as lack of equipment that could have facilitated troop movements and helped in the detection of hostile belligerents, which would have made many confrontations and battles unnecessary. Effectively, Lt-General Quainoo is here pointing to avoiding the use of compelling force and increasing the efficiency of the peace operation (Quainoo, personal communication, January 2008).

The operation also lacked helicopters, boots, trucks, and water rehabilitation units, all of which were particularly crucial given the rough terrain in which the operation was being waged. Other challenges included the fact that the ECOMOG troops were not rotated frequently enough, and that the $\$ 5$ daily stipend for peacekeepers usually arrived late, which became an incentive for them to engage in corrupt practices (Adebajo, 2003a: 77). These corrupt practices undermined ECOMOG's general political support, as did the toleration of torture, 
rape, pillaging and even occasional instances of cannibalism by ECOMOG supported factions (Howe, 1996-1997:163).

ECOMOG did succeed in mounting aerial bombardments of Taylor's strategic and economic assets, including the Roberts International Airport (used by Taylor as an entry point for arms supplies), the Firestone Plantation (a key economic asset, which Taylor exploited to boost his war economy), the Buchanan Port (used by Taylor as a loading point for illegal exportation of iron ore, timber and rubber), and the highway town of Kakata (a key supply route) (Adebajo, 2003a: 121).

ECOMOG troops were convinced that Charles Taylor's forces were illtrained and poorly equipped, and estimated that they numbered perhaps 10,000 , with $30 \%$ of them under the age of 17 (Howe, 1996-1997: 149). In the words of Adebajo, they thus expected that the "ragtag NPFL force would flee at the sight of professional soldiers" (Adebajo, 2003a: 75). Yet they did not flee, instead continuing their activities in the country. As the peacekeepers increasingly took recourse in the use of force, and as peacekeeping practices came to increasingly resemble conventional warfare, the peacekept grew wary of the interveners and eventually turned against them.

Ultimately then, the compelling use of force alienated part of the population. ECOMOG gained more credibility as a warring faction than as a peacekeeping force. Notwithstanding the fact that ECOMOG lacked manpower and equipment, its offensive capabilities and determination against the rebel factions - most notably the INPFL - convinced the parties either to cooperate or to 
retreat and start political negotiations. Yet this was only done to gain time. ECOMOG did not have the credibility of a peacekeeping force, and its strategy was not tailored to the setting and the situation. ECOMOG's peace enforcement actions did not succeed in convincing the population or the rebel factions that its role was to restore democracy or even the rule of law (Scott, 1995).

\section{Knowledge}

Despite their geographic closeness to Liberia, ECOMOG contributors lacked sufficient tactical intelligence. They had not previously fought in terrain like that in Liberia (their recent peacekeeping experiences had been in Chad and Sudan). ECOMOG members had little counterinsurgency experience, and in 1990, only Ghana and Senegal had any jungle warfare training centers. Finally, almost none of ECOMOG's pilots had worked in combat situations. They did nonetheless succeed in disrupting the NPFL's supply lines and affecting its morale, and also forcefully counterattacked against a military operation ("Operation Octopus") launched and led by the NPFL to capture the Liberian capital of Monrovia (Howe, 2001). But problems in discipline and logistics lead ECOMOG planes to hit relief convoys and humanitarian aid facilities by accident but numerous times, prompting severe criticism that led to restraints being placed

upon ECOMOG's air power. Ultimately, ECOMOG's experience in Liberia confirmed the advantages that local irregular forces may have against conventionally-trained foreign interveners (Howe, 2001: 157). 
Other complicating factors for ECOMOG included the magnitude of the Nigerian involvement (which made things difficult because the close relationship between Nigeria's president and the former Liberian president affected the appearance of neutrality), the fact that several ECOMOG member nations established a privileged group of discussion that excluded other members and the unwillingness of the international community to participate in the mission, all of which fuelled the belligerents' and even the civilians' perception of the operation as biased (Adibe, 1997). These perceptions were further burnished by the actions of Nigerian troops that made them seem like just another party to the conflict; according to Dr. Aning:

The Nigerians, they were totally intolerant of any bullshitting and they know who was killing. I mean the Nigerian troops, or the mere mention of Nigerian troops was more than enough. For the Nigerians, if you crossed the line they would just kill you (...) the Nigerians just blew off their heads (Aning, personal communication, January 2008).

The cumulative effect of these perceptions about ECOMOG was that while it could easily coerce, it could not so easily convince belligerents to hold to their peace commitments.

\subsection{ECOMOG in Sierra Leone}

\subsubsection{Type of Intervener}

ECOMOG came from the same Monitoring Group initially established by ECOWAS to monitor the ceasefire in Liberia in 1990. The ECOMOG intervention in Sierra Leone, which was to be undertaken using aerial and naval 
forces, was led by Nigeria (Adebajo, 2003a:2). In Sierra Leone, ECOMOG was composed of 18 battalions and 15,000 supporting units. Of these, Nigeria accounted for 11 battalions, three naval assets and one air force detachment (Peacekeeping Best Practices Unit, 2003: 83). Moreover, Nigeria agreed to bear the financial burden of the operation, spending more than $\$ 1$ million per day on the mission (Bangura, 2000: 563). The Nigerian army also provided most of the senior command structure for this ECOMOG operation. The ECOMOG contingent in Sierra Leone was led by Nigerian Commander Brigadier General Maxwell Khobe and composed of approximately 9,000 troops, predominately Nigerian with several Guinean support battalions.

\subsubsection{Choice of Strategy}

Hirsh explains that ECOMOG was asked to take all necessary measures to persuade the faction to abdicate power (Hirsh, 2001a:60). In the words of Fortna, “(...) the rebel strategy was not to refuse to sign agreements calling for peacekeepers, but rather to resist the actual deployment of international personnel" (Fortna, 2008:67). With the failure of diplomatic efforts and the escalation of tensions, ECOMOG's mandate was upgraded from sanctions enforcement to actual military intervention to forcefully ousting the AFRC/RUF.

\section{Communication}

Far from using or investing in the media to inform the population of its mandate goals and means, ECOMOG in Sierra Leone in fact bombed the 
communications tower thereby temporarily suspending radio and television broadcasts country-wide. This left the country with only pirate radio stations able to reach the population. As in Somalia and Liberia, opposition factions made the most of these non-official media in order to discredit the work of the peacekeepers. Thus the Sierra Leone Broadcasting Service radio station and a privately owned station were used to wage a campaign of misinformation and propaganda against the Nigeria-led ECOMOG intervention.

ECOMOG used stunning coercive actions to quickly liberate Freetown from the rebels. Yet the use of lethal force heavily impacted civilians, who became trapped between the interveners and the parties to the conflict. Densely populated areas were caught in the cross-fire and were shelled by ECOMOG. ${ }^{49}$ ECOMOG advanced toward the rebel held territory by blocking two of three routes out of Freetown (ICG, 1998). Heavy artillery fighting subsequently made certain areas inaccessible to relief workers. For instance, an ICG reports describes that "ambulances trying to reach the Kissy area, one of Freetown's most populous, had to turn back due to the fighting. Injured civilians were unable to move out of the area, and many died for lack of medical attention" (ICG, 1998).

Perceptions of ECOMOG were further affected when its ground commander, Colonel Maxwell Khobe, began to address the citizens "almost as if he were their governor" (ICG, 1998). The ICG reports concludes that "The irony of troops from Nigeria - a country with a military government and a lax

\footnotetext{
${ }^{49}$ In its report, ICG adds that it included "the downtown port area, causing part of the roof to collapse at the Connaught Hospital, one of two functioning hospitals in the city." (ICG, 1998).
} 
commitment to democracy and human rights - helping to restore democracy to a neighbouring country was not lost on the citizens of Sierra Leone” (ICG, 1998).

There were also severe communication and coordination problems amongst the intervening troops of ECOMOG. Contingents were unequally prepared and equipped. Some even tricked other ECOMOG troops in order to steal their food rations, their weapons, etc., often by making deals with the belligerents. The Malian troops were known to be particularly easy targets in this regard (Utas \& Jörgel, 2008: 496). The Nigerian section of ECOMOG leaked information to a rebel faction known as the West Side Boys (WSB), who were thus able to wage 'food finding missions' against the Malians, as well as more generally to steal significant quantities of military and other supplies. In exchange, the WSB would trade diamonds with their Nigerian accomplices (Utas \& Jörgel, 2008: 496).

Rebel factions made good use of a variety of communication means, establishing close personal relationships and advanced commander/soldier networks. ${ }^{50}$ They also regularly used radio communications to gather intelligence, by intercepting ECOMOG radio traffic. Their ability to do so was greatly enhanced by the fact that many of the WSB's initial leaders had a background in radio communications from their time in the Sierra Leonean military (Utas \& Jörgel, 2008: 500).

\footnotetext{
${ }^{50}$ Utas and Jörgel explain that "WSB members were able to travel widely through ECOMOG checkpoints into Freetown and to RUF-held areas. A range of communication devices (...) was either given to the WSB by various parties or acquired by means of ambushes: 'Communication radios were looted; we took them from the Nigerians. We had a signal group; we channelled them to our own channel and used it. We use some of them to monitor them [ECOMOG/UNAMSIL]. If they attacked us we would know." (Utas \& Jörgel, 2008: 500)
} 


\section{Capacity}

Nigeria provided at least $80 \%$ of ECOMOG's troops (12,000 out of 16,000 in Liberia, and 12,000 out of 13,000 in Sierra Leone) and $90 \%$ of its funding during the military interventions in Liberia and Sierra Leone. Weak command and control and poor training of ECOMOG's troops led to widespread and unpunished abuses against the population by the peacekeepers. ICG reports that: "When ECOMOG entered Freetown, there were some reports of drunken ECOMOG soldiers looting along with the population, and some civilians were harassed at checkpoints and encouraged to pay their way through.” (ICG, 1998). The report also notes that "ECOMOG appeared to work responsibly to prevent reprisal killings, and guaranteed the safety of junta members or collaborators who surrendered themselves to ECOMOG custody." (ICG, 1998). ECOMOG also succeeded in forcefully ousting troops from the capital, though they ended up bombing several towns while doing so. Moreover, due to miscommunication with relief agencies on the ground and the population alike, ECOMOG mistakenly bombed humanitarian convoys moving to provide aid to trapped civilians. The junta and rebels ousted by ECOMOG also inflicted widespread damage with civilians often caught in the fighting. Taken all together, these factors meant that it was difficult for most civilians to consider ECOMOG as anything other than another party to the conflict (ICG, 1998). Hirsh (2001a :74-75) summarizes:

ECOMOG's lack of familiarity with the bush terrain of eastern Sierra Leone was as serious as its logistical problems. ECOMOG forces repeatedly fell prey to ambushes, fake surrenders and surprise attacks. As their 
convoys became bogged down by fallen logs, trenches, and other devices meant to slow or stop their advance, it became ever more difficult for the Nigerians to take the initiative. The Nigerian soldiers were ill-prepared to engage in hand-to-hand combat deep in the bush (...). Neither ECOMOG nor the humanitarian agencies could operate freely in the country, and the government's writ was virtually nonexistent" (Hirsh, 2001a: 74-75).

\section{Knowledge}

The Sierra Leonean belligerents were closely connected to the warring factions in Liberia, and had learned about the experience of ECOMOG in this latter country. Since the intervention in Sierra Leone was carried out by the same organization and was led by the same regional power, such knowledge allowed the belligerents to act based upon the strengths and weaknesses of their adversary. Thus the RUF, which badly wanted to deter the regional organization's intervention and was well-aware of the interveners' aversion to casualties ${ }^{51}$, undertook what they called "Operation No Living Thing", a campaign aimed at striking fear into their adversary (Hirsh, 2001a: 75). ECOMOG responded forcefully. The violent confrontation between the peacekeepers and the RUF resulted in the death of more than 6000 people, most of them civilians as well as the displacement of some 150000 from the capital Freetown (UN 1999; S/1999/836; Hough, 2007). This war-like interaction reinforced ECOMOG's image as being one of the warring parties.

\footnotetext{
51 The West African troops retreated from Liberia following massacres of some of their peacekeepers (Hirsh, 2001a).
} 


\section{Conclusion}

UNOSOM II is a prime example of why one cannot look exclusively at the establishment of order to assess a peace operation's success/failure. In this case, the peace operation's mandate was broad, unclear and unrealistic in terms of its goals and the means deployed. Authors who have qualified this operation as an outright failure have failed to look at the bigger picture. That is, assessing the accomplishment of the mandate by looking solely at the tasks to be achieved fails to properly consider the important achievements of the operation, particularly given the hostile context, the limited resources available and the short duration.

A comparison of the setting before and after the operations highlights how UNOSOM II and ECOMOG in Liberia and in Sierra Leone successfully secured the delivery of humanitarian relief, and also contributed to a more generalized improvement in the situation in the three countries. Due to their technological superiority, the great powers involved in the peace operations were able to use a compellence strategy to act quickly. Yet this same readiness i.e. speed of action and technological superiority- hindered the re-establishment of order. And according to my frame of analysis, this is the most significant reason for the failure, partial though it may be, of the peace operations.

In all three cases, the lack of communication and the lack of knowledge about their adversaries hindered the mission. The lack of communication with the peacekept weakened support for the operations in the country in which they were taking place, in the peacekeepers' home countries, and internationally. It also undermined the legitimacy of the operations, and consequently the desire of the 
peacekept to collaborate with the interveners. The adoption of a compellence strategy contributed to the accomplishment of the mandate in all three operations, since it allowed for greater efficiency in delivering humanitarian relief. But the application of a compellence strategy that followed the Powell \& Weinberger Doctrine - "the fast, overwhelming and decisive application of maximum force in the minimum time [to produce] effective, short-term results" (cited in Cassidy, 2008: 66) - ultimately proved counter-productive in the context of an intra-state war within a failed state (Cassidy, 2008).

The experiences of UNOSOM II and ECOMOG both in Liberia and Sierra Leone illustrate that while the possession of sufficient military means to address failed state settings is important, the modalities of its use are still more important. The use of force for means other than self-defence is seen as legitimizing warfare (Anderson, 1999). By using coercive force, peacekeepers can come to be seen as also being part of the conflict, which undermines perceptions of the operation's impartiality and neutrality by belligerents and civilians (Roberts, 1995-1996; Lavoyer, 1998). The after effects of casualties either amongst belligerents or civilians risk creating resentment and thus undermining the long term accomplishment of the mandate. As events in Somalia, Liberia and Sierra Leone demonstrated, peace operations cannot succeed when faced with entrenched and widespread opposition. Moreover, the drastic removal of one of the main warring is not a useful or effective method for fulfilling the objectives of peace operations (Cassidy, 2008: 70). Using dialogue to gain and maintain the consent and 
cooperation of a majority of the peacekept, which includes the main rebel factions, remains an essential ingredient for the success of peace operations. 


\section{Chapter 4}

\section{FAILURE: \\ NON-ACCOMPLISHMENT OF MANDATE \& NO ORDER RE-ESTABLISHED}

The term "failed peace operations" refers to missions that did not accomplish their mandate and that proved unsuccessful at re-establishing order. The puzzle addressed in this chapter is twofold: 1) under what conditions do peace operations fail both at accomplishing their mandate and at re-establishing order? 2) Which elements contribute most to such an outcome? In a context of civil war within a failed state, the adoption of a non-coercive strategy seems counter-intuitive at best, and bound to fail at worst. Indeed, the high level of insecurity and instability characteristic of such settings should in itself justify the need for forceful intervention. Yet as was demonstrated in the previous chapter, the use of force is not without its trade-offs, including potentially making the intervener a party to the conflict and thus hindering the prospect of order being reestablished. Over the past decades, non-coercive strategies have occasionally been preferred to coercive ones when peace operations within failed states were being set-up. The nature of the crisis (whether it was perceived as being predominantly humanitarian or political), the timing of the peace operation (whether it was coming immediately after the signing of a truce between warring factions or before a peace agreement) and the type of peace operation (whether it was led by 
a great power or an international/regional power, and whether it was being undertaken in cooperation with a regional organization) have all played a role in justifying the adoption of a non-coercive strategy for a peace operation.

By drawing upon official documents, interviews and expert reports, I will show how, in the context of an intra-state war within a failed state, the adoption of a self-defence strategy by a peace operation led by a collective intervener impedes the fulfillment of the mission's mandate and undermines its capacity to reestablish order. I will compare three peace operations that occurred at different stages of a conflict and that involved different kinds of belligerents, but which were all led by the United Nations under the authority of the UN Charter's Chapter $6^{52}$ : the United Nations Operation in Somalia (UNOSOM I, 1991-1992); the United Nations Observer Mission in Liberia (UNOMIL, 1993-1997) and the United Nations Observer Mission in Sierra Leone (UNOMSIL, 1998-1999). The variation in terms of settings and timing will allow us to more fully elaborate the role played by the combination of communication, capacity and knowledge of both the peacekeepers and the peacekept in the crafting of the common outcome.

This chapter will be divided into two sections. The first will focus upon the similarity in outcome for different peace operations, by closely examining the extent to which each operation failed at accomplishing its mandate and at reestablishing order. To do so, I will compare the setting prior to, and after, each intervention. The constraints linked to the context, the mandate, the resources and the duration of each operation will be taken into account to assess the inefficiency

\footnotetext{
${ }^{52}$ According to Chapter 6 of the Charter of the United Nations, peacekeeping missions can only use force in self-defense (S/11052/Rev.1, para.4d).
} 
of the mission. I will highlight the dynamic between the re-establishment of order and the accomplishment of the mandate, and how the failure of the former may lead to the failure of the latter, as well as how such failures may contribute to a worsening of the initial situation. I will argue that peace operations within the context of an intra-state war in a failed state are bound to fail at achieving their mandate and to fail at ultimately re-establishing order when they do not include an intentional and strategic coercive aspect. In the second section, I will assess the process that made these operations "complete failures". The limited impact of a peace operation that is framed as non-coercive will be discussed. I will conclude by highlighting how, in the context of an intra-state war within a failed state, the adoption of a self-defence strategy by a collective intervener may not only fail to pacify the setting but may actually contribute to fuelling conflict.

\section{Assessing Outcomes}

The peace operations described below occurred in different contexts, at different stages of the conflict, and with different timing for the interventions. They involved an assortment of actors, had different mandates, mobilized a variety of resources, and had varying durations. And ultimately, they all failed at re-establishing order and at accomplishing their mandate. This prompts two questions: how is it that each peace operation failed in these two dimensions?; and, what were the conditions that caused each dimension to reinforce the other's failure? Effectively then, we are analyzing the different dynamics between the two dimensions of success. To do so, I focus upon: 1) the extent to which the lack of 
capacity for re-establishing order impaired the accomplishment of the mission's mandate; 2) the extent to which the failure to fulfill the mandate hampered the reestablishment of order; and 3) the extent to which the failure of each dimension contributed to a worsening of the initial situation on a political, humanitarian and security level.

\subsection{UNOSOM (1991-1992)}

\subsubsection{Initial Setting}

In chapter 3, we saw that the Somali government was overthrown in 1991. Political upheaval combined with a severe drought devastated the country, and deadly quarrels between political factions worsened the generalized humanitarian crisis. Weary of the region's increasing insecurity, the UN ordered the evacuation of its personnel in January 1991 (Minear \& Weiss, 1995).

The famine that afflicted Somalia was one of the most severe of the $20^{\text {th }}$ century based on death rates as a percentage of the affected population. By March 1991, 300,000 Somalis had died, 3,000 Somalis were dying per day, and neighbour countries had counted more than 500,000 Somali taking harbour within their frontiers. More than $70 \%$ of the livestock had been destroyed (Rutherford, 2008: 38).

Warfare was waged along lineage lines within the different clans. In the capital of Mogadishu, violence pitted the aspiring leaders of the Hawiye clan against each other: Ali Mahdi vs. Farah Aideed. Sub-clan factions fought using mortars and rocket propelled grenades within the capital, causing extensive 
damage and casualties, both intentionally and collaterally. In the south of the country, fighting erupted within the Darood clans, which spurred destructive clashes between Ogadeni clan fighters (led by Colonel Omar Jess) and a coalition of sub-clans, as well as the Somali Patriotic Movement (SPM, led by General Morgan) (Menkhaus, 2000). In general, clan militias operated independently of one another (Menkhaus, 2000). Each committed human rights abuses against civilians who were members of enemy clans, or even against members of weaker clans caught in the middle of the fighting (Menkhaus, 2002d).

The inter and intra-clan fighting was exacerbated by the presence of a large number of armed groups in Somalia, many of which were informal gangs not under the control of any faction or organization. Indeed by 1992, there were at least 40 distinct bandit groups just in Mogadishu (Peterson, 2001:21). Clashes with enemy groups were often engineered to steal the other's supplies, since militiamen depended on what they pillaged from villages and from government buildings to look after their families. Villages and groups of civilians were looted and abused with the aim of attracting relief agencies and food aid. Factions fought to prevent competing factions from receiving food and relief supplies, so as to physically weaken the members of the other faction, but also so as to weaken their loyalty to the faction, based on the logic that their loyalty depended on the faction's ability to provide its members with protection, basic supplies, and perhaps even a salary (Menkhaus, 2003: 415-416). Belligerents also sold stolen 
materiel on the black market, as well as diverting food aid, exporting scrap metal and selling guns (Menkhaus, 2003: 415-416). ${ }^{53}$

The context in which UNOSOM was to intervene was thus one of countrywide fighting and anarchy. These conditions made the promises of cooperation by identified sub-national actors very hard to depend upon in practice, though early mediation efforts did seem to produce limited success. This included a ceasefire agreement in March 1992 between the leaders of two major factions, those of General Mohammed Farah Aideed and of Ali Mahdi. Furthermore, both agreed to the deployment of unarmed UN peacekeepers (Murphy, 2007).

In April 1992, the UN passed Resolution 751 establishing the UN Operation in Somalia (UNOSOM), allocating more than $\$ 20$ million in food aid, and sending a lightly armed, 550-man Pakistani peacekeeping force to Somalia behind a massive humanitarian operation consisting of 30 NGOs (Rutherford, 2008; Hirsh \& Oakley, 1995). UNOSOM's strategy was framed with a view to the warring clans' compliance, based upon the most recent mediation efforts and results, which had seemed to produce a truce between the country's warring factions. It is in light of this that UNOSOM I was established under the authority of UN Chapter 6, which restricts the use of force to self-defence (Murphy, 2007; UN 1992, S/RES/775; UN 1992, S/24343). It depended upon the consent of the warring factions, and focused on the humanitarian aspect of the crisis. Thus the

\footnotetext{
${ }^{53}$ According to Menkhaus (2003): "Many features of protracted conflict depicted in the literature of the political economy of war closely match patterns of conflict in southern Somalia in the early 1990s; except for the fact that Somalia has not attracted the sort of external predatory interest, as did the mineral and timber-rich countries of Sierra Leone, Angola, and Congo" (Menkhaus, 2003: 416).
} 
international community was seen as being there to facilitate political reconciliation by alleviating the humanitarian challenge for the authorities in place. This meant that UNOSOM would give priority to the provision of relief and supplies, as well as smoothing relations between the factions' leaders, so as to accelerate the re-establishment of the Somali government.

\subsubsection{No Order}

"No good deeds go unpunished", goes the Somali proverb. The United Nations and its partners were ready and had the capacity to provide substantially increased assistance, but they were prevented from doing so by the lawlessness and lack of security that prevailed throughout the country. Heavily armed gangs overran delivery and distribution points and looted supplies directly from docked ships as well as from airports and airstrips. The security conditions did not permit the assured delivery of humanitarian assistance by overland transport and thus did very little to alleviate the food crisis in Somalia. The lack of an effective ceasefire and the fluidity of the fighting hindered the deployment of military observers for cease-fire monitoring purposes outside of Mogadishu, and also put the security of unarmed military observers severely at risk (UN 1992, S/24480).

Throughout the operation, the UN remained unable to establish security and to deliver aid (Rutherford, 2008). ${ }^{54}$ Clans were unwilling and/or unable to comply with the demands of the intervener, largely due to their limited or lack of

\footnotetext{
${ }^{54}$ Peterson explains that "Despite Aideed's assurances and new political clout, the situation worsened. Competition among looters was so fierce that one could trace the route of food convoys through the city by charting on a map the casualties as they came into the hospitals" (Peterson, 2001:45).
} 
control over large numbers of militiamen (Peterson, 2001). ${ }^{55}$ Thus the main leaders remained unwilling to surrender for fear that an opposing group might not give up its weapons. They also unexpectedly refused the deployment of United Nations troops to secure delivery of relief in areas that had the greatest need.

These circumstances meant that UNOSOM's troops, which were conceived of as "friendly" (that is, as non-coercive and thus only lightly-armed), were fired upon and their vehicles and arms were looted by warring factions (Sahnoun, 1994). Relief ships were prevented from docking, were threatened, and were even shelled. Airports and seaports came under fire. Large sums of cash and relief aid were extorted from donor agencies and organizations, and the lives of their personnel who were attempting to distribute supplies to starving people were put in danger, which meant that almost none of the goods reached those in need. In October and November 1992, despite UNOSOM's efforts, the situation in Somalia continued to deteriorate (Hirsh \& Oakley 1995; Rutherford, 2008). By December 1992, the widespread and mounting insecurity of the setting made it seem clear that a more robust peace operation was needed (UN 1992, S/RES/794). The failure of UNOSOM I at re-establishing order was clear.

\footnotetext{
${ }^{55}$ Peterson quotes Mohamed Farah Jumaale , one of Aideed's main adviser who explains that:"It was difficult to control the militia. They were everywhere. They are loyal to the clan when the clan is going to fight. But when you are sitting in town and not giving them salary, they start robbing and are beyond anybody responsibility" (cited in Peterson, 2001:46). Some authors also argue that there might have been a lack of will: the leaders purposefully letting delinquent elements loose amongst their ranks to disturb relief operations.
} 


\subsubsection{Non- Accomplishment of Mandate}

The ubiquity of violence and the near-total absence of infrastructure made the efforts of humanitarian organizations seem to be almost completely in vain. And the increasing insecurity of the region rendered food distribution programs inoperative, since food was either stolen or diverted by the various militias (Sahnoun, 1998) ${ }^{56}$ and thus failed to reach the victims of starvation (Rich, 1999). In fact, "even though the volume of food arriving in Somalia increased significantly - in September alone, it rose from 20,000 to 37,000 metric tons - the percentage of the total actually reaching those in dire need fell by 40\%" (Hirsh \& Oakley, 1995:25).

By October 1992, belligerents were destroying their cities and killing their fellow citizens in order to control food supplies, which had become the most valuable currency in the country (Rutherford, 2008; Hirsh \& Oakley 1995; Sahnoun, 1998).${ }^{57}$ Moreover without the consent of all the warring parties, the UN relief distribution system was unworkable - and because it was not working, it ironically ended up reinforcing the new Somali economic system that was based on looting and diverting relief supplies, since this system became the only reliable source of desperately needed goods.

Ultimately then, UNOSOM not only failed at accomplishing its mandate but was in fact making the situation worse: "The famine was intensifying and expanding, and death rates were rising" (Rutherford, 2008:55); villages were

\footnotetext{
56 "Trucks with food are like trucks full of money" (Peterson, 2001: 23).

${ }^{57}$ Rutherford explains that the then Secretary of the State Department, William Cohen, "believed that Somalia was the only case where there was 'an inability to get aid through because food was used as a currency'." (Rutherford, 2008: 54).
} 
being taken hostage in order to attract food and humanitarian goods; armed gangs were stopping aid workers and taking their supplies; and looting, hoarding, and diversions were so ubiquitous that while the volume of food coming into Somalia was increasing, the percentage reaching those in need was actually decreasing (Baumanns, Yates \& Washington, 2004). ${ }^{58}$ Moreover, moving food by air was not optimal because aircraft were unable to move sufficient quantities - thus the key to transporting the required amounts of food was to regain control of the ports from the Somali warlords, which depended upon robust military action (Rutherford, 2008:66). Indeed, if the UN reported a decrease in death rates in peripheral Somali cities like Baidoa, as one weary relief worker put it, it was good news only in so far as "people can only die once" (Hirsh \& Oakley, 1995:32).

\subsection{UNOMIL (1993-1997)}

\subsubsection{Initial Setting}

The United Nations Observer Mission in Liberia (UNOMIL) was deployed three years after the beginning of the civil war. From 1990 until 1993, the UN agencies active in the country were primarily involved in humanitarian endeavours. On September 22, 1993, the UN Security Council adopted Resolution

${ }^{58}$ Baumanns, Yates and Washington (2004) explain that "By 26 July, 1992, Security Council Resolution 767 demonstrated that this was not at all clear to the UN. The resolution called for the immediate airlift of food aid to the "triangle of death" in southern Somalia. President George Bush authorized a US operation that would be known as Operation Provide Relief. This operation flew nearly 2,500 flights out of Mombasa, Kenya, and although the operation provided nearly 28,000 metric tons of food aid, it failed. The airfields and landing strips in south Somalia had no protection, so looters and even local militias extorted money and supplies for the "right" of landing. US forces gained valuable experience from the operation through working closely with the non-governmental community, but despite the enormous costs of the operation, most of the food never reached the people for whom it was intended" (Baumanns, Yates \& Washington, 2004:19). 
866, which gave the UN's mandate a political orientation (UN 1993, S/RES/866;

Marley, 1997). The original operation, led by ECOMOG, had the responsibility to implement the accords, while UNOMIL was assigned a supervisory role (Olonisakin, 1996: 39). ${ }^{59}$

UNOMIL was conceived as a legitimising element for the international community to back ECOMOG's mission in the country. UNOMIL was the first UN peacekeeping mission undertaken in cooperation with a peacekeeping mission set up by another organization (Adibe, 1997). Through the appointment of a special representative to the Secretary-General, the UN aimed to become an integral part of the diplomatic effort to resolve the conflict, by directly influencing the process.

Shortly after the start of the operation, the Secretary-General's special representative succeeded in brokering negotiations in Geneva between the different warring factions. These resulted in the adoption of the Cotonou Peace Accords in Benin in July 1993. Kihunah explains that the Accords were

59 "For example, ECOMOG was required to create buffer zones or seal borders between Liberia and its neighbours (Côte-d'lvoire, Guinea and Sierra-Leone), as well as to monitor and supervise all points of entry. On the other hand, UNOMIL was to be present in such zones to "monitor, verify and report on any and all of the foregoing and implementation thereof" [Art. 4(3)]. As regards disarmament the warring parties were required "to disarm and surrender" their arms to ECOMOG, while this would be "monitored and verified by UNOMIL" [Art. 6]. Furthermore encampment centres would also be established by ECOMOG, to be monitored and verified by UNOMIL [Art. 7(a)]. Although ECOMOG was authorized to enforce peace, the Cotonou Accord placed restrictions on such powers [Art. 8(13)]. Unlike previous cases where ECOMOG could enforce peace immediately upon instruction from ECOWAS, it could now only embark on these actions after a given process had failed. The Violation Committee (provided for under Art. 8(2) of the Accord), had to first report ceasefire violations to UNOMIL, which would investigate cases and attempt to "cure" them. Upon a failure to "cure" the violations, UNOMIL was required to "submit its findings" to the Violation Committee, which had to first try to persuade the concerned party or parties to correct the situation. Upon the parties' failure to rectify the violations, ECOMOG had to then be informed and "thereupon resort to the use of its peace-enforcement powers against a violator" [Art. 8(3)]" (Olonisaksin 1996: 3940) 
significant for several reasons. They involved warring parties that had been excluded from previous peace negotiation meetings, called for demobilization as a first step towards elections, and stipulated that all rebel factions were to observe a ceasefire. They established the Liberian National Transitional Government (LNTG) in all belligerent groups were represented. The Accords also laid out the shared responsibility of ECOMOG and UNOMIL to take charge of its implementation (Kihunah, 2005: 124-125).

\subsubsection{No Order}

The success of UNOMIL was conceived as being intimately linked to the implementation of the Cotonou Agreement. The collaboration of ECOMOG with the UN aimed to further legitimise the ECOWAS operation.

The joint UN-ECOMOG operation led to the signing of the Akosombo Agreement, a supplement to the Cotonou Accords. Yet the fighting continued. In fact, even as the Agreement was being signed, two of its three signatories were being expelled from their headquarters by rival factions. As explained in chapter 3, the parties had been efficiently "bombed" to the negotiating table by a forceful ECOMOG. But the mission failed to convince the parties to accept the Agreement as binding.

Despite the visible efforts to generate momentum amongst the international agencies and to strengthen disarmament, demobilization, and reintegration procedures, there was no movement toward peace between the warring factions, which with few exceptions, did not disengage (Alao, Mackinlay \& Olonisakin, 1999: 84). 
Fighting thus continued, despite the presence and efforts of UNOMIL's troops.

By the end of 1994, fighting was taking place in 80 percent of the country. The widespread insecurity prompted the Security Council to amend UNOMIL's mandate and decrease the size of the mission, as well as transfer its personnel to neighbouring countries (Olonisakin, 1996). But things did not immediately improve. Indeed, the three warehouses that were storing all the materiel and goods earmarked for the demobilization and reintegration effort were completely looted during the April 1996 crisis. And fighters from all factions grew increasingly hostile toward UN personnel (Human Rights Watch, 1997). ${ }^{60}$ Workers in the humanitarian/relief community were forced to abandon their tasks in the Liberian capital, and UN staff contracts were terminated, with the exception of 10 UNOMIL and 15 civilian staff. Ultimately then, UNOMIL failed not only at reestablishing order, but even at contributing to the re-establishment of order.

\subsubsection{Non- Accomplishment of Mandate}

Given the insecurity of the setting, UNOMIL's ability to implement its mandate depended entirely on ECOMOG's military protection and support. Yet because of the high level of violence and hostility towards the peacekeepers, ECOMOG was unable to carry out its mission while simultaneously providing security for UNOMIL observers. Moreover, neither the Cotonou Accords nor the

\footnotetext{
60 "The United Nations humanitarian assistance office in Monrovia stated that 489 vehicles valued at US\$8.2 million were stolen from the UN and various nongovernmental organizations (NGOs). According to the UN, by 1994, the majority of UN vehicles in Liberia were in the hands of factional leaders and fighters "who, despite concrete evidence and repeated appeals by the international community, refused to return them so that we can assist Liberians as needed." (Human Rights Watch, 1997).
} 
UN-ECOWAS agreement had specified how UNOMIL would exercise its supervision over a military force that was under a separate command structure and which, by virtue of its size and control on the ground, exercised greater power in the partnership. Hence due to the absence of order and the rising risk for the unarmed observers, in November 1995 the Security Council reduced the UNOMIL presence to 160 observers and amended the mission's mandate, giving it a lower profile role in support of ECOMOG and the transitional government (UN Security Council Resolution 1041, 1996). ${ }^{61}$

According to Adebajo, "ECOMOG were heard complaining that the United Nations did not make its vehicles and helicopters available for their use and felt that the better-paid UN staff flaunted their status while leaving most of the difficult tasks to ECOMOG" (Adebajo, 2003a: 141). ${ }^{62}$ In many respects, the progress achieved in the phases of the disarmament and demobilization process was cosmetic. By April 1996, the worsening conflict in Monrovia had forced additional evacuations, and UNOMIL's strength was reduced to fewer than 20 observers. Its reduced mandate and negligible presence continued until the

61 "The Council regrets that the deterioration of the situation in Liberia has forced the evacuation of significant numbers of personnel of the United Nations Observer Mission in Liberia. The Council reminds all States of their obligation to comply with the embargo on all deliveries of weapons and military equipment to Liberia imposed by resolution 788 (1992). (...)" (UN Resolution 1041, 1996). In its 1059 resolution, the UN also explains that" By a letter dated 19 April 1996, addressed to the President of the Security Council, the Secretary-General described the widespread looting and complete breakdown of law and order since the eruption of fighting in Monrovia on 6 April 1996. Given the security situation, civilian and military non-essential personnel of UNOMIL, United Nations agencies and non-governmental organizations had been relocated to neighbouring countries. Thousands of people had been displaced and were living in desperate conditions (UN Resolution 1059, 1996).

${ }^{62}$ Adebajo (2003a) cites the UN Special Representative, Trevor Gordon-Somers, who later admitted: "You can imagine how we were looked at by the (ECOMOG) soldiers who were fighting and dying, and I am not sure that we were sufficiently sensitive to this issue. That caused a lot of hostility." (Adebajo 2003a: 141). 
security situation improved enough for elections to be held, in 1997, bringing an end to UNOMIL's mission in Liberia (Kihunah 2005: 127).

\subsection{UNOMSIL (1998-1999)}

\subsubsection{Initial setting}

UNOMSIL, the United Nations Observer Mission in Sierra Leone, was deployed to supervise and complement ECOMOG's activities in the country. On 13 July 1998, the Security Council authorized 70 unarmed military observers to deploy in Sierra Leone for an initial period of six months, under the protection of ECOMOG. In accordance with its mandate, the mission monitored and gave advice regarding efforts aimed at disarming combatants and restructuring the nation's security forces (UNDPKO, 2000). UNOMSIL's deployment was prompted by the optimism that followed the successful expulsion of the Johnny Paul Koromah/RUF junta from Freetown by ECOMOG and the restoration of the Kabbah regime. A peace agreement, the Conakry Communiqué, had been signed and the international community was hopeful this accord would finally bring peace to the country. UNOMSIL was to monitor ECOMOG's efforts to disarm the RUF combatants and to help restructure the government's security forces. It was also meant to document reports of on-going atrocities and human rights abuses committed against civilians (UNDPKO, 2000). 


\subsubsection{No Order}

As seen in chapter 3, ECOMOG had been sufficiently powerful to restore the Kabbah government, and had succeeded in persuading the government to negotiate with the RUF rebels. Yet ECOMOG's limited mandate and military weaknesses left the RUF in control of much of the eastern and southern parts of Sierra Leone (UNDPKO, 2000).

Despite the cease-fire agreed upon in the Conakry Communiqué, clashes between warring factions continued, with the rebel alliance gaining control of more than half the country. Given the acute insecurity of the setting, the poorly equipped and poorly armed UNOMSIL was entirely dependent on ECOMOG. As had previously been the case in Liberia, ECOMOG could not protect UNOMSIL while achieving its mandate (Olonisakin, 1996).

In December 1998, the RUF and its allies launched an offensive to retake Freetown, and in January 1999 overran most of the city. This led to the evacuation of UNOMSIL personnel to Guinea, and the subsequent downsizing of the Mission's military and civilian personnel. By the $1^{\text {st }}$ of March, 1999, the mission consisted of only nine civilian and military personnel, while only the Special Representative and the Chief Military Observer remained in the country (UNDPKO, 2000).

After undertaking consultations with neighbouring states, UNOMSIL's Special Representative initiated a series of diplomatic efforts aimed at opening up a dialogue with the rebels. Negotiations between the government and the rebels began in May 1999, and on the $7^{\text {th }}$ of July of that year, all parties to the conflict 
signed an agreement in Lomé to end hostilities and form a government of national unity. In return for putting a stop to the fighting, Kabbah had no other choice than to agree to significant concessions to the RUF in the Lomé Agreement (Woods \& Reese, 2008: 51). But clashes between warring factions continued, with the rebel alliance gaining control of more than half the country. Thus these political attempts at re-establishing order failed.

In the Fall of 1999, clashes between former elements of the Sierra Leone Army and the RUF resumed. This led to increasing insecurity in some areas of the country, which once again jeopardized humanitarian operations at the national level (UN 1999b, S/1999/1003).

Because of the mounting tensions between the parties to the conflict, as well as the inability of UNOMSIL to accomplish its mandate, the Security Council decided to terminate UNOMSIL on 22 October 1999 (Neethling, 2007). That Fall witnessed a continuing deterioration in the human rights situation, with an escalation of attacks on civilians by former rebels, to the point that freedom of movement was curtailed in many parts of the country (UN 1999c, S/1999/1223). By December 1999, Sierra Leone was again divided between areas under ECOMOG control and areas under RUF control (Hirsh, 2001a).

\subsubsection{Non- Accomplishment of Mandate}

UNOMSIL efforts at supporting the actions of ECOMOG in Sierra Leone were meant to demonstrate international backing for the return of the government in Sierra Leone (ICG, 2001). Yet as had been the case in Liberia, the cooperation 
between ECOMOG and UNOMSIL was never optimal (Adebajo, 2003a). ${ }^{63}$ The disparities in the two organizations' resources and the imbalance between their roles in the field heightened tensions amongst the interveners. UNOMSIL was mandated to monitor the military, the security situation in the country, and the disarmament and demobilization of former combatants. It was also to assist ECOMOG in the provision of security and in the collection and destruction of arms, to help in monitoring international humanitarian law, as well as help with the voluntary disarming and demobilization of the members of the Civil Defence Force (CDF) (UN 1998, S/Res/1181). The systematic use of force by ECOMOG, both to signal resolve and as a negotiation tactic, caused ECOMOG to once again be thought of as a party to the conflict, and hence as a potential target for attacks by the remnants of the junta. This jeopardized the safety of unarmed UN personnel under its protection.

The mission had the task of monitoring and facilitating efforts to disarm the combatants and restructure Sierra Leone's security forces. "The initial response to the start of [the] DDR programme has been very poor. (...) the DDR process continues to suffer because of several security and organizational problems. Continuing movement of RUF troops and the fighting at Makeni have deepened mistrust among the rebels" (UN 1999b, S/1999/1223).

${ }^{63}$ Cooperation between ECOMOG and UNOMSIL was hampered by the lack of a proper mechanism for liaison and coordination, which was never put in place. In addition, differences concerning the relative status of military officers, assignment of specific tasks, ways of conducting military operations, all gave rise to unhealthy comparisons and were a source of tension (Adebajo 2003a: 125). 
By December 1999, the disarmament process was barely under way, with at most 100,000 of 450,000 combatants presenting themselves at demobilizing centers (Hirsh, 2001a). The UN Secretary-General's report from that year said that

(...) deteriorating security conditions throughout the country have reversed gains in access and prevented further expansion of humanitarian activity despite commitments by all parties of the Lomé Agreement to allow unhindered access countrywide. (....) Disturbingly high rates of malnutrition previously assessed in other areas of the northern and eastern provinces remain unaddressed" (UNSG Report 1999a).

By the end of 1999, the unabated humanitarian crisis, the serious human rights abuses, ceasefire violations, extensive movements of troops and weapons by the RUF and AFRC, and the increasing targeting of humanitarian personnel, all attested to the failure of both the ECOMOG and UNOMSIL missions in the country (UN 1999c, S/1999/1223). From a theoretical point of view, the inability of the peace operation to accomplish its mandate worsened the order dimension, and helped to fuel the destabilization of the country.

\subsection{Different Dynamics between an Efficient Process \& the Establishment of Order}

The failure of each of the three peace operations that we have examined resulted from a different dynamic between the non-accomplishment of the mandate of the interveners and their incapacity to re-establish order. In the case of UNOSOM, its inability to re-establish order hampered the efficiency of the 
mission; in the case of UNOMIL, the inability of the mission to fulfill its mandate hampered its capacity to re-establish order; and in the case of UNOMSIL, both its non-accomplishment of the mandate and its inability to re-establish order helped to fuel the conflict. In the following section, I outline the processes by which these operations produced these results and arrived at these outcomes.

\section{Assessing Process}

What explains the dynamics that cause peace operations to fail at fulfilling their mandate and at re-establishing order? In the following section, I present the factors that explain why peace operations fail in intra-state wars. More specifically, I will show how peace operations led by collective interveners confined to non-coercive strategies may in fact inspire/attract/entice more violence and aggression from the belligerents. This reaction might flow from the belligerents' perception that the interveners: 1) do not understand the setting and thus could tend to underestimate the belligerents' numbers, equipment, and ability to mobilize, and to misunderstand their motivation and aims; 2) are weak/unmotivated, and thus easy to deter from getting involved in what they see as local/regional politics; and 3) are easy to manipulate and use for the belligerents' own benefit, by taking villages hostage in order to attract the interveners and then steal their valuable goods, such as food and relief equipment.

I will also show how the idea of sending actors to act as 'observers' is not appropriate in failed state settings, since there are no such things as 'mere observers' in a conflict within a failed state setting. Strategies of self-defence may 
work well when there is a political order in place, when one of the actors in the field has a monopoly on coercion, and when these actors agree to the presence of interveners. But intra-state wars are characterized by both a lack of political order and a lack of consent regarding the deployment of outside actors. Interveners thus become de facto participants in the conflict, and hence a potential target for belligerents wishing to take advantage of the war setting. We can consequently see that lightly equipped peacekeepers may even encourage belligerents on the ground to undertake violent actions against them. Finally, the type of interveners - both in terms of the individuals chosen to represent the mission and the type of mission - also signals the extent to which the situation is being taken seriously, and the underlying resolve for stopping the conflict.

\subsection{UNOSOM I}

"Q: Isn't there a better way to control these gunmen? A: Somebody did suggest one carpet bomb Somalia with "ecstasy", because it curbs hunger and makes everyone love each other. It's not a bad idea..." UN envoy Mohamed Sahnoun (quoted in Peterson 2001: 37)

\subsubsection{Type of intervener}

UNOSOM I was led by the United Nations under the authority of Chapter 6, which limits the use of force to self-defence. Mohammed Sahnoun of Algeria was appointed Special Representative. In accordance with the agreements reached with the two main Somali factions in Mogadishu, the ceasefire in the capital was to be monitored by a group of 50 unarmed, uniformed United Nations military observers. As regards humanitarian assistance, the security personnel envisaged in 
the agreements were "to provide protection and security for United Nations personnel, equipment and supplies at the seaports and airports in Mogadishu, and to escort deliveries of humanitarian supplies from there to distribution centres in the city and its immediate environs" (UNDPKO, 1993).

\subsubsection{Choice of Strategy}

UNOSOM I was established approximately a month after the signing of a cease-fire between two of the most important Somali warlords: Mahdi and Aideed. Subsequent letters of peace had also been signed in the country's three main cities, Mogadishu, Hargeisa and Kismayo. Most de facto authorities in Somalia seemed to agree on the mechanism for monitoring the cease-fire, and most seemed to favour the distribution of humanitarian assistance. The Security Council was confident that these gestures from the warring factions were a sign of the beginning of country-wide political reconciliation. Given the seemingly cooperative behaviour of the warring parties, as well as the consent of local authorities to go forward with the operation, the Security Council believed that a limited, traditional operation could be effective. UNOSOM was thus initiated under Chapter 6 of the UN Charter, which limits the use of force to self-defence (Hirsh \& Oakley, 1995; UN 1992b, S/24480).

\section{Communication}

The first UNOSOM Special Representative of the Secretary-General (SRSG), Mohammed Sahnoun, made establishing contacts and meeting with the 
peacekept the mission's top priorities. For Sahnoun, the only way for UNOSOM to fulfill its mandate was to win the confidence of faction leaders by responding seriously to their concerns and acting as a "sympathetic outsider". In the seven months of his tenure, Sahnoun held meetings with almost all the faction leaders (Hirsh \& Oakley 1995:21-22).

If this modus operandi was much appreciated by the Somalis (both belligerents and civilians), it caused a mixed reaction at UN headquarters. Some suspected that the warlords were using Sahnoun to gain time, as well as to loot and gain more exactions from the population. The proximity to the belligerents also worried UN officials, who felt that Sahnoun was being too independent and even disrespectful of the organization's agenda and authority. In fact, the Secretary-General criticized him for giving faction leaders too much veto power regarding troop deployments (Hirsh \& Oakley, 1995).

In June 1992, Sahnoun succeeded in getting the factions to sign an agreement regarding the deployment of 500 armed peacekeepers. Yet UN headquarters ignored the arrangement. And despite the fact that Chapter 6 requires the consent of the parties to the conflict, neither Aideed nor Sahnoun two key figures whose support was critical for the cease-fire to take effect, to ensure the security of food aid and to alleviate the crisis in general - were consulted on the resolution. This lack of consultation led to a hostile response from Aideed, who felt that he had been tricked into agreeing with Sahnoun. The SRSG also publicly blamed the UN leadership for failing to communicate, undercutting his cease-fire efforts and endangering the "UN's major asset- 
impartiality" (Rutherford, 2008:57). In spite of his being appreciated by Somali factions and the progress made toward negotiating a cease-fire, Sahnoun resigned (Peterson, 2001).

From then on, the credibility of the UN leaders was severely undermined in Somalia. Faction leaders felt they had been deceived, and their suspicion toward the organization grew (Sahnoun, 1998; Hirsh \& Oakley, 1995). Sahnoun was replaced by Ismaat Kitani, who had a more distant management style, for instance asking the belligerents to come to him rather than him going to meet them. He also was suspicious of the different warlords, who in turn also grew wary of the representative and of his organization. These suspicions were transmitted to the general populace, who also grew more suspicious and increasingly hostile toward the mission. This situation was exacerbated by the insufficient efforts to keep the population informed of the mission's intentions. Violence soon resumed between the different factions and towards the peacekeepers and NGOs (Hirsh \& Oakley, 1995; Peterson, 2001; Rutherford, 2008).

\section{Capacity}

Both the lack of military and of humanitarian resources in a situation characterized by a high degree of anarchy prevented the mission from operating efficiently. For instance, the Pakistani battalion was charged with securing the port, safeguarding food shipments to and from the airport and escorting food convoys to feeding stations in Mogadishu. But Hirsh and Oakley describe that 
the Pakistanis remained encamped at the airport, hobbled by stringent rules of engagement imposed by their national government that allowed them to shoot only in rigidly defined cases of self-defence and to move only when granted permission by their own government. They thus found themselves in an impossible situation, ridiculed and humiliated by the armed looters and gangs and unable to carry out their mission (Hirsh \& Oakley, 1995: 27).

At the same time, UNOSOM troops in Mogadishu were fired upon and their vehicles and arms stolen. Relief ships were prevented from docking, were threatened, and were shelled. Airports and seaports were under near constant fire. Relief aid was being extorted from donor agencies and organizations, and the peacekept were growing hostile towards the personnel attempting to distribute humanitarian supplies (UNDPKO, 1993). Ultimately, there were too few blue helmets, they were too thinly dispersed across the territory, and they were too lightly armed to operate efficiently. Indeed, the severity of the situation meant that the Pakistani force eventually "hired Somali gunmen to guard their position" (Peterson, 2001:47; UN 1992, S/24992).

In an early report, the UN Representative highlights how a show of force was needed to deter the belligerents. Deterrence was identified as necessary for protecting international and local personnel providing humanitarian assistance, but also to more generally stabilize the situation in Mogadishu (UN 1992a, S/24343: 22). Yet without any coercive power, UNOSOM was far from being an effective deterring actor. The organization remained powerless and paralyzed in its activities. Both Aideed and Mahdi ordered the evacuation of UN security personnel from their territory. The obvious impotence of the international 
community resulted in increased violence and attacks on humanitarian convoys. This showed that faction leaders had understood the narrow margin of manoeuvre afforded to the peacekeepers, and they capitalized on the poor protection offered to NGOs by continuing to plunder them (Peterson, 2001; Hirsh \& Oakley, 1995).

\section{Knowledge}

Aideed and Boutros Boutros-Ghali shared an history of disagreements and the animosity between the warlord and the new Secretary-General tainted the UN intervention in Somalia (Murphy, 2002: 34). Mohammed Aideed had reluctantly agreed to the peacekeepers' presence when he realized it was inevitable. This reluctance, which was shared by Mahdi, arose out of concern that the peacekeepers would deprive them of the presidency. Aideed distrusted UN Secretary-General Boutros Boutros-Ghali, considering him to have been "proBarré ever since his tenure as Deputy Foreign Minister of Egypt" (Adebajo, 2003b: 81). Aware of his reputation among the Somali warlords, Boutros-Ghali asked the experienced Algerian diplomat Mohamed Sahnoun to win the confidence of the warring parties. Sahnoun had represented Algeria at the United Nations, served as Assistant Secretary-General of the OAU, was knowledgeable about Somalia's history, and was known for having an understanding of the Somali character (Hirsh \& Oakley, 1995: 21).

The resentment of the warlords regarding the deployment of soldiers was not because they opposed an international presence on their territory, but rather stemmed from their fear that the international community may privilege one party 
over the other. ${ }^{64}$ Their refusal to allow the deployment of troops was also meant as a signal to the international community that they were still "Masters in their own house", and that they did not fear the organization's reprisals (Drysdale, 1997).

The warlords largely cooperated with Sahnoun. Yet Sahnoun's resignation reignited their suspicions toward the Secretary-General and the international organization as a whole. Sahnoun's successor, Ismat Kittani, fuelled their suspicions, since they questioned his neutrality. ${ }^{65}$ The cumulative effect was a change in the relationship of trust between the UN and the Somali warlords. From then on, the latter were more reticent to cooperate, and sought to make the most of the organization's dissensions (Hirsh \& Oakley 1995; Rutherford, 2008).

\subsection{UNOMIL}

\subsubsection{Type of Intervener}

UNOMIL was the first peacekeeping mission undertaken by the United Nations in cooperation with a peacekeeping mission already set up by another organization. It was composed of 303 military observers, 20 medical personnel, 45 military engineers, $58 \mathrm{UN}$ volunteers, 89 international personnel and 136 local staff.

${ }^{64}$ An event added to this fear. In mid-June 1992, an airplane bearing UN markings delivered military equipment and newly printed Somali currency to Mahdi's faction. The airplane was in fact an engine bought by the Russians but which had previously served UN airlift operations. Someone had failed to repaint the plane before using it for other business. This event was nonetheless enough to spur concerns regarding the UN's neutrality, and for Aideed's faction to seize upon the event to withdraw its consent for the deployment of the organization's new troops. (Hirsh \& Oakley, 1995: 23).

${ }^{65}$ According to Hirsh and Oakley, "the dismissive way (his relationships with the faction leaders) were handled, and the contrast with Sahnoun's more personal, conciliatory style, together with the obvious impotence of UNOSOM I's Pakistani battalion, further damaged relations between UNOSOM I and the factions leaders." (Hirsh \& Oakley, 1995: 32). 


\subsubsection{Choice of Strategy}

The joint peace operation was mandated to implement the disarmament plan contained in the Cotonou Agreement. ECOMOG was to take on the main duties, and the UN observers were to supervise the process (Olonisakin, 1996). ECOMOG could use coercive force under specific conditions and upon authorization of the UNOMIL mission. ECOMOG was responsible for the implementation of the ceasefire and disarmament. UNOMIL was restricted to using non-coercive means and UNOMIL observers were given the role of monitoring ECOMOG's activities, including enforcement actions. On the basis of an agreement between the UN and ECOWAS, UNOMIL and ECOMOG were conceived as distinct operations under the authority of two different organizations.

It was up to each mission to choose its own method of operations, yet it had to be in consultation with the other. ECOMOG was expected to ensure the safety of UNOMIL observers and civilian staff. Therefore, UNOMIL was expected to temporarily withdraw from the areas in which ECOMOG would enter into combat (Kihunah, 2005: 125).

\section{Communication}

Communication was never optimal between UNOMIL and ECOMOG. The two forces were not always working in tandem. The difficulty in achieving the envisaged co-operation between ECOMOG and UNOMIL resulted from several factors. 
First, the foundation for a smooth working relationship between both forces was never laid. This was partly due to the late date at which the UN became politically involved in the crisis - the reason for UNOMIL's late deployment - which created some animosity with ECOMOG troops. Many ECOMOG soldiers resented the fact that UNOMIL was deployed after they had done the "dirty work" of shedding their blood for Liberians. They argued that UNOMIL had arrived when peace was almost concluded, and would share in the glory that should be ECOMOG's alone. Moreover, "ECOMOG perceived the UN as a latecomer that was incapable of properly dealing with belligerents. It was also seen by many as merely a political tool, with little practical purpose except the appeasement of Charles Taylor" (Kihunah, 2005: 126).

ECOMOG often treaded a fine line between protecting UNOMIL and attempting to dictate its conduct. For instance, ECOMOG occasionally restricted observers at road blocks and required them to observe civilian night time curfews despite an initial agreement "that they would enjoy freedom of movement throughout Liberia" (Kihunah, 2006: 127; see also Olonisakin, 1996; Marley, 1997). In general, ECOMOG officers and soldiers resented UNOMIL, though the officers were relatively better able to hide their discontent and exhibited cordial relations with UNOMIL officials. ${ }^{66}$ ECOMOG troops were reluctant to work with UNOMIL, and "often gave the appearance of being in competition with them. In

\footnotetext{
${ }^{66}$ The ECOMOG Field Commander was reported to say that: "At the soldier level, it is difficult to understand why UNOMIL is here. At the officer level, we understand why they are here and we try to educate the soldiers." The remarks of another ECOMOG officer, however, offer a more (missing word) view within ECOMOG regarding UNOMIL's presence in Liberia: "Those ordinary people who enjoyed ECOMOG facilities since 1990 appreciate ECOMOG. They do not feel the practical effects of UNOMIL. Monitoring ECOMOG symbolizes mistrust."(Olonisakin, 1996:41).
} 
spite of this, the UNOMIL Commander sought to maintain cordial relations with ECOMOG, maintaining that there was no "conflict of interest" between the forces and as such that any differences that may have existed between them were not irreconcilable" (Olonisakin, 1996:42).

Little effort had been made to specify/clarify UNOMIL's purpose and its relationship with ECOMOG, particularly how UNOMIL was to operationalize its supervisory role over ECOMOG. UNOMIL thus had to improvise in enforcing its supervision over a military force that was under a separate command structure and which, by virtue of its size and control on the ground, exercised greater power in the partnership.

The bad feelings between ECOMOG soldiers and UN military observers at least partly stemmed from the UNOMIL mandate. One of UNOMIL's responsibilities was to verify the neutrality and human rights record of the ECOMOG contingents. This tended to give ECOMOG a sense that UNOMIL was "looking over their shoulder", an obvious source of tension between the organisations (Marley, 1997:118).

Secondly, the problems with the ECOMOG operation even before the establishment of UNOMIL undoubtedly added to the antagonism that later emerged between the forces. In particular, the poor relationship between ECOMOG and its authorizing body ECOWAS affected the working relationship between ECOMOG and its UN counterpart, since ECOWAS' efforts at collaboration with the UN at a policy level were resisted at an operational level by ECOMOG. The relationship was further hampered by ECOMOG's own institutional shortcomings. Not only did the force receive little political direction from ECOWAS, but there was no functional mechanism that made the force 150 
accountable to ECOWAS' political authority (Quainoo, personal communication, January 2008). The force thus became used to taking control of both the political and the military aspects of the operation. Ultimately, the absence of a political authority that could control its excesses was the main reason for ECOMOG's hostile actions towards UNOMIL.

Command problems within ECOMOG became obvious when ECOMOG soldiers stopped and searched UNOMIL staff at checkpoints despite the outwardly smooth working relationship between senior ECOMOG officials and UNOMIL. ${ }^{67}$ There was also confusion over areas of responsibility between ECOMOG and UN operations in Liberia, which stemmed from poor coordination between the two organisations. ${ }^{68}$

The reaction of the peacekept towards both organizations fuelled antiUNOMIL sentiments within ECOMOG. Liberians tended to identify more with ECOMOG troops than with their UN counterparts. The former were stationed at checkpoints throughout the country and were particularly numerous around the capital, while the UN units were either absent or unnoticed in these locations. The Liberian population saw UNOMIL as chic troops driving around Monrovia in

${ }^{67}$ This was reflected in the report of the UNSG: "While ECOMOG and UNOMIL continue to enjoy close working relations, especially between the top levels of their command structures, the co-operation required for UNOMIL to carry out its tasks has not always been satisfactory at the working level." (Olonisakin, 1996: 42)

${ }^{68}$ One example relates to the "Carter Camp Massacre" in 1993. "The massacre of several hundred displaced Liberian civilians near Harbel in June 1993, attributed to soldiers belonging to the AFL, highlighted confusion concerning responsibility for protection of displaced persons. ECOMOG denied that it had the responsibility to protect displaced persons' camps, claiming that camp security was the responsibility of either the United Nations or the Red Cross. The excuse is not credible since the UN's military observer force had not yet been established and the Red Cross has no security force; it does however point to the failure to clearly identify and delegate areas of responsibility between international organisations and agencies operating in Liberia" (Marley, 1997:119). 
luxury vehicles. By contrast, ECOMOG soldiers, with their often worn-out uniforms and vehicles, could be more easily related to by the poor that predominated in many parts of the country (Olonisakin, 1996:43).

The disparity between the salaries in ECOMOG and UNOMIL also fuelled tensions between the two. The latter's per diems were at UN rates (over \$100 US per day), while ECOMOG soldiers received a bonus of $\$ 5$ per day that was paid irregularly by their home country. This difference in pay resulted in a visible difference in the quality of life enjoyed by UNOMIL and ECOMOG personnel in Liberia (Marley, 1997: 118).

\section{Capacity}

As we have seen, UN-ECOWAS collaboration at a policy level did not translate into cooperation on the ground. ECOMOG was also logistically hampered by a lack of funding, equipment and troops, and had problems disarming and demobilizing the warring factions while simultaneously deploying troops in all areas alongside UNOMIL. With only 86 military observers, UNOMIL was unable to carry out many of its mandated activities, and was even occasionally forced to evacuate its observers from the country (Adebajo 2003a). ${ }^{69}$

In November 1995, the Security Council reduced the UNOMIL presence and amended the mission's mandate, giving it a lower profile role in support of ECOMOG and the transitional government. By April 1996, the worsening conflict

\footnotetext{
69 According to Olonisakin "The effects of such an independent operation were demonstrated when, in the summer of 1994, UNOMIL observers were kidnapped following allegations of arms deals with a warring faction in lower Lofa County" (Olonisakin, 1996:41).
} 
in Monrovia had forced additional evacuations, and UNOMIL's strength was reduced to fewer than 20 observers. Thereafter, UNOMIL's role was uncertain and its presence negligible despite the renewal of its mandate (UNDPKO, 2001; Adibe, 1997).

\section{Knowledge}

Because of its long-standing relationship with Liberia, Nigeria considered itself to be more experienced and more knowledgeable about the country than any other intervener (Adebajo, 2003a). As a result, UNOMIL's supervisory mandate was not well received by ECOMOG leaders and troops. They felt that external supervision implied that the UN did not trust in their abilities and intentions. Moreover, West African countries, and more specifically Nigeria, had invested time, troops and money in ECOMOG, and they perceived the UN as a newcomer to the situation. They saw UNOMIL as weak in light of the insecurity of the setting, and as lacking the necessary knowledge about the local context to be able to deal with Liberian belligerents. Indeed, as we have seen, UNOMIL was perceived by many as merely a political tool with little practical purpose beyond appeasing Charles Taylor. This perception hampered the working relationship between the two organizations (Kihunah, 2005: 126). At the same time, the belligerents were aware of the existing tensions, and they sought to play upon them to advance their own agendas (Kihunah, 2005; Adebajo, 2003a). 


\subsection{UNOMSIL}

\subsubsection{Type of Intervener}

After ECOMOG's initial military intervention in the conflict, UNOMSIL was meant to serve alongside ECOMOG forces in a limited role. They were to supervise the disarmament and demobilisation of former combatants and other participants in the conflict, as well as ECOMOG's provision of security and its collection and destruction of arms in secure areas. UNOMSIL's military contingent was also to help ensure respect for international humanitarian law in the execution of tasks by Sierra Leone's military. Its civilian contingent, which made up the bulk of the UN mission, was mainly tasked with advising the government of Sierra Leone and police officials on matters such as the reform and restructuring of the Sierra Leone police force, as well as monitoring progress in this regard, in co-operation with other international efforts. Furthermore, they were to report on violations of international humanitarian law by the belligerents, as well as by ECOMOG troops (Neethling, 2004:60).

\subsubsection{Choice of Strategy}

UNOMSIL was conceived as a traditional peacekeeping mission whose main purpose was to give legitimate backing to the enforcement mission led by ECOMOG. It was established under Chapter 6 of the UN Charter to help in national reconciliation and the demobilisation of former soldiers following the restoration of the government of President Ahmed Tejan Kabbah in March 1998. UNOMSIL adopted a self-defence strategy, i.e. a non-coercive strategy. 


\section{Communication}

UN agencies had communication problems with NGOs and relationships were tensed between the UN political and military staff (Porter, 2003). Neither ECOMOG nor UNOMSIL succeeded in providing the information about the security situation throughout the country, as it was required by their mandate. UNOMSIL was almost totally dependent on ECOMOG for security assessments. Misinformation significantly harmed the credibility of the peace operation, and put both UN aid agency personnel and civilians at risk (Berman \& Labonté, 2006: 159).

The main parties in the conflict refused both the military and the political strategy put forward by ECOMOG and the UN in Sierra Leone. The RUF took advantage of the absence of international resolve and the lack of a coherent strategy, as well as the poorly designed peacekeeping mission command and control structure and discordant agendas, to advance its own programme (Berman \& Labonté, 2006). In the few areas where NGOs could operate, there was harassment of aid agencies by pro-government CDF forces and by ECOMOG soldiers. Porter describe that "As the situation deteriorated, humanitarian staff accused UNOMSIL of 'politicising' the security situation, by downplaying the strength and continuing threat" posed by the belligerents and by the ECOMOG troops (Porter, 2003: 23). The belligerents thus gained power over the territory and destroyed most UNOMSIL offices while also looting and stealing almost all of UNOMSIL's material and operational assets such as vehicles and cars. 
UNOMSIL remained powerless as ECOMOG soldiers also detained and physically mistreated the personnel of a number of humanitarian NGOs and the ICRC, apparently accusing them, without evidence, of being collaborators.

A ceasefire was finally signed between Sankoh and Kabbah in 1999. UNOMSIL's SRSG Okelo was acknowledged to have played a key role in the negotiations. The signing of the peace agreement had an immediate positive impact on humanitarian efforts.

One of the main tasks of UNOMSIL was to gather security information for the UN system, including humanitarian agencies. But UNOMSIL was slow to share information with these agencies. UNOMSIL, ECOMOG and the government described a steadily improving situation, while NGOs and ICRC officials noted an increasingly insecure situation across the country. A Humanitarian Affairs Coordination Unit (HACU) official complained that SRSG Okelo "equated support for the Government with ignoring the reality of what was going on in the country" (cited in Porter, 2003: 23). While UNOMSIL military observers had weekly meetings with the humanitarian agencies, the situation on the ground was not always accurately depicted. UNOMSIL military observers were often accused of minimising the insecurity of the situation so as to pressure the NGOs into staying in the country even if it was not safe to do so (Porter, 2003: 23-24).

Even though the UN adopted a more important political role in Sierra Leone, and albeit the arrival of UNOMSIL, no great effort was made towards a better integrated UN mission (Porter, 2003:30). According to Sommers: "the 
entrance of UNOMSIL into Sierra Leone did not upset the existing coordination structure: it simply assumed the position at the top of it" (cited in Porter, 2003:29). There was neither formal nor informal means of communication put in place to facilitate the coordination between the different UN entities. According to Porter, "by 1998, most international NGOs and ICRC officials seemed to view UNDP, UNOMSIL and the Sierra Leone government as essentially a single unit." (Porter, 2003: 29). Most of the humanitarian work was carried through by the NGOs and were coordinated by HACU. Surprisingly, UNOMSIL also hampered the sharing of information with other UN agencies. Hence there were two parallel UN security systems, "lacking a formal system for information management or information sharing." (Porter, 2003: 29). At one point, just before the January 1999 attack on the Sierra Leonean capital, UNOMSIL was accused by the humanitarian organizations operating in the country of having deliberately lied to them about security for political reasons. The results were disastrous, as the humanitarian agencies were left unaware of the worsening of the security situation in the country. Sommers concluded that "the lack of coordination between UNOMSIL and the UN Security Officer (and by extension all other UN agencies) effectively threatened the entire humanitarian operation. UNOMSIL's stance on this issue seemed unnecessary and even reckless." (Sommers, 2001: 76, cited in Porter, 2003:30). This of course put the humanitarian agencies at risk, and contributed to the failure of the accomplishment of the mandate. 


\section{Capacity}

UNOMSIL was established in June 1998, with an authorized strength of 70 military observers (Porter, 2003:22). By the end of August 1998, UNOMSIL had completed the first phase of the deployment of its military component, consisting of 40 military observers, a chief military observer and a medical team of 15 personnel (UNDPKO, 2000). UNOMSIL was to help with national reconciliation and with the DDR programme. Yet the hostility of the setting impaired the progress of UNOMSIL's mandate. Indeed, the instability of the setting reached such a dangerous level that most of UNOMSIL's personnel (and equipment) were evacuated in December 1998. In January 1999, rebel fighters (AFRC and RUF) overwhelmed ECOMOG forces and invaded Freetown, which resulted in thousands of civilians being killed and approximately 150,000 being displaced. By March 1999, UNOMSIL had only nine civilian and military personnel under the authority of the SRSG (Malan, 1999).

The Security Council subsequently approved an extended mandate for UNOMSIL. But even with 100 more troops, it was unable to be effective in such an insecure and unstable environment, despite the protection of ECOMOG. To put the situation into perspective, at the height of the fighting in 1998, between 60,000 and 80,000 combatants were active in Sierra Leone out of a population of about 4.5 million (Ginifer, 2005).

ECOMOG, with its 20,000 troops, represented a weak force in the face of such numbers (Malan 2001). Moreover, ECOMOG had fewer resources than the international mission, despite the fact that it was assigned the majority of the 
operation's tasks. This included Chapter 7 authorization to establish security in the country by flushing out the remnants of the AFRC/RUF, as well as to conduct disarmament and demobilization operations and to protect the UN personnel. The differences in the danger of tasks and the disparities in pay between the regional and international staff continuously created tensions between the two organizations (Malan, 2001).

\section{Knowledge}

The withdrawal of UNOMSIL and ECOMOG from the country gave an indication to the belligerents about which strategy they should adopt. They determined that if massive casualties were incurred by the Nigerian interveners, the great power would be forced to withdraw its remaining troops. The belligerents also knew that upcoming elections in Nigeria would make it more difficult for the country to keep troops in what was being called "Nigeria's Vietnam" (Doyle, 1999). The unprepared and ill-equipped UN force would be unable to disarm them without Nigerian troops, and would soon be forced to withdraw.

The deterrence strategy had thus been gutted. Soon, the belligerents made clear that they would attack the Nigerians if they stayed in the field, and demonstrated their resolve by taking several Nigerians as prisoners of war. ECOMOG soon suffered heavy casualties in the fierce fighting, and Nigeria did indeed decide to withdraw in January 1999 (UNDPKO, 2000). Violence quickly escalated, and Sierra Leone once again descended into civil war. By June 1999, 
the UN had decreased its troop numbers in the field to a mere 24 observers. As in the case of Liberia, the joint operation and its resulting mixed signals had not succeeded in deterring the belligerents from spoiling the peace agreement, or in muting the violence. The belligerents had seen more opportunity and more security in violating the accords than in sticking with them.

\section{Conclusion}

No peace operation in an intra-state war within a failed state setting can succeed when under the auspices of Chapter 6. Most specialists who have studied the missions described above agree that all three were failures. However, these failures are not explained by reference to the same reasons. The focus is on one of the ingredients mentioned above, on the failure to achieve the mandate or the failure to re-establish order. This chapter sheds new light on the outcome and on the process of each operation. Combining our two dimensions of success helps to distinguish two effects of a Chapter 6 intervention within a hostile setting: impeding the mandate and hampering the re-establishment of order. By disaggregating the ingredients of a strategy of intervention, this chapter highlights key processes by which such outcomes are reached.

UNOSOM I was mainly crafted as a mission to alleviate the humanitarian crisis and to facilitate political reconciliation amongst consenting political parties. Warring faction leaders had signed a cease-fire, and a truce seemed to prevail in the country. The most urgent problem seemed to be the widespread famine among the poverty-stricken population. The need for forceful strategies seemed to be 
superfluous in such a context. UNOMIL was deployed in concert with a mission by ECOMOG, which was allowed to use coercive force. It was to assist the coercive mission, and was hence to provide international backing for an ongoing mission. The need to use coercive force was again perceived as unnecessary. In Sierra Leone, a non-coercive intervention was conceived as such because it was implemented after local elections, when it seemed that the state was about to regain the legitimate monopoly on force. Once again, framing the intervention in coercive terms seemed inadequately tailored to the situation at the time.

In Liberia as in Sierra Leone, the UN collaborated with the regional intervener and succeeded in giving an appearance of greater impartiality to the operation. However, the partnership and the need for collaboration complicated communications between the interveners, and as a result, between the interveners and the belligerents. The differences in terms of intervening cultures and of understandings of local dynamics combined to hinder the implementation of the joint operations. Moreover, after the failure of peace operations in Somalia and Bosnia, the belligerents had learned that casualties could cause interveners to hastily withdraw from an operation. The continuing use of force by the regional organization gave the belligerents the ideal pretext not only to forcefully reply to the coercive actions but also to target UN personnel. Taking revenge on ECOMOG and discouraging the targeted international personnel worked well for the belligerents. Moreover, that ECOMOG proved incapable of protecting its personnel was seen as an opportunity for the belligerents to discredit the regional organization in the eyes of the international community. By reacting robustly to 
force, the belligerents gained credibility on the international scene. From the point of view of the interveners, the compellence had caused a deterioration in the situation in the field such that the implementation of the peace agreement seemed even less likely. Ultimately, the failure of both operations stems from the fact that no adversaries were deterred from engaging in violence, and no adversaries were reassured that the agreement would be respected.

The third chapter demonstrated that the use of force is not in itself very effective, and may in fact slow the peace process by making the interveners party to the conflict. Similarly, and as the earlier examination of the UN mission demonstrated, the lack of coercive means also hampers the peace operation. This phenomenon can be partly explained by the fact that interveners lose - or simply do not gain - credibility in the eyes of the belligerents. Hence a low profile intervention may not only fail to stop violence, but might in fact trigger violence since the perceived benign nature of the operation risks becoming an incentive for belligerents to target international organizations' resources and workers/peacekeepers, thereby increasing insecurity for both civilians and intervening troops (Lisher, 2003; Anderson, 1999). 


\section{ChAPTER 5}

\section{Partial Success: \\ NON-ACCOMPLISHMENT OF MANDATE \& ORDER}

Over the past decades, international and regional organizations have taken

the lead in peace operations. As was explained in chapter 1 , the location of the crisis (including regional spill-over), the swift deployment of troops from neighbouring countries, the regional actors' knowledge and understanding of the terrain, and their stakes in the resolution of the conflict, are all reasons justifying the need for regional interveners to step in. The interventions of international organizations are advantageous because of burden-sharing and their perceived impartiality toward the conflict.

International and regional organizations have also taken the lead in peace operations by default or due to a lack of alternatives. This is largely because of the great powers' reluctance, since the Somalia debacle, to deploy troops in countries in which they have few interests, which are in remote locations relative to their worldwide network of military bases, and for which exit strategies seem too risky. It has also proven hard to convince the great powers' populations that their respective countries should sacrifice its troops and resources for a war that is not 
an immediate threat to security and/or that does not represent an opportunity of significant material/strategic gains. ${ }^{70}$

Partial Success is achieved when the peace operation has re-established order without achieving its mandate. I contend that this will happen if a deterrence strategy is adopted by an actor other than a great power. Because collective interveners have to deal with a great number of members and might have coordination problems which leave them with less means and leverage, they might be seen as less credible and/or less committed, less likely to mobilize sufficient troops and adequate equipment to accomplish their mandate.

These interveners might be able to adopt a successful strategy yet not to succeed in accomplishing their mandate. Hence their operation may succeed in reestablishing order yet fail at fulfilling the operation's mandate. The puzzle is thus: how can a peace operation bring back order while failing at accomplishing its mandate?

This section highlights the extent to which having a great power's "boots on the ground" counts. The missions studied were logistically or financially supported by the U.S. (ECOMIL) or by the U.K. (UNAMSIL), yet neither of these great powers took the lead in the operation or committed their troops. ${ }^{71}$ Financial and/or logistical support by the great powers was insufficient for either mission to achieve its mandate.

\footnotetext{
${ }^{70}$ For example, it was easier to convince the European great powers to intervene in the Balkans for there was a fear for a spill-over that would have affected the security of the region; it was also quite easy to convince the Americans to intervene in operation Provide Comfort in Iraq, were strategic gains were expected were the operation's activities successful.

${ }^{71}$ The United States positioned a task force of over 2,000 marines off the coast of Liberia and committed \$26 million to transport all the contingents and to fund contracted logistics support and equipment for ECOMIL (Kansteiner, 2003).
} 
As in the other chapters, this section draws upon official documents, expert reports and interviews with regional experts to assess the arguments and hypotheses advanced. My research on the particular peace operations in this chapter was supplemented by an interview with a key figure in one of the main rebel movements in Liberia at the time, General Joe Wylie, spokesman and military advisor for the Liberians United for Reconciliation and Democracy (LURD). General Wylie was one of the group's founders, and was its military advisor, spokesman and a leadership contender between 2003 and $2005 .{ }^{72}$ His key positions during the period and his insights provided me with a rare, inside-view to the conflict.

I will show how the adoption of a deterrence strategy in a peace operation led by a collective intervener while allowing for order to be re-established does not guarantee the accomplishment of the mandate. I will compare two peace operations that occurred at different stages of a conflict and that involved different kinds of belligerents, but which were led by the United Nations or by ECOWAS under the authority of the UN Charter's Chapter 7 and which both adopted a deterrence strategy: the ECOMOG Intervention Mission in Liberia (ECOMIL2003), and the United Nations Assistance Mission in Sierra Leone (UNAMSIL, 1999-2000). It is important to underline that the variation in terms of setting and timing will allow us to more fully elaborate the role played by the combination of communication, capacity and knowledge of both the peacekeepers and the peacekept in the crafting of the common outcome.

\footnotetext{
${ }^{72}$ Still an influential character at the time of the interview, General Wylie is said to be planning to run for Liberian's presidency once Ellen Johnson-Sirleaf's term is over.
} 
This chapter will be divided into two sections. The first will focus upon the similarity in outcome for each peace operation, by closely examining the extent to which each operation succeeded at re-establishing order while failing to accomplish its mandate. To do so, I will compare the setting prior to, and after, each intervention. I will highlight the dynamic between the re-establishment of order and the accomplishment of the mandate, and how the success of the former does not necessarily lead to the success of the latter. In the second section, I will assess the process that made these operations "partial successes". The limited impact of a peace operation that is led by a regional or international organization will be discussed. I will conclude by highlighting the extent to which "boots on the ground" count when it comes to great power intervention in the context of an intra-state war within a failed state.

\section{Assessing Outcomes}

The two peace operations described below occurred in different contexts, at different stages of the conflict, and with different timing for the interventions. They involved an assortment of actors, had different mandates, mobilized a variety of resources, and had varying durations. And ultimately, they succeeded at establishing order yet failed at accomplishing their mandate. This prompts two questions: how is it that each peace operation's success in one dimension did not lead to the success of the other?; and, what were the conditions that caused the first dimension to reinforce the other's failure? Effectively then, we are analyzing the different interactions between the two dimensions of success. To do so, I focus 
upon two aspects: 1) the extent to which the capacity of re-establishing order is not a sufficient condition for the accomplishment of the mission's mandate; 2) the extent to which the failure to fulfill the mandate did not hampered the reestablishment of order.

\subsection{ECOMIL (2003)}

\subsubsection{Initial Setting}

Even though the ECOMOG intervention in Liberia (ECOMIL) was put in place after a peace agreement was signed, the setting was challenging. Numerous actors were opposed to the operation, there was a weak desire by the conflictual parties to stop fighting, command and control within each group was loose, and external regional financial and military support to the belligerents fuelled national tensions. Moreover, the Liberian infrastructure (roads, buildings, health facilities, etc.) had mostly been destroyed by the previous years of conflict, and $85 \%$ of the population lived below the poverty line.

As seen in Chapter 3, ECOMOG's troops had left Liberia since 1998, following Charles Taylor's return to power. Yet while the new president had won the elections, his government was much contested, which compromised its ability to keep order in the country. Between 1998 and 2003, new rebel groups had formed in order to battle what was seen as an illegitimate, corrupt and brutal government. Two main movements emerged: the first was Liberians United for 
Reconciliation and Democracy (LURD) and the second was the Movement for Democracy in Liberia (MODEL). ${ }^{73}$

In April 2003, the spread of violence in Liberia led to calls for a renewed peacekeeping presence in order to prevent a full collapse of the government and a worsening of the situation. Both the international community and the parties in conflict called for the United States to lead a new multi-national force. The Americans refused but nonetheless agreed to provide financial and transport support to ECOMIL, an ECOWAS advance force. The formation of the ECOMIL force was encouraged by the Secretary-General Kofi Annan by Security Council Resolution 1497 (in August 2003), which called for member states to form a multinational force (Jones with Cherif, 2004: par. 16). Yet this was not what the Liberian populace wanted. General Wylie, the then-spokesman and military advisor to the LURD, summarizes what seemed to be the general perception at the time: "The presence of the US is what we wanted. Once Taylor leaves we want the US to come." (Wylie, personal communication, January 2008)

On August $4^{\text {th }}, 2003$, ECOWAS deployed ECOMIL to Liberia, and on the $18^{\text {th }}$ of August 2003, the Comprehensive Peace Agreement was signed in Accra by the Liberian Government and rebel groups (United Nations Peacekeeping Best Practice Unit, 2004). The parties had agreed to install an interim government that

${ }^{73}$ The LURD was founded in 1999 mostly by Liberian refugees in Guinea. Their leader was then Sekou Conneh and was divided between the Krahn, Mandingo and Gio factions. It controlled the North and West of the country. MODEL was an offspring of the LURD formed in 2003 as a result of opposition to Conneh's leadership of the LURD. Most of their members were Krahns Liberian refugees based in Côte d'Ivoire. Their leader was Thomas Nimely and the group controlled most of the South and East of the country. As for LURD, the group's main aim was the overthrow of Charles Taylor. Mounting opposition to Taylor's government resulted in a resumption of fighting in the country in early 2003. 
would be led by an independent civilian, that is, someone not related to the former President Charles Taylor, to the LURD, or to the MODEL rebel movement. The new government came to power in October, and was mandated to rebuild the state and prepare for elections to be held before 2005. ECOWAS was to monitor the compliance of the different parties to the peace agreement (Accra Peace Agreement, 2003).

As described in chapter 1, the more parties to the dispute, the more chances some of them will be opposed to the peace agreement. As well, the more parties to the conflict, the more chances there are for some of them to become spoilers in the peace agreement process, and the more difficult the task of aggregating multiple preferences in support of a peace operation. Such was the case in Liberia. The peace agreement was not unanimous, either between each signatory group, or indeed within each signatory group. After the signing of the peace accord, both the LURD and the MODEL opposed the deployment of ECOMIL troops. Some parties considered that they had been forced to make unacceptable compromises, and hence were not willing to sustain their support for the agreement. It seemed that the peace was more a way for the signatories to gain time and seek advantages in the war rather than to win the peace (Accra Peace Agreement, 2003).

As was also described in Chapter 1, the characteristics of the disputants and the involvement of external actors may also contribute to fuelling the conflict, magnifying the challenges for peacekeepers in seeking to re-establish order and/or to accomplish their mandate. Such was the case in Liberia, where Guinea was a 
big supporter of the LURD and Côte d'Ivoire was helping MODEL, with both governments providing each group with arms and financial support.

\subsubsection{Order}

Notwithstanding the challenging setting, ECOMIL succeeded at reestablishing order. By the end of its mission, ECOMIL had created a safe and secure environment in Monrovia and its surrounding areas ${ }^{74}$ such that humanitarian organizations could resume their operations (Ross, 2005). The situation in the capital was representative of the security improvements in the country as a whole (Ross, 2005).

ECOMIL's presence slowed down the amount of bloodshed caused by the rebel factions (Wylie, personal communication, January 2008; ICG, 2006). It was able to do so because the major complaints or problems for the belligerents were the impression that they needed to fight because no other organizations were able to defend them. General Wylie explains that: "The reason why we (the LURD) started to fight was not to seize the presidency: we were fighting because people were killing us" (Wylie, personal communication, January 2008). Once ECOMIL showed its capacity to defend civilians and belligerents alike, the LURD reduced its activities. Both the LURD and MODEL handed control of certain parts of their territory (notably the port in Monrovia) to the West African Peacekeepers (BBC, 2003a). Another peace agreement was signed a few weeks after the arrival of

\footnotetext{
${ }^{74}$ Monrovia as far as Robertsfield International Airport, about 55 kilometres to the south and the Po River Bridge, 14 kilometres to the north of the city.
} 
ECOMIL. However, this is not to say that ECOMIL succeeded in being efficient/accomplishing its mandate.

\subsubsection{Non-Accomplishment of Mandate}

Even though order was re-established, ECOMIL never achieved its mandate. It did successfully convince the LURD and MODEL to pull back from many of their key positions ${ }^{75}$, and most of each organization's commanders appeared to be unarmed. However, it was well known that while the rebel movements had withdrawn, they still retained the option of a quick redeployment in the event of the failure of the peace agreement. Hence there was an "invisible frontline" between the location to which they had retreated and the territory that they could quickly re-occupy (Hennop, 2003: 4).

Hence despite the re-establishment of the government and the capacity of ECOMIL to impose order, the persistent resumption of violence once the peacekeepers retreated from key areas continuously impeded the delivery of humanitarian assistance throughout the country. All sectors of Liberian society, from civilians and civil society groups to fighters from all the warring parties, repeatedly called for an intervention by the US.

ECOWAS was there for what? Ten years, it didn't stop Taylor as a matter of fact, at the end of the game, some of the Nigerians and the Ghanaians collaborated into getting power, it was difficult (...). Nigeria and Ghana were right was behind them. They don't just act on their own." (Wylie, Personal communication, January 2008). ${ }^{76}$

\footnotetext{
${ }^{75}$ Its positions were on Bushrod Island, north of Monrovia's Mesurado River, which is spanned by the city's only two bridges, scene of the heaviest fighting in July.

${ }^{76}$ General Wylie refers to the American intervention (UNITAF) in Somalia.
} 
The difficult conditions in the country continued, with marauding armed bands (often including child soldiers) terrorizing and abusing civilians, committing murder, rape, forced recruitment and looting. Still unpaid government militias and fighters from both rebel groups operated with loose command and control. Soldiers continued to extort money and other goods from those seeking refuge, and blocked them from moving to safety. Most of the population outside of Monrovia remained in dire need of basic necessities (U.S. Committee on International Relations, 2003).

Thus although the ceasefire has been signed, the situation on the ground in Liberia remained tense. There were regular reports of skirmishes between government forces and militias who remained loyal to Taylor, as well as between LURD and the smaller group, MODEL. Battles between troops continued both because these were the signs of an ongoing offensive between government and rebel forces, and because in some cases, news of the peace deal had not yet reached the troops fighting in Liberia (Hennop, 2003: 3).

\subsection{UNAMSIL Take 1 (1999-2000)}

"Rebels will always rebel. Even though they sign documents one hundred times, they can always renege on such accords."

General Maxwell Khobe (cited in Olonisakin 2007: 46)

\subsubsection{Initial setting}

As explained in Chapter 4, UNOMSIL personnel were evacuated in 1998, allowing ECOMOG troops to retake the capital and install the civilian government (UNDPKO 1998). The UN sought to re-initiate a series of diplomatic 
efforts between the government and the rebels, which led to a peace agreement being signed at Lomé in 1999. Berman explains that

According to the terms of the Lomé Peace Agreement, in exchange for calling a halt to the war and disarming, The RUF was granted a general amnesty, given jobs within the government, and guaranteed the right to form a political party to contest the elections (Berman, 2000: 12)

The peace accord was essentially a bilateral agreement between the RUF and the government, since it ignored other major stakeholders in the conflict, especially the local militias, Kamajors, and remnants of the Sierra Leonean Army (SLA) that had supported the rebel leader, Major Koroma. Moreover, given that the rebel groups did not make any compromises and were granted their demands mostly control of the diamond producing districts; one could imply that the RUF and the Armed Forces Revolutionary Council (AFRC) were the main beneficiaries of the Lomé agreement rather than the Sierra Leonean population as a whole.

Sierra Leonean President Kabbah understood that the government forces no longer had the capacity to repel RUF offensives. Sensing that the international community was unprepared/unwilling to protect the government, he negotiated a peace deal that would be easy for the RUF to accept, in the hope that stability would follow. The Lomé Peace Agreement represented more of an opportunity for the RUF to buy time rather than a true bid for peace on their part. The government had hoped that by signing the peace agreement, the other actors would choose to join in the peace, with the Kamajors siding with the government and the AFRC siding with the RUF. Yet this hope proved false: both parties 
dissented, having taken offense at not being individually invited to join in the talks.

The population was expecting some visible changes after the signing of the agreement, yet despite the concessions granted to the RUF, trouble continued. These troubles were mostly linked to the divisions that appeared within the signatory parties (Alao \& Ero, 2001). ${ }^{77}$ The parties that had signed the peace accord had pledged to stop fighting and to form a new government. All the parties requested a new UN mission, with more troops and better equipment than the previous UNOMSIL. The United Nations Assistance Mission in Sierra Leone (UNAMSIL) was created accordingly. Resolution 1289 authorized troops acting under Chapter 7 to provide security at key locations (government buildings, airports, etc.) so as to facilitate the free flow of people, goods and humanitarian assistance along specified thoroughfares. It was to provide security at disarmament, demobilization and reintegration sites, to guard weapons, ammunition and other military equipment collected from ex-combatants, and to assist in their subsequent destruction. ECOMOG began a phased exit, and a United Nations team arrived to supervise the ceasefire, the disarmament and the demobilisation plans. UNAMSIL operated on the assumption that the peace agreement would work, and acted accordingly (Francis et al., 2005; Nuamah \& Zartman, 2001). The United States agreed to provide financial and logistical backing, yet refused to send troops. The UK - the great power with more ties to

77 Alao and Ero explain that the exit of two key personalities (Sam Bockarie "Moskitoe and Golley") from the movement "immediately after the peace agreement created doubts in the minds of many observers about the extent to which Foday Sankoh, the RUF leader, exercised control over individuals within his movement" (Alao \& Ero, 2001: 125) 
the country - also refused to take the lead in the mission. A multinational operation was thus deployed, with several units from previous ECOMOG missions being re-hatted as UN blue helmets to help out in the mission.

\subsubsection{Order}

UNAMSIL succeeded in re-establishing order, yet as in the Liberian case, the situation in Sierra Leone remained tense (UN 2000a, S/2000/13). UNAMSIL re-established order at the airport, in the main cities of Freetown and Lungi, and in the southern part of the country. UNAMSIL had successfully deployed in areas where no ECOMOG troops had been able to deploy (UN 2000b, S/2000/186). The display of overwhelming force and the communication undertaken by the leaders of the mission stabilized the security situation (UN 1999c, S/1999/1223). Because of the improvement in the security conditions in the capital, the government shortened Freetown's existing curfew by two hours (UN 2000a, S/2000/13).

The security situation was stable although still precarious (UN 2000a, S/2000/13). The levels of banditry and looting remained high. Meanwhile, the rehatting of certain ECOMOG troops into UN blue helmets blurred the distinction between the types of peacekeepers (ECOWAS vs. UN). Since the belligerents considered the ECOMOG forces to be part of the conflict, skirmishes would sometimes break out between the newly deployed troops and rebel factions. But large-scale violence only resumed when the belligerents realized the 
unwillingness of the great powers to commit themselves to the mission (Olonisakin, 2003; Berman, 2001).

\subsubsection{Non- Accomplishment of Mandate}

UNAMSIL was successful in keeping order where its troops deployed. However, as soon as the peacekeepers would leave an area, violence would resume, hindering the relief aid and the activities of NGOs.

The DDR programme envisioned in the Lomé Peace Agreement was significantly delayed due to weak donor support, administrative shortcomings, late deployment of peacekeepers, and the RUF's disinterest in complying with the terms of the peace accord (Berman, 2001). Within four months, the disarmament process had collapsed, as a result of the RUF attacking UNAMSIL peacekeepers in early May 2000. Only 12,500 weapons and 250,000 rounds of ammunition had been collected by this time (Berman, 2001). Without the disarmament program, no peaceful elections could be held. The new government feared a resumption in violence by the different rebel groups, who had been armed and equipped by neighbouring countries. Ultimately, the financial and even the logistical backing of the US was not enough for the tasks of UNAMSIL to be accomplished.

\subsection{Comparative Assessment}

The partial success of both peace operations that we have examined resulted from a similar dynamic between the successful establishment of order and the failure to accomplish the mandated tasks. In both cases, the peace 
operations succeeded in establishing order in the short term. In the following section, I outline the processes by which these operations produced these results and arrived at these outcomes.

\section{Assessing Process}

Since intra-state wars are characterized by both a lack of political order and a lack of consent regarding the deployment of outside actors, strategies of deterrence seek to discourage belligerents from violent actions. Yet the type of interveners is important to the credibility of the intervention (particularly the quality and quantity of troops and the means deployed for the mission), as is the underlying resolve and capacity of the interveners to put an end to the conflict. The presence of a great power seems key for order not just to be reached but to take root, and for mandates to be achieved.

What explains the dynamics that cause peace operations to re-establish order yet fail to accomplish their mandate? In the following section, I present the factors that explain why peace operations partially succeed in intra-state wars. More specifically, I show how peace operations led by a collective intervener who uses a deterrence strategy may succeed at temporarily re-establishing order yet fail to accomplish their mandated tasks.

Three causal process can account for this kind of outcome 1) the belligerents being motivated by the advantages that will accrue to them by gaining time (as long as international/regional organization have their peacekeepers on the ground, the great power can benefit from the collateral gain of stability without 
having to intervene itself); 2) collective interveners may be strong enough to impose order yet too weak to enforce disarmament, demobilization, reintegration, security sector reform, etc.; 3) in the long run, collective organizations perceived as easier to manipulate for the belligerents' own benefit, to negotiate access to power or their exit to safety. According to Adebajo because regional actors were becoming tired, they were prepared to cut a deal with the rebels (Adebajo, personal communication, February 2008). Often they run out of resources and therefore of motivation sooner than great power, because they have less resources and mobilization power than great power, they have less political and economic incentives to offer and hence less leverage over the warring parties.

\subsection{ECOMIL}

\subsubsection{Type of Intervener}

"There is an old maxim in peacekeeping - before you ask a wise man, ask someone who has done it" Jacques Klein, 2003 (in Yücel \& Boothby, 2003: 19)

The help of a great power was perceived as being needed to mobilize sufficient means "to facilitate the delivery of humanitarian assistance, to establish conditions for the safe and sustainable return of refugees and internally displaced persons, and to support disarmament and demobilization efforts" (HRW, 2003b). In the absence of such involvement, the rebel factions and the government remained doubtful about the possible success of any peace operation. Taking a look back, the LURD spokesman explains that, 
(...) the role of the big powers had been very ambiguous indeed. They didn't intervene until more than 300000 people died and didn't intervene until the Liberian people and Sierra Leone children founded their own organization called the LURD. (...) We were hit by two layers of betrayal. First, the UN failure to intervene (before the massacre) and (the) start (of) Mr. Taylor killing our people. Second, was the US poor part up there let our people to the dogs and there to kill. (...) All was needed was 3000 (US) troops and they would have started to be afraid but they didn't and it resulted into (prolonging) our war. (...) US (could have) played a big role: If they had done it in 1991 or 1992, they would have stopped the war. (Wylie, personal communication, January 2008).

According to General Wylie, the late intervention of the UN was partly to blame for the level of conflict that was reached in Liberia. Yet more importantly, he placed the lion's share of the blame on the unwillingness of any great powers to get involved. Refusing to step in, the US nonetheless agreed to back the intervention financially (UNDPKO, 2005). Yet with the US unwilling to commit troops to police the Liberian peace process, ECOWAS was called upon to deploy its peacekeeping force. According to General Wylie, the non-involvement of the US discredited the peace operation. This opinion is shared by authors who have also studied the mission closely (Nowrojee, 2004; Bah, 2005). ${ }^{78}$

\footnotetext{
${ }^{78}$ According to Nowrojee "Given its historic ties to Liberia, the United States seemed the obvious candidate to lead an international peacekeeping mission, as the United Kingdom and France had done in Sierra Leone and Côte d'Ivoire, respectively. Yet the U.S. refused to assume any risk or responsibility for curtailing the crisis in Liberia. (...) The U.S.'s paltry intervention came as a huge disappointment; many believed that the presence of U.S. troops would have calmed significantly the volatile situation and enabled West African peacekeepers to deploy outside the capital where serious abuses were continuing. It also would have made recruiting forces for the U.N. peacekeeping force much easier" (Nowrojee, 2004: 9). Bah also decries that "Despite the United States' historical ties with Liberia and the unfolding humanitarian tragedy, the US did not to intervene to stop the carnage. This forced ECOWAS to send troops to Liberia for a second time, while the US only deployed a small force of marines for a limited time. Although a UN force has since
} 
The deployment of ECOMIL troops started with a vanguard force from the Nigerian contingents serving in UNAMSIL. Having spent the last years mobilized in difficult war zones, these soldiers were too few in number, were suffering from exhaustion, and were inadequately equipped. In spite of having spent years in the region, the troops still did not know the terrain as well as the belligerents who had lived and trained there their entire life. Moreover, the belligerents' numbers were actually increasing. As the war went on it became easier to recruit (forcibly and/or on a voluntary bases) (HRW, 2003a; Child Soldiers Report, 2004). ${ }^{79}$ The reputation of their enemy made the peacekeepers fearful of their next encounters with the rebel troops, especially of Taylor's troops, which seemed to be the most merciless. Thus although they were deployed, many ECOMIL contingents refused to fight the rebels (UN 2003, S/2003/875). This fact became known, and members of the rebel groups suggested a solution to the leaders of the troops deployed: exchanging uniforms with peacekeepers. According to General Wylie, "It is the Liberians rebels who were wearing peacekeeping uniforms that were fighting" (Wylie, personal communication, January 2008). ${ }^{80}$

taken over from the ECOWAS force (ECOMIL), the initial task of pacifying the belligerents was left to ECOWAS (Bah, 2005: 81).

${ }^{79}$ Recruitment was being done by all warring parties whether inside Liberia or in neighbouring countries such as Guinea. According Child Soldiers Global Report, "the use of child soldiers by government forces was systematic, widespread and endorsed at the highest level (...) As conflict intensified in 2002 the government stepped up conscription of former combatants in the capital Monrovia, recruiting former child soldiers and other children into the armed forces the paramilitary Anti-Terrorits Unit (ATU) and associated militias (...) Both LURD and later MODEL systematically recruited, used and abused child soldiers" (Child Soldiers Global Report, 2004).

${ }^{77}$ There are reports from the US Department which seem to corroborate the truthfulness of this practice amongst the members of the LURD. For example, in a report by the Bureau of Democracy, Human Rights, and Labor of 2004 published on the US Department website on February 28, 2005, it is stated that "During the year, LURD claimed to have investigated the 2003 disappearance of foreign citizen Nabil Hage and uncovered no 180 
Thus General Wylie underlined the importance of the partnership - and even collusion - between peacekeepers and members of some rebel groups (mostly MODEL and LURD). Members of the LURD or of MODEL would offer their services to the ECOMIL troops, which seemed to be a win-win situation for both groups. $^{81}$ The exhausted, poorly-equipped Nigerians were not as knowledgeable about the terrain and the different dynamics going on between the actors they were meant to battle, while the rebels were well equipped and knowledgeable about the terrain and the inter-group dynamics. As a result, they represented the most credible and tailored threat, and therefore the most effective deterrent force, both toward their own group (who would follow the command of their co-fighters) and toward the adversaries.

As far as interacting with their own group, these rebels would wear the ECOMIL troops' uniforms. This would help them to maintain appearances for their adversaries, who would believe that they actually were the peacekeepers. This masquerade made the peacekeepers appear very efficient to outside observers

information surrounding the incident; Sekou Kamara, the LURD member who reportedly had been seen wearing Hage's army uniform, remained in self-imposed exile in Guinea at year's end. In December, UNMIL opened an investigation into the incident" (U.S.Department of State Bureau of Democracy, Human Rights, and Labor, 2004). Exchanges of uniforms seemed also a common practice by MODEL. In its 2003 report, ICG explains that "Western diplomats confirm that during all its attacks, MODEL was fully supplied by Ivorians with uniforms, weapons and money." (ICG, 2003:11).

${ }^{81}$ Hill refers to something quite similar by explaining that "early as 1994, the US Department of State noted that ECOMOG troops were inflicting 'suffering on the civilian population' (US Department of State, 1995: 10) by facilitating the abuse human of rights, violating such rights themselves, and failing to take all necessary precautions to minimise civilian casualties when conducting combat operations. To begin with, and perhaps most remarkably, some of their number supplied 'weapons and ammunition' to the NPFL, LURD and MODEL forces they were fighting against" (Hill, 2009: 296). However, a significant problem with such source of information is that both LURD and MODEL were created in 2000. Citing a document from the US Department dating of 1995 leaves one wondering where Hill got his information. 
even though in reality, the disguised troops would just march into their own sector and peacefully put in place any arrangements that they had previously agreed upon with the Nigerian troops (UN 2003, S/2003/875).

Interacting with their adversaries would also entail wearing the ECOMIL peacekeepers uniforms as they marched into their adversaries' camp. This option was the most aggressive and entailed battle and bloodshed, since the disguised rebels would attack their adversaries as ECOMIL peacekeepers. Such punctual but convincing punishment would serve to reinforce the general deterrence strategy applied by the peacekeepers. In other words, this exchange of uniforms could be a fairly significant factor in explaining why the "peacekeepers" were able to successfully apply the deterrence strategy, and consequently succeed at establishing order yet fail to accomplish their mandate. ${ }^{82}$ Since in the case of some troops, the ones fighting were not the intended peacekeepers but rebel members, this could also explain why many authors who have studied the conflict complained/reported that some contingents seemingly ignored the rules of engagement and the mandates to be accomplished (Itano, 2003; Pugel, 2007). The problem was not so much that the peacekeepers did not know, or did not respect

\footnotetext{
${ }^{82}$ This phenomenon has also been highlighted in other context but also in Liberia. Sawyer notably explains that: "Even as president, (Taylor's) his regime's character and methods reflected the behaviour of the National Patriotic Front of Liberia (NPFL), the rebel force composed of networks of plundering, pillaging and murderous bands, including children, that operated under his direct control. These bands were deployed as part of the national security system in outfits such as the so-called Anti Terrorists Unit, the Special Operations Division and the security units of parastatals and logging companies. Others constituted residual pools and were used to reinforce state security and undertake private assignments for the president and some his principal henchmen. With or without uniforms, individuals moved in and out of these units, engaging in pillage, plunder and murder." (Sawyer, 2004: 445).
} 
the rules of engagement $(\mathrm{BBC}, 2003 \mathrm{~b})^{83}-$ it was rather that they weren't the peacekeepers at all. ${ }^{84}$

\subsubsection{Choice of Strategy}

On August $1^{\text {st }} 2003$, the Security Council unanimously adopted Resolution 1497. It assigned ECOMIL a robust mandate under Chapter 7 of the UN Charter in order "to ensure that it has a credible deterrence capability" (Quist-Arcton, 2003). The multinational force - once again led by Nigeria - would support the June 17 cease-fire and establish the initial conditions for disarmament, demobilization, reintegration, and repatriation of ex-combatants. Furthermore, ECOMIL was mandated to help with the establishment and maintenance of security to prepare for the takeover by the new government and to prepare for the

${ }^{83}$ According to a BBC report (2003b): "The Nigerians were the hard men of the ECOMOG force. On checkpoint duty they were considered rude and arrogant, but when there was fighting to be done they were usually the ones who did it, even if they were not too fussy about the finer points of their peace-keeping mandate"(BBC, 2003b). In a study on the perception of peacekeepers, Sanghera, Henri and Higate (2008: 9-10) gather the following testimony:"For some Liberians, the idea that Nigerians could be both peacekeepers and soldiers was problematic, because as one young male resident of Monrovia put it, 'they don't handle you "like a peacekeeper" - they have handled people very badly'. Participants talked openly about how Nigerian peacekeepers continued to be linked to organized gangs, the drugs trade and crime in Liberia. For example a Liberian male university student argued that: The Nigerians harbour criminals, they are involved in criminal activities. At night they give arms to gangs and carry out robberies. Last night at eight o'clock there was an armed robbery, they tried calling the Nigerian peacekeepers but they waited until after the robbery had been accomplished to come. There was also a certain anxiety about the approaches adopted by the Nigerian contingent. One Liberian female NGO worker suggested that 'the only contingent that the Liberians are really afraid of is the Nigerians. When the Nigerians arrive, everyone starts to panic' (Sanghera, Henri \& Higate 2008: 9-10).

${ }^{84}$ Collusion between peacekeepers and Liberian rebel groups have been mentioned in several work on the different peace operations that had been waged in Liberia since the beginning of the 1990s, by Sesay, 1996: 404; Howe, 1997; Kabia, 2009). According to Kabia "Human rights groups have accused ECOMOG of using overwhelming force in response to the NPFL invasion.(...) ECOMOG's alliance with various warring factions (...) have come under heavy criticism by human rights groups. These groups were also used as frontline of attack with ECOMOG troops at the rear thus reducing casualties of peacekeepers." (Kabia, 2009: 86-87) 
deployment of a UN peacekeeping force by October $1^{\text {st }}$ (U.S. Department of State 2003).

\section{Communication}

The communication between ECOMIL and the peacekept was generally good and productive. This was in contrast with the communication within ECOMIL and within the rebel groups, which was poor. Hence there were problems of command and control amongst the competing groups which hindered the possibility to well accomplish the mandate.

Communication between ECOMIL and most of the rebel groups was good and productive. General Wylie explained that because "the rebels wanted a big role", both of the main rebel movements, the MODEL and the LURD, cooperated at some point with the peacekeepers. The LURD worked with the international community, complying with their demands and going back to the bush, i.e. retreating from the prohibited areas. According to General Joe Wylie,

Rebel groups that were collaborating with the peacekeepers to make sure (that they were able to protect them) (...) The peacekeepers really (did) appreciate us. They like(d) us because we walked with them. They could not believe we walked with them like that." (Wylie, personal communication, January 2008).

And indeed, as explained above, many of them fought for them, in every sense of the expression. The rebels' decisions to help the peacekeepers were not always orchestrated "from above". The warring parties often lacked disciplined (especially MODEL) (Itano, 2003). As for LURD, discipline in the ranks was said 
to be essentially dependent upon the unit commander (Pugel, 2007: 10; Brabazon, 2003) In fact, according to the LURD spokesman:

We (the rebels) had reached a point where we didn't give a damn anymore on what was going to happen. We were fed up with all these superpowers playing game and eating money. (Prince) Johnson didn't give order for them to do that. People that were on the ground, the guys that were on the grounds took their own decisions themselves" (Wylie, personal communication, January 2008).

The lack of consistent orchestration from above created considerable turmoil, since it meant that although agreement could be reached with the rebel leaders, it did not necessarily follow that the troops would comply.

Communication with the rebel groups was generally good, although it was tense at times (Brabazon, 2003; Pugel, 2007). ECOMIL was successfully managing to re-establish security, yet the conditions remained volatile, which made the rebels reluctant to comply with certain orders from the peacekeepers such as giving up their arms or retreating from certain areas which they feared would be taken back by their own adversaries. According to General Wylie,

The international community told us to pull back (from our fighting area) (...) (This) time we said no. We will not pull back unless you bring the Americans." We added a (...) demand for Charles Taylor to leave and for the international peacekeepers to take the territory that we control. We ceded it to international peacekeepers because we came to liberate Liberia we cannot hold on that territory forever but we will not leave the territory for Taylor to come and kill the poor kids, the people. (...) And (when we were about to leave) the people themselves (...) started demonstrating for us not to leave the city. They said no: you cannot leave the city because they will kill all of us when you leave. So we stayed until peacekeepers come.(...) Peacekeepers came, we pulled back: five miles outside the city. We wanted international community. In 
fact we insisted it shouldn't just be African peacekeepers this time because we didn't want them to come to the city and say they ran out of money and wait for US Congress (...) The entire international community we asked for them to come. The 1992/1993 American(-like) intervention would have been better." (Wylie, personal communication, January 2008).

Combined with other authors' assessments (O'Connell, 2004; Moran 2005), Wylie's comments make it clear that while the African peacekeepers were credible, it was in fact the Americans that were really wanted and that could have represented the most effective deterrent.

The quality of communication within the rebel movements varied depending on the groups yet it did not go along the quality of the troops discipline.. Many of the rebel movements such as MODEL were fragmented, and the directions given by the rebel groups' leaders were not always followed by the local authorities/leaders. For instance, referring to Prince Johnson's troops, General Wylie explained that,

People said this is Johnson's guys who are attacking (the people). Johnson said 'when?' He did not even know when was the attack. Because you are leader of the organization, people are saying it's your forces. Johnson was brought in for the peace. Yet the forces on the ground did not comply."(Wylie, personal communication, January 2008)

This affected the command and control within the movements, and had an impact on the level of compliance with the peacekeepers' orders. Communication was good amongst the LURD (Brabazon, 2003). ${ }^{85}$ Yet, communication was better

\footnotetext{
85 "Maintaining communications with HF radios and Motorola field radios, which are often used to communicate with government forces, LURD fighters enjoy a high degree of mobility and inter-unit communication in theatre. Contrary to certain media reports, LURD are not 186
} 
inside local units in which there are senior commanders, hence the coordination and discipline amongst the troops significantly varied from one unit to another (Brabazon, 2003) $)^{86}$.

War exhaustion, coupled with a lack of adequate and sufficient equipment and means, fuelled tensions amongst the peacekeepers. The poor quality of infrastructure also impaired the means of communication between the operation's leaders, who were usually based in the capital, and the operation's subcommanders, who were spread across the country. Actions by the various contingents were not always coordinated or proportionate, in terms of obeying the rules of engagement. And the fact that some contingents also paid belligerents to fight for them certainly had a detrimental effect on communication amongst the peacekeepers.

To maximize its communication with the peacekept, the peacekeepers put in place a radio program called "ECOMIL and You". ${ }^{87}$ The program announced and emphasized ECOMIL's successes (securing Monrovia, distributing relief aid, opening up routes in the country), and also announced ECOMIL's future operations countrywide (Ross, 2005: 66). This was aimed at reinforcing the

comprised of isolated groups of loosely affiliated rebels, but are a coherent and integrated mobile irregular army." (Brabazon, 2003: 9).

${ }^{86}$ According to Brabazon: "Troops under the command of Brig. Gen. Sekou Kamarra (AKA 'Dragon Master') and also the late Brig. Gen. Musa Donso (AKA 'Deku') in June and July 2002 showed a remarkable degree of military discipline, including regular salutes, the honorific reference to rank, and a willingness to carry out life threatening orders without question. Field discipline is enforced by a rigorous system of corporal punishment, and the very real threat of execution for mutiny. (...) Yet ," In areas where senior commanders are not present, such as in Salayie in late July 2002, discipline disintegrates rapidly and almost completely. Firing becomes random and indiscriminate, the civilian population is harassed, and territory is quickly lost as government troops capitalize on their opponents' disorganization." (Brabazon, 2003: 7).

${ }^{87}$ With the help of the Americans 
mission's appearance of success and hence emphasizing its deterring dimension. According to General Okonkwo: "In case there is any more violation of the ceasefire, the ECOMIL would take appropriate punitive measures against the parties involved in such violation." (IRIN News, 2003).

\section{Capacity}

The ECOMIL peacekeepers improved the security situation, yet the international community continued to move too slowly in its deployment of an adequate number of well-equipped peacekeepers (Human Rights Watch, 2003a). The arrival of Nigerian armoured personnel carriers in the city of Monrovia gave a strong impression of deterring power, as did the arrival of forces at the airport. ECOMIL deployed an expeditionary force of some 1,000 troops, establishing control in Monrovia and along key roads leading out from the city. By the end of August, the peace operation had about 3,500 men in Liberia. ${ }^{88}$ Because ECOMIL lacked the capacity to deploy throughout the rebel-held north and east of the country, they focused on strengthening their positions near the capital. These troops formed part of the 3,500 strong ECOWAS mission in Liberia (ECOMIL), although many were later reallocated to the UNMIL force when it finally deployed on October $1^{\text {st }}$ (Bah \& Aning, 2008).

\footnotetext{
${ }^{88}$ The US sent a small force of 200 soldiers to provide limited logistical support for ECOMIL, Nevertheless, the force was credited with supporting ECOMIL, as it oversaw "the separation of the warring factions, the opening of seaports so that the UN and other humanitarian organizations could resume operations', and paved the way for the deployment of the UN Mission in Liberia (UNMIL) in October 2003." (Bah \& Aning, 2008: 124).
} 
In the absence of a great power, it was difficult for ECOMIL to accomplish its mandate. That is, while the US supported the mission financially and diplomatically, the lack of a great power's 'boots on the ground' made it difficult for the peace operation to be efficient/to accomplish its mandate. ECOMIL's limited logistical capacity challenged its ability to effectively accomplish its mandated activities in key areas (Accra Peace Agreement, 2003). This was also the case in Liberia, where Guinea was a big supporter of the LURD and Côte d'Ivoire was helping MODEL, with both governments providing each group with arms and financial support. As we will see, this was an obstacle to the peacekeepers' success.

\section{Knowledge}

Knowledge of both the human and geophysical terrain mattered in bolstering the credibility of the interveners. Previous encounters between the different types of peacekeepers and belligerents, as well as between the specific individuals involved in the mission, also played a role in enhancing the deterring force of the threat and commitment to the success of the mission. ${ }^{89}$

ECOMIL had fought in the region for a long time. Most of the peacekeepers were used to the type of terrain and hence were more knowledgeable of the geophysical setting than Western troops would have been. Yet, they still were not as knowledgeable as the belligerents themselves. By hiring

\footnotetext{
${ }^{89}$ To be in line with the structure of the other chapters, we present this section following the section on communication. However, knowledge is also useful prior to the crafting of communication methods. Hence, as for the other chapters, these two sections are not meant to represent a chronological order of events.
} 
rebels to fight for them, they were able to gain an advantage and boost their credibility with the peacekept.

Who was in charge made a big difference in whether the peacekept obeyed the orders or not. Personalities and previous experience in the country also appeared to matter significantly in boosting credibility and hence the efficacy of the threat used through the deterrence strategy. For example, the Nigerian Force Commander had a strong command presence as well as previous experience in Liberia. He had thus identified the mission's particular challenges and had developed plans for overcoming these challenges.

Determined to overcome the stigma of ECOMOG, ECOWAS leaders selected Nigerian Brigadier General Festus Okonkwo to lead ECOMIL. In 1997, Okonkwo had served as a battalion commander during the ill-fated ECOMOG mission, and was keenly aware of the need for ECOMIL to perform well. Okonkwo and many of his subordinate leaders in the ECOMIL force had trained in U.S. Army schools. They were professional, competent, experienced commanders, and word of their abilities spread quickly throughout the country, making the warring parties more wary of confronting them openly.

The rebels however were more 'manipulative' than they were given credit for. According to General Wylie, the rebels complied with ECOMIL's reestablishment of order because they believed that if they could stop them from achieving their mandate, ECOMIL would ask for help from the great powers. Wylie explains, "Taylor wanted to do this: Let ECOWAS send their troops first 
and then the Americans will back them up. That's how they send general Okonkwo" (Wylie, personal communication, January 2008).

Analysts disagree as to the rebels' motivations for presenting an obstacle to the full success of the peace operations. According to Lt. Colonel Larry Gbevlo Lartey, former head of the 64 Infantry Battalion of the Ghana Armed Force, a senior officer in the first ECOMOG mission in Liberia who had become a close assistant to Lt. General Quainoo (former head General of the first ECOMOG operation in Liberia), LURD just wanted power. Yet for the aspiring leader of the LURD, General Wylie, the incentives to fight were much more concrete:

We managed to play on the sub regional dynamics of the conflict to Sierra Leone, Guinea (...) (to) free Sierra Leone. The reason why we started fight was not to seize the presidency. ${ }^{90}$ I w(ould) not stop while Taylor lives. Until they kill me. Taylor and myself we are at war. (...) . They knew what everybody was doing. The intelligence people knew what Taylor was doing (and) where he was. They knew so he was talking to everybody. We needed to take those things into our hands. We all watch TV every day, we all see aggression we're used to aggression. We wanted to solve political problems. Yet efforts to respect laws of war were met with limited success. Rebel groups either committed systematic violations or did not commit (them): there is no midway. (...) The other problem the LURD faced was that if you catch up a prisoner from the opposite side don't kill them (...) that problem had a big side effect that it's good not to kill your prisoner. But when prisoner join you, these are prisoners that are use to human rights abuses, so you live with them in the jungle... After they get out, they start doing the same thing that

\footnotetext{
90 "They said that) because they think I can't live the United States and (decide to) come to Africa (just) like that just because I love my people. No I must (do it to) take for power in that bush. I was in the bush for 5 days into the whole Liberia's war. When we were operating in Guinea and Sierra Leone that's when I was acting my own politicians were listening. Fucking CIA we were just pushing. They were just thinking wrong about it. I came from America. The man speak to rebel groups in Washington so I can get arrested. Because my fucking cause You are going to arrest me?" (Wylie, personal communication, January 2008).
} 
they were doing" (...) we freed (some of) them because of the Geneva convention. Some of them (were) very good. But few of them would do funny funny things. People bring their own ugly ways into your organization. (Wylie, personal communication, January 2008).

Hence the fighting could be characterized as not so much a failure by the interveners to deter the warring parties as flowing from a lack of command and control within the rebel groups. These groups were composed of their own members, but also included prisoners from diverse groups who would sometimes join their ranks and disobey orders in order to tarnish the reputation of the group that had taken them prisoner. Knowledge, interest and previous encounters between the peacekeepers and the peacekept, as well as amongst the peacekeepers and amongst the peacekept, all played a role in the success of ECOMIL in Liberia. All of these factors help to explain why a deterrence strategy worked in stabilizing the security situation, i.e. in maintaining order, yet failed to accomplish the operation's mandate.

\subsection{UNAMSIL Take 1}

\subsubsection{Type of Intervener}

UNAMSIL replaced ECOMOG in Sierra Leone, though it included some re-hatted ECOMOG soldiers. More specifically, "Nigeria reportedly withdrew 8,500 of its troops from the Sierra Leone operations, while 3,500 were 're-hatted' as UNAMSIL peacekeepers" (Obi 2009: 126).

The Liberians rebel groups also played a role in Sierra Leone. According to the LURD spokesman, General Wylie, 
(...) We saw the RUF as an extension of Taylor ('s group). At anytime the (Liberian forces) fought alongside with CDF which include the Kamajors. Or at another time, the peacekeepers come for them put them the uniform and take them to the battle front and give them small things (Wylie, personal communication, 2008).

As in the Liberian case, the United States refused to get too involved in the Sierra Leonean mission. According to Alao and Ero, "Washington effectively disowned a peace agreement that its officials forced President Ahmed Kabbah to sign" (Alao \& Ero, 2001: 131). Refusing to lead the operation, the US nonetheless agreed to train and equip Nigerian, Ghanaian and Senegalese troops for the peacekeeping operation (Alao \& Ero, 2001). As de Jonge Oudraat suggests,

international interventions need strong leaders who can coordinate and give focus to the intervention. The UN Secretariat, because of its chronic lack of resources, is often unable to provide this type of leadership. The difficulties of the mission in Sierra Leone exemplify the type of problems the UN runs into when it does not have the support of any of the major powers (cited in Alao \& Ero, 2001: 131).

Yet in the absence of a great power, such order could not take root, and the mandate of DDR and development could not be accomplished.

\subsubsection{Choice of Strategy}

As was the case with ECOMIL, a deterrence strategy was adopted. Unlike UNOMSIL, UNAMSIL had numerous and well-equipped troops on the ground. Yet although the mission was authorized under Chapter 7 of the UN Charter, UNAMSIL leaders were determined to give priority to the use of non-compelling means. Various mechanisms of communication were established between the 
interveners and the belligerents to enhance the deterring capability of the mission. Decision makers wished to make clear that it carried a "robust" chapter 7 authorization, which allowed the mission to "take necessary action to ensure the security and freedom of movement of its personnel and to afford protection to civilians under imminent threat of physical violence." (UN 2000, S/RES/1289). Furthermore, the SRSG highlighted that "contravention of the Lomé Peace Accord, such as the seizure of weapons from UN peacekeepers, mounting illegal road blocks and blocking the free movement of UN troops in the discharge of their mandate, must stop immediately or would 'invite forceful response'." (Radio Netherland, 2004). Force could be used, but non-coercive means would be preferred.

\section{Communication}

UNAMSIL achieved partial success mostly due to its effective communication of its deterrent threat to the peacekept. Communication with the belligerents and the population alike was good, although communication amongst the peacekeepers was problematic.

From the beginning, UNAMSIL invested in means to communicate with the population. Radio UNAMSIL (Radio U) was established, and ran 24 hours a day, 7 days a week, reaching most of the country and some areas of neighbouring Guinea. Radio U would air the aims and accomplishments of the UN mission in Sierra Leone, with the programs tailored to appeal to local cultural norms and regional languages. This involved consultations with local and regional 
authorities, as well as with civil society groups, to determine what the peacekept wanted to know about the UN mission (Dallas, 2000). Local staff was also hired to boost the credibility of the information transmitted. In many reports, civil society groups confirmed their confidence such in UNAMSIL initiative in order to reassure the population.

Communication with the warring factions was more problematic. The lack of command and control within the different rebel groups rendered many agreements between the decisions makers ineffective. Indeed, the parties could agree on particular modus operandi, yet local authorities could then decide not to comply with their leaders' initiatives. These problems of communication thus stem from communication issues both within the ranks of the peacekeepers and within the warring parties themselves.

Problems of communication were identified as mostly taking place between the different contingents.

UN staff argued that the real challenge was not the mandate itself but its interpretation by troop-contributing states and their troops on the ground. The mandate was sufficiently robust to allow for forceful action by UNAMSIL troops to defend themselves when they faced rebel attack. (...) The issue of contingents taking orders directly from their home capitals is a serious problem that has plagued many other peacekeeping missions (Olonisakin, 2008: 62).

Many contingents were not adequately equipped and lacked of adequate orientation in general: they had no maps of the terrain for which they would be responsible; some were not even aware of UNAMSIL's rules of engagement and standard operating procedures. There were expectations that the re-hatting of 
some ECOMOG contingents into UNAMSIL would guarantee a certain level of troop readiness and institutional memory. Yet most of the troops deployed did not have the requisite logistical support agreed upon with the UN and many lacked basic communication equipment. Olonisakin explains that UNAMSIL was thus "in an extremely vulnerable position without proper communication between force headquarters and, the field [and the] absence of coordination at all levels strategic, operational and tactical" (Olonisakin, 2008: 88).

Moreover, there was a lack of cohesion, mostly due to the lack of a common understanding of the mission's aims and of the rules of engagement authorized by the UN resolution (UN 2000, S/2000/751; Olonisakin, 2008: 87). There were many shortcomings in the command and control, with some contingents preferring to obey their home government rather than their direct commander on the ground (UN 2000, S/2000/751: 9; SG/SM/7514 2003; Bernath \& Nyce 2002; Ramsbotham, Woodhouse \& Miall, 2005: 152; Olonisakin, 2008). The unequal levels of training and readiness of the different troops severely compromised integrated planning, logistical support and coordination with the civilian components of the operation. UNAMSIL also moved the location of its headquarters during the mission which contributed to worsen the problems of communication between the different contingents (UN 2000, S/2000/751: 9).

The greater issue of command and control was particularly problematic between the Indian Force commander Major General Jetley and the Nigerian Deputy Force Commander Brigadier General Mohammed Garba. The latter sometimes refused to obey direct orders from Jetley, for instance opposing the 
deployment of Nigerian troops to the area outside Freetown (Dobbins et al., 2005). And the deployment to which he did agree was fatally undermined because the DPKO checklist was ignored, thus the troops had insufficient arms and communications equipment. The failure resulted in many peacekeepers being taken hostage, since they were unable to receive warnings or call for reinforcements. ${ }^{91}$ This also sent a signal to the belligerents that UNAMSIL was inadequately prepared to enforce its mission.

This situation underlined the disagreements between the different contingents, and also created tensions with the peacekept. At the same time, Sierra Leone Army commanders resisting RUF attacks "complained that UNAMSIL forces had declined to support their operations" (Londono, 2001: 24). Many found that UNAMSIL's strategy was unclear. There was also a dispute between Jetley and Major-General Gabriel Kpamber, former head of the ECOMOG force that had withdrawn from Sierra Leone. Jetley accused Kpamber, UN UndersecretaryGeneral Oluyemi Adeniji and Brigadier-General Mohammed Garba of colluding with the RUF and mining diamonds. This accusation spread quickly within the country and was said to be widely believed in Sierra Leone. At the same time, the Nigerian authority was disapproving of the choice of an Indian to command the mission. According to the former, Nigeria's long time involvement in the country, which included contributing troops to guard key installations in the early 1990,

${ }^{91}$ Olonisakin explains "that the two key assumptions of UNAMSIL's planners (...) - that the RUF would abide by the terms of the Lomé Agreement, and that the UN force could cope with challenges after ECOMOG's withdrawal- proved disastrously wrong. (...) second, UNSMASIL proved unable to tackle the threats to the fragile peace once ECOMOG was withdrawn. Clearly, the RUF had attacked UNAMSIL at its weakest points: remote areas outside Freetwon to which the UN had been under pressure to deploy but lacked significant strength to accommodate" (Olonisakin, 2008: 61). 
entitled the Nigerian generals to be put in command of collective peace operations in Sierra Leone (Alao \& Ero, 2001).

There were problems with the civilian administration of UNAMSIL. There were allegations that the UN SRSG, Olu Adeniji, was having problems with his staff on the ground and did not sufficiently kept informed the UN Secretariat of his activities. Alao and Ero explain that "The lack of coordination among the UN officials reflect clearly when the mission had to negotiate the release of its captured staff from the rebel force." (Alao \& Ero, 2001: 127).

The power struggle at the top of the mission between the Indian commander and head of UNAMSIL, Major General Vijay Jetley, and the Nigerian contingent exposed severe strains in the command and control structure of UNAMSIL. The withdrawal of the Indian and Jordanian contingent highlighted the deep divisions within the UN mission. Their exit left a serious gap in the mission. The Security Council changed its mandate under Resolution 1289 to boost the operation's power within Chapter VII of the UN Charter "“to take the necessary action in the discharge of its mandate', in particular ensuring 'the security and freedom of movement of its personnel and civilians under imminent threat of physical violence"' (Alao \& Ero, 2001: 129).

The Lomé Peace Agreement had been signed by what were considered to be the main warring parties prior to the deployment of UNAMSIL. However, many local authorities did not recognize the terms of the accord, and thus many local rebel leaders refused to comply with the orders of the peacekeepers and indeed of their own leaders. The geophysical terrain characterized by an almost 
non-existing road network also complicated negotiations between the different warring parties. The roads from the capital to the region were rarely practicable and the belligerents did not have any helicopters or planes to travel otherwise. ${ }^{92}$ Many regional cities are surrounded by dense jungle vegetation, swamps, marshland, and woodlands which complicates their access (Woods \& Reese, 2008: 67). The orders could come from the capital or from the capitals of neighbouring countries supporting their groups, yet by the time the orders reached the local leaders they were often out of date, with the prohibited actions already having been taken. The problem of command and control and the lack of overall deterring capacity by the peacekeepers were identified as the main reasons for explaining the failure to accomplish the peacekeepers' mandate.

Without the involvement of a great power capable of inflicting great levels of punishment on the warring factions and thus seen as credible, the factions would agree to stop fighting but would still make manifest their opposition by hampering the peacekeepers' efforts to accomplish their mission. They would

${ }^{92}$ Woods and Reese describe Sierra Leonean geophysical landscape the following way: "Modern Sierra Leone is slightly smaller than the state of South Carolina with 70 miles of coastline and 27,925 square miles of land. The land is a mixture of mountains rising to 6,000 feet, wooded hills, swamps, and plateaus. A hilly peninsula dominates the western coast of Sierra Leone and together with the Sierra Leone river estuary, this region became the economic and political center of the region. It is a tropical environment with hot, rainy, humid summers from May to October and dry winters with a cold Saharan wind in December and January. Rainfall is plentiful on the coast and southern regions, but declines markedly in the northern grasslands. Sierra Leone has 373 miles of navigable waterways with ports in Bonthe, Freetown, and Pepel. Its infrastructure is extremely limited with only 372 miles of paved highways; 7026 miles of unpaved highways; 52 miles of railways; and 10 airports covering the coast and inland areas, only one of which is paved at Lungi (near Freetown) with about 10,500 feet of paved runway.. (...)The country's roads and ferry networks, in bad shape before the war, suffered even more damage as the rebellion continued. In many places outside Freetown, villages were accessible only by helicopter due to poor road conditions and ambushes" (Woods \& Reese, 2008: 41). 
refuse to disarm and demobilize, and orders from their own leaders would not be respected. Ultimately then, in the absence of a great power commitment, the mission could not sustain the order it had restored, and hence could not accomplish its mandate.

\section{Capacity}

As Chantal de Jonge Oudraat argues, "Sierra Leone showed that the political and operational lessons from failed UN missions in Rwanda, Bosnia and Somalia had not been learned." (cited in Alao\& Ero, 2001: 130). Indeed, the same mistakes continued to be made, particularly the sending of lightly armed peacekeepers into violent or potentially violent situations. "The Zambian peacekeepers in Sierra Leone were not equipped to carry out a mandate to enforce the peace" (Alao \& Ero, 2001: 130).

"The lack of confidence in UNAMSIL produced strange bedfellows, bringing together renegade soldiers, bandits, armed civilians, and professional soldiers as Sierra Leoneans scrambled to defend their country against another RUF onslaught" (Olonisakin 2008: 4). Two Nigerian battalions were re-hatted as blue helmets to bridge UNAMSIL's deployment gap, while two Indian battalions were also mobilized. The different contingents were unequally and unevenly equipped, and many of the soldiers had a poor understanding of the tasks ahead. There was also little coherent command and control, and an absence of essential communication equipment (Londono, 2001). 
In February 2000, mounting violence in the field convinced the Security Council to increase the strength of the 17,000 strong UN force. Resolution 1289 authorized troops acting under Chapter 7 to provide security at key locations (government buildings, airports, etc.), as well as to facilitate the free flow of

people, goods and humanitarian assistance along specified thoroughfares. Troops were also to provide security at disarmament, demobilization and reintegration sites, to guard weapons, ammunition and other military equipment collected from ex-combatants, and to assist in their subsequent disposal or destruction.

\section{Knowledge}

Just like UNOSOM described in Chapter 4, UNOMSIL was first conceived to support the mission of ECOMOG. However, as the West African forces retreated, the UNAMSIL mandate was enlarged. After the failures of peacekeeping missions in Somalia, Rwanda and Angola, the stakes in the success of this operation became larger than just the Sierra Leonean situation. The reputation of the SRSG and indeed of the peacekeeping system as a whole was at stake (Denselow, 2000). The peacekept welcomed the UN intervention in Sierra Leone, but many doubted its capacity to re-establish order and accomplish its mandate. Unlike in Liberia, the populations had come to trust ECOMOG more than the international community. Although previous ECOMOG missions had failed, their peacekeepers were perceived as being more committed and more capable of intervening in the conflict. According to Olonisakin: "They had been 
tested on the ground and were feared by the Revolutionary United Front (RUF)" (Olonisakin, 2008: 3).

ECOWAS had agreed to re-hat Nigerian contingents of ECOMOG into UN peacekeepers to accelerate the deployment of troops and to save on costs. The initial objective was thus to expedite deployment and to save on transportation costs as well as to allow the new operations to benefit from the experience acquired by the ECOMOG troops, who had been on the ground for decades (Londono, 2001: 30). It had however not taken into account, the degree of exhaustion of the troops deployed, the handicapped caused by the lack of training, formation with regards to operations under UN authority.

The difficulties reverberated both in the field and in the international political arena: the re-hatted peacekeepers had difficulties adapting quickly to their new mandates and had troubles understanding their new command structure, while developed countries continued to be unwilling to contribute large numbers of troops for UNAMSIL. This reticence seemed to indicate to the belligerents the fragility of the commitment of the interveners to their mission, and the warring parties drew upon lessons learned from past failed UN peace operations to destabilize the mission (Connaughton, 2001). ${ }^{93}$

\footnotetext{
${ }^{93}$ Richard Connaughton thus reports the comments of a Freetown business man to the effect that "The United Nations is not very good at using force (..) and, believe me, the RUF knows that. That's why the UN can't win" (Connaughton, 2001: 252).
} 


\section{Conclusion}

Both operations in Liberia and Sierra Leone accomplished partial success. The stand-alone operation ECOMIL allowed for easier coordination of the activities on the ground and minimized the problems of communication both between the participants in the operation and with the belligerents. In Sierra Leone, UNAMSIL's strategy of deterrence also proved successful in reestablishing order, yet without the physical involvement of a great power, this order remained precarious.

The unwillingness of great powers to commit themselves to the operations sowed doubts among the peacekept regarding the resolve of the participants to ensure the success of the operation. This gave the belligerents some room to manoeuvre. Both in Liberia and Sierra Leone, the belligerents were willing to cooperate with the peacekeepers to gain time (or in some cases money and equipment), but none put an end to their activities, even though they were prohibited by the peace operations. In both cases, order was re-established, yet without the credible commitment of a great power, order could not take root in the countries. Neither ECOMIL nor UNAMSIL (part I) could successfully accomplish their mandate. We can therefore conclude that the adoption of a deterrence strategy by a collective intervener may succeed in re-establishing order, yet such order cannot hold unless a great power is willing to step in to secure and consolidate the achievements on the ground. 


\section{Chapter 6}

\section{SUCCESS:}

\section{ACCOMPLiShMENT OF MANDATE \& ESTABLishing ORDER}

Over the past decades, great powers have often taken the lead in peace operations. As explained in previous chapters, great powers may be initially reluctant to deploy in intra-state wars. Casualties are often hard on great powers, since the loss of troops and resources on behalf of countries that do not represent a clear strategic interest are difficult to justify to home constituencies. Adversaries are aware of this, and thus have an incentive to inflict casualties as a way of getting rid of a great power's peacekeepers (Adebajo, personal communication, February 2008). This adds to the great power's disinterest in getting “physically involved" in a mission taking place in a remote and hostile context.

Nonetheless, when an international/collective intervener is unable to handle a situation which represents a potential regional/international threat, great powers are often considered the only remaining option. As explained in chapter 2 , once such powers are intervening, i.e. once "their boots are deployed on the ground", they both are and appear to be more committed to the success of the mission. This enhances the mission's deterrence character and hence increases the probability that the mandate will be accomplished. Often, the intervention of great

powers can be conceived as the "ultimate solution" when all other options have 
failed, because these powers have meaningful and robust means to impose their will.

Great powers have the capacity to mobilize more resources, both human and material, and to do so more efficiently. Military actions in the context of a peace operation require close coordination between intelligence gathering and operations, a smoothly functioning decision-making machine, and forces with some experience of working together so as to successfully perform dangerous and complex tasks. These things are more likely to be achieved within existing national armed forces, alliances and military relationships than they are within the structure of a multi-national UN command (Roberts, 1994). This fact bolsters the efficiency and is most likely to also raise the credibility of great power commitment in peace operations within failed states. Moreover, it is more likely that a great power can offer a more tailored intervention, because it has more resources for gathering and collecting information. And because their resources are more integrated and better coordinated, it is more likely that this information will be taken into account during the intervention.

I thus contend that the success - the establishment of order and the accomplishment of the mandate - of a peace operation in an intra-state war is most likely to occur when a deterrence strategy is adopted and when a great power leads the peace operation. Great powers are more likely to succeed in accomplishing their mandate. In light of the challenges - outlined in previous chapters - to success in both re-establishing order and accomplishing the 
mandate, the question is thus: how can a peace operation succeed in both dimensions?

The following section highlights the extent to which having a great power's "boots on the ground" counts. The missions studied were backed by the US (UNITAF/Operation Restore Hope and UNMIL) or by the UK (UNAMSIL), and in all three cases the great power took the lead in the operation or committed its troops. ${ }^{94}$ Such support by the great power seemed to be key for all three missions to achieve their mandate and to achieve order.

The chapter will show how the adoption of a deterrence strategy in a peace operation led by a great power allows for order to be re-established and for the mandate to be accomplished. I will compare three peace operations that occurred at different stages of a conflict, and that involved different kinds of belligerents but which were led by a great power - i.e. the United States or the United Kingdom - that had adopted a deterrence strategy. The United Nations International Task Force (UNITAF, also named Operation Restore Hope; 19921993), under the authority of the UN Charter's Chapter 7, was led by the United States and adopted a deterrence strategy; the United Nations Mission in Liberia (UNMIL; 2003-2009) was also under the authority of UN Chapter 7, was led by the United States, and adopted a deterrence strategy; and the United Nations Assistance Mission in Sierra Leone (UNAMSIL Part II; 2000-2005), which adopted a deterrence strategy and was backed by the United Kingdom under

\footnotetext{
${ }^{94}$ The United States positioned a task force of over 2,000 marines off the coast of Liberia and committed \$26 million to transport all the contingents and to fund contracted logistical support and equipment for ECOMIL (Kansteiner, 2003). 
Chapter 7 of the UN Charter. It is important to underline that the variations in terms of setting and timing will allow us to more fully elaborate the role played by the combination of communication, capacity and knowledge of both the peacekeepers and the peacekept in the crafting of similar outcomes across the three cases.

As in previous chapters, this one draws upon official documents, expert reports and interviews with regional experts to assess the arguments and hypotheses advanced. My research on the UNITAF peace operation was supplemented by interviews with Somalis who lived in three of the main Somali cities at the time of Operation Restore Hope (Mogadishu, Kismayo and Baidoa). Then refugees, I met them in the Ogaden region and interviewed them on their perception of the peace operations in Somalia from 1991 until 1995. Their memories of these marking events and their insights provided me with a rare, inside-view to the conflict. Such a peacekept' perspective is rarely taken into account when validating our understanding of the impact of an intervention.

This chapter will be divided into two sections. The first will focus upon the similarity in outcome for each peace operation, by closely examining the extent to which each operation succeeded in re-establishing order and accomplishing its mandate. To do so, I will compare the setting prior to, and after, each intervention. I will highlight the dynamic between the maintenance/reestablishment ${ }^{95}$ of order and the accomplishment of the mandate, and will show

${ }^{95}$ UNMIL and UNAMSIL part II both took place following operations which had successfully reestablished order. Hence their success stems from their capacity to maintain order and to 
how in this case, the success of the former led to the success of the latter. In the second section, I will assess the processes that made these operations successful. The impact of a peace operation that is led by a great power will be discussed. I will conclude by highlighting the extent to which "boots on the ground", combined with the adoption of a deterrence strategy, count when it comes to great power interventions in the context of an intra-state war within a failed state.

\section{Assessing Outcomes}

\subsection{UNITAF (1992-1993)}

\subsubsection{Initial Setting}

As seen in Chapter 4, the United Nations' efforts in Somalia between 1991 and 1992 (UNOSOM I) failed to achieve the desired results. The Somali warlords opposed to the UN peace operation took villages hostage to steal food and relief equipment (Rutherford, 2008). By 1992, the capital of Mogadishu was a battlefield for the two main opposing factions of Mahdi and Aideed, which had both acquired a significant number of heavy weapons. The belligerents each controlled their piece of territory and harassed relief workers, refusing to allow them access to food convoys or indeed to the populace more generally (Rutherford, 2008). Somalia's humanitarian crisis thus grew ever deeper.

The prolonged nature and the magnitude of the deteriorating situation attracted the attention of US representatives, who increasingly called on President Bush for robust American action in Somalia. The heavy media coverage of the 
humanitarian crisis was certainly a key element in convincing the US to intervene. War was also raging in the Balkans at the time, and calls were being made for a US intervention in that region. The United States calculated that Somalia would be easier to tackle, and chose to prioritize an intervention that they felt would most probably succeed (Rutherford, 2008; Hirsh \& Oakley, 1995). On December 3, 1992, the Security Council adopted resolution 794 authorizing a peace operation to be commanded by the United States and under the aegis of Chapter 7 of the UN Charter. Resolution 794 constituted a precedent in many ways. It was the first resolution to authorize the use of force for means other than self-defence and that did not require the consent of the parties to the conflict. The extent of international support for this operation was also a first, since China and many African countries also expressed their support for the mission (Mayall \& Lewis, 1996). ${ }^{96}$

The decision to have the United States intervene, coupled with the creation of UNITAF, changed the belligerents' behaviour towards the new peace operation. The US' tough rules of engagement and the magnitude of the robust means ${ }^{97}$ put in place to intervene in the country convinced Somali leaders of the dangers of opposing the newcomers, and thus to at least "start on the good side of U.S. military and civilian leaders" (Hirsh \& Oakley, 1995: 55). The warlords

\footnotetext{
${ }^{96}$ James Mayall stresses the importance and novelty of the support by China and by a great number of African countries, countries which "in the aftermath of Operation Desert Storm had expressed their suspicions that the West might use humanitarian arguments to mask their interference in the domestic affairs of other states." (Mayall \& Lewis, 1996: 111).

${ }^{97}$ These means are detailed in the second part of this chapter, in the section "Capacity", page 221. 
considered it be strategically wiser to welcome the new interveners. Their bet was that:

by biding their time, they would later encounter a militarily weaker UN force. There were no long term strategic or political objectives that might threaten the warlords' supremacy and it soon became apparent that adopting a wait-and-see policy was the most prudent response until UNITAF left (Murphy, 2007: 61).

The operation had three main objectives: to control the harbour installations in Mogadishu and Kismayo; to protect humanitarian convoys; and to make the necessary provisions for the transfer of responsibilities to UNOSOM II. Hence, unlike the other peace operations (UNOSOM I and UNOSOMII), this peace operation was provided with a clear time horizon for the exit of the mission. Compared to resolution 751 (UNOSOM I), resolution 794 had three assets: by allowing the coercive use of force, it gave a large degree of operational latitude and decision-making authority to the operation's participants; Restore Hope had a limited and clearly defined mandate and set of objectives; the resolution and the operation had the support of the international community.

\subsubsection{Order}

UNITAF succeeded in quickly re-establishing order, managing to secure Mogadishu's airport, harbour and the main roads leading to distribution sites three weeks ahead of schedule (Rutherford, 2008: 102). In March 1992, the two main belligerents, Ali Mahdi and General Aideed, signed a cease-fire thus ending most of the attacks/armed confrontations in the Somali capital. In addition, both leaders agreed to remove their checkpoints along the "green line" that had kept the city 210 
divided for the past two years. The two also agreed to restrict weapons and combatants to designated areas outside of the city (Hirsh \& Oakley, 1995). There was almost no resistance to UNITAF troops, and only a very few armed encounters between them and the belligerents (Human Rights Watch, 1993b). Within a month of UNITAF's arrival, the number of casualties had dropped significantly and food and relief aid convoys could move freely around the country (Hirsh \& Oakley, 1995: 81-82). Two months after their initial deployment, the peace operation had secured most of the country and had reestablished public order (Hirsh \& Oakley, 1995:82).

\subsubsection{Accomplishment of Mandate}

UNITAF's mandate was "to use all necessary means to establish a secure environment for humanitarian relief operations in Somalia as soon as possible." (UN 1992, S/RES/794). Measured against the objectives of the operation, Restore Hope was a success (Oakley, 2000: 331). Looting of equipment and food decreased in the country's two main cities of Mogadishu and Kismayo. Humanitarian corridors were secured and UNITAF successfully installed numerous logistical storage sites throughout the country in order to facilitate the delivery of relief. In the region of Baidoa, famine-related deaths decreased from 325 per day in December 1992 to less than 5 per day in March 1993 (Oakley, 2000: 342). The prices of weapons increased substantially. ${ }^{98}$ Many groups of

\footnotetext{
${ }^{98}$ For example: The cost of an AK-47 went from US\$50 to US\$1000 between November 1992 and March 1993. (Oakley, 2000: 342) 
Somalis returned from exile. ${ }^{99}$ By March 1993, attacks on humanitarian organizations had decreased significantly. According to Ambassador Oakley, "By February, 35 feeding stations were operating in Mogadishu, feeding one million persons per week and protected in the first instance by a new Somali police force backed by UNITAF-units from Nigeria Zimbabwe, Italy, Pakistan, and the U.S. Marine Corps" (Oakley \& Tucker, 1997:8).

One month after their arrival in Somalia, the American-led peace mission had suffered fewer casualties than expected, had secured the delivery of food to ports and airports as well as its transportation within Somalia, and had made possible the provision of relief aid throughout the country (Human Rights Watch 1993b; Hirsh \& Oakley, 1995). Within four months, humanitarian NGOs were coming into the country, and massive quantities of food and essential equipment could be delivered to those in need (UN 1993c, A/48/504). Politically, the two main belligerents had signed the cease-fire. UNITAF had thus succeeded in securing the capital and in extending the delivery of humanitarian relief to the countryside.

\subsection{UNMIL (2003-2009)}

\subsubsection{Initial Setting}

As seen in Chapter 5, while ECOMIL succeeded in re-establishing order, it failed to accomplish its mandate. The LURD rebel movement still had an estimated 5,000 fighters, concentrated primarily in western Liberia, while

${ }^{99}$ In Somalia's South-West Baidoa province, there was an increase from 10 families in 1992 to 800 families in 1993 (Oakley, 2000: 342). 
MODEL had between 1,500 and 3,000 fighters, operating in eastern parts of the country. There was still widespread population displacement and poverty, unemployment levels remained high, there was a proliferation of small arms which raised the security stakes and stoked suspicion between the parties, there were continued attempts to consolidate territorial gains, and the presence of criminal elements was adding to the volatility of the situation (UN 2003, S/2003/875). While the belligerents welcomed the new mission, they were frustrated and resentful at its late arrival. According to General Wiley,

Only when 300000 people were dead, that's when America decided to come in. By then, we are a rebel force that was knocking on the door. On it all we didn't care whether America was coming or who was coming, we were doing our own 'shit' (Wiley, personal communication, January 2008).

Thus when UNMIL arrived, it faced a fragile situation in which order had been re-established but remained precarious, to the point that conditions seemed to be on the verge of reverting to those that had prevailed before ECOMIL. The population was widely frustrated that the international community had not intervened more massively and sooner. At the same time, the general populace and belligerents alike welcomed the new enforced mission and appreciated the American involvement.

\subsubsection{Order}

UNMIL succeeded in maintaining order previously (and precariously) established by the ECOMIL intervention. The deployment of the UN troops backed by the United States put a halt to most of the hostilities between the 213 
belligerents. The ceasefire in Monrovia was largely respected but for a few minor violations (UN 2004, S/2004/428). The deployment of UNMIL in the four sectors of Liberia succeeded in maintaining stability to the country (UNDPKO 20042008). By 2003, Charles Taylor had been expelled from Liberia. By 2004, the disarmament and demobilisation programme was in place and security had been re-established in most parts of the country (ICG, 2006: 7). In 2005, free and fair elections were held, resulting in the election of Ellen Johnson-Sirleaf. Legitimate institutions and rules were soon put in place.

\subsubsection{Accomplishment of Mandate}

UNMIL had an all-encompassing mandate: to observe and monitor the implementation of the ceasefire; to investigate violations; to observe and monitor disengagement and cantonment of all the parties' military forces; to support the work of the Joint Monitoring Committee (JMC); to develop an action plan for the overall implementation of a disarmament, demobilization, reintegration, and repatriation programme (DDRR) for all armed parties; to facilitate the provision of humanitarian assistance, including by helping to establish the necessary security conditions; and to contribute towards international efforts to protect and promote human rights in Liberia (UNDPKO, 2004-2008). The speed with which the operation convinced the most rebellious factions to disarm and to start negotiations, as well as the swiftness of its deployment in the rural areas (in this regard, UNMIL accomplished in less than six months something that ECOMOG struggled to do for seven years) underlines its emphatic accomplishment of the 
mandate. By the end of its mission, UNMIL had trained civilian police and a national army, had contributed to the re-establishment of the government and the rebuilding of the country's infrastructure, had significantly improved humanitarian conditions, had supervised the holding of free and fair elections, and had overseen the dismantling of most belligerent organizations (ICG, 2006).

\subsection{UNAMSIL Take II (2000-2005)}

\subsubsection{Initial Setting}

As explained in Chapter 5, UNAMSIL take I (1999-2000) had succeeded in re-establishing order in the country yet had failed to accomplish its mandate. Though the situation remained fragile and even volatile, it had improved significantly, with UNAMSIL deployed in most areas of the country. However, the rebels still held onto several sectors, in which conditions remained precarious. Just before the reinforcement of UNAMSIL (i.e. the beginning of UNAMSIL take II), in the absence of credible and tailored backing, UNAMSIL suffered setbacks in the peace process: an increase in armed attacks on UN peacekeepers, kidnapping of UN personnel, and the sabotage of disarmament and demobilization camps by fighters of the RUF (UN 2000c, S/2000/455). According to the Secretary General's report:

one of the main priorities for the United Nations in Sierra Leone remains the speedy establishment of a credible peacekeeping presence throughout the country to create the necessary climate of confidence and security conditions for the implementation of various aspects of the peace process (UN 2000b, S/2000/186). 
At this time, the belligerents were still very wary of the interveners (Olonisakin, 2008). Disarmament had so far proven ineffective, and the situation still did not seem ripe for elections. The Lomé Peace Agreement had collapsed (Hirsh, 2001a: 89), and Sierra Leone remained in the midst of a humanitarian crisis. Most observers of the mission in Sierra Leone expected a "Somalia-type retreat" by the UN. Thanks to the help offered by the United Kingdom however, the international organization chose to bolster its troops and its engagement in Sierra Leone (Olonisakin 2007: 91). The main warring factions (with the exception of the RUF) welcomed this promising initiative as an opportunity to secure the country and to engage in political negotiations.

\subsubsection{Order}

UNAMSIL take II succeeded in maintaining order in the country. By 2005, the armed conflict had "entirely stopped" (Olonisakin, 2007: 123). Responsibility for security was handed over to the government of Sierra Leone, which was by then strong enough to ensure the safety of its citizens and to implement the rule of the law. Credit was given to UNAMSIL for "the stabilization and maintenance of a secure environment throughout Sierra Leone." According to a 2005 BBC public opinion survey carried out in Sierra Leone, "nearly $100 \%$ of respondents agreed that Sierra Leone's security situation improved immensely due to UNAMSIL's presence" (Olonisakin 2007: 2). By 2004, National security agencies had been trained and put in place by UNAMSIL. Frameworks of coordination on security matters at the district level had been put 
in place between provincial and district security committees, the Sierra Leone Office of National Security, the Sierra Leone police, the Republic of Sierra Leone Armed Forces, and local authorities (UN 2005, S/2005/777). From that point on, these agencies proved able to manage their tasks properly, tackling riots and criminal activities according to the re-established rule of law (UN 2005, S/2005/777). In the words of the International Crisis Group,

Since the UN peacekeeping force (UNAMSIL) withdrew in December 2005, no security incident has required outside intervention. Youth unemployment and disillusionment remain serious threats and core state institutions are still untested, but Sierra Leone is no longer a failed state (ICG, 2007).

\subsubsection{Accomplishment of Mandate}

"There are peacekeeping missions that have been there forever, some are clocking 50 years with no end in sight. This one in six years has successfully ended its mission" Daudi Mwakawago, SRSG 2005.

UNAMSIL had successfully accomplished its mandate by December 2005 (UNDPKO, 2009). During its six-year mandate, UNAMSIL disarmed and demobilized over 75,000 combatants and collected more than 42,000 weapons. ${ }^{100}$ It dismantled the main belligerent groups and military structures (mostly those of the RUF). UNAMSIL provided training for the new national police personnel and

\footnotetext{
${ }^{100}$ The significance of these numbers has been contested. According to the International Crisis Group "While DDRR is widely considered a success in Sierra Leone, the numbers there, too, raise questions. UNAMSIL had estimated there were between 300,000 and 1.5 million weapons in country at war's end, but it collected only 2 to 10 per cent, fewer than 30,000 from 76,200 ex-combatants. Many weapons leaked over the borders into Guinea and Liberia" (ICG, 2004:11). Discussing the discrepancy, a DDRR specialist said "The best disarmament initiative in Sierra Leone has been [continued fighting in] Liberia and Ivory Coast - for me that's without any doubt"." (ICG, 2004:11).
} 
the army, and played a role in the rehabilitation of the country's main infrastructure. It also contributed to the consolidation and the decentralization of governmental authority (UN 2005, S/2005/777), and successfully supervised the holding of two free and fair elections (Olonisakin, 2008: 126). At a macro level, it played an important part in the reconciliation of the government's authority with civil society (UNDPKO, 2009).

\section{Assessing Process}

Because intra-state wars are characterized by a lack of political order and thus by a lack of consent by a nationally acknowledged authority regarding the deployment of outside actors, strategies of deterrence seek to discourage belligerents from violent actions. Yet the type of intervener is important to the credibility of the intervention (particularly the quality and quantity of troops and the means deployed for the mission), as is the underlying resolve and capacity of the intervener to put an end to the conflict. The presence of a great power seems key for order not just to be reached but to take root, as well as for mandate to be achieved.

What explains the dynamics that cause peace operations to re-establish order and to accomplish their mandate? In the following section, I present the factors that explain why peace operations succeed in intra-state wars. More specifically, I will show how peace operations led by a great power that uses a deterrence strategy succeed at re-establishing order and at accomplishing their mandated tasks. 
This outcome might flow from 1) the credibility of the great power; 2) its strength and capacity to impose robust rules of engagement and to provide adequately equipped and trained troops to enforce disarmament, demobilization, reintegration, security sector reform, etc.; 3) the perception that in the long run, great powers are more committed and determined for the mission to succeed, and have greater leverage to force the belligerents to work towards the achievement of sustainable peace.

\subsection{UNITAF}

\subsubsection{Type of Intervener}

UNITAF was led by the United States. It was composed of allied troops from 24 nations, all under the command of US Lieutenant General Robert Johnson, who in turn reported to US General Joseph Hoar, Commander-in-Chief of CENTCOM. Reporting responsibilities followed the military hierarchy through the American Department of Defense and the Joint Chiefs of Staff to the US President (Hirsh \& Oakley, 1995: 149).

\subsubsection{Choice of Strategy}

Restore Hope was conceived as a short-term operation. American authorities wanted it to be fast and not costly, especially in human lives. Many scholars have demonstrated how governmental and popular acceptance of the loss of soldiers' lives is proportional to the perception of a link between a particular operation and the national interest (Jakobsen, 2000; Western, 2002). As explained 
above, few direct links could be established between the United States' national interest and the Somali crisis. Moreover, the operation was launched in December 1991. And because Americans were anxious to avoid incidents that could cost their soldiers' lives, authorities sought to minimize unexpected and dangerous events that could affect domestic political support (Western, 2002). The operation's aims could be summarized as follow "In short, the means were calculated to make sure that the ends would be achieved in short order with minimal disruption" (Hillen, 1998: 212). A deterrence strategy seemed most appropriate. A deterrence strategy seemed most appropriate.

Recognizing that operations would take place in a situation of near anarchy, General Hoar proposed using unprecedented Chapter 7 authority for peace enforcement by all necessary means. A deterrence strategy would "allow the on-scene commander maximum flexibility to determine what constituted a threat and what response was appropriate, including the use of deadly force" (Hoar, 1993 cited in Hirsh \& Oakley, 1995: 43). The peace operation was to be carried out by following the Weinberger-Power Doctrine principles: "clear, finite, doable mission, involving the deployment of overwhelming efficient force with rules of engagement that allowed the expeditious use of force when necessary" (Hirsh \& Oakley, 1995:47). Deterrence maximized the pressure on the belligerents and worked as a powerful disincentive for direct confrontations, hence decreasing the possibility of casualties. UNITAF was using force strategically, to signal both capacity and resolve (Hirsh \& Oakley, 1995). 


\section{Communication}

Because communication is the backbone of a deterrence strategy, the Americans invested a lot in this dimension of the mission. Communication was to be optimized "on three fronts": with the various partners of the peace operation, with the peacekept and with the international community. The coherence and coordination of the operation required strict discipline amongst the troops, unequivocal rules of engagement, a clear command and control structure, as well as a commonly agreed-upon mandate. Effective communication with Somalis enabled a closer partnership with the peacekept. It facilitated intervention and gave credibility to the negotiations with the belligerents. Finally, the operation's transparency before the international community increased legitimacy and encouraged national political support. These elements made the operation all the more tailored to the context and more credible to the belligerents.

Given the high number of incidents involving UNITAF forces (sporadic shootings, stone-throwing riots, etc.), the low number of Somali casualties testifies to UNITAF's success at instilling restraint and discipline amongst its troops (Hirsh \& Oakley, 1995:82).

Communication within the organization was of primary importance in order to ensure that the group's actions and speeches were consistent. The delimitation of the mandate facilitated its comprehension, and thus allowed for better communication and an easier execution process. The clarity of objectives allowed troops to better understand them, and made it easier for the troops to communicate them to the populace and to the conflictual parties. This meant that 
the populace and the belligerents were better able to understand them, which in turn reassured the various actors and fostered their cooperation. Moreover, the clarity of objectives allowed for a faster accomplishment of the mandate (Hirsh \& Oakley, 1995).

The ROE were clear and the operation provided each contingent with adequate means to follow them. Convoys were heavily armed, yet strict guidelines were placed on the use of weapons. First, peacekeepers had to maximize deterrence through high visibility with weapons. If belligerents still did not comply, warning or containment shots were then allowed. If this step also failed, the instructions were to fire at the 'legs and extremities', and in the last resort, to shoot to kill (Murphy, 202: 186).

Committees were formed in order to support cooperation and coordination between the various organization members. A Civil Military Operations Center (CMOC) was established to coordinate the HOC operations with US military efforts. Weekly meetings between the various NGOs and Restore Hope members were aimed at ensuring information exchange as the operation evolved (Hirsh \& Oakley, 1995; Rutherford, 2008). As well, a newspaper, "The Somalia Sun Times", was published weekly so as to inform the Joint Task Force personnel of the mission's progress, its main challenges, the latest news etc. (Oakley, 2000: 329). The operation's military officials also met with the NGOs on a weekly basis to coordinate relief operations. A Humanitarian Operations Center (HOC) was established to coordinate relief operations, and a Humanitarian aid convoys were 
thus assured of international protection, and so could maximize the volume of relief aid that was delivered to the population (Rutherford, 2008: 92).

UNITAF made it a priority to inform the Somali people about the operation. Restore Hope members sought to frequently notify the populace of its purposes and functions. The operation's leaders were clear about what behaviours were proscribed, and spelled out the associated sanctions. The clarity of the aims and of the ROE also helped to clarify what behaviours were proscribed and what the associated punishments were.

Interviews with current Somali refugees who lived in Mogadishu throughout the American intervention have confirmed this perspective. They recalled the clarity of the American operation: its aims, the means to be used, and its achievements. This inspired both trust and respect among the people. The refugees interviewed were very critical of UNSOM operations, yet hoped for more missions like UNITAF: with a credible intervener that was adequately equipped, and was well understood by the populace and the belligerents alike (Personal communication with refugees, January 2008). The cultural-awareness of the interveners and their proximity to the people was both noticed and appreciated, and reinforced the credibility that they assigned to the American instructions regarding acceptable and prohibited behaviours (Personal communications with refugees, January 2008).

According to Oakley, the key to getting better cooperation from the Somali warlords was:

forward leaning ROE exercised by backward leaning troops because they understood ...that by showing restraint 
we were going to be less endangered than by shooting every time we had a chance(Oakley cited in Rutherford, 2008: 99).

UNITAF was very much invested in the PSYOP dimension. Its main aim was to alleviate the concerns of Somalis, who might think of the US and other UNITAF forces as an invading and occupying force. In so doing, it sought to decrease the chances of misunderstanding and of ensuing armed confrontations (Rutherford, 2008). The leader of the peacekeeping mission also made a point of ensuring that any action by a military unit was preceded by a meeting with the local authorities (clanic, military, religious) (Rutherford, 2008: 101-102). The aim was to maximize both popular and factional support and to make sure that the mission's objectives and the means to be used were well understood (Hirsh \& Oakley, 1995: 157). As well, hundreds of pamphlets explaining the mission's actions and aims were distributed to the populace before each intervention. Operation members regularly updated Somalis about the mission's progress and development. For instance, there were eight teams that spoke Somali and were equipped with loudspeakers so as to broadcast the operation's objectives in public places. A newspaper, "Rajah" ("Hope"), was published and distributed to the populace. ${ }^{101}$ More than 20,000 copies were put into circulation (Oakley, 2000:327). ${ }^{102}$ UNITAF also broadcast a daily radio show in Somali. During the four-month UNITAF operation, PSYOPs hosted 750 news media representatives,

\footnotetext{
${ }^{101}$ The first edition being published less than two weeks after the start of the operation, i.e. on December $20^{\text {th }} 1992$ (Oakley, 2000:327).

${ }^{102}$ In order to appease the Islamists, they would always start with a verse from the Koran (Oakley, 2000:327).
} 
wrote more than 250 stories, and filed more than 50 radio reports on Armed Forces Radio. ${ }^{103}$ The way the Americans communicated and signalled the operation's ROE also had a decisive impact on the peacekept, since it was made very clear that the ROE allowed the US military personnel to shoot if threatened by a Somali. ${ }^{104}$

Rutherford explains that:

UNITAF forces employed air support operations (OAS) as a psychological weapon to serve as a deterrent to Somali militias. During the first stages of the UNITAF landing, more than 2,500 sorties per day were recorded. UNITAF's warning to militias not to be hostile, coupled with UNITAF's shows of force, made the Somalis less prone to take on UNITAF forces, which led to fewer casualties on both sides and contributed to the operation's initial success (Rutherford, 2008: 100)

UNITAF authorities made a point of meeting personally with the peacekept. Every two weeks, Oakley would meet with the moderate Islamic Higher Council, some of whose members he knew from his former job, to explain what UNITAF was doing and to get their views. Oakley listened to their criticism and shared it with UNITAF, who in turn adopted more religiously-sensitive practices (Rutherford, 2008).

The acknowledgement and respect that the operation's leaders gave to the warlords helped to create an atmosphere of trust. Because the Somali militia

\footnotetext{
${ }^{103}$ The radio aimed (and succeeded) in countering misinformation broadcast by Aideed. As a result, US forces did not have to take Aideed's station off the air. Aideed and other warlords tried to get UNITAF radio off the air, but they couldn't do it since UNITAF was too well organized (Rutherford, 2008: 103). The success of the UNITAF radio broadcasts thwarted the efforts by the warlords' radio stations to mobilize Somalis against the intervention.

${ }^{104}$ Interviews with current Somali refugees who had lived in Mogadishu throughout the American intervention confirmed this perspective. (Personal communication with refugees, January 2008).
} 
leaders were solicited for their support, this made them more inclined to agree to cooperate with the mission.

The "Joint Information Bureau Highlights" was created to increase communication with the international community. The leaders of the operation organized the media coverage of events on the ground. More than 750 media representatives from all over the world followed the operation. Radio programs related to the intervention in Somalia were broadcast on Armed Force Radio. The operation's concern with transparency ultimately strengthened public support (Oakley, 2000). ${ }^{105}$

\section{Capacity}

Operation Restore Hope was the largest UN peace operation at the time, involving the most logistical coordination, manpower and equipment (Hillen, 1998). General Powell considered that, "A large force, capable of controlling the violence, not just in Mogadishu, would make clear to the faction leaders that order would be restored with or without their cooperation" (Hirsh \& Oakley 1995: 46).

UNITAF was also meant to be a multinational combat force. The American contingent was divided into two main formations: Tenth Mountain Command infantry and Navy forces, each composed of approximately 10,000 soldiers. In mid-January 1993, more than 25,000 troops were participating in the

\footnotetext{
${ }^{105}$ According to Oakley "Since the objective was to support humanitarian operations while simultaneously conducting these stability missions, we understood that psychological operations in the theatre had to be complemented by public affairs operations to communicate news of Somalia back home and to the rest of the world (...) We got pretty good press because we worked hard at it. This bolstered public opinion and congressional support" (Oakley, 2000: 329).
} 
operation, drawn from 24 countries and under American command. The largest non-American contributions came from Australia, Belgium, Canada, France, Italy and Pakistan, for a total of more than 12,500 soldiers (Hillen, 1998:191). The Americans backed up their troops with air power, particularly helicopter gunships, which were used to neutralize technicals i.e. vehicles driven by men equipped with machine-guns (Hillen, 1998). UNITAF also had heavy artillery at its disposal.

According to Hirsh and Oakley, UNITAF's effectiveness was largely due to the US military's organizational and managerial strengths, which enabled 28,000 US troops and over 10,000 troops from 20 other countries to be deployed very rapidly to one of the most remote locations in the world (Hirsh and Oakley, 1995:165).

Command and control were clearly established at the outset, with all US and foreign contingents under General Johnston's overall command. The unique logistical capabilities of US forces, which included pre-positioning of equipment in the Indian Ocean, the rapid availability of suitable ships and quick access to worldwide Air Force and commercial charter transport, enabled UNITAF "to overcome the many infrastructure shortcomings in Somalia" (Hirsh \& Oakley 1995: 165). Rutherford specifies that "Helicopters and off-road vehicles gave UNITAF forces the ability to move quickly into the interior without using the main roads" (Rutherford, 2008: 92). 


\section{Knowledge}

Knowledge of one's opponent and the ability to anticipate their moves are also crucial elements in a successful deterrence strategy. The fact that a great power decided to join the mission had a significant psychological impact on the peacekept. Somalis were also aware of leaders' reputations, for instance those of Colin Powell and of Robert B. Oakley. General Oakley had worked for the American diplomatic mission in Somalia during the 1970s, and his work inspired respect from Somalis and Americans alike (Drysdale, 1997: 129).

The previous experience of UNITAF's military officers also contributed to the success of the mission. Most of them had been involved in, and had gained experience from, other military relief operations, such as Operation Provide Comfort in Iraq. The lessons learned from the Iraqi operation, which had taken place the year before, were applied to Operation Restore Hope (Rutherford, 2008: 92). The working relations between the mission's officials were also made easier by the fact that they had similar backgrounds. Oakley, Johnston and Zinni had all been involved in the American intervention in Vietnam, and all agreed that nation-building could not be imposed from the top-down. All laid great emphasis on understanding local dynamics before acting (Rutherford, 2008: 92). As a result, the operation invested a significant amount of effort in enhancing the locals' knowledge, and in understanding the area's social and political dynamics (Oakley, 2000; Peterson, 2001). ${ }^{106}$

\footnotetext{
${ }^{106}$ Oakley explains that "The Somali police had little sticks that they used for crowd control. They didn't have to use tear gas, pepper spray, nonlethal weapons, or anything of that kind. They knew how to control crowds and the people obeyed them. If we'd gotten UNITAF
} 
The extent of American investment in the Somalia mission was an indication of the magnitude of their interest in the operation's success. ${ }^{107}$ The willingness of American leaders to make concessions to factions, coupled with their determination to impose sanctions against those who transgressed the agreements, convinced potential attackers of the seriousness of their threats. The Americans also drew upon their knowledge of warlords' known interests to discourage the proscribed behaviours and/or to stress the advantages of cooperation. Benefits granted to the cooperating factions varied from greater visibility on the international scene to material aid.

\subsection{UNMIL}

\subsubsection{Type of Intervener}

UNMIL took over ECOMIL in October 2003. The United States took a proactive stance in favour of the mission, positioning a task force of over 3,000 marines off the coast of Liberia to back up the UN mission and offering troops to train the Liberian army. The total authorized strength of 15,000 military personnel and the proposed budget of $\$ 564.61$ million made it the largest peace operation in the world at the time (UNDPKO 2004-2008). The United States invested more than $\$ 240$ million in humanitarian and reconstruction aid, and another $\$ 245$ million in the operation, making it the main broker (Dukulé, 2004; Reilly, 2004). It also committed strong military support, sending a warship and troops to provide

into a situation like that, there would've been a huge riot and who knows what would've come of it" (Oakley, 2000:336).

${ }^{107}$ It cost more than $\$ 500$ million to send soldiers to Somalia for six months (Minear \& Weiss, 1995:176). 
the bulk of the logistical assistance to Nigerian peacekeepers. To stress the level of involvement of the great power in the operation, an American, Jacques Klein, was made the Special Representative of the UN Secretary General (Adebajo, 2004). An ICG report (2006) stated that "the U.S. (was) doing more in Liberia than any other donor, including taking on the training of the new army" (ICG, 2006:8).

\subsubsection{Choice of Strategy}

UNMIL was conceived as both a peace building and a peace enforcement operation, and hence was operating under UN Chapter 7 authority. The mission leaders had overwhelming force and the authority to use it. They chose to adopt a deterrence strategy (ICG, 2003). Deterrence was chosen as the best military strategy for reconciling the possibility of using force with the prioritization of non-coercive force.

\section{Communication}

Communication was made a priority from the outset of the operation. Within UNMIL's UNITAF mission, communication was organized along several axes: between the peacekept, the peace operation's members and the international community.

Communication with the peacekept was an enormous challenge because most of the media infrastructure in the country had been destroyed, roads and other transportation systems were almost unusable, and electricity supplies were 
very undependable. There were few local personnel that could be hired without training, particularly given that illiteracy rates hovered around $75-80 \%$. The population outside of the main cities was sparsely distributed and was located in rural areas that were inaccessible to mainstream media even once the communication networks were re-established on the first day of the mission (Hunt, 2006). Nonetheless, UNMIL radio immediately began broadcasting across almost the entire Liberian territory. ${ }^{108}$ It continued to do so every day, 24 hours a day, offering over 48 different programmes (UNDPKO 2004-2008). ${ }^{109}$ The idea was to inform the population about the mission, its progress, the means being used, and its objectives. It also offered air time for citizens and the government to express their views on the mission, as well as to share details concerning key activities, etc.

${ }^{108}$ UNMIL Radio is the first radio station in Liberia to broadcast from Monrovia to any part of the country, the first radio station to broadcast live events from places such as Voinjama, the first UN Radio facility to broadcast live to the nation, and the first radio station in Liberia's history to provide 24-hour service. According to Hunt: "Existing radio stations based in Sierra Leone and Liberia use limited FM or shortwave transmission. UNMIL radio utilise the technological advantage gained by FM transmission and frequency boosters situated around the country. This provided the missions with an increasing breadth of coverage, culminating in UNMIL radio currently covering approximately 95\% of Liberian territory on FM frequencies which are of a good quality and are relatively easy to find" (Hunt, 2006:38).

109 "UNMIL Radio offered a total of 48 programmes in different formats, covering children and young person's issues, both the civilian and military aspects of the work of the mission, humanitarian activities, current affairs, human rights, repatriation, reconciliation, health (including HIV/AIDS), Rule of Law, security, women's issues, journalism, civic education, DDRR, among others. It broadcasts 12 daily news bulletins, in both English and Special English, and is soon to start additional news broadcast in local languages. In the coming months it is planned to increase and re-direct programming to deal with the Elections, to be held in October, and this will consist mainly of education on Electoral Law, Voter Registration, Civic Education on Roles, Rights and Responsibilities, among others." (UNDPKO, 2004-2008). 
UMMIL created a Public Information Office to facilitate communication

between the peacekept, the operation's members and partners, and the international community.

This office aimed at bringing stakeholders together, to inform them and discuss with them the activities related to the peace mission. It sought to widen public support for the mission and avoid misunderstandings about the overall objectives and goals. It made great use of traditional communication methods. The meetings and information sessions were held in more than 16 languages, and they took place in even the most remote parts of the country. ${ }^{110}$ Flyers explaining the mission were also distributed each month to provide an update on the operation achievements and activities. ${ }^{111}$

UNMIL also put in place a Community Outreach Union to raise awareness about the mission. It used theatre, dance, music and other traditional Liberian media. It also organized football tournaments that brought together ex-

${ }^{110}$ Since the beginning of the Mission, the Unit has organized up to 270 outreach events in various parts of the country. Some of these events are in the form of soccer matches, music concert, drama/theater and road shows. A nation-wide campaign to raise awareness about the Comprehensive Peace Agreement at a grassroots level was carried out. Popular understanding of the Agreement also helped to engender the population's support for the DDRR process. Other issues tackled by the Unit have been HIV/AIDS, Rule of Law, Gender (encouraging women to be part of the new police force), the return of Internally Displaced Persons, Polio Immunization and Truth and Reconciliation Commissions (TRC). The Unit is currently carrying out a campaign on voter/civic education in anticipation of the October general elections (UNDPKO, 2004-2008).

111 On the United Nations website for the mission, it is explained that "The Unit is currently distributing 50,000 flyers on average every month. They depict messages of peace and reconciliation, and sometimes carry messages on special issues like elections, HIV/AIDS and Polio. Some 5,000 t-shirts carrying appropriate messages will be distributed every month during the run up to the elections. Seventy-five bill boards will be erected throughout the country, and posters indicating the steps in the electoral process are being planned. A Video Cell within the Unit carries out outreach activities by distributing video tapes covering events and issues to various video viewing centers where people gather. The Unit also has produced a Peace Album done by 26 famous Liberian musicians, containing songs about peace as well as human rights and elections. (UNDPKO, 20042008). 
combatants, peace concerts, the production of reconciliatory music albums, as well as quiz competitions and high-school debates about peace and reconciliation. From January 2006 onwards, UNMIL used the mobile phone networks to send out SMS-text messages to Liberian mobile phone users on the issue of rape and gender-based violence. ${ }^{112}$ Finally, UNMIL sought to include leaders of local NGOs, religious institutions and youth networks in its community outreach activities, to cultivate an inclusive process and to facilitate the opening of networks through which it could diffuse information at a faster pace (Hunt, 2006: 36).

All of these activities demonstrate the mission's success at establishing communication with Liberia's civilians and rebel leaders. This success helped the mission to unfold smoothly, as did the public support that it received from senior officials of each of the three warring factions (Gelfand, 2004a, 2004b). Fighters were said to hold a certain degree of respect for the mission, especially for the military component, and reports concluded that ordinary Liberians liked UNMIL and saw the SRSG as their "advocate" (ICG, 2004).

Efforts were also made to facilitate communication between the peacekeepers themselves. The mission established liaison mechanisms between the different military and civilian members of UNMIL. Daily humanitarian briefings were organized, to maximize the sharing of information between the different actors involved in the operation, as well as to maximize the coordination

\footnotetext{
${ }^{112}$ According to Charlie Hunt, "Of an estimated post-war population of three million, this method reached approximately 500,000 people, $80 \%$ of whom were 18 years of age or older". The persistent inventiveness in reaching its target audience was key to the operation's success (Hunt, 2006:43).
} 
of each section's activities. The ultimate objective was to "synchronise" the delivery of assistance (Fiawosime, 2005:174).

The communication units put in place by the operation also provided information to the international community about the mission's aims, activities and achievements. Frequent statements were made in the media and reports given to the Security Council. Hence the UNMIL Public Information Office was also seeking to optimize the transparency of the mission.

\section{Capacity}

In 2003, the total authorized strength of the mission was 15,000 military personnel and 1,115 international civilian police. UNMIL was meant to become "the largest and most robust UN mission in the world" at the time (ICG, 2003:1). From 2005 to 2009, the authorized strength rose to 14,875 military personnel and 1,240 police officers (UNDPKO, 2004-2008). The equipment provided was well adapted for the terrain, particularly the helicopters, which were critical in their ability to cover great distances and to ensure transportation of relief aid despite the absence of usable roads. The troops were well armed, and the near-absence of major qualitative discrepancies between each contingent's equipment also contributed to a more capable task force.

\section{Knowledge}

The mission officials had experience in the field of peacekeeping. The SRSG, Jacques Klein, had served as the UN Transitional Administrator for 
Eastern Slavonia, Baranja and Western Sirmium during the Bosnian War. In 1999, he was the Coordinator of United Nations Operations in Bosnia and Herzegovina. In all these assignments, he held the rank of Under-SecretaryGeneral. Klein's approach was described as “"refreshing” by some of his staff; others (were) concerned that in the long run his "lucid tongue" might pose problems for consensus building" (ICG, 2003:13).

The troops were also knowledgeable about the mission, the context and the environment. Most of the initial troops were ECOMIL soldiers re-hatted as UNMIL soldiers. As seen in Chapter 5, these troops were very experienced in the country's terrain, both physical and human.

The fact that the bulk of US support for the mission was financial was said to have created a mixed impression amongst the peacekept, and might have been responsible for the several setbacks suffered by the operation. The most serious blow occurred in December 2003, when the SRSG started the disarmament process prior to the complete deployment of the mission's troops. These premature actions, which ultimately hampered the operation, arose due to pressure to spend the money allocated by the great power rapidly because of fear that it could be reallocated (ICG, 2004). The financial contribution thus seemed to create certain obstacles that would not have developed if more American troops had been directly involved in the mission. 


\subsection{UNAMSIL}

\subsubsection{Type of Intervener}

The United Kingdom's deployment of troops to Sierra Leone was very rapid. When the West Side Boys ${ }^{113}$ kidnapped the British contingent in August 2000, the United Kingdom responded with a degree of force that had not been seen since the Gulf War. This signalled to the belligerents not only the capability but the resolve of the United Kingdom to use powerful means in order to achieve its ends (McGreal \& MacAskill, 2000; Smith, 2000). The troops' initial assignment was to secure the airport and thus allow for the evacuation of UK nationals. However, they ended up providing security in Freetown, and engaged in a highly visible rescue of UK citizens that had been captured by rogue elements of the Sierra Leone military (inflicting high numbers of casualties on their adversaries in the process) (A Review of Peace Operations: A Case for Change, 2003).

Although the United Kingdom intervened separately from UNAMSIL, most analysts agree that the UK was instrumental in the success of the peace operation (Adebajo, personal communication, February 2008; Olonisakin, 2008; Findlay, 2002; Francis, Faal, Kabia \& Ransbotham, 2005) ${ }^{114}$. According to Adebajo,

\footnotetext{
113 The West Side Boys are described as a "maverick group" that is not connected to the main rebel group in Sierra Leone, the Revolutionary United Front (BBC, 2000).

114 According to Francis, Faal, Kabia \& Ransbotham, their involvement arguably saved the mission (Francis, Faal, Kabia \& Ransbotham , 2005:46).
} 
They made sure because of their seats on the Security Council that the UN deployed 20,000 troops in Sierra Leone, which was the biggest peacekeeping force in the world. It would not have happened without the British. (...)As for UNMIL, they kept their troops outside of the UN command. So you have two Security Council Members which strengthened but did not keep their troops under the UN command (Adebajo, personal communication, February 2008).

According to the International Crisis Group, the UK intervention became the key factor in altering the military balance in favour of the government and encouraging the RUF to sign a ceasefire agreement in Abuja in November 2000 (ICG, 2001). After this agreement, the UK displayed their military force in the Sierra Leonean capital in order to deter the RUF from sabotaging or bypassing the accord (Reno 2001:224, Hough, 2007:14). Hough cited Findlay according to whom the UK military presence "acted as a deterrent, a confidence-building measure and a source of moral and actual support to UNAMSIL and government forces" (Hough, 2007: 14) Hence the presence of UK which maintained its troops and continued to invest in its training programme in collaboration with UNAMSIL is seen by most analysts to have directly contributed to the gradual decline in violence and the relative peace and stability that have held since 2002 (Hough, 2007:14; Findlay 2002).

Olonisakin's description of how the belligerents understood the situation and viewed UNAMSIL once the British intervened is telling: "we understood there was a new Sheriff in town" (Olonisakin, 2008: 95).

According to Bruce Jones, "notwithstanding the multiple coordination efforts of the UN, a significant - if unofficial - coordinating agent in Sierra Leone 
was the British government. Sierra Leone became, in effect, a case of 'lead state coordination', though this was never officially recognized" (Jones 2002: 107). The United Kingdom took responsibility for significant coordinating and leadership functions. Jones describes

it chaired a donor forum to galvanize international financial support; it took the lead in financing ECOMOG's mission when ECOMOG re-intervened in Sierra Leone following the take-over attempt by the joint forces of the AFRC/RUF; it provided critical funds for demobilization when there was a shortfall; and, in a number of other ways, it ensured a degree of consistency, forward planning, and sustained international commitment to Sierra Leone (Jones, 2001:20).

\subsubsection{Choice of Strategy}

The United Kingdom sponsored the modification of the UNAMSIL mandate at the Security Council on August $4^{\text {th }} 2000$. UNAMSIL would maintain the security of the Lungi and Freetown peninsulas, as well as the major approach routes to the peninsulas; it would also "deter and, where necessary, decisively counter the threat of RUF attack by responding robustly to any hostile actions or threat of imminent and direct use of force" (UN 2000d, S/RES/1313). Deterrence was thus the chosen strategy of intervention (Ginifer, 2005). ${ }^{115}$

\section{Communication}

As was the case with the two other operations analyzed in this chapter, the communication aspect of UNAMSIL was well organized on three fronts.

\footnotetext{
115 According to Ginifer, the UK presence, along with that of UNAMSIL, contributed to the deterrence of external threats as well as internal challenges (Ginifer, 2005:4). 
UNAMSIL utilized various means to optimize communication both with the belligerents and with the general populace. It implemented a strategy of negotiation with the RUF and dialogue with all parties to the conflict, combined with what was later described as the "progressive demonstration of deterrence".

The mission also invested significant effort in public information networks. Radio UNAMSIL was established to wage a mass media campaign, informing the populace in even the most remote parts of the country about the activities of the peacekeepers (Olonisakin, 2007).

UNAMSIL put in place a Community Liaison and Public Outreach Unit (which would later be imitated by UNMIL). The operation would

employ theatre groups, traditional dance troupes and musicians to perform dramas, comedies, dances and songs in local languages explaining the mission mandate, the areas of deployment and the workings of the DDRR programme to grassroots audiences across the country (Hunt, 2006: 35). ${ }^{116}$

Ultimately, despite the hostile attitude of the rebel forces toward the UN contingents, and despite the mission's authorization and capacity for using force, UNAMSIL strove to keep open the lines of communication with civilians and the rebels, thus privileging a non-coercive approach (United Nations Association of Great Britain and Northern Ireland, 2002).

\footnotetext{
116 According to Charles Hunt, "One of the most significant occasions was a peace concert organised by Community Outreach with famous Sierra Leonean musicians in Makeni, the Revolutionary United Front of Sierra Leone (RUF) HQ and strong-hold, bringing together ten government ministers who were sitting side by side with RUF leaders. The climax saw representatives from the government, UNAMSIL and the RUF on stage singing and dancing together. As well as breaking some of the tension between these important actors, the symbolism for the people of Makeni and all those who saw media coverage of it after the event was clear." (Hunt, 2006: 35).
} 
If the commitment of overwhelming force had immediately deterred the belligerents during the previous operation, the intervention of the United Kingdom sent a clear signal to the warring parties about the resolve of the international community to end the fighting. This forceful message was made even stronger through a successful psychological operation that relied very heavily upon collaboration with the intelligence assets of the Sierra Leone army, creating fear and uncertainty in the minds of targeted rebel commanders such that they literally abandoned their positions and fled into the interior of Sierra Leone.

UNAMSIL also engaged in direct discussions with the Government of Sierra Leone (instead of indirectly communicating via the media). Contacts with the RUF were established later, in support of a key aspect of the mandate: to extend government authority throughout Sierra Leone (Malan, Rakate \& McIntyre, 2002).

Efforts were made to establish and maintain good communication networks amongst the peacekeepers. UNAMSIL collaborated closely with other UN agencies in this regard. ${ }^{117}$

The military headquarters of UNAMSIL established a joint operation cell, which involved officers from all contingents. It also established mixed civilianmilitary coordination mechanisms. Regular meetings were held between the Secretariat and troop contributors to address issues of command and control and

\footnotetext{
${ }^{117}$ In the UNDG report on the result of the UN Coordination System in Sierra Leone, it is stated that "In terms of governance, the OCHA, UNDP and UNAMSIL collaborated closely to support the overall recovery process across the country and to provide technical capacity support to the District Recovery Committees (DRCs). The DRCs became the District Councils, which were elected in May 2004" (UNDG, 2004).
} 
shortfalls in equipment. Similar meetings were held in the field between the leadership of UNAMSIL and commanders of contingents, to discuss the mandate, the ROE, and to find ways to improve internal communication. An internal training programme on the rules of engagement was set-up. Consultations with United Nations agencies and non-governmental organizations were strengthened and made more frequent. Finally, an experienced peacekeeping official was appointed as the Deputy Special Representative in order to reinforce to reinforce control of the peace operation's overall (UN 2000, S/2000/751).

The Security Council helped to galvanize support for the peace operation in the region and with the troop-contributing countries. And while diplomatic channels remained open, West African leaders, and most especially the highly influential president of Nigeria, made it clear to the RUF that this was their last chance. Olonisakin explains that

Despite the RUF's initial hostility, UNAMSIL used "contact groups"- consisting of military and civilian representatives from UNAMSIL and representatives from the RUF - to keep open the lines of communication with the rebels (Olonisakin, 2007: 101).

\section{Capacity}

The UK intervention in Sierra Leone amounted to 'its largest unilateral deployment of forces abroad since the 1982 Falklands Conflict". Its arsenal included a force of approximately 4,500 personnel; an aircraft carrier; an Amphibious Ready Group; a parachute battalion; an air force capable to combine air defense, strike and reconnaissance, as well as transport aircraft and helicopters; a significant Special Forces contingent; and command and control mechanisms 
"to support the operation over a distance of 3,500 miles". But most determining, Dorman underlines that "The force was made operational in less than seven days" (Dorman, 2007:188).

This intervention also came with the promise of "over-the-horizon" support, meaning that the UK forces and military equipment also offer help to the government of Sierra Leone (A Review of Peace Operations: A Case for Change, 2003). According to Olonisakin, "The presence [of the UK] (..) lifted the spirits of Sierra Leoneans. It also gave UNAMSIL much needed support and allowed it to re-deploy to other parts of the capital where security was urgently needed" (Olonisakin, 2007:63). The British launched a number of operations intended to show the strength of their forces. A series of offshore firepower demonstrations of "over-the-horizon" force -were the most highly visible. The "over-the-horizon" concept was not new, having been used by NATO in the former Yugoslavia and by the UN in East Timor. In Sierra Leone, the "over-the-horizon" displays was regarded as a proof that the British were resolved to punish the rebels if they did not comply (Olonisakin, 2007: 64).

The UK intervention that backed UNAMSIL proved that an highly capable joint services force can contribute to creating the conditions confidence in the wider population, while at the same time helping to destroy the opposing belligerent forces from within by breaking their morale. ${ }^{118}$

${ }^{118}$ For a direct discussion of the west and south/central African contexts (Prins, 2006). 


\section{Knowledge}

The UK had a strong interest in the success of the mission. The operation in Sierra Leone was viewed in London as a test case for Britain's post-Cold War capabilities (Dorman, 2008). Britain's strong interest in Sierra Leone and its position as a permanent member of the Security Council was likely a major reason for the Council's agreement to expand UNAMSIL's strength to 17,500 troops (Curran \& Woodhouse, 2007).

The rapidity with which the UK intervened in Sierra Leone signalled their strong interest in the mission. Within a week, military and political assessments had been done and the British forces had been deployed (Dorman, 2007).

Many of the troops participating in the UNAMSIL mission were re-hatted ECOMOG troops. These troops had experience with the terrain in the country. And the new working conditions under the UN assured them of better training and equipment, and higher pay. All of these elements reinforced their capacity to be effective, a fact that was not lost on the belligerents.

\section{Conclusion}

All three operations, in Somalia, Liberia and Sierra Leone, were successful. The intervention of a great power in each operation sent clear signals to the belligerents about the determination of the international community to resolve the conflict. With knowledge of the great power's strong commitment to the peace operation, as well as of the operational latitude and capabilities granted 
to the peace operation's forces, the belligerents were soon convinced to avoid the prohibited actions.

The prioritization of non-coercive means, albeit coupled with overwhelming forces and the authority to use them, make the strategy one of deterrence as opposed to compellence. Peacekeepers spent significant amounts of energy communicating with the belligerents, signalling the intent of the operation and the sanctions if transgressions were to occur. The deterrence strategy adopted by all three peace operations, the clear communication of the operation's aims and mandate, of its capacity for action yet of its will to negotiate, significantly reduced the violence. The combination of a deterrence strategy and great power intervention produced fewer casualties and less confrontation with the warring parties, and ultimately led to a level of success that previous peacekeeping operations had been struggling to achieve for a number of years. This success suggests another track of study regarding the relationship between the type of great power intervention (for example, commitment of troops on the ground vs. financial support) and the likelihood of a successful peace operation. 


\section{CONCLUSION}

"You cannot afford to say 'Oh stop fighting!' (because) that's the only way to survive: You fight back." - General Wiley

When the state fails to impose security to such an extent that individuals and groups engage in serious conflict, intervention by outsiders is sometimes seen as the only remaining option to restore a monopoly on the legitimate use of force. This dissertation has sought to understand the conditions under which peace operations succeed in failed states. I have addressed two main questions: What is peace operation success, and what contributes to such an outcome?

\section{Contributions}

My dissertation has two types of contributions to the literature: theoretical and empirical.

\subsection{Theoretical contribution}

In the first chapter, I went over the literature to highlight how scholars have recently arrived at a relative consensus that peace operations can be effective, while still debating what constitutes a successful peace operation (Pushkina, 2006) and how to account for success or failure (Bellamy \& Williams, 2005; Downs \& Stedman, 2002). I then identified two gaps in the literature: 1) a clear understanding of the multidimensionality of peacekeeping success, which 
has been an obstacle to fully conceptualizing and measuring such success (Pushkina, 2006); and 2) a full apprehension of what makes peace operations successful. My dissertation has thus focused upon these two related questions: what constitutes a successful peace operation and how can we account for success or failure?

In Chapter 2, I elaborated my theoretical contribution, and offered a new definition of peace operation success based on two indicators: the (re)establishment of order and the accomplishment of the mandate. This dissertation thus puts forward a new framework to determine the success of peace operations, one that moves beyond previous explanations with their focus on either the (re)establishment of order or the accomplishment of the mandate, by innovatively combining the two dimensions.

The order dimension is important because it allows us to assess the extent to which a state has emerged from "failed state status" by re-acquiring institutional capacity and the ability to use cohesive and coherent coercive force to ensure rules are followed. Yet the success of a peace operation in creating these conditions can only be deemed "partial" if the mandate of the mission was not fulfilled. Hence to the dimension of order we add the need for the peace operation to accomplish its mandate. Many authors (Bellamy \& Williams, 2005; Downs \& Stedman, 2002) who focus on this dimension to judge the success/failure of a mission have highlighted how the success of a particular mission might be directly related to the quality of the mandate. That is, the broader and more ambiguous a mandate is, the less chance there is for the peace operation to 
succeed. This dissertation has addressed this issue by assessing the accomplishment of the mandate, taking into account three main elements that play a key role in determining whether the mandate will be accomplished or not: the context, the duration of the peace operation and its resources. Doing so also allows our assessment to be more thorough regarding what is being accomplished by the mandate. This also has the benefit of considering the accomplishment of the mandate based upon the particular conditions of peace operations in failed states settings, something that is relatively rarely done in the literature. Ultimately then, the contribution of this dissertation is to outline a new typology for better assessing and classifying peace operations, as failures, partial failures, partial successes, or successes.

The second contribution is to provide a theoretical framework of explanation for these different outcomes of peace operations - that is, their failure, partial failure, partial success, or success - based on the type of strategy, the ingredients of the strategy and the type of intervener(s). I have suggested that the three major ingredients of any strategy are communication, capability and knowledge. Hence to assess the process by which peace operations arrive at their different outcomes, I examined the communication between the belligerents and the interveners, among the belligerents, and among the interveners. I also considered the communication between the intervening groups and third parties. Indirect communication, which sends "cues" to the adversary with regards to the operation's aims and resolve, was also taken into account. I looked at the peace operation's capability and demonstration of resolve to punish a transgression of 
prohibited actions. The interveners' and belligerents' knowledge of each other based on reputation and known interests was assessed, to determine to what extent strategies were calibrated to the specific adversary.

My analysis has looked at three types of strategies pursued in peace operations (compellence, deterrence and self-defence) and three types of

interveners (great power, regional power, and collective intervener). Deterrence strategy involves a combination of coercive and non-coercive means aimed at convincing a potential aggressor to refrain from committing a certain action. Compellence refers to the use of coercive means to persuade an adversary to undertake a certain action. Self-defence is adopted when the peacekeepers are limited to non-coercive means to perform their mandated activities.

These ingredients (types of strategies and types of interveners) have been taken into account by authors studying peace operations, yet have never been systematically combined to highlight the process by which peace operations become successful or unsuccessful.

\subsection{Empirical contribution}

In the subsequent chapters (3-6), I examined the peace operations in Somalia (1991-1995), Sierra Leone (1999-2005) and Liberia (1990-2009), explaining each of the four outcomes by looking at the role of the type of strategy adopted and the type of intervener. Based on my definition of peace operation success (the accomplishment of the peace operation's mandate and the establishment of order within the state, by the state), my premise was that peace 
operations can vary in the details of their mission and thus in what constitutes the successful accomplishment of that particular mission, but all share the common aim of restoring order that is legitimately enforced by the state. The goal was to provide a clearer definition of peace operation success, as well as to address the gap in the current analyses of peace operation success, which are useful for understanding the impact of each criterion separately but which say very little about the impact of the various criteria when combined together.

Each operation was classified into one of four categories: failure, partial failure, partial success, and success. More particularly, I examined the process by which each peace operation succeeded/failed at accomplishing its mandate while simultaneously contributing to/hindering its chances at re-establishing order. Since the ingredients (communication, capability and knowledge) interacted differently depending on which strategy was adopted, I highlighted how the strategy (compellence, deterrence or self-defence), combined with the type of intervener (great power, regional power, or collective intervener), influenced the communication, the use of capabilities, and the knowledge of the intervener and of the peacekept (based on reputation and known interests). I thus showed how the strategy frames the operation in such a way as to either enable or hinder the intervener(s) in quickly achieving an important part of their mandate, but that in doing so either sabotages or contributes to the sabotage of the very means by which they could re-establish order in the country, that is, by establishing a monopoly on coercive means within and by the state. 


\section{Comparing Outcomes}

In both Chapters 3 and 6, I looked at the outcome for a peace operation adopting a coercive strategy (compellence or deterrence) in which a great power was involved. Only one of the coercive strategies, deterrence, came out as being key in re-establishing order, while the presence of a great power appeared to be necessary for the mandate to be accomplished in all peace operations considered.

Chapter 3 showed how for the ECOMOG missions in Liberia (1990-1997) and Sierra Leone (1997-1998), as well as for the UN mission in Somalia (UNOSOM II, 1993-1995), the adoption of a compellence strategy in a peace operation led by a great power or by a collective intervener (led by a regional great power) facilitated the accomplishment of the mission's mandate yet hindered its capacity to re-establish order.

By comparison, Chapter 6 examined the operations in Somalia (UNITAF 1992-1993), Liberia (UNMIL 2003-2009) and Sierra Leone (UNAMSIL part II, 2000-2005), and underlined that the combination of a deterrence strategy and great power intervention led to fewer casualties and less confrontation with the warring parties, and ultimately produced a level of success that previous peacekeeping operations had been struggling to achieve for a number of years: order was re-established and the mandate was accomplished.

Chapter 5 confirmed the determining role of the deterrence strategy in the re-establishment of order and the extent to which the absence of a great power could hinder the accomplishment of the mandate. Both in Liberia (ECOMIL 2000-2003) and Sierra Leone (UNAMSIL part I, 1999-2000) the adoption of a 
deterrence strategy worked well in terms of re-establishing order, yet without the involvement of a great power, the mandate was not accomplished and hence a lasting peace could not be reached.

Chapters 3, 5, and 6 all showed the extent to which the use of force alone is not in itself very effective, and in fact may contribute to slowing the peace process by making the interveners party to the conflict. Comparing these three chapters thus revealed the extent to which the possession of sufficient military means to address failed state settings is less important than the modalities of its use.

In this vein, Chapter 4 proved useful for highlighting the extent to which coercion, while not a sufficient component, is still a necessary one for assuring the success of a peace operation in a failed state setting. By closely examining the UNOMIL operation in Liberia (1993-1997), the UNOMSIL operation in Sierra Leone (1998-1999) and the UNOSOM I operation in Somalia (1991-1992), I highlighted that a low profile intervention may not only fail to stop the violence, but might in fact trigger violence. This is because the perception that the operation is benign risks becoming an incentive for belligerents to target international organizations' resources and workers/peacekeepers, thereby increasing insecurity for both civilians and intervening troops. The chapter thus showed that even though the use of non-coercive means is crucial for the success of a peace operation, a focus on non-coercive means alone will not ensure the success of peace operations in intra-state wars. 


\section{Comparing Processes}

Perceptions of both the interveners and the peacekept are key in explaining the outcome of a peace operation. All case studies showed the extent to which local conditions factor into the success of a peace operation. Most notably, considering local conditions proved crucial to understanding why a partially failed operation such as UNOSOM II could follow a successful one like UNITAF. In this case the main puzzle was: why did UNOSOM II failed if UNITAF had been such a success?

Chapter 3 showed how the changes in local conditions combined with inappropriate answers by peacekeepers undermine the success of a peace operation. The process by which UNOSOM II was carried out, particularly its use of communication, its capacity and its knowledge of the situation, reversed the situation, from a successful one (under UNITAF) to a partially failed one. It was the failure to intervene in a credible and tailored manner that led to the partial failure of the operation.

The consequences of a lack of credibility were obvious in Chapter 4, where it was shown that the interveners, due to their lack of coercive power, simply did not gain credibility in the eyes of the peacekept. Ultimately, the failure of all three operations examined in this chapter stemmed from the fact that no adversaries were deterred from engaging in violence, and no adversaries were reassured that the peace agreement the interveners were there to implement would be respected. 
Chapter 5 showed that although the peacekeepers had the authority and equipment to use coercive force, the non-commitment of great powers signalled a lack of resolve to ensure the return to lasting peace in both countries. This undermined their credibility in the eyes of the peacekept. And while the belligerents did cooperate with the peacekeepers, their motivation was more about gaining time, money and/or equipment than working towards putting an end to their activities.

The extent to which perception matters was also clearly highlighted in Chapter 6. The involvement of the United States in Liberia was perceived as credible and strong by the belligerents, hence the Americans had deterring capability. However, one could easily argue that such support and commitment were quite fragile. Indeed, after the Somalia debacle and the quick retreat from Haiti, the perception of US backing could have been different on the ground. Yet perceptions that the commitment in Liberia was robust ultimately outweighed the influence of outside events.

Perceptions are very much shaped by the various ingredients of each peace operation. Chief amongst them is good communication, a point that emerged clearly in all chapters.

Chapter 3 showed the impact of a compellence strategy framing the communication between the peacekept. There was no investment in communication but rather all energy was focused on forcing the belligerents to comply with the terms of the missions. The interveners overlooked the timeintensive traditional peacekept practices of political legitimisation. More 
surprising is that for compellence missions that which could have been expected to act more like a well organized warring party, there was also poor communication between the members of the operations. This exacerbated the problems of command and control within the peace missions. The lack of communication with the international community also contributed to turning public opinion against the missions, and was a significant factor in the operations' failure to re-establish order.

By contrast, in Chapter 4, it was shown that the total absence of coercion undermined the interveners' credibility and thus hindered communication between the peacekeepers and the belligerents, as well as between the peacekeepers and the population in general. In addition, communication was never optimal between the different intervening groups. Relationships between UN agencies and NGOs on one hand and UN political and military figures on the other were very poor in all three peace operations examined in this chapter. In the absence of a war-like mobilization that would have gotten all actors onto the same page, it appeared that the differences in terms of intervening cultures and of understandings of local dynamics also played a bigger role in hindering the process and outcome of the missions.

Chapters 5 and 6 showed that the adoption of a coercive strategy is no obstacle to good communication with the peacekept. Yet when compared with Chapter 3, what emerged was that not just any coercive strategy is compatible with good communication. Instead, good communication seemed to flow from a deterrence strategy rather than from a compellence one. In Chapter 5, it was 
shown that ECOMIL and UNAMSIL did a good job of coordinating their activities on the ground and thus minimized the problems of communication both between the participants in the operation and with the belligerents, thereby gaining credibility in the eyes of the peacekept. The three missions examined in Chapter 6 invested significantly in establishing good communication with the peacekept, and also made sure to maintain good communication amongst their troops and with the international community. Doing so helped each operation to gain and maintain wide support for their mission. This contributed significantly to the success of the peace operations.

All case studies confirmed that capacity matters, not so much in terms of quantity but in terms of the extent to which the equipment and means are tailored/well-adapted to the setting of the intervention. In Chapter 3 , the interveners mobilized significant capacity yet the equipment proved inadequate in the context of a peace operation. Moreover its use in a war-like manner hindered the re-establishment of order in all three cases, by making the interveners appear to be yet another party to the conflict. In Chapter 4, it was shown that both the lack of military and of humanitarian resources in a situation characterized by a high degree of anarchy prevented the operations from operating efficiently. Chapter 5 underlined that even if they are well equipped, peacekeeping missions in intra-state wars still need the robust backing of a great power to fully succeed. Even though the peacekeepers succeeded in re-establishing order, they lacked the necessary means to accomplish the mandate. Only in Chapter 6 was order reestablished and the mandate accomplished, largely thanks to the quantity and 
quality of the material deployed by the peacekeepers, whose ranks included a great power.

All the case studies confirmed that peace operations work best when they are tailored to the specifics of their settings. Chapter 3 showed the consequences of missions failing to properly analyze the intentions of the belligerents, as well as the impact that an intra-state war environment can have on strategy, operations, and tactics. In all three peace operations presented in this chapter, troops were insufficiently informed about both the geophysical and human terrain. The knowledge of the population at large was also underestimated. Indeed, the local population were aware of the tensions between the different interveners, and played on the dislikes between different contingents to intensify competition and to exacerbate tensions between them.

Chapter 4 was useful for highlighting the learning effect on current missions that results from the failure of peace operations elsewhere. Following the failure of peacekeeping missions in Somalia and Bosnia, the belligerents understood that casualties could cause interveners to hastily withdraw from an operation, and thus did everything in their power to ensure that the peace missions operating in their country ended in the same manner.

Chapter 5 highlighted the extent to which previous encounters between different types of peacekeepers and belligerents, as well as between specific individuals involved in the mission, may enhance the deterring force of the threat, and hence contribute to the successful processing and outcome of the mission. Chapter 6, with knowledge of the great power's strong commitment to the peace 
operation, as well as of the operational latitude and capabilities granted to the peace operation's forces, the belligerents were soon convinced to avoid the

prohibited actions. Reputation and known interests were used to tailor the intervention to the setting and to the peacekept, and such adaptation was key in assuring both the re-establishment of order and the accomplishment of the mandate.

\section{For further investigation}

My dissertation addresses important aspects of peace operation success, yet the findings could be further honed by more detailed investigation of each peace operation. Such a project could focus upon the type of commitment and of great power intervention, as well as the sharing of information between peacekeepers and the decision-making process.

\subsection{Type of Great Power Intervention}

Chapter 6 confirmed the hypothesis that success flows from the adoption of a deterrence strategy combined with the intervention of a great power. Yet the case studies also suggested the need to examine more broadly whether/how the type of great power intervention matters. Chapter 5 showed that the logistical or financial support of the US (ECOMIL) or the UK (UNAMSIL) were insufficient for either mission to achieve its mandate. Chapter 6 demonstrated that the commitment of the United Kingdom combined with the deterrence strategy adopted by UNAMSIL produced a clear success. In less than two years, civil war 
ended, belligerents complied with the parameters of the peace agreement and free elections were held. UNMIL can also be qualified as a success. However, the failure of the United States to commit troops on the ground, the disappearance of arms, and the ongoing, threatening struggle in the Ivory Coast all point toward a need for prudence in any long-term assessments of UNMIL. Such issues also indicate avenues of further research, regarding the type of commitment of a great power and its effect on the success of a peace operation. All the case studies showed the importance of a great power putting "boots on the ground". However, what remains less clear is the extent to which a significant financial commitment by a great power, either in combination with or instead of the commitment of troops, may also contribute to the success of a peace operation in an intra-state war within a failed state. Put another way, does a great power's commitment to financially support a mission have a positive or negative deterrence effect on the peacekept?

\subsection{From Communicating to Sharing Information}

All my case studies confirmed that communication with the peacekept, in combination with the capacity and resolve to use force, is a key ingredient in the success of any peace operation. It should thus be the cornerstone of any intervention strategy. They also made it clear that communication is central to any tactic adopted by the belligerents. Belligerents are increasingly using the Internet, wireless communications, satellite TV and other communication tools to collect and disseminate information as part of their struggle. Communication in 
intervention missions is widely used, from psychological operations to information operations, from gathering "human terrain" data so as to facilitate operations to aiding with the capacity-building of local governments. While my dissertation addressed the importance of information and how to get it, it said much less regarding how to share it.

It would thus be fruitful to conduct a research project more focused upon information gathering, particularly the sharing and use of information among outside interveners, with the locals, and with the belligerents. Improved communication would enhance every aspect of interventions, making the use of force less necessary and more effective, while also potentially affecting perceptions as to the legitimacy of its use. The sharing and use of information by intervening forces and agencies and local security services have been poor relative to 1) what is needed, 2) how well sophisticated insurgents use information, and 3) what technology allows one to do, in terms of when and how information is used, by whom it is used, and what the related costs are.

\subsection{Decision-Making Process}

The process by which decisions are made was not fully analyzed in this dissertation. We looked at how the choice of strategy affected the success of a peace operation. However, further investigation of how the type of operation leads to a choice of strategy, which in itself leads to the type of outcome of the peace operation, merits further investigation. The question of mission creep would be interesting to address, as would the extent to which it can even lead to a 
successful outcome. The example of Sierra Leone could be employed to examine such a situation. For UNAMSIL part II, a deterrence strategy was adopted and a great power intervened - but I did not consider how the UK came to such a decision. In fact, the government was engaged in what it believed to be a short evacuation operation. It was the commander on the ground that decided otherwise, by using the evacuation operation as an excuse to get his country involved in a robust way so as to deter the rebels and successfully convince them to back down (BBC 2010). This points toward another avenue of investigation: how does each great power or each intervener decide which strategy to adopt, why do they make that choice, and what are the costs involved? Such an investigation could also improve my own conclusions, by giving a clearer picture of the causal line between the choice of strategy and the success of a peace operation.

\section{Extending the case studies}

It would be useful to test my doctoral findings with more case studies of intra-state wars, both inside and outside Africa. Such research could focus on a number of case studies in five regions: Africa (Somalia, Liberia, Sierra Leone, DR Congo, Sudan), the Balkans (Bosnia-Herzegovina and Kosovo), Asia and the Middle East (Afghanistan and Iraq), and Latin America (Colombia and Haiti). 


\subsection{The Peacekept in Intra-state Wars: All Alike?}

An issue that this dissertation has not addressed is the diversity of settings and the impact of different settings on the "deterrability" of the peacekept. This dissertation assumed that the contexts of intra-state wars were similar. Yet are failed state settings like the ones in Africa in the 1990s contextually similar to the one in Afghanistan today? And to what extent does this impact upon the deterrability of the actors? Is there a clear difference between insurgents and belligerents? Are insurgents as deterrable as belligerents? Might it be possible that some intra-state wars present more difficult contexts than others for peace operations? For instance, the contexts in Somalia, in Liberia and in Sierra Leone were ones of intra-state war within a failed state - yet are these contexts equivalent to the one found in Afghanistan today, a failed state in which an interstate war is superimposed upon an intra-state war?

Current operations in Afghanistan are not clear peace operations. NATO and the United States and its allies are waging a war. Yet there is a blurred line between what constitutes a classic peace operation (with a "peace to keep") and a peace enforcement operation. The Bonn Agreement and the UN mandate for ISAF are all elements that contribute to making the intervention in Afghanistan a type of peace operation. Thus if one wanted to draw conclusions from this dissertation regarding how to best intervene in such a context, this question of the equivalence of intra-state wars would need to be thought through in more detail.

In the case studies presented in this dissertation, the configurations of the warring groups were similar: well-defined groups with reasonably clear and stable 
official authorities/hierarchies. This contrasts with the configuration of the warring groups in Afghanistan, commonly referred to as insurgents: each insurgent cell has a different hierarchical structure, with chains of command that mix together both local and international components. This potentially complexifies interactions with the peacekept, and almost certainly compromises the deterring ability of interveners.

In my dissertation, the peacekept were assumed to be "equivalent", meaning that the premise was that the belligerents and the population alike were all equally susceptible to being deterred by a peace operation, depending on the type of strategy adopted and on whether a great power was involved. However, an inter and intra-state war setting like the one in Afghanistan prompts the question, ceteris paribus, as to whether some peacekept are less "deterrable" than others.

\subsection{A combination of Qualitative and Quantitative Methods}

Along with more case studies, a methodology that combined both qualitative and quantitative methods would also be worthwhile. The case study approach would allow for a more detailed examination of individual cases in order to highlight not only if, but also how deterrence strategy works, as well as how the involvement of a great power influences its success. Such a comparative method would permit both within-case comparisons and across-case comparisons. This would be particularly salient as each of the countries under study has experienced at least two militarized peace operations with relatively similar mandates but with widely divergent mission compositions, structures and 
strategies (UN, NATO, AU, compellence/deterrence, etc.). Further comparative analysis could be organized according to the four categories of peace operations outlined in my theoretical model.

The case studies listed above as being useful for further testing my doctoral findings were chosen to test both components of my argument: the type of strategy used and the presence or absence of a great power (and the resultant effects). In all the cases, strategies of self-defence, deterrence, and compellence were adopted by the three possible types of actor: a great power, a regional organization and/or an international organization. These further case studies could use both qualitative and quantitative analysis (based upon multiple correspondence analysis). Given the large number of operations proposed for investigation, as well as the significant variation in the times and locations in which those operations took place, this qualitative and quantitative data would offer a representative sampling that would be useful for other peacekeepingrelated research. It would also help me to develop a quantitative tool to improve my analysis, and would draw upon the variables identified in my project to further build the multiple correspondence analysis presented in this dissertation. SPAD software could be used to do a factorial plan associated with the characteristics of the operations under study. Eight variables could be examined: deterrence strategy, success of deterrence strategy, type of intervener, communication, capability, level of interest, reputation, and command \& control. The success of the operation could be used as an illustrative variable. 
It would also be valuable to compare military strategies used in peace operations with the military strategies used in military interventions such as NATO in Afghanistan or the United States in Iraq. Both countries are failed states, yet the missions were not oriented toward peace operations but rather toward war-like operations. Comparing differently oriented missions and determining how each mission's orientation affected the strategies and the ensuing success of the mission would be fruitful. This highlights a new avenue of research: applying my model so as to clarify how different strategies and contexts interact differently depending on the interveners, their commitment and the setting in which the operation takes place. Such a project would address an empirical gap in the literature, by generating data on the interactions between variables rather than following previous studies, which have usually examined each variable in isolation.

\section{Concluding remarks}

From operations in Somalia to Haiti and Afghanistan, great powers have been increasingly called upon to collaborate with other countries and with international/regional organizations to help bring about peace, deliver humanitarian assistance and rebuild shattered communities. This dissertation has made clear the degree to which settings are complex and dynamic in failed states. Threats are dispersed, hidden, mobile, cunning, and ever-changing. The ability to scatter forces, delegate authority, improvise operations, work across organizational boundaries, and make difficult yet time sensitive decisions, is 
absolutely key (Libicki, Gompert, Frelinger \& Smith, 2007:4). Successful peace operations require understanding the human/physical terrain and building support for the operations at home. Recent discussions regarding what to do in Afghanistan, in Darfur and in the Democratic Republic of the Congo point to the need for greater input from local and regional organizations. These organizations can be extremely useful because of their perceived stake in the conflict and their understanding of the ongoing disputes, as well as due to the proximity of their troops and their willingness to commit themselves to the operation. At the same time however, their impartiality and their capabilities on the ground should not be overestimated. Indeed, these limitations point toward the need for further great power intervention in these conflicts. Great powers seem to retain this unique capacity and credibility. Deterrence, with all that it entails in terms of combining communication, capability and knowledge, while costly in terms of mobilization, may when combined with great power involvement ultimately save time and money while also producing a successful outcome to the peace operation. 


\section{BIBLIOGRAPHY}

Accra Peace Agreement of August 2003 brings high hopes for peace but instability remains (October 2003). International Displacement Monitoring Center. Available at http://www.internaldisplacement.org/idmc/website/countries.nsf/(httpEnvelopes)/9951589B02 25A93C802570B8005AAC65?OpenDocument (Accessed May 31 2010)

Addis Ababa Agreement concluded at the first session of the Conference on National Reconciliation in Somalia, 27 March 1993. Available at http://www.incore.ulst.ac.uk/services/cds/agreements/somalia.html (Accessed May 31 2010).

Adebajo, Adekeye (2004a). Pax West Africana? Regional Security Mechanisms. In Adekeye Adebajo and Ismail O. D. Rashid (Eds). West Africa's security challenges: building peace in a troubled region (pp. 291-318). Boulder, CO: Lynne Rienner Publishers.

$$
\text { Dialogue, April. }
$$

(2004b). "Great Expectations in West Africa". Global (2004c). ECOMOG: Problems, Progress and Prospects. Center for Conflict Resolution.

(2003a). Liberia's Civil War: Nigeria, ECOMOG and Regional Security in West Africa. Boulder: Lynne Rienner.

(2003b). "In Search of Warlords: Hegemonic Peacekeeping in Liberia and Somalia”. International Peacekeeping, 10, 4: $62-81$.

Adebajo, Adekeye and Christopher Landsberg (2003). "South Africa and Nigeria as Regional Hegemon". In Mwesiga Laurent Baregu and Christopher Landsbergeds (Eds). From Cape to Congo: Southern Africa's evolving security challenges. (pp. 171-204). Boulder and London: Lynne Rienner Publishers. 
Adibe, Clement (1997). "The Liberian Conflict and the ECOWAS-UN Partnership". Third World Quarterly, 18, 3: 471-488.

Alao, Abiodun and Ero, Comfort (2001). "Cut short for taking short cuts: The Lomé peace agreement on Sierra Leone”. Civil Wars, 4, 3, 117-134.

Alao, Abiodun, Mackinlay, John and Olonisakin, Funmi (1999). Peacekeepers, politicians and warlords: the Liberian peace process. United Nations University Press.

Anderson, Mary B. (1999). Do No Harm: How Aid Can Support Peace or War. Boulder and London: Lynne Rienner Publishers.

A Review of Peace Operations: A Case for Change (2003). King's College London. March. Available at http://www.reliefweb.int/rw/lib.nsf/db900SID/LGEL5LLH7D?OpenDocument (Accessed May 31 2010).

Atkinson, Rick (1994a). “The Raid That Went Wrong”. Washington Post. 30.01, A27.

(1994b). "Night of a Thousand Casualties: Battle Triggered U.S. Decision to Withdraw from Somalia”. Washington Post, 31.01, A1.

Ayoob, Mohamed (1996). "State-Making, State-Breaking and State Failure: Explaining the Roots of "Third World Insecurity". In van de Goor L. Rupesinghe, K. and Sciarone, P. (Eds.) Between Development and Destruction. An Enquiry into the Causes of Conflict in Post-Colonial State. (pp.67-90). London: MacMillan.

Bah, Alhaji M.S. (2005). "West Africa: From a security complex to a security community". African Security Review, 14, 2: 77-83.

Bah, A. Sarjoh and Aning, Kwesi (2008). "US Peace Operations Policy in Africa: From ACRI to AFRICOM". International Peacekeeping, 15: 1, 118 132. 
Bangura, Yusuf (2000). "Strategic policy failure and governance in Sierra Leone". The Journal of Modern African Studies, 38, 4: 551-577.

Baumanns, Robert F., Yates, Lawrence A. and Washington, Versalle F.(2004). My Clan Against the World: US and Coalition Forces in Somalia 19921994. Fort Leavenworth, Kansas: Combat Studies Institute Press. . Available at http://cgsc.edu/carl/download/csipubs/clan.pdf (Accessed on May 31 2010).

BBC. (2010). "The brigadier who saved Sierra Leone". BBC News, BBC Radio 4, From Our Own Correspondants. Available at http://news.bbc.co.uk/2/hi/programmes/from_our_own_correspondent/868 2505.stm (Accessed May 31 2010).

------(2003a). "Peacekeepers secure Liberian town". BBC News, Tuesday, September 19. Available at http://news.bbc.co.uk/2/hi/africa/3094180.stm (Accessed on May 31 2010).

-(2003b). "The Perils of Liberian Peacekeeping". BBC News, Monday, August 3.Available at http://news.bbc.co.uk/2/hi/africa/3113009.stm

------(2000). "Who are the West Side Boys?". BBC News, Thursday August 31. Available at http://news.bbc.co.uk/1/hi/world/africa/901209.stm.

Bellamy, Alex J., Paul Williams (2005). "Who's Keeping the Peace? Regionalization and Contemporary Peace Operations", International Security, 29, 4 : 157-195.

Berman, Eric G. (2003). "The Provision of Lethal Military Equipment: French, UK, and US Peacekeeping Policies Towards Africa". Security Dialogue, 34, 2: 199-214.

(2001). "Arming the Revolutionary United Front". African. Security Review, 10, 1. Available at http://www.iss.co.za/pubs/asr/10no1/Berman.html (Accessed May 31st 2010) 
(2000). "Re-Armament in Sierra Leone: One Year After the Lomé Peace Agreement”. Small Arms Survey. Occasional Paper. No. 1. December. Available at

http://www.reliefweb.int/library/documents/2001/sas-sie-dec00.pdf

Berman, Eric G. and Labonté, Mélissa T. (2006). "Sierra Leone". In Wiliam Durch (Ed.). Twenty-First Century Peace Operations (pp.141-228). United States Institute of Peace.

Berman, Eric and Sams, Katie (2000). Peacekeeping in Africa: capabilities and culpabilities. Geneva: United Nations Institute for Disarmament Research.

Bernath, Clifford and Nyce, Sayre (2002). "UNAMSIL--A Peacekeeping Success Lessons Learned". Refugee International. Report on the United Nations Mission in Sierra Leone.

Betts, Richard K. (2000). "Is Strategy an Illusion?". International Security, 25, 2: 5-50.

(1994). “The Delusion of Impartial Intervention". Foreign Affairs, 73, 6 (Nov. - Dec.): 20-33.

Borchini, Charles P. And Borstelmann, Mari. 1994. "PSYOP in Somalia: The Voice of Hope". Special Warfare. October: 2-9.

Brabazon, James (2003). "Liberia: Liberians United for Reconciliation and Democracy (LURD)”. The Royal Institute of International Affairs. Armed Non-State Actors Project Briefing Paper No. 1.

Bratt, Duane (1997). "Explaining Peacekeeping Performance: The UN in Internal Conflicts". International Peacekeeping, 4, 3: 45-70.

(1996). "Assessing the Success of UN peacekeeping Operations". International Peacekeeping, 3, 4: 66-83. 
Brown, Ann (1993). "United Nations Peacekeeping: Historical Overview and Current Issues". Report for Congress. Washington DC: Congressional Research Service.

Brown, Michael E. and Rosecrance, Richard N. (1999). The Costs of Conflict: Prevention and Cure in the Global Arena. Lanham: Rowman \& Littlefield.

Brunné, Jutta and Toope, Stephen J. (2004). "Slouching Towards New Just Wars: International Law and the Use of Force after September 11". Netherlands International Law Review, L1: 363-392.

Bunn, Elaine (2007). "Can Deterrence Be Taylored?" Strategic Forum, January no. 225. Institute for National Strategic Studies National Defense University.

Bures, Oldrich (2006). "Regional peacekeeping operations: Complementing or undermining the United Nations Security Council?". Global Change, Peace \& Security, 18, 2: $83-99$.

Call, Charles T. (2008). "Knowing Peace When You See It: Setting Standards for Peacebuilding Success". Civil Wars 10, 2: 174-195.

Call, Charles T. and Cousens, Elizabeth. (2008). "Ending Wars and Building Peace: International Response to War-Torn Societies". International Studies Perspective. 9, 1: 1-21.

Carment, David and Rowlands, Dane (1998). "Three's Company: Evaluating Third-Party Intervention in Intrastate Conflict". Journal of Conflict Resolution, 42, 5: 572-599.

Cassidy, Robert M. (2008). "Counterinsurgency and Military Culture: State Regulars versus Non-State Irregulars". Baltic Security \& Defence Review, 10: 53-85.

(2004). Peacekeeping in the Abyss: British and American peacekeeping doctrine and practice after the Cold War. Greenwood Publishing Group. 
Chesterman, Simon (2004). You, the People: The United Nations, Transitional Administration and State-Building. Oxford: Oxford University Press.

Child Soldiers Global Report. (2004). "Coalition to Stop the Use of Children".Available at http://www.reliefweb.int/rw/lib.nsf/db900sid/LHON66UJKU/\$file/child_soldiers_CSC_nov_2004.pdf?openelement (Accessed May 31 2010).

Clausewitz, Carl von (1976). On War. (Michael Howard and Peter Paret, Eds. and Trans.). Princeton, NJ: Princeton University Press.

Coleman, Katharina Pichler. (2007). International organisations and peace enforcement: the politics of international legitimacy. Cambridge: Cambridge University Press.

Collier, Paul (2001). "Economic Causes of Civil Conflict and Their Implication for Policy". In Chester A. Crocker, Fen Osler Hampson and Pamela Aall (Eds.), Turbulent Peace: The Challenges of Managing International Conflict, (pp. 143-162). Washington, DC: United States Institute of Peace Press.

Connaughton, Richard (2001). Military Intervention and Peacekeeping: The Reality. Burlington: Ashgate.

Cooper, Neil. (2003a). "State Collapse as Business: The Role of Conflict Trade and the Emerging Control Agenda". In Jennifer Milliken (Ed). State failure, collapse and reconstruction (pp.179-200). Wiley-Blackwell.

(2003b) "Liberal Governance, War Economies and the Emerging Control Agenda". Paper for the Conference on Resource Politics and Security in a Global Age University of Sheffield, June 26-28.

Crigler, Frank T. (1993). "The Peace-Enforcement Dilemma". Joint Forces Quarterly, Autumn: 64-70. 
Crocker, Chester (1995). "The Lessons of Somalia: Not Everything Went Wrong”. Foreign Affairs, 74, 3:2-8.

Crocker, Chester A., Hampson, Fen Osler and Aall, Pamela. (2005). Grasping the nettle: analyzing cases of intractable conflict. Washington, D.C: United States Institute of Peace Press.

(2004). Taming intractable conflicts: Mediation in the hardest cases. Washington, D.C: United States Institute of Peace Press.

Curran, David and Tom Woodhouse (2007). "Cosmopolitan peacekeeping and peacebuilding in Sierra Leone: what can Africa contribute?", International Affairs ,83 (6):1055-1070.

Dallas, Sheila Patricka (2000). "Radio UNAMSIL: A Weapon For Peace". Media Channel. Available at http://www.mediachannel.org/originals/unradio.shtml (Accessed May 31 2010).

Daniel, Donald, Charles, Hayes, Bradd C. and de Jonge Oudraat, Chantal (1999). Coercive Inducement and the containment of international crises. Volume 31, Issue 2. USIP.

De Jonge Oudraat, Chantal (2000). "Making Economic Sanctions Work". Survival, 42, 3: 105-27.

(1996) "The United Nations and Internal Conflict”. In International Dimensions of Internal Conflicts (pp. 489-536). In Michael E. Brown (Ed). Cambridge, MA: MIT Press.

Denselow, R. (2000). "Disarming Sierra Leone's Rebels". BBC News. Available at news.bbc.co.uk/1/hi/world/africa/694209.stm (Accessed May 31 2010).

De Waal, Alex (1997). Famine Crimes: Politics and the Disaster Relief Industry in Africa. Oxford: James Currey. 
De Waal, Alex and Omaar, Rakiya (1994). "Can Military Intervention Be "Humanitarian"?" Middle East Report, 187/188: 2-8.

Diehl, Paul F. (1996). “With the best of intentions: Lessons from UNOSOM I and II". Studies in Conflict \& Terrorism, 19, 2: $153-177$.

Press.

Dobbins, Jones et al. (2005). The UN's Role in Nation-Building from Congo to Iraq. Rand Publications.

Dorman, Andrew (2008). "Transforming to Effects-Based Operations: Lessons from the United Kingdom Experience". Strategic Studies Institute. Available at https://www.strategicstudiesinstitute.army.mil/pdffiles/PUB831.pdf (Accessed May 31 2010).

(2007). "The British Experience of Low-Intensity Conflict in Sierra Leone". Defense \& Security Analysis, 23, 2: 185 - 200.

Downs, George W. and Stedman, Stephen John (2002). "Evaluation Issues in Peace Implementation". In Stephen John Stedman, Donald Rothchild, and Elizabeth M. Cousens (Eds). Ending Civil Wars: The Implementation of Peace Agreements. (pp.43-70).Boulder, CO: Lynne Rienner.

Doyle, Mark (1999). "World: Africa Nigerian Election "Threatens" Sierra Leone". BBC News, Saturday, February 27. Available at http://news.bbc.co.uk/2/hi/africa/287236.stm (Accessed May 31 2010).

Doyle, Michael W. and Sambanis, Nicholas (2006). Making War and Building Peace: United Nations Peace Operations. Princeton: Princeton University Press.

Draman, Rasheed and Carment, David (2003). "Managing Chaos in the West African Sub-Region: Assessing the Role of ECOMOG in Liberia”. Journal of Military and Strategic Studies, 6, 2. Available at 
http://www.ciaonet.org/olj/jmss/jmss_2003/v6n2/jmss_v6n2b.pdf (Accessed May 31 2010).

Drysdale, John (1997). "Foreign Military Intervention in Somalia: The Root Cause of the Shift from UN Peacekeeping to Peacemaking and Its Consequences". In Walter Clarke and Jeffrey Herbst (Eds.). Learning From Somalia: The Lessons of Armed Humanitarian Intervention (pp.118134) Oxford: Westview Press.

Duffield, Mark (1994). “The Political Economy of Internal War". In Joanna Macrae and Anthony Zwi (Eds.). War and Hunger: Rethinking International Responses to Complex Emergencies (pp.50-69). London: Zed Pres.

Dukulé, A.W. (2004). "The US and Liberia: Can We Prevent a Repeat of the Haiti Scenario?". The Perspective, March 4. Available at www.theperspective.org/2004/mar/usandliberia.html (Accessed on May 31 2010).

Eggenberger, David (1967). A Dictionary of Battles. New York: Crowell.

Eichenberg, Richard C. (2005)."Victory Has Many Friends: U.S. Public Opinion and the Use of Military Force, 1981-2005”. International Security, 30, 1: 140-177.

Fanta, Emmanuel (2009). "The Capacity of African Regional Organisations in Peace and Security". Paper presented at the ERD Workshop: Transforming Political Structures: Security, Institutions, and Regional Integration Mechanisms, Florence, 16-17 April. Available at http://erd.eui.eu/media/fanta.pdf (Accessed May 31 2010)

Fearon, James D. (2004). "Why Do Some Civil Wars Last So Much Longer than Others?". Journal of Peace Research, 41, 3: 275-301.

Fearon, James D. and Laitin, David (2003). "Ethnicity, Insurgency, and Civil War". American Political Science Review, 97, 1: 75-90. 
Fiawosime, Albert (2005). “An Integrated Approach to Peace Support Operations Overview of UN and International Humanitarian Agencies in Liberia". In Festus Aboagye and Alhaji M S Bah (Eds). A Tortuous Road to Peace: The Dynamics of Regional, UN and International Humanitarian Interventions in Liberia (165-190). Pretoria: ISS.

Field Manual No. 3-25.26 (2001). Map Reading and Land Navigation. Washington, DC: Headquarters Department of the Army. Available at http://www.globalsecurity.org/military/library/policy/army/fm/3-2526/ch13.htm (Accessed May 31 2010)

Findlay, Trevor (2002). The Use of Force in UN Intervention. SIPRI. Oxford: Oxford University Press.

Freedman, Lawrence (2005). "Deterrence: A Reply". Journal of Strategic Studies, 28, 5: $789-801$.

Fortna, Virginia Page (2008). Does Peacekeeping Work? Shaping Belligerents' Choices After Civil War. Princeton, NJ: Princeton University Press.

Fortna, Virginia Page and Howard, Lise Morjé (2008). "Pitfalls and Prospects in the Peacekeeping Literature”. Annual Review of Political Science, 11: 283301.

Francis, David J., Faal, Mohammed, Kabia, John and Ramsbotham, Alex, (2005). Dangers of Co-Deployment: UN Co-operative Peacekeeping in Africa. Aldershot, UK: Ashgate.

Franke, Benedikt (2006). "In defence of regional peace operations in Africa". Journal of Humanitarian Assistance. Available at http://www.jha.ac/articles/a185.pdf (Accessed May 31 2010).

Gelfand, L. (2004a) "Ivorian or Liberian, Few Fighters Show Up to Disarm in Buchanan". Reliefweb, May 4. Available at www.reliefweb.int/w/Rwb.nsf/6686f45896f15dbc852567ae00530132/a1c7 e267381a0d6885256e8a00595a93?OpenDocument (Accessed May 31 2010). 
Gelfand, L. (2004b). "UN Opens Last Phase of Liberian Disarmament Amid Questions Over Missing Guns". Relief web, April 30. Available at www.reliefweb.int/ rw/rwb.nsf/db900sid/OCHA64DAGA?OpenDocument\&query=UN\%20opens $\% 201$ ast $\% 20$ phase $\% 20$ of $\% 20$ Liberian\%20disarmament\%20amid\%20questions\%20over\%20missin g\%20guns (Accessed May 31 2010).

George, Alexander and Smoke, Richard (1989). "Deterrence and Foreign Policy". World Politics, 41: 170-82.

Gilligan, Michael and Stedman, Stephen John (2003). "Where do the peacekeepers go?". International Studies Review, 5, 4: 37-54.

Ginifer, Jeremy (2005). Armed violence and poverty in Sierra Leone: A case study for the Armed Violence and Poverty Initiative. Centre for International Cooperation and Security. Department of Peace Studies. University of Bradford. Available at

http://info.brad.ac.uk/acad/cics/publications/AVPI/poverty/AVPI_Sierra_L eone.pdf (Accessed on May 31 2010).

(2004). Evaluation of the Conflict Prevention Pools. Sierra Leone. Bradford University, Channel Research Ltd, PARC \& Associated Consultants. Country, Regional Case Study 3. Available at http://www.oecd.org/dataoecd/59/50/35096535.pdf (Accessed on May 31 2010).

Goemans, Hein Erich (2000). War and Punishment: The Causes of War Termination and the First World War. Princeton: Princeton University Press.

Goertz, Gary, Diehl, Paul F. and Harvey, Frank (2002). "Conceptualizing and Measuring Conflict Management Success: An Overview". International Negotiation, 7: 291- 98.

Goodwin, Deborah (2002). Negotiation in International Conflict: Understanding Persuasion. Taylor \& Francis. 
Gowan, Richard (2008). "The Strategic Context: Peacekeeping in Crisis, 200609”. International Peacekeeping, 15, 4: 453-469.

Gray, Colin S. (1999). "Inescapable Geography”. Journal of Strategic Studies, 22, 2: $161-177$.

Gundel, Joakim (2002). "The migration-development nexus: Somalia case study". International Migration, 40, 5: 255-281.

Gutner, Tamar and Alexander Thompson. 2010. "The Politics of IO Performance: A framework". The Review of International Organizations, 5, 3:227-248.

Halim, Omar (1996). A peacekeeper's perspective of Peacebuilding in Somalia. International Peacekeeping,3,2:70 - 86.

Harman, Danna (2002). "Sierra Leone: The Path from Pariah to Peace". Christian Science Monitor, September 18.

Harvey, Frank (1999). "Practicing Coercion: Revisiting Successes and Failure Using Boolean Logic and Comparative Methods". Journal of Conflict Resolution 43, 6: 840-871.

Heinrich, Wolfgang (1997). Building the Peace: Experiences of Collaborative Peacebuilding in Somalia, 1993-1996. Uppsala: Life \& Peace Institute.

Heldt, Birger (2001). Conditions for Successful Intrastate Peacekeeping Missions Uppsala University.

Hennop, Jan (2003). "Liberia: Peace at last?". African Security Analysis Programme Report. September. Available at http://www.iss.co.za/uploads/LIBERIASEP03.PDF (Accessed May 31 2010).

Hill, J. N. C. (2009). "Thoughts of Home: Civil-Military Relations and the Conduct of Nigeria's Peacekeeping Forces". Journal of Military Ethics, 8, 4: 289-306. 
Hillen, John. (2000) Blue Helmets: The Struggle of UN Military Operations, Washington DC: Brassey's, 2nd edition.

(1998). Blue helmets: the strategy of UN military operations. London: Brassey's.

(1995). "Killing With Kindness: The UN Peacekeeping Mission in Bosnia". The Cato Institute Foreign Policy Briefing, 34. Available at http://www.ciaonet.org/wps/hij01/ (Accessed May 31 2010).

Hirsh, John L. (2001a). Sierra Leone: Diamonds and the Struggle for Democracy. International Peace Academy Occasional Paper Series. Boulder, CO: Lynne Rienner Publishers.

(2001b).“War in Sierra Leone“. Survival, 43, 2: 145-162.

Hirsh, John L. and Oakley, Robert B. (1995). Somalia and Operation Restore Hope: Reflections on Peacemaking and Peacekeeping. Washington, D.C.: United States Institute of Peace Press.

Hough, Leslie (2007). "A study of peacekeeping, peace enforcement and private military companies in Sierra Leone”. African Security Review, 16.4.

Howard, Lise Morjé. (2008). UN Peacekeeping in Civil Wars. Cambridge University Press.

Howe, Herbert M. (2001). Ambiguous Order: Military Forces in African States. Boulder, CO: Lynne Rienner.

(1996-7). "Lessons of Liberia: ECOMOG and regional peacekeeping”. International Security 21, 3: 145 - 176.

Howe, Jonathan T. (1995) "The United States and United Nations in Somalia: The limits of involvement”. The Washington Quarterly, 18, 3: 47-62. 
Human Rights Watch (HRW) (2003a). "Liberia: Greater Protection Required for Civilians Still at Risk”. Human Rights Watch Briefing Paper. September 9.

(2003b) "U.N. Actions Needed to End Rights Abuses". Human Rights Watch News. September 15. Available at http://www.hrw.org/en/news/2003/09/15/liberia-un-action-needed-endrights-abuses (Accessed May 31 2010).

(1997). Human Rights Watch World Report 1997 - Liberia, 1 January 1997. Available at http://www.unhcr.org/refworld/docid/3ae6a8b128.html (Accessed May 31 2010).

(1993a). "Waging War to Keep the Peace: The ECOMOG Intervention and Human Rights". Human Rights Watch Reports, 5, 6.

Available at http://www.hrw.org/legacy/reports/1993/liberia/\#3 (Accessed May 31 2010).

(1993b). "Somalia Beyond the Warlords: The Need for a Verdict on Human Rights Abuses". Human Rights Watch Report, V, 2, March 7.

Hunt, Charles (2006). Public Information as a Mission Critical Component of West African Peace Operations. Accra: Kofi Annan International Peacekeeping Training Centre.

Huntington, Samuel P. (1968). Political Order in Changing Societies. New Heaven: Yale University Press.

Huth, Paul K. (1999). "Deterrence and International Conflict: Empirical Findings and Theoretical Debates". Annual Review of Political Science, 2: 25-48

Institute for National Strategic Studies (INSS) (2004). "Liberia: From Intervention to Stabilization". INSS Roundtable Series on Post-Conflict Stabilization and Crisis Management. . Available at 
http://www.ndu.edu/inss/Repository/INSS_Proceedings/Post_Conflict_Sta bilization_Series/PostConflict_March2004.pdf (Accessed May 31 2010).

International Crisis Group (ICG) (2007). "Sierra Leone: The Election Opportunity". 12 July, Africa Report $N^{\circ} 129$. Available at. http://www.unhcr.org/refworld/docid/469727c72.html (Accessed June 3 2010)

(2006). “Liberia: Staying Focused". 13 January. Africa -Briefing $N^{\circ} 36$ Dakar/Brussels.

(2004). "Liberia and Sierra Leone: Rebuilding Failed States". ICG Africa Report $N^{\circ} 87.8$ December. Available at http://www.unhcr.org/refworld/docid/41b9a2304.html (Accessed June 5 2010).

(2003). "Liberia: Security Challenges". ICG Africa Report $N^{\circ} 71$ Freetown/Brussels. 3 November 2003. Available at http://www.crisisgroup.org/ /media/Files/africa/westafrica/liberia/Liberia\%20Security\%20Challenges.ashx (Accessed May 31 2010). Africa Report. No.35. 24 October.

(2001). "Sierra Leone: Managing Uncertainty".

March. Available at (1998). "Situation Analysis: Sierra Leone". 18 http://www.unhcr.org/refworld/docid/3ae6a6e010.html (Accessed May 31 2010)

International Peace Academy (IPA) (2001). Peacekeeper's Handbook. New York, NY: Pergamon Press.

York, NY: Pergamon Press.

(1984). Peacekeeper's Handbook. New 
Irin News (2003). "Liberia: ECOMIL says it will only deploy troops close to capital Monrovia". Irin News. 15 September 2003. Available at http://www.irinnews.org/report.aspx?reportid=46169 (Accessed May 31 2010).

Itano, Nicole (2003). "Liberating Liberia Charles Taylor and the rebels who unseated him". ISS Paper 82. November.

Jakobsen, Peter Viggo (2000). "Focus on the CNN Effect Misses the Point: The Real Media Impact on Conflict Management is Invisible and Indirect". Journal of Peace Research, 37, 2: 131-143.

(1996)."National interest, humanitarianism or CNN: what triggers UN peace enforcement after the Cold War?". Journal of Peace Research 33, 2: 205-215.

Johansen, Robert C. (1994). "U.N. Peacekeeping: How Should We Measure Success?”. Mershon International Studies Review, 38: 309-10.

Jones, Bruce D. (2002). "The Challenge of Strategic Coordination". In S.J. Stedman, D.S. Rothchild and E. M. Cousens (Eds). Ending Civil Wars: the Implementation of Peace Agreement (pp.89-116). Boulder, CO: Lynne Rienner Publisher.

Jones, Bruce D. with Feryal Cherif (2004). Evolving Models of Peacekeeping, Policy Implications and Responses. Paper prepared for UNDPKO Best Practices Unit New York: NYU Center on International Cooperation. Available at http://smallwarsjournal.com/documents/pkomodels.pdf (Accessed May 31 2010).

Johnson, Dominic D.P. and Tierney, Dominic (2006). Failing to win: perceptions of victory and defeat in international politics. Harvard University Press.

Kabia, John (2009). Humanitarian intervention and conflict resolution in West Africa: from ECOMOG to ECOMIL. Ashgate Publishing, Ltd. 
Kansteiner, W. H. (2003). Assistant Secretary of State for African Affairs. Testimony to House Committee on International Relations Subcommittee on Africa, 2 October 2003. Available at:

http://www.state.gov/p/af/rls/rm/24839.htm. (Accessed on May 31 2010).

Kihunah, Milkah (2005). "Monitoring the Monitors: UN-ECOMOG Peacekeeping in the Liberian Civil War". Yale Journal of International Affairs, 1: 120132.

Kilcullen, David (2008). Accidental Guerrilla: Fighting Small Wars in the Midst of a Big One. New York: Oxford University Press.

(2006a). Three Pillars of Counterinsurgency. Remarks delivered at the U.S. Government Counterinsurgency Conference, Washington D.C., 28 September. Available at

http://www.au.af.mil/au/awc/awcgate/uscoin/3pillars_of_counterinsurgenc y.pdf (Accessed May 31 2010)

(2006b). “Counter-insurgency Redux”. Survival, 48, 4: 111-130.

Kim, Haklin (2005). What explains the success of United Nations Peacekeeping Operations?: An analysis of the conditions for peacekeeping success in civil conflicts. $\mathrm{PhD}$ Dissertation. Graduate School of Binghamton University State University of New York.

Kydd, Andrew and Walter, Barbara F. (2002). "Sabotaging the Peace: The Politics of Extremist Violence". International Organization, 56, 2: 263296.

Lacina, Bethany (2006). "State Strength and the Prediction of Insurgency and Civil War". Available at http://www.stanford.edu/ b. Available at lacina/Lacina_Statestrength.pdf (Accessed May 31 2010).

Laitin, David (2001). "Somalia: Intervention in Internal Conflict". CISSM. 67 National Intelligence Council Project. 
Lake, David A. (2003) "International Relations Theory and Internal Conflict: Insights from the Interstices". International Studies Review, 5, 4: 81- 89.

Lake, David A. and Donald Rothchild (1998). The international spread of ethnic conflict: fear, diffusion, and escalation. New Jersey: Princeton University Press.

Lavoyer, Jean-Philippe (1998). "International humanitarian law, protected zones and the use of force". In W. Biermann and M. Vadset (Eds.). U.N. Peacekeeping in Trouble: Lessons Learned from the Former Yugoslavia (pp. 262-279). Brookfield: Ashgate.

Lebow, Richard Ned and Stein, Janice Gross (1990). "Deterrence: The Elusive Dependant Variable". World Politics, 42: 337- 369.

Libicki, Martin C., Gompert, David C., Frelinger, David R and Smith, Raymond (2007). Byting Back: Regaining Information Superiority Against $21^{\text {st }}$ Century Insurgents. Rand Counterinsurgency Study, Vol 1.

Lipson, Michael. 2010. "Performance Under Ambiguity: International organization performance in UN peacekeeping", The Review of International Organizations, 5, (3): 249-284.

Lischer, Sarah Kenyon (2003)."Collateral Damage: Humanitarian Assistance as a Cause of Conflict”. International Security, 28, 1: 79-109.

Londono, Peter V. (2001). "Transitioning from a UN Chapter VI Observer Mission to a Robust Peacekeeping Operation: Lessons from Sierra Leone”. Joint Military Operation Department. Available at http://www.dtic.mil/cgibin/GetTRDoc?AD=ADA394120\&Location=U2\&doc=GetTRDoc.pdf (Accessed May 31 2010).

Mackinlay, John (1995). "Military Responses to Emergencies". In Thomas G.Weiss, (Ed). United Nations and Civil Wars (pp.1-67). Boulder, Colo.: Lynne Rienner. 
Malan, Mark (2001). "Layered Response To An African Conflict or Muddling Through in Sierra Leone?". African Security Review, 10, 2.

(1999). "Leaner and meaner? The future of peacekeeping in Africa". African Security Review. Institute for Security Studies. Available at

http://www.iss.co.za/pubs/ASR/10No2/Malan.html (Accessed May 31 2010).

Malan, Mark, Rakate, Phenyo and McIntyre, Angela (2002). Peacekeeping in Sierra Leone: UNAMSIL Hits the Home Straight. ISS Monograph Series No. 68. Pretoria: Institute for Security Studies, January.

Manseau, Nicole C. (2008). Deterring Spoilers: Peace Enforcement Operations and Political Settlements to Conflict. Master's Thesis. Naval Postgraduate School. Monterrey.California. Available at http://edocs.nps.edu/npspubs/scholarly/theses/2008/Mar/08Mar_Manseau. pdf (Accessed May 31 2010).

Månsson, Katarina (2005). "Use of Force and Civilian Protection: Peace Operations in the Congo". International Peacekeeping, 12, 4: 503-519.

Maraia, John (1997). Policy Paper: Peace Implementation in Liberia. Washington Department of International Affairs. Available at http://www.dtic.mil/cgibin/GetTRDoc?AD=ADA330040\&Location=U2\&doc=GetTRDoc.pdf (Accessed May 31 2010)

Marley, Anthony D. (1997). "Too Many Cooks in the Kitchen: International Intervention in Liberia". Small Wars \& Insurgencies, 8, 2: 109 - 124.

Marr, Jack, Cushing, John Garne and Thompson, Richard (2008). "Human Terrain Mapping: A Critical First Step to Winning the COIN Fight". Military Review. March-April.

Mayall, James and Lewis, Ian (1996). "Somalia". In James Mayall, (Ed.). The New Interventionism 1991-1994: United Nations Experience in Cambodia, Former Yugoslavia and Somalia. Cambridge: Cambridge University Press. 
McGreal, C. and MacAskill, E. (2000). "Hostages Freed in Jungle Battle". The Guardian. September 11. Available at www.guardian.co.uk/sierra/article/0,2763,366964,00.html (Accessed May $312010)$.

Menkhaus, Ken (2008). "Somalia: A Country in Peril, A Country in Nightmare". Enough Strategy Paper. September.

(2007). "Governance without Government in Somalia: Spoilers, State Building, and the Politics of Coping". International Security, 31, 3:74-106.

(2004). "Vicious circles and the security development nexus in Somalia". Conflict, Security \& Development, 4, 2: 149 - 165.

--(2003). "State collapse in Somalia: second thoughts". Review of African Political Economy, 30, 97:405-422.

(2002a). "Somalia: Next Up in the War on Terrorism?". CSIS Africa Notes no 6 (January). Available at http://www.csis.org/ANotes/ index.htm

(2002b). "Political Islam in Somalia". Middle East Policy, 9, 1:109- 123 .

(2002c). "Somalia: In the Crosshairs of the War on Terrorism". Current History, 101, 655: 210-218.

(2002d), "Somalia Situation Analysis". October 2002. Writenet Independent Analysis, UK, for UNHCR.

(2000). "Somalia: A Situation Analysis". UNHCR. Centre for Documentation and Research WRITENET Paper No. 07/2000. November. 
Menkhaus, Ken and Prendergast, John (1995). "Political Economy of PostIntervention in Somalia". Somalia Task Force Issue Paper \#3. Available at http://www.asylumlaw.org/docs/somalia/country_conditions/menkhaus.PD F (Accessed May 31 2010)

Mearsheimer, John J. (1983). Conventional Deterrence. Ithaca: Cornell University Press.

Minear, Larry and Weiss, Thomas G. (1995). Mercy under fire: War and the Global Humanitarian Community. Boulder: Westview Press.

Mitchell, Colin W. (1991). Terrain Evaluation. Oxford: Longman Scientific and technical.

Mockaitis, Thomas R. (1995). "Peacekeeping in intra-state conflict". Small Wars \& Insurgencies, 6, 1, 112-125.

Moran, Mary H. (2005). "Social Thought and Commentary: Time and Place in the Anthropology of Events: A Diaspora Perspective on the Liberian Transition". Anthropological Quarterly, 78, 2: 457-464.

Morgan, Patrick M. (2005). Deterrence Now. Cambridge: Cambridge University Press.

Murphy, Ray (2007). UN Peacekeeping in Lebanon, Somalia and Kosovo: Operational and Legal Issues. Cambridge: Cambridge University Press.

(2002). "The Political and Diplomatic Background to the Establishment of UNIFIL in Lebanon and the UNITAF and UNOSOM Missions in Somalia". The Journal of Conflict Studies: 25-56.

Nathanail, Paul C. (2001). Terrain evaluation for military purposes: examples from the Balkans. Geological Society, 18: 205-208.

Natsios, Andrew S. (1997). "Humanitarian Relief Intervention in Somalia: The Economics of Chaos". In Walter Clarke and Jeffrey Herbst (Eds.). 
Learning From Somalia: the Lessons of Armed Humanitarian Intervention (pp.77-95). Boulder, Colo.; Oxford, U.K.: Westview Press.

Neethling, Theo (2007). "Pursuing sustainable peace through post-conflict peacebuilding: The case of Sierra Leone". African Security Review 16, 3 Institute for Security Studies.

(2004). "International peacekeeping trends: the significance of African contributions to African peacekeeping requirements". South African Journal of Political Studies, 31, 1:49-67. Available at http://www.essex.ac.uk/ecpr/events/generalconference/marburg/papers/3/4 /Neethling.pdf.

Nowrojee, Binaifer (2004). "Africa on its Own: Regional Intervention and Human Rights". Human Rights Watch Report. Available at http://65.202.220.120/wr2k4/download/4.pdf (Accessed May 31 2010).

Nuamah, Kwaku and Zartman, William I. (2001). "Case Study: Intervention in Sierra Leone”. National Intelligence Council Project. CISSM 89.

Oakley, Robert B. (2000). "The Urban Area during Support Missions Case Study: Mogadishu: the Strategic Level". In Russ Glenn, (Ed.). Capital Preservation: Preparing for Urban Operations in the 21st Century (pp. 309-354).Santa Monica, Calif: RAND.

Oakley, Robert B. and Tucker, David (1997). Two Perspectives on Interventions and Humanitarian Operations. Earl H. Tilford, Jr., ed. School Symposium on Military Operations Other Than War. July. Available at www.carlisle.army.mil/ssi/pubs/1997/humanops/humanops.pdf (Accessed May 31 2010).

Obi, Cyril I. (2009). "Economic Community of West African States on the Ground: Comparing Peacekeeping in Liberia, Sierra Leone, Guinea Bissau, and Côte D'Ivoire". African Security, 2: 2, 119-135.

O’Connell, Jamie (2004). "Here Interest Meets Humanity: How To End the War and Support Reconstruction in Liberia, and the Case for Modest American Leadership". Harvard Human Rights Journal, 17: 207-247. 
Olonisakin, Funmi (2008). Peacekeeping in Sierra Leone: The Story of UNAMSIL, Boulder Co: Lynne Rienner Publishers.

(2003). "African Peacekeeping and the Impact on African Military Personnel”. In T.W. Britt and A.B. Adler (Eds). The Psychology of Peacekeepers: Lessons from the Field (pp.299-312). Greenwood Publishing Group.

(2000) Reinventing Peacekeeping in Africa: Conceptual and Legal Issues in the ECOMOG Operations. The Hague: Kluwer Law International.

(1996). "UN co-operation with regional organizations in peacekeeping: The experience of ECOMOG and UNOMIL in Liberia”. International Peacekeeping, 3: 3, 33-51.

Orogun, Paul (2004). "Blood Diamonds and Africa's Armed Conflicts in the PostCold War Era". World Affairs, 166, 3: 151-161.

Paris, Roland (2004). At War's End .Building Peace After Civil Conflict. Cambridge, U.K.; New York, NY: Cambridge University Press. -(2002). "International Peacebuilding and the 'mission civilisatrice"”. Review of International Studies, 28: 6374-656.

--(1997). "Peacebuilding and the Limits of Liberal Internationalism”. International Security, 22: 54-89.

Peacekeeping Best Practices Unit. 2003. Lessons Learned from United Nations Peacekeeping Experiences in Sierra Leone. Department of Peacekeeping Operations. September. http://www.peacekeepingbestpractices.unlb.org/pbps/Library/SLLL\%20Report.pdf 
Peters, Ralph (2000). "The Human Terrain of Urban Operation". Parameters, Spring: 4-12. Available at

http://users.jyu.fi/ aphamala/pe/issue2/urban.htm (Accessed May 31 2010)

Peterson, Scott (2001). Me Against My Brother. London: Routledge.

Porter, Toby (2003). "The Interaction between Political and Humanitarian Action in Sierra Leone, 1995 to 2002." Henry Dunant Centre for Humanitarian Dialogue March 19. Available at http://www.jha.ac/articles/a117.pdf (Accessed May 31 2010).

Pouligny, Béatrice (2006). Peace Operations Seen From Below: UN Missions and Local People. Bloomfield,CT: Kumarian.

Powell, Robert. (2006). "War as a Commitment Problem". International Organization, 60,1: 169-203.

Prins, Gwyn (2006). "An interpretation of the significance of the second battle of Waterloo." Economic Affairs, 26, 4: 12-19.

Pugel, James B. (2007). "Disaggregating the Causal Factors Unique to Child Soldiering: The case of Liberia". Ford Institute for Human Security. Child Soldiers Initative: Building Knowledge about Children and Armed Conflict.

Pugh, Michael Charles, Cooper, Neil and Goodhand, Jonathan (2004). War Economies in a Regional Context: challenges of transformation. Boulder: Co, Lynne Rienner Publishers.

Pushkina, Darya (2006). “'A recipe for success?' Ingredients of a successful peacekeeping mission”. International Peacekeeping,13, 2:133 - 149.

Quist-Arcton, Ofeibea (2003). "Still No Sign of Peacekeepers for Liberia: Annan Presses Security Council to Act." All Africa Website. Available at http://allafrica.com/stories/200307300818.html (Accessed May 31 2010). 
Radio Netherlands (2004). Peace Radio: Sierra Leone. Available at www.radionetherlands.nl/features/media/dossiers/sierra-leone-p.html (Accessed May 31 2010).

Ramsbotham, Olivier, Tom Woodhouse and Hugh Miall (2005). Contemporary conflict resolution: the prevention, management and transformation of deadly conflicts. UK: Polity.

Regan, Patrick M. (2002). "Third-party Interventions and the Duration of Intrastate Conflicts". Journal of Conflict Resolution, 46: 55-73.

Reiter, Dan (2009). How Wars End. Princeton: Princeton University Press.

Reilly, W.M. (2004) "\$500M Pledged at UN for Liberia Recovery". The Washington Times, February 6. Available at www.washtimes.com/upi-breaking/20040206-055947-2668r.htm (Accessed May 31 2010)

Rich, Paul B. (1999). "Warlords, state fragmentation and the dilemma of humanitarian intervention”. Small Wars \& Insurgencies, 10, 1: 78 - 96.

Richards, Paul (2004). "Controversy over Recent West African Wars: An agrarian question?". Occasional Paper. Centre of West African Studies: University of Copenhagen.

Roberts, Adam (1995-1996). "From San Francisco to Sarajevo: the UN and the Use of Force". Survival 37, 4: 7-28. 120.

(1994). "The Crisis in UN Peacekeeping". Survival, 36, 3: 93 -

Rose, E.P.F. and C. Pareyn (1998). "British applications of military geology for Operation Overlord and the battle in Normandy, France 1944". In Underwood, J.R., Jr. And Guth, PL (Eds). Military Geology in War and Peace: Geological Society of America. Reviews in Engineering. Geology v 13: 55-66. 
Ross, Blair (2005). "The U.S. Joint Task Force Experience in Liberia". Military Review, May-June, 1:60-6.7

Rutherford, Kenneth (2008). Humanitarianism under fire: the US and UN intervention in Somalia. Kumarian Press.

Sahnoun, Mohamed (1998). "Mixed Intervention in Somalia and The Great Lakes: Culture, Neutrality and the Military." In Jonathan Moore, (Ed.). Hard Choices: Moral Dilemmas in Humanitarian Intervention. Oxford: Rowman\&Littlefield Publishers.

(1994). Somalia: The Missed Opportunity. Washington, D.C.: Cambridge University Press.

Saideman, Stephen M. and Zahar Marie-Joëlle J. (2008) (Eds.). Intra-State Conflict, Governments and Security Dilemmas of Deterrence and Assurance. New York: Routledge.

Sanghera, Gurchathen, Marsha Henry and Paul Higate (2008). "Peacekeepers as New Men? Security and Masculinity in the United Nations". Centre for Governance and International Affairs. Working Paper No. 02-08. University of Bristol. Available at http://www.bris.ac.uk/politics/grc/workingpapers/02-08mhpaper.pdf (Accessed May 31 2010).

Sawyer, Amos (2004). "Violent conflicts and governance challenges in West Africa: the case of the Mano River basin area". The Journal of Modern African Studies, 42: 437-463.

Scott, Colin in collaboration with Larry Minear and Thomas G. Weiss (1995). "Humanitarian Action and Security in Liberia 1989-1994". Occasional Papers No. 20. Thomas J. Watson Jr. Institute for International Studies. . Available at http://watsoninstitute.org/pub/OP20.pdf (Accessed May 31 2010). 
Sesay, Max A.(1996). "Civil war and collective intervention in Liberia". Review of African Political Economy, 23, 67, $35-52$.

Shaw, Carolyn (1995). "Regional Peacekeeping: An Alternative to United Nations Operations?". The Journal of Conflict Studies.15, 2: 59-81. Available at http://www.lib.unb.ca/Texts/JCS/Fall95/shaw.pdf (Accessed May 31 2010).

Sierra Leone News (1999). January. .Available at http://www.sierraleone.org/Archives/slnews0199.html (Accessed May31 2010).

Slantchev, Branislav L. (2005). Military Coercion in Interstate Crises. American Political Science Review, 99: 533-547.

Smith, R. (2000). The UK in Sierra Leone: What next?. BBC News, September 11, Available at news.bbc.co.uk/1/hi/world/africa/919942.stm. (Accessed on May 31 2010).

Snow, Donald M. and Drew, Dennis M. (1994). From Lexington to Desert Storm. M.E. Sharpe: New York.

Solarz, Stephen J. and Michael E. O'Hanlon (1997). Humanitarian Intervention: When is Force Justified?. The Washington Quarterly 20, 4: 3-14.

Sommers, Marc (2001). "The Dynamics of Coordination". Occasional paper 40, Thomas J Watson Jr. Institute for International Studies. Available at http://hwproject.tufts.edu/publications/electronic/e_op40.pdf (Accessed May 31 2010).

Spink, K. (1996). Geological constraints at the battle of Waterloo: Bath, Geological Society. London.

Stedman, Stephen John (1992). “The New Interventionists". Foreign Affairs, 72,1, America and the World 1992/93: 1-16. 
Stephens, Dale G. (2005). "The Lawful Use of Force by Peacekeeping Forces: The Tactical Imperative". International Peacekeeping, 12: 157-172.

Thürer, Daniel (1999). "The 'failed State' and international law". International Review of the Red Cross, 836: 731-761.

Tierney, Dominic (2005). "Irrelevant or malevolent? UN arms embargoes in civil wars". Review of International Studies, 31, 4:645-664.

Touval, Saadia (1996). "Coercive mediation on the road to Dayton". International Negotiation, 1, 3: 547-570.

-(1994). "Why the UN Fails". Foreign Affairs, 73, 5: 44-57.

Truth and Reconciliation Commission of Liberia. (2009). Volume II: Consolidated Final Report. Available at http://www.sida.se/Global/trc-ofliberia-final-report-volume-ii.pdf (Accessed May 31).

Tuck, Christopher (2000). "Every Car Or Moving Object Gone". The ECOMOG Intervention in Liberia. Available at http://web.africa.ufl.edu/asq/v4/v4i1a1.htm (Accessed May 31 2010).

United Nations Association of Great Britain and Northern Ireland (2002) "Elections in Sierra Leone - An Essential Step Towards Lasting Peace", Available at www.una-uk.org/UN\&C/sierraleonepeace.html.

United Nations (2005). Twenty-seventh report of the Secretary-General on the United Nations Mission in Sierra Leone, (S/2005/777), 12 December.

(2004) Report of the Secretary-General pursuant to Security Council resolution 1521 (2003) regarding Liberia (S/2004/48), 26 May.

(2003). Report of the Secretary-General to the Security Council on Liberia, (S/2003/875), 11 September, 
(2000a). Second Report on the United Nations Mission in Sierra Leone, (S/2000/13), 11 January.

(2000b). Third Report on the United Nations Mission in Sierra Leone, (S/2000/186), 7 March.

(2000c). Fourth report of the Secretary-General on the United Nations Mission in Sierra Leone, (S/2000/455), 19 May.

(2000d). Fifth report of the Secretary-General on the United Nations Mission in Sierra Leone (S/2000/751), 31 July.

--(2000e) United Nations Security Council Resolution 1313, S/RES/1313. 4 August.

-(2000f). General Assembly and Security Council. Report of the Panel on United Nations Peace Operations (A/55/305-S/2000/809), 21 August. ("Brahimi Report").

(2000g). Secretary General stresses need to address issues related to UNAMSIL's Command and Control, and Structure, Equipment shortfalls and Mandate.SG/SM/7514, AFR/265, PKO/95, August 23.

(1999a). Seventh Report of the Secretary-General on the United Nations Observer Mission in Sierra Leone, (S/1999/836), 3 July.

(1999b) Eight Report of the Secretary-General on the United Nations Observers Mission in Sierra Leone, (S/1999/1003), 28 September.

(1999c).First report of the Secretary-General on the United Nations in Sierra Leone (UNAMSIL), (S/1999/1223), 6 December.

(1998). UN Security Council, Resolution 1181 (1998), (S/Res/1181), 13 July. 
(1997). General Assembly, (A/RES/51/243), 15 September.

(1993a) "Report Pursuant to Paragraph 5 of Security Council Resolution 837 (1993) on the investigation into the 5 June 1993 attack on United Nations Forces in Somalia", conducted on behalf of the SecretaryGeneral, (S/26351), 24 August.

(1993b) Security Council Resolution, S/RES/866 (1993), 22 September.

(1993c). "Report of the Secretary-General on emergency assistance for humanitarian relief and the economic and social rehabilitation of Somalia", A/48/504, 29 Oct. 1993, para.25

(1992a) Security Council report of the Secretary-General on the Situation in Somalia, (S/24343), 22 July.

(1992b) "Report of the Secretary-General on the situation in Somalia" (S/24480), 24 August.

(1992c) Security Council, Resolution 775 (1992), 28 August.

(1992e) Security Council, Resolution, S/RES/794 (1992), 3 December.

(1992f). "Report of the Secretary-General on the situation in Somalia". (S/24992), 19 December.

United Nations Consolidated Inter-Agency Appeal for Liberia (1996.) September 1995 - August 1996, Information Note to Donors, Extension of the Appeal through 31 -December 1996. United Nations, Department of Humanitarian Affairs. Available at http://www.reliefweb.int/OCHA_ol/pub/appeals/96appeals/liberia/021096. html (Accessed on May 31 2010). 
United Nations Peacekeeping Best Practice Unit (2004). Lessons Learned Study on the Start-up Phase of the United Nations Mission in Liberia. April. Available at http://www.peacekeepingbestpractices.unlb.org/PBPS/Library/Liberia\%20 Lessons\%20Learned\%20(Final).pdf (Accessed May 31 2010)

UN Security Council Resolution 1289 (2000), S/RES/1289 (2000), 7 February.

UN Security Council Resolution 1059 (1996), S/RES/1056 (1996), 31 May.

UN Security Council Resolution 1041, (1996), S/RES/1041 (1996), 29 January.

UN Security Council, Resolution 837 (1993), S/RES/837 (1993), 6 June.

UN Security Council, Resolution 775 (1992), S/RES/775 (1992), 28 August.

UN Security Council, Resolution 794 (1992).S/RES/794 (1992), 3 December.

United Nations Department of Peacekeeping Operations (2009). "United Nations Mission in Sierra Leone (UNAMSIL)". Available at http://www.un.org/en/peacekeeping/missions/past/unamsil/(Accessed May $312010)$.

United Nations Department of Peacekeeping Operations (UNDPKO) (2008), United Nations Peacekeeping Operations Principles and Guidelines. Available at http://pbpu.unlb.org/pbps/Library/Capstone_Doctrine_ENG.pdf (Accessed September 2010).

(2004-2008). "United Nations Mission in Liberia (UNMIL)". Available at http://unmil.org/index.asp (Accessed May 31 2010).

(UNOMIL)".

(2001). "United Nations Observer Mission in Liberia Available at http://www.un.org/en/peacekeeping/missions/past/unomil.htm (Accessed May 31 2010). 
(2000). "United Nations Operation in Sierra Leone (UNOMSIL)".Available at http://www.un.org/Depts/DPKO/Missions/unomsil/Unomsil.htm (Accessed May 31 2010)

-(1997a). “UNOSOM II”. United Nations Operation in

Somalia II.

Available at

http://www.un.org/en/peacekeeping/missions/past/unosom2.htm

(Accessed May 31 2010) p.136

UNDG (2004). "Residents Coordinator Annual Report.” Available at http://cfapp2.undp.org/dgo_unct_report/reports/index.cfm?fuseaction=sho w_report_results\&cty_id_c=Sil (Accessed May 31 2010).

U.S. Army Peacekeeping Institute (1994). United States Forces Somalia After Action Report. Carlisle, PA: U.S.

U.S. Army Center for Army Lessons Learned (1994). "U.S. Army Operations in Support of UNOSOM II. Lessons Learned Report". Ft Leavenworth, KS: U.S. Army.

U.S. Army Field Manual 3-06. "Operations in Somalia: Applying the Urban Operational Framework to Support and Stability". Urban Operations. Appendix C.

U.S. Committee on International Relations (2003) U.S. Policy Toward Liberia. Hearing Before the Subcommittee on Africa of the Committee on International Relations. House of Representatives. One Hundred Eight Congress. First Session. Serial No. 108-58. Available at http://commdocs.house.gov/committees/intlrel/hfa89671.000/hfa89671_0. htm (Accessed May 31 2010)

U.S. Department of State Bureau of Democracy, Human Rights, and Labor (2004). Liberia. U.S. Department of State. Available at http://www.state.gov/g/drl/rls/hrrpt/2004/41611.htm (Accessed on May 31 2010) 
U.S. Department of State (2003). "United States Participation in the United Nations for 2003". Report by the Secretary of State to the Congress. November.

Utas, Mats and Jörgel, Magnus (2008). "The West Side Boys: military navigation in the Sierra Leone civil war". Journal of Modern African Studies, 46, 3: 487-511.

Van der Lijn, Laïr (2009). "If Only There Were a Blueprint! Factors for Success and Failure of UN Peace-Building Operations". Journal of International Peacekeeping, $13: 45-71$.

Walter, Barbara F. (2002). Committing to Peace: The Successful Settlement of Civil Wars. Princeton, NJ: Princeton University Press.

-(1997). "The Critical Barrier to Civil War Settlement". International Organization, 51, 3: 335-364.

Weber, Max (1978). Economy and Society. (Guenther Roth and Claus Wittich, Eds). Berkeley: University of California Press

Western, Jon (2002). "Sources of Humanitarian Intervention". International Security, 24, 4: 112-142.

Williams, Gabriel I. H. (2002). Liberia: the heart of darkness: accounts of Liberia's civil war and its destabilizing effects in West Africa. Trafford Publishing

Woodhouse, Thomas and Ramsbotham, Oliver (2005). "Cosmopolitan Peacekeeping and Global Security". International Peacekeeping, 12, 2: $139-156$.

Woodward, Susan (2006). "Institutionally Fragile States: Fragile States, Prevention and Postconflict: Recommendations". FRIDE Working Paper \#19 (February) and FRIDE E-Newsletter (March-April) at www.fride.org 
Woods, Larry J. and Reese, Timothy R. (2008). "Military Interventions in Sierra Leone: Lessons From a Failed State". The Long War Series Occasional Paper 28 Combat Studies. Institute Press US Army Combined Arms Center Fort Leavenworth, Kansas. Available at http://www.cgsc.edu/carl/download/csipubs/OP28.pdf (Accessed May 31 2010)

Yoroms, Gani J. (1993). "ECOMOG and West African Regional Security: A Nigerian Perspective". Issue: A Journal of Opinion, 21, 1-2: 84-91.

Yost, David (2009). "Introduction: Special Issue on NATO and Deterrence". Strategic Insights, VIII, 4, September.

Yücel, Hsan and Boothby, Derek. (2003). The Challenges of Change: the Nature of Peace Operations in the 21st Century and Continuing Need for Reform. International Ankara Seminar of the Project on Challenges of Peace Operations: Into the 21st Century. Center for Strategic Research Ankara. 18-20 November. Available at www.sam.gov.tr/reports/Ankaraseminarreport.pdf (Accessed May 31 2010).

Zagare, Frank C. and Kilgour, Marc D. (2000). Perfect Deterrence. Cambridge: Cambridge University Press.

Zartman, I William (2001). "The timing of peace initiatives: Hurting stalemates and ripe moments". Ethnopolitics, 1, 1: 8-18.

(1995). Collapsed states: the disintegration and restoration of legitimate authority. Boulder, CO: Lynne Rienner Publishers.

Zartman, William I. and Touval, Saadia (2001). "International Mediation". In Chester A. Crocker, Fen Osler Hampson and Pamela R. Aall (Eds). Turbulent Peace: The Challenges of Managing International Conflict (pp. 427-444). Washington, DC: United States Institute of Peace Press. 